Florida International University FIU Digital Commons

6-9-2010

\title{
Placing Immigrant Incorporation: Identity, Trust, and Civic Engagement in Little Havana
}

Richard N. Gioioso

Florida International University, rgioi002@fiu.edu

DOI: $10.25148 /$ etd.FI10081205

Follow this and additional works at: https://digitalcommons.fiu.edu/etd

Part of the Civic and Community Engagement Commons, Human Geography Commons,

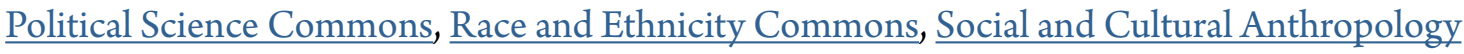
Commons, and the Urban Studies and Planning Commons

\section{Recommended Citation}

Gioioso, Richard N., "Placing Immigrant Incorporation: Identity, Trust, and Civic Engagement in Little Havana" (2010). FIU Electronic Theses and Dissertations. 263.

https://digitalcommons.fiu.edu/etd/263 


\title{
FLORIDA INTERNATIONAL UNIVERSITY
}

Miami, Florida

\section{PLACING IMMIGRANT INCORPORATION: IDENTITY, TRUST, AND CIVIC ENGAGEMENT IN LITTLE HAVANA}

\author{
A dissertation submitted in partial fulfillment of the \\ requirements for the degree of \\ DOCTOR OF PHILOSOPHY \\ in \\ INTERNATIONAL RELATIONS \\ by
}

Richard N. Gioioso

2010 
To: Dean Kenneth Furton

College of Arts and Sciences

This dissertation, written by Richard N. Gioioso, and entitled Placing Immigrant Incorporation: Identity, Trust, and Civic Engagement in Little Havana, having been approved in respect to style and intellectual content, is referred to you for judgment.

We have read this dissertation and recommend that it be approved.

Damián J. Fernández

Gail M. Hollander

Alex Stepick

Patricia L. Price, Major Professor

Date of Defense: June 9, 2010

The dissertation of Richard N. Gioioso is approved.

Dean Kenneth Furton College of Arts and Sciences

Interim Dean Kevin O'Shea University Graduate School

Florida International University, 2010 


\section{DEDICATION}

I dedicate my dissertation to all those family members, friends, and colleagues that have accompanied me during the years I have spent in graduate school, especially David Jaramillo. Your help, support, advice, tolerance, intelligence, wisdom, joy, and patience have been invaluable to me through the ups and downs, and have made this dissertation possible. 


\section{ACKNOWLEDGMENTS}

There are many people to acknowledge and thank for their contributions to this dissertation. The research project team consisted of Dr. Daniel Arreola, Dr. Chris Lukinbeal, Dr. Timothy Ready, Dr. Maria de los Ángeles Torres, Frances Spiegel, and Michelle Zapiain. The members of my writing review group - Emily, Karen, Marcos, Tekla, and Tricia - have given me endless constructive criticism. Dr. Paulette Johnson and Holli Thometz of FIU's Statistical Consulting have offered countless hours of statistical support and advice. With Amy Ritterbusch, my graduate research assistant companion and grad school buddy, I have survived crisis after crisis by seeking and finding a third space for reading, studying, writing, laughing, processing, and constantly checking-in.

The members of my dissertation committee have been, over my years at FIU, a source of constant learning. Thanks to Dr. Damián Fernández, Dr. Gail Hollander, and Dr. Alex Stepick for the hours in class, meetings, conferences and presentations, and for keeping me and my career in mind. I especially thank my advisor, Dr. Patricia Price, for the tireless efforts she has made and help that she has given me in and out of the classroom. Her caring as both mentor and friend has never faltered, and because of her I have grown as a person and a scholar.

Funding for the research project upon which this dissertation is based was provided by the National Science Foundation Human and Social Dynamics program under Award No. 433947. Any opinions, findings, and conclusions, or recommendations expressed in this paper are those of the author and do not necessarily reflect the views of the National Science Foundation. 
The financial support of a Florida International University Dissertation Year Fellowship in 2009 was integral to making a year of analysis and writing possible. 


\title{
ABSTRACT OF THE DISSERTATION \\ PLACING IMMIGRANT INCORPORATION: IDENTITY, TRUST, AND \\ CIVIC ENGAGEMENT IN LITTLE HAVANA
}

by

\author{
Richard N. Gioioso
}

Florida International University, 2010

Miami, Florida

\section{Professor Patricia L. Price, Major Professor}

Immigrant incorporation in the United States has been a topic of concern and debate since the founding of the nation. Scholars have studied many aspects of the phenomenon, including economic, political, social, and spatial. The most influential paradigm of immigrant incorporation in the US has been, and continues to be, assimilation, and the most important place in and scale at which incorporation occurs is the neighborhood. This dissertation captures both of these integral aspects of immigrant incorporation through its consideration of three dimensions of assimilation - identity, trust, and civic engagement - among Latin American immigrants and American-born Latinos in Little Havana, a predominantly immigrant neighborhood in Miami, Florida. Data discussed in the dissertation were gathered through surveys and interviews as part of a National Science Foundation-funded study carried out in 2005-2006. The combination of quantitative and qualitative data allows for a nuanced understanding of how immigrant incorporation is occurring locally during the first decade of the twentieth century.

Findings reveal that overall Latin American immigrants and their American-born offspring appear to be becoming American with regard to their ethnic and racial identities 
quickly, evidenced through the salience and active employment of panethnic labels, while at the same time they are actively reshaping the identificational structure. The Latino population, however, is not monolithic and is cleaved by diversity within the group, including country of origin and socioeconomic status. These same factors impede group cohesion in terms of trust and its correlate, community. Nevertheless, the historically dominant ancestry group in Little Havana - Cubans - has been able to reach notable levels of trust and build and conserve a more solid sense of community than non-Cuban residents. With respect to civic engagement, neighborhood residents generally participate at rates lower than the overall US population and ethnic subpopulations. This is not the case for political engagement, however, where self-reported voting registration and turnout in Little Havana surpasses that of most benchmarked populations. The empirical evidence presented in this dissertation on the case of Latinos in Little Havana challenges the ways that identity, trust, and civic engagement are conceptualized and theorized, especially among immigrants to the US. 


\section{TABLE OF CONTENTS}

CHAPTER

I. INTRODUCTION 1

Research Questions $\quad 4$

Relevance and Impact of Dissertation Topic 6

$\begin{array}{ll}\text { Structure of the Dissertation } & 10\end{array}$

II. PLACING NEIGHBORHOOD AND LITTLE HAVANA

IN SOCIAL SCIENCE 13

Introduction $\quad 14$

$\begin{array}{ll}\text { Placing the Neighborhood } & 14\end{array}$

Origins of Neighborhood Studies $\quad 14$

Operationalizing Neighborhood 16

The Neighborhood and Becoming American 22

Beyond the Chicago School 28

The Los Angeles School of Urbanism 31

Placing Little Havana 33

An Introduction to Little Havana 33

Bounding Little Havana $\quad 34$

Defining Little Havana $\quad 40$

Little Havana Today $\quad 45$

Little Havana as Hub of Culture and Activity 49

Research Design, Methodology, and Data Analysis 52

Introduction $\quad 52$

Research Design $\quad 54$

Phase 1: Survey $\quad 54$

Phase 2: In-depth Interviews 56

Data Analysis

III. BECOMING AMERICAN: PLACING ASSIMILATION, IDENTITY, TRUST, AND CIVIC ENGAGEMENT 61

Introduction $\quad 63$

Assimilation $\quad 64$

Critiques of the Assimilation Paradigm $\quad 67$

Alternative Approaches to the Assimilation Paradigm 71

$\begin{array}{ll}\text { Ethnic and Racial Identity } & 74\end{array}$

Ethnicity and Race in the United States 75

Theorizing Ethnicity and Race in the United States 77

Latino Ethnicity and Race in the United States 82

$\begin{array}{lr}\text { Trust } & 90\end{array}$

$\begin{array}{ll}\text { Introduction } & 90\end{array}$

$\begin{array}{ll}\text { Operationalizing Trust } & 93\end{array}$ 
Major Theories on the Formation of Trust 95

Major Findings on Trust 99

$\begin{array}{ll}\text { Civic Engagement } & 104\end{array}$

Introduction 104

Operationalizing Civic Engagement 106

The Socioeconomic Model of Political and Civic Engagement 108

Other Theories of Civic and Political Engagement 112

Immigrant Incorporation and Civic Engagement 115

IV. PLACING ETHNICITY AND RACE IN LITTLE HAVANA 120

$\begin{array}{ll}\text { Introduction } & 122\end{array}$

$\begin{array}{ll}\text { Changing Neighborhood Demographics } & 123\end{array}$

$\begin{array}{lr}\text { Primary Identifications } & 129\end{array}$

$\begin{array}{ll}\text { Panethnic Identifications } & 132\end{array}$

$\begin{array}{ll}\text { Panethnic Solidarity } & 141\end{array}$

Racial Identifications $\quad 143$

Discussion $\quad 152$

$\begin{array}{ll}\text { Conclusion } & 155\end{array}$

V. PLACING TRUST AND FORGING COMMUNITY

IN LITTLE HAVANA 158

$\begin{array}{lr}\text { Introduction } & 160\end{array}$

$\begin{array}{lr}\text { Sociability } & 162\end{array}$

$\begin{array}{ll}\text { Trust Variables } & 169\end{array}$

$\begin{array}{lr}\text { Neighborhood Trust } & 170\end{array}$

$\begin{array}{ll}\text { Ethnic Trust } & 177\end{array}$

$\begin{array}{ll}\text { Neighborhood Trust and Community } & 185\end{array}$

$\begin{array}{ll}\text { Ethnic Trust and Community } & 193\end{array}$

$\begin{array}{lr}\text { Conclusion } & 199\end{array}$

VI. PLACING CIVIC ENGAGEMENT IN LITTLE HAVANA 203

$\begin{array}{ll}\text { Introduction } & 205\end{array}$

Civic Engagement Variables 206

Neighborhood Civic Engagement 208

Associational Civic Engagement 215

$\begin{array}{ll}\text { Political Civic Engagement } & 221\end{array}$

Beyond the Numbers: Understanding Civic Engagement in Little Havana 226

$\begin{array}{ll}\text { Neighborhood Associations } & 227\end{array}$

Discussing Politics $\quad 238$

Impediments to Participation 246

$\begin{array}{ll}\text { Conclusion } & 250\end{array}$

$\begin{array}{ll}\text { VII. CONCLUSION } & 252\end{array}$

Assimilation Theory 256

The Importance of Place $\quad 257$ 
Social Capital 258

Conflicted Incorporation 259

$\begin{array}{ll}\text { BIBLIOGRAPHY } & 262\end{array}$

$\begin{array}{ll}\text { APPENDICES } & 325\end{array}$

$\begin{array}{ll}\text { VITA } & 366\end{array}$ 


\section{LIST OF TABLES}

TABLE

PAGE

2.5: Basic Demographic Profile of Little Havana

2.6: Countries of Origin of Little Havana's Latino Survey Respondents

2.7: Age Breakdown by Cuban vs. non-Cuban Respondents (Recoded)

2.8: Breakdown of Income of Respondents (Recoded)

2.9: Breakdown of Level of Education of Respondents (Recoded)

2.10: List of Independent Variables and Type of Variable

4.1: Percentages Countries of Origin of Survey Respondents

Collapsed into Dominant-Subordinate Groups

4.2: Percentages Primary Identifications (Q\# 7, collapsed-1)

4.3: Percentages Primary Identifications (Q\# 7, collapsed-2)

4.4: Percentages Primary Identifications (Q\# 7, collapsed-2)

Cuban vs. Other Latino

4.5: Percentages Identification with Latino/Hispanic Panethnic Labels Do you identify yourself as Latino/Hispanic? (Q\# 8)

4.6: Percentages Identification with Latino/Hispanic Panethnic Labels

Do you identify yourself as Latino/Hispanic? (Q\# 8, collapsed)

4.7: Percentages Identification with Latino/Hispanic Panethnic Labels Do you identify yourself as Latino/Hispanic? (Q\# 8)

Cuban vs. Other Latino

4.8: Percentages Identification with Latino/Hispanic Panethnic Labels Do you identify yourself as Latino/Hispanic? (Q\# 8, collapsed) Cuban vs. Other Latino

4.9: Percentages Solidarity

Do you feel solidarity with other Latinos in the US? (Q\# 8-A) 
4.10: Percentages Solidarity

Do you feel solidarity with other Latinos in the US? (Q\# 8-A)

Cuban vs. Other Latino

4.11: Percentages Racial Identification (Q\# 9)

4.12: Percentages Racial Identification (Q\# 9, collapsed-1)

4.13: Percentages Voluntary Other Responses for Race (Q\# 9, collapsed-1)

4.14: Percentages Voluntary Other Responses for Race

(Q\# 9, collapsed-2)

4.15: Percentages Racial Identification (Q\# 9, collapsed-2)

Cuban vs. Other Latino

4.16: Percentages Voluntary Other Responses for Race

(Q\# 9, collapsed-2), Cuban vs. Other Latino

5.1: Percentages Sociability

In an average week, how many times do you converse with your neighbors? (Q\# 17)

5.2: Social Capital Community Benchmark Survey Sociability Benchmark

5.3: Summary of Significance, Independent Variables on Sociability (Q\# 17)

5.4: Percentages Neighborhood Trust (Q\# 20-A, 20-B, 20-C)

5.5: Social Capital Community Benchmark Survey Trust Benchmark

5.6: Pew Research Center Trust Benchmark

5.7: Summary of Significance

Dichotomous Independent Variables on Neighborhood Trust

(Q\# 20-A, 20-B, 20-C)

5.8: Summary of Significance

Continuous Independent Variables on Neighborhood Trust

(Q\# 20-A, 20-B, 20-C)

5.9: Summary of Significance

Dominant-Subordinate Independent Variable on Neighborhood Trust (Q\# 20-A, 20-B, 20-C) 
5.10: Percentages Ethnic Trust

How much do you trust the following groups?

(Q\# 21-A through 21-G)

5.11: Summary of Significance

Dichotomous Independent Variables on Ethnic Trust

(Q\# 21-A through 21-G)

180

5.12: Summary of Significance

Continuous Independent Variables on Ethnic Trust

(Q\# 21-A through 21-G)

5.13: Summary of Significance

Dominant-Subordinate Independent Variable on Ethnic Trust

(Q\# 21-A through 21-G)

5.14: Percentages Ethnic Trust

Dominant-Subordinate Independent Variable on Ethnic Trust in Cubans (Q\# 21-B)

6.1: Percentages Neighborhood Civic Engagement

In the past two years, have you ever...?

(Q\# 36-A, 36-C, 36-D, 36-E)

6.2: Social Capital Community Benchmark Survey

Percentage YES on Neighborhood Civic Engagement

In the past twelve months, have you...?

6.3: Summary of Significance

Dichotomous Independent Variables on Neighborhood

Civic Engagement (Q\# 36-A, 36-C, 36-D, 36-E)

6.4: Summary of Significance

Continuous Independent Variables on Neighborhood

Civic Engagement (Q\# 36-A, 36-C, 36-D, 36-E)

6.5: Summary of Significance

Dominant-Subordinate Independent Variable on Neighborhood

Civic Engagement (Q\# 36-A, 36-C, 36-D, 36-E)

6.6: Percentages Participation

Dominant-Subordinate Independent Variable on Protest

or Demonstration (Q\# 36-E) 
6.7: Percentages Associational Civic Engagement

In the past two years, have you ever...?

(Q\# 39, 40, 42)

6.8: Social Capital Community Benchmark Survey

Percentage YES on Associational Civic Engagement

Have you...?

6.9: Summary of Significance

Dichotomous Independent Variables on Associational

Civic Engagement (Q\# 39, 40, 42)

6.10: Summary of Significance

Continuous Independent Variables on Associational

Civic Engagement (Q\# 39, 40, 42)

6.11: Summary of Significance

Dominant-Subordinate Independent Variable on Associational

Civic Engagement (Q\# 39, 40, 42)

Cuban vs. Other Latino

6.12: Percentages Associational Civic Engagement

(Q\# 39, 40, 42)

Cuban vs. Other Latino

6.13: Percentages Political Civic Engagement

(Q\# 43 through 45)

6.14: Social Capital Community Benchmark Survey on Political

Civic Engagement

Percentage YES Participation

6.15: Pew Research Center Electoral Benchmark

6.16: Summary of Significance

Dichotomous Independent Variables on Political Civic Engagement

(Q\# 43 through 45)

6.17: Summary of Significance

Continuous Independent Variables on Political Civic Engagement

(Q\# 43 through 45)

6.18: Summary of Significance, Dominant-Subordinate Independent

Variable on Political Civic Engagement

(Q\# 43 through 45) 
6.19: Percentages Participation

Dominant-Subordinate Independent Variable on Political

Civic Engagement (Q\# 43, 44) 


\section{Introduction}

On April 23, 2010, Governor Jan Brewer of Arizona signed into law Senate Bill 1070 with the aim of identifying, prosecuting, and deporting illegal immigrants. This law authorizes a reasonable attempt by officials and agencies of the state, county, city, town, or other political subdivision to determine the immigration status of a person during any legitimate contact already made if reasonable suspicion exists that the person is an alien who is unlawfully present in the US. It also allows people to sue local government or agencies if they believe federal or state immigration law is not being enforced, among many other points of further enforcement of immigration laws (Arizona Senate Fact Sheet for SB 1070, 2010). The passage of SB 1070 has caused much controversy, including accusations of racist, anti-Latino, and anti-immigrant sentiment. It has also been criticized for endorsing a policy of racial and ethnic profiling (Archibold, 2010). Protests, marches, and demonstrations against SB 1070, some with hundreds of thousands of participants, have sprung up across the United States.

Just a few weeks earlier, on March 25, 2010, tens of thousands of people, most of them Cuban immigrants, took to the streets of Little Havana, Miami, to show their solidarity with Cubans on the island. The event, organized by Cuban exile cum music icon in the United States, Gloria Estefan, demonstrated support for and solidarity with the Damas de Blanco (Ladies in White), peaceful dissidents in Cuba who were attacked by government security forces in Havana a week prior; the event was also a show of defiance and protest of the continued human and political rights abuses of the communist Castro government (Yanez et al., 2010). Both of these stories are brief but poignant illustrations of the continued vibrancy of, contention around, and place-specificity of 
responses to immigration, ethnicity, solidarity, and civic engagement on various scales in contemporary life in the United States.

Indeed the history of the United States is often said to be the history of immigrants (Castle and Miller, 2003; Joppke, 1999; Handlin, 1973). Scholars commonly categorize the two majors waves of migration to this country in the late $19^{\text {th }}$ and $20^{\text {th }}$ centuries as the 'old immigration' from 1890-1920 - consisting mostly of Italians and Russian Jews - and the 'new immigration' from 1965 to the present - consisting mostly of non-Europeans from Asia, the Caribbean, and Latin America (Foner, 2005; Alba and Nee, 2003; 1997; Glick Schiller, 1999; Portes and Rumbaut, 1996). The diverse character of these waves is rooted in numerous factors, including changing US immigration policy and politics, immigrants' varied economic motivations, familial ties, and events occurring in world region of origin.

The importance of immigration to the national social, political and economic fabric of the US has led social scientists across the disciplines to study myriad aspects of the immigrant experience, including geographic settlement patterns (Allen and Turner, 2005; Friedman et al., 2005; Pandit and Holloway, 2005; Alba et al., 1997; Park et al., 1984 [1925]; 1928), psychological effects of the process of adaptation to life in the adopted country (Portes and Rumbaut, 1996; Mahler, 1995), and the economics of migrant communities (Waldinger and Lichter, 2003; Bohon, 2001; Portes and Stepick, 1993; Waldinger, 1989; Portes and Manning, 1986; Pedraza-Bailey, 1985; Light, 1984; Bonacich, 1980). The field of immigration studies has often intersected with topics of ethnicity and race; the successive waves of voluntary and involuntary immigrants over the decades since the foundation of the nation have shaped the meaning and reality of 
race and ethnicity in this country, influencing the very meaning of what it means to be American (Gaultieri, 2001; King, 2000).

South Florida is one of the regions in the US that has experienced dramatic changes as a result of the arrival of immigrants over the course of the last 50 years (Boswell and Jones, 2007; Airriess and Miyares, 2006; Alberts, 2006; Mormino, 2005; Frazier and Margai, 2003; Portes and Stepick, 2003; 1993; Reisinger and Tettey-Fio, 2003; Nijman, 2000; Boswell and Curtis, 1982). Immigration from Latin America and the Caribbean has shaped South Florida's demographic, political, economic, and cultural landscapes. The arrival of Cubans, beginning in 1959 after the political revolution on the island, has continued to the present. The Cuban group was joined by large numbers of Nicaraguans in the late 1970s and 1980s. Since that time, immigration to South Florida has come to include people from all over Latin American and the Caribbean (Stepick et al., 2003; Boswell, 2001; Portes and Stepick, 1993). The influx of Spanish-speaking Latin American immigrants has been accompanied by large numbers of Haitian and West Indians as well, adding to the region's longstanding Bahamanian population (Portes and Stepick, 1993). In fact, the city of Miami has the highest percentage of foreign-born residents in the entire world (Human Development Report, UNDP, 2004). The heavy flow of immigrants settling in South Florida has resulted in an intricate mix of peoples, languages, and ideas, and has produced a unique local, Latinized culture. It has even been argued by some scholars that Miami is the capital of the Caribbean (McHugh et al., 1997; Portes and Stepick, 1993) and of Latin America (Stepick et al., 2003; Nijman, 2000). 


\section{Research Questions}

Since the early $20^{\text {th }}$ century, scholars have studied how immigrants incorporate into various aspects of life in the United States. The diversity found within South Florida, and more specifically Miami, its recent history of immigrant arrival, and concentrated immigrant population makes it an excellent place to study immigrant incorporation. This dissertation explores three aspects of immigrant incorporation: ethnic and racial identity, trust and community, and civic engagement. ${ }^{1}$ All three are intertwined in complex ways with theories of immigrant incorporation, especially the assimilation paradigm, as well as popular beliefs and assumptions about the attitudes and behaviors that immigrants to the United States do (and should) have.

The quantitative and qualitative research upon which this dissertation is based was carried out in the Little Havana, an overwhelmingly immigrant and Latino ${ }^{2}$ neighborhood of Miami, Florida. As such, the data on Latin American immigrants and American Latinos offer the opportunity to empirically answer the following three sets of research questions:

\footnotetext{
1 This dissertation is based on research conducted for 'Comparative Civic and Place Engagement in Three Latino Enclave Neighborhoods in Transition’ from January 2005 through December 2006. The project was funded by the National Science Foundation Human and Social Dynamics program under Award No. 433947. Any opinions, findings, conclusions, or recommendations expressed in this paper are those of the author and do not necessarily reflect the views of the National Science Foundation.

${ }^{2}$ In this dissertation, Latino refers both to Spanish-speaking immigrants from Latin American countries as well as the offspring of this group. The panethnic identifiers Latino and Hispanic are used interchangeably here, although the author acknowledges each term's unique history and development. There continues to be debate over the origins, meanings, and nuances of these terms. In general, use of these terms is posited to vary such that, on the one hand, Latino is used in the Western part of the US, whereas Hispanic, on the other hand, is used in the East and by the federal government (Affigne [2000]; Kanellos, [1994]). For lengthier discussion on this topic, see Committee on Transforming our Common Destiny (2006); Arreola (2004); Dávila (2001); De Genova and Ramos-Zayas (2003); Stepick and Stepick (2002); Gracia (2000); Calderón (1992).
} 


\section{Regarding Ethnic and Racial Identities:}

How do residents of Little Havana identify ethnically and racially?

If common identifiers and identities do exist, how and when are they expressed? Do neighborhood residents feel a sense of group solidarity? If so, with what groups? Upon what are their feelings of solidarity based and how do they manifest? Do tensions exist with the Latino panethnic group? If so, upon what are they based? Do data suggest that residents of Little Havana are incorporating identificationally or not?

\section{Regarding Trust and Community:}

What are the levels of sociability, neighborhood and ethnic trust in Little Havana? What are the factors that influence levels of trust between individuals and groups? Is there a sense of community in Little Havana? If so, upon what is it based? If trust and community are not present, what is impeding their development or success?

Do data suggest that residents of Little Havana are incorporating with respect to trust and community or not?

3. Do Latino residents of Little Havana engage civically? If so, how? Why? When? Around what issues? If they do not engage, why not? At what scales do they engage? Do data suggest that residents of Little Havana are incorporating civically or not? 


\section{Relevance and Impact of Dissertation Topic}

This dissertation is relevant and important for several reasons. First, since 2003 Latinos have displaced African Americans as the largest minority group in the United States (at $15 \%$ and $13 \%$, respectively; US Census, 2003). Focused and specific research on the growing Latino minority group is essential to understanding the nation's changing ethnic and racial panorama, especially as it relates to recently arrived immigrants. As the settlement of Latin American immigrants is not an isolated phenomenon particular to South Florida, but rather generalized throughout the United States, urban and rural alike, a study of the place-specific ways that this population incorporates into various aspects of life in the US can be used to compare and contrast similar populations in other US locations. The diverse composition of the Little Havana neighborhood allows for a nuanced understanding of the ways that Latin American immigrants might incorporate in different ways, moving the discussion away from the perception of Latinos as an unproblematically monolithic ethnic group.

Second, this dissertation touches upon aspects of society that for centuries have been considered hallmarks and foundations of American life. Alexis de Tocqueville's work (1973 [1840]) on civic life in the expanding United States posited high levels of trust and participation in civic organizations as essential to the fiber of the social fabric in the country. More recently, the work by scholars (Putnam, 2007; 2000; 1999; 1995; Paxton, 2007; 2005; 2002; 1999; Putnam et al., 2006; Skocpol, 2003; Uslaner and Conley, 2003; contributors to Skocpol and Fiorina, 1999; Uslaner, 1999) posits that this social fabric has slowly become frayed, leaving a void of sociability, trust, and civic participation. Some immigrant groups, especially Latin Americans, have been blamed by 
some (e.g., Huntington, 2004) as a major factor in this process of civic erosion. Data from this research are used to confirm, contradict, nuance, and expand upon various facets of previous work on this matter.

Third, as far as issues of generalized trust and civic engagement are concerned, Latinos and immigrants are both understudied groups, and focused studies on this population are needed (Stepick et al., 2009; Putnam, 2007; Marschall and Stolle, 2004; Ramakrishnan and Baldassare, 2004; Leighley and Vedlitz, 1999). When the Latino group is considered vis-à-vis other ethnic and racial groups, the statistical analysis performed is often not adequate. ${ }^{3}$ Furthermore, Latinos are usually studied as an unproblematically monolithic ethnic group, thus ignoring the differences and diversity that exist within the socially-constructed panethnicity (Price, 2007; Arreola, 2004; Arreola et al., 2004). Panethnic identifiers can and often do erase or obscure the particularities of individuals and groups from the twenty or so Spanish-speaking countries of Latin America and their US-born children. The consideration of intra-Latino diversity in this dissertation contributes greatly to the body of literature on these issues where there is a dearth of research on Latino diversity vis-à-vis identity, trust, and civic engagement.

Fourth, this dissertation is based upon research that is inter-disciplinary between geography, political science, and anthropology, and employs a multi-method data collection approach. The majority of the current literature that examines the intersection of ethnic and racial groups and civic engagement does so within the framework of one academic discipline, political science (Ramakrishnan and Baldassare, 2004; Putnam,

\footnotetext{
${ }^{3}$ See Leighley and Vedlitz (1999) and Verba et al. (1999) for reasons as to why this is the case, including under-sampling and low sample sizes.
} 
2000; Leighley and Vedlitz, 1999; Verba et al., 1993), although some recent work (e.g., Stepick et al., 2009; Edmondson, 2001) provides ethnographic evidence from an anthropological point of view. Furthermore, ethnic and racial identity, generalized trust, and civic engagement have only rarely been discussed together (e.g., Putnam, 2007; Uslaner and Conley, 2003); instead most work analyzes two of the three topics together (e.g., McPherson et al., 2006; Marschall and Stolle, 2004; Alesina and La Ferrara, 2000). In this dissertation, perspectives and theories from various disciplines are interwoven with quantitative and qualitative data to examine the three topic areas individually and in tandem.

A limitation of many of the studies mentioned above is the scale at which they collect and analyze data; i.e., their data are aggregated at the county, metropolitan area, state, or national scale. Studying identity, trust, and civic engagement in a specific neighborhood contributes to a return to and re-focus on the local, where life is actually lived and decisions made (Orosco, 2007; Arreola et al., 2004; Marschall and Stolle, 2004). The complexities of the local can be blurred by research performed in the aggregate.

Focusing research on the neighborhood scale also contributes to a greater understanding of the often confusing and confounded concept of community. Some scholars have pointed out that community has often been used interchangeably and conflated with neighborhood (Herbert, 2005; Martin, 2003; Forrest and Kearns, 2001; Mercer, 1995; Hunter, 1979). This is a result of the fact that propinquity has been assumed to be the foundation for sociability, solidarity, and action. Whereas this might have been the case in the past, increased distances and mobility, and technological 
advances such as the Internet, may put into doubt such a notion (Herbert, 2005; Swyngedouw, 1989). Empirical data from this study is used to flesh out the role played by the neighborhood in the formation and execution of community as both a lived, and sometimes spatially discontinuous, entity. As will be discussed in the following chapter, Little Havana is a neighborhood where the issues facing both immigrant and US-born Latinos, especially those who live in urban areas, can be studied.

Fifth, Miami has begun to take a more prominent position on both the national and international scale. Substantial focus has been given to the growth of Miami as a city, both in terms of its population, as well as its relative importance as an international and global city (Nijman, 2000; Sassen and Portes, 1993). It has become an important center for technology, international banking, shipping and transportation, as well as a cultural hub for the United States, Latin America, and the Caribbean. If Miami is, as Nijman (2000) argues, a "paradigmatic" city, a greater depth and breadth of understanding of Miami will serve to understand and explain other cities throughout the United States.

Sixth, this research contributes significantly to theoretical discussion in social science literature. It adds to the body of knowledge on ethnic and racial identity formation, with an emphasis on the nuanced employment of the panethnic label Latino. As some authors (Price, 2007; Campbell and Rogalin, 2006; Arreola, 2004; Arreola et al., 2004; De Genova and Ramos-Zaya, 2002; Calderon, 1992) point out, the creation, employment, and validity of a panethnic identity is, at the very least, problematic. The complexities of Latino identity can shed light on the greater issues of trust and community-building as well as collective action.

Structure of the Dissertation 
Chapter Two discusses various aspects of neighborhood. Part I explores the origins of neighborhood studies, debates around operationalizing the concept, and a consideration of the oft-confused relationship between neighborhood and community. A discussion of the role of the neighborhood in immigration incorporation follows. Part II specifically addresses the neighborhood of Little Havana, describing its boundaries, socioeconomic profile, demographic changes, and history as an ethnic neighborhood. The chapter ends with a description of the research design, methodology, and data analysis upon which the dissertation is formulated.

Chapter Three serves as a literature review of the four main aspects of immigrant incorporation that will be examined in this dissertation. First, assimilation theory is discussed, including its critiques and alternative approaches. Next, scholarship on ethnic and racial identity is traced historically, ethnicity and race are operationalized, and the nuances of Latino ethnicity and race are explored. Trust is next defined, followed by a discussion on its formation and important empirical findings on trust from the social science literature. In the final section of this chapter, civic engagement is operationalized, the most influential model to explain civic and political engagement (the socioeconomic model) is considered, followed by findings on civic engagement and immigrant incorporation.

Chapter Four reports and interprets data on ethnic and racial identity and identifications in Little Havana. Quantitative data are used to describe and analyze the ways that neighborhood residents identify primarily, panethnically, in regards to panethnic solidarity, and racially. They reveal that primary identification continues to be dominated by country of origin, though other identifications (e.g., panethnic, hyphenated) 
are also quite popular. At the same time, the vast majority of residents identify using a panethnic label and report feeling solidarity with other Latinos. Data also indicate the salience of panethnic labels for racial identification. In short, Latin American immigrants and American Latinos in Little Havana appear to be incorporating identificationally into life in the US. Nevertheless, ethnic and racial identities are not uncomplicated, as the data reveal both cleavages and prejudices among neighborhood residents, often based on country of origin, socioeconomic status, and culture.

Chapter Five explores data on sociability and two kinds of trust: neighborhood and ethnic. Levels are each are presented and benchmarked to the extent possible. The relationships between neighborhood and ethnic trust and widely-accepted factors that are theorized to affect them are discussed. Trust is then considered vis-à-vis community. Overall, quantitative data reveal notable levels of sociability and neighborhood trust, but lower levels of ethnic trust. Qualitative data reveal the nuances of the ways that trust and community are built and expressed, and point to the limited value of panethnic labels for bridging differences between members of different Latin American-origin groups. Though there is limited evidence of a panethnic Latino community in Little Havana, residents, there are strong indications that Little Havana is still a hub for Cuban community.

Chapter Six describes and analyzes the levels of three types of civic engagement in Little Havana: neighborhood, associational, and political. Civic engagement indicators were analyzed for their relationship with the same set of independent variables used in Chapter Five on trust. Low levels of participation were found for most civic activities, although formal political participation in the form of registering to vote and turning out at 
the polls was very high. The limited civic engagement found in Little Havana might not be surprising given the over low socioeconomic profile of the neighborhood, except that education and income are rarely consistently statistically significant. Overall, findings point to the place-specific ways that immigrants, Latinos, and neighborhood residents more generally, participate civically, as well as the ways that immigrants from Latin America incorporate into US society.

Chapter Seven summarizes research findings and by way of conclusion engages with the problematic conceptualization of social capital and the supposed relationships between identity, trust, and civic engagement. The data discussed throughout the dissertation point to different ways that identity, trust, and civic engagement are practiced in Latin American immigrant neighborhoods and reveal new understandings of the ways they incorporate into life in the US. 


\section{Placing Neighborhood and Little Havana in Social Science}

'Community' is term which is applied to societies and social groups where they are considered from the point of view of the geographical distribution of the individuals and institutions of which they are composed.

- Robert Park and Ernest Burgess, Introduction to the Science of Sociology (1921)

A successful city neighborhood is a place that keeps sufficiently abreast of its problems so it is not destroyed by them. An unsuccessful neighborhood is a place that is overwhelmed by its defects and problems and is progressively more helpless before them.

- Jane Jacobs, The Death and Life of Great American Cities (1961)

The unique features of the local neighborhood, its locus as the grounded point of intersection of diverse interests from the larger society, coupled with the sentiments of place that inhere within it, will keep the neighborhood alive as an important social unit. It is up to social scientists to continue to explore the intersection of these sentiments...

- Albert Hunter, The Urban Neighborhood: Its Analytical and Social Contexts (1979) 


\section{Introduction}

The neighborhood has been an integral aspect of scholarly discussions of immigrant incorporation for at least the past 100 years. This dissertation, based on the scale of the neighborhood, contributes to the understanding of how new geographies of citizenship, identity, community, and civic and political participation are being negotiated at various scales, including the scale of the neighborhood (Amin, 2005; 2004; 2002; Arreola, 2004; Amin and Thrift, 2002; Mayo, 2000; Sanjek, 1998; Flores, 1997; Rocco, 1996; Gupta and Ferguson, 1992).

Chapter Two explores three background areas that are necessary to understand the research presented here, and is divided into three parts. First, theoretical and conceptual frameworks in scholarly social science literature are reviewed with respect to the ways that the neighborhood has figured in the study of immigrant incorporation. Then, Little Havana - the neighborhood upon which this dissertation is based - is discussed. Its historical, social, political, and economic context is considered as a place embedded within the Miami metropolitan area. ${ }^{4}$ Finally, the research design, methodology, and data analysis are detailed.

\section{Placing the Neighborhood}

\section{Origins of Neighborhood Studies}

The concept of neighborhood appears in social science literature as early as the late- $19^{\text {th }}$ and early-20 ${ }^{\text {th }}$ centuries. Scholars including Tönnies (1963 [1887]), Durkheim (1984

\footnotetext{
${ }^{4}$ Miami can refer to the City of Miami, Miami-Dade County, or the Miami metropolitan area. The City of Miami has about 375,000 residents and is the largest municipality in Miami-Dade County. The Miami metropolitan includes Miami-Dade, Broward, and Palm Beach Counties and has a total population of about 5.4 million. In this dissertation, Miami refers to the City of Miami unless otherwise specified.
} 
[1893]), Simmel (1971 [1903]), and Weber (1968 [1922]) were provoked to question how social life and the connection between individuals, their communities, and society were changing due to the intense industrial urbanization of their time. In his work, Community and Society (Gemeinschaft und Gesellschaft), published in 1887, for example, Ferdinand Tönnies contrasted modern Western society to more tradition practices of extended families residing together, guilds, and village communities. The former was characterized by expediential, atomized, rationalistic, and individualistic characteristics (Gesellschaft), while the latter was characterized by highly integrated, intense solidarity, and bound by highly affective overtones (Gemeinschaft). Simmel (1971 [1903]) echoes Tönnies when he criticized the extremely individualistic, tradition-destroying forces of modern urban society, as did Durkheim (1984 [1893]) in his focus on mechanical solidarity. ${ }^{5}$

The notion of community for the above-mentioned scholars was localized, at times on the scale of the neighborhood, where personal contact and relations cohered to foster a collective sentiment. Urban and community studies have continued the tradition of analyzing the relationship between community and neighborhood, giving rise to enduring concepts such as Whyte's (1943) “street-corner society” and Gans' (1962) "urban villages." These ideas have framed social scientists' understandings of local-level social organization throughout the $20^{\text {th }}$ century (Sullivan, 1995; Shils, 1957).

Neighborhood studies, which since their inception have gone hand-in-hand with community studies, have focused on change, focusing first on change caused by industrial urbanization, and later by immigration. Scholars developed various models to

\footnotetext{
${ }^{5}$ Cooley (1922 [1902]; 1918; 1909) also focused his attention on similar topics, solidarity and 'we-ness,' manifested, for example, in neighborhoods, families, and children's play groups. He called these 'primary groups.'
} 
explain neighborhood change (e.g., invasion-succession, neighborhood life cycle) as well as several theoretical perspectives such as demographic/ecological, sociocultural/organizational, political-economy, social-movements (Schwirian, 1983). The most enduring and influential body of work was created by members of the Chicago School of sociology (discussed in detail below). Members of this school created a typology of neighborhoods and described cycles of land-use change that fostered neighborhood change over time (see Park et al., 1984 [1925]). They emphasized the role of the immigrant neighborhood, a distinctive element in the American landscape for decades, for immigrant incorporation (Conzen, 1979).

\section{Operationalizing Neighborhood}

Despite the copious amount of work done on neighborhoods across the social sciences, there is still no easy consensus as to how to define the concept. Minimally, scholars agree that neighborhoods are residentially-based; or, at least, are the site of daily life and social interaction (Martin, 2003; Galster, 2001; 1986; Kearns and Parkinson, 2001; Park et al., 1984 [1925]; Olson, 1982; Hunter, 1979). Galster (2001) believes that a neighborhood is "a term that is hard to define precisely, but everyone knows it when they see it" (2111).

Such a reliance on shared experience and feelings to delineate the neighborhood follows the tendency mentioned above to equate neighborhood with community (Martin, 2003; Forrest and Kearns, 2001; Raco and Flint, 2001; Mayo, 2000; Wellman and Leighton, 1979).

The notion of neighborhood as a community of shared sentiment rightly or wrongly rests on ideals of what urban neighborhoods are expected to be. A normatively 
'good' neighborhood, therefore, consists of residents who share values and lifestyles, and feel a sense of common purpose or solidarity (Herbert, 2005; Sullivan, 1995; Hunter, 1979). Robert Park (1984 [1925]) explains the convergence of neighborhood and community in the following way: "Each separate part of the city is inevitably stained with the peculiar sentiments of its population. The effect of this is to convert what was at first a mere geographical expression into a neighborhood, that is to say, a locality with sentiments, traditions, and a history of its own. Within this neighborhood the continuity of the historical processes is somehow maintained" (6).

The connection between residential propinquity and shared sentiment took root, resulting in what has become the assumption of a 'spatial match' between community and neighborhood. Burgess (1984 [1925]), for example, asserts that "[w]hatever else community may be, it signifies individuals, families, groups, or institutions located upon an area and some or all of the relationships which grow out of this common location" (144). Assuming the existence of community based solely on the fact of residential propinquity, however, leads to various problems. Wellman and Leighton (1979) argue that the conflation of community and neighborhood results in an unfair pessimism because of a focus on the loss of community and therefore a loss of traditional ways of life (as in Putnam, 2000; Park et al., 1984 [1925]; Tönnies, 1995 [1887]). These authors advocate that researchers separate conceptually neighborhood and community.

Work in the field of immigration studies, such as the ethnic enclave theory (Portes and Schaefer, 2006; Min Zhou, 2004; Yu Zhou, 1998; Portes and Jensen, 1987; Portes and Manning, 1986; Wilson and Martin, 1982), the ethnoburb (Li, 1998; see also Skop and Li, 2002), and heterolocalism (Zelinsky and Lee, 1998) are examples of work that 
shows that community does not have to be spatially constrained by the common locality of the neighborhood. This work is based on empirical examples in which neighborhood and community do not coincide, and offer a more nuanced understanding than that allowed by the historic conflation. If scholars limit their focus on spatially delineated settings like neighborhoods, then the social ties that may, and probably do, exist at different scales and within different boundaries might be obscured (Martin, 2003; see also McCann, 2003; Raco and Flint, 2001; Massey, 1997). In sum, neighborhood is a place that sometimes constitutes community, but is not limited to that meaning, and vice versa (Wright et al., 2004).

Galster's notion of a 'self-evident' neighborhood, mentioned above, allows scholars to ignore the intentionality of community creation. As Martin (2003) emphasizes, neighborhoods are always constructions, either for research or other practical social purposes by people either within or outside the boundaries of the neighborhood. Often neighborhoods are defined by social interactions or particular events (including conflicts). As such, neighborhoods can be contested and re-defined through continued and/or different interactions or events.

Some of the early sociologists mentioned above (e.g., Durkheim (1984 [1893]; Park, 1984 [1925]; Simmel, 1971 [1903]), as well as more contemporary scholars (e.g., Martin, 2003; Taylor, 2003; Meegan and Mitchell, 2001; Hunter, 1979) emphasize that the creation and assignment of meaning to neighborhoods is a co-constitutive process. This means that neighborhoods are created not only by individual perceptions or actions, but the "social structures that create and maintain particular neighborhood circumstances and character are also constitutive of individual behavior and neighborhood meaning" 
(Martin, 2003: 365). The view of a co-constitutive neighborhood reflects a more general understanding that individual agency, social structure, and space are dialectically related and mutually constitutive (see Massey, 1997; 1994; 1991; Lefebvre, 1991 [1974]; Harvey, 1989; Soja, 1989; Pred, 1986; 1984).

Following Suttles' (1972) work on neighborhoods, Hunter (1979) advocates the approach that is used in this dissertation, characterizing the neighborhood as "a uniquely linked unit of social/spatial organization between the forces and institutions of the larger society and the localized routines of individuals in their everyday lives" (269). This approach considers neighborhood in 'context,' i.e., as an embedded phenomenon, linked to other places and processes both greater and smaller, and forming part of a nested set of social, political, and economic forces. From this perspective, neighborhood as multiscalar entity comes into relief. "The combination of individual or group behavior and attitudes, and broad social, economic and political processes that all constitute neighborhoods means that they are truly multiscalar" (Martin, 2003: 366; see also Taylor, 2003; Kearns and Parkinson, 2001). As Meegan and Mitchell (2001) point out, "it is crucially important to view neighborhoods in a city/city-region context and to recognize the importance of neighborhood agency...in both the definition of neighborhood and the 'up-scaling' of relationships across and beyond neighborhoods" (2174). Devolved forms of government and privatized government function along with down-scaled decisionmaking to local levels due to neoliberal forms of governance reinforce the importance of the neighborhood for enacting multiscalar economic, political, and social processes in a place (Herbert, 2006; 2005; Harvey, 2005; Elwood and Leitner, 2003; Taylor, 2003; Laurier et al., 2002; Swyngedouw, 1989). 
Another trend in the neighborhood literature, also rooted in the work of the Chicago School, assumes a correlation between the neighborhood environment and social outcomes; this body of literature is known as the 'neighborhood effects' theory. Underlying this theory is the assumption of a social boundary firm enough for a distinctive culture to arise. This approach is part and parcel of an ecological paradigm that underpinned all Chicago School work - the belief that cultures are mosaic-like, i.e., side by side but not interacting (discussed below). Localized neighborhood cultures affect the attitudes, behaviors, and life-chances of individuals, typically in a negative fashion. The theory builds upon the classic, though severely critiqued, work of Oscar Lewis (1959), who argued that a "culture of poverty" restricted life chances of residents in very poor neighborhoods of Mexico City. ${ }^{6}$ In a similar (and similarly-critiqued) fashion, William Julius Wilson (1987) focused on social organization of inner-city neighborhoods; he posited that the concentration of poverty leads to certain individual attitudes and behaviors that foster deviance. More recent research, however, disputes such singular causal approaches and has shown that other factors play a significant role in life opportunities (Buck, 2001; Ellaway et al., 2001; Forrest and Kearns, 2001; Talen, 1999). Bauder (2002), for example, points out the underlying normative assumptions inherent in this literature: if the residents of a community do not meet a given standard of behavior, they are seen as abnormal or aberrations. He advocates instead for the non-

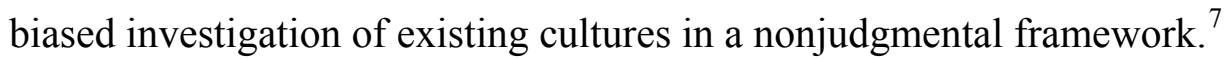

\footnotetext{
${ }^{6}$ Lewis continued this line of study in later works, including his ethnographic work on a family in Puerto Rico. See Lewis (1966).

${ }^{7}$ A possibilistic approach, not a deterministic approach, is taken in this dissertation, i.e., the local cultural context shapes, not determines, outcomes; nor is it the only factor at play. Possibilism is a distinct approach
} 
The final strain of neighborhood literature bearing directly on this dissertation locates the roots of 'neighborhood' in collective action or activism. When neighbors interact socially and a feeling of cohesion exists, political action results more often and fluidly. Sentimental community, thus, is seen as a building block of political community. The works of Taylor (2003), Escobar (2001), Robinson (2001), and Jonas (1998) show that political communities are created and nurtured through interactions in everyday life, be they based in the workplace, home, or neighborhood. ${ }^{8}$ Similarly, Forrest and Kearns (2001) defined "community spirit" as "the capacity to act collectively," which they linked to social cohesion in neighborhoods (2131). Furthermore, Robinson (2001) argues that there is a relationship between space, identity, and political opposition, in which residents of a community may use their individual and group identifications with self and place to create a shared 'oppositional consciousness' that motivates community action. Oppositional consciousness can arise from the day-to-day interactions among residents that foster a sense of community and shared concerns or values. One limitation of this approach is that it can conflate neighborhood and community, and as such suffers from the same problems discussed above. A second limitation to this literature is that it does not pay sufficient attention to the co-constitutive dynamics between sentimental and political community. Emphasis is given to the necessary precursor of a sentimental community to foster political community, and not the how political community changes, influences, helps, or hinders the existence of sentimental community.

to geographical knowledge, directly opposed to geographical determinism. See Gregory (1981) for an indepth discussion.

${ }^{8}$ For an ethnographic study of the nuances of community enacted in suburbia as seen through the practice of 'neighbouring' occasioned by the search for a lost cat, see Laurier et al. (2002). 
In conclusion, three main points from the above discussion are worth reiterating. First, defining neighborhood is not easy and any particular neighborhood cannot be taken as a given. Rather it is an empirical question to be teased out. The perspective used in this dissertation is understanding a neighborhood 'in context,' as embedded within and linked to people and institutions on a variety of scales, with its own set of social and spatial dynamics. Finally, assumptions about socio-spatial relations in place, namely the conflation of neighborhood and community, can obscure the contours and processes of immigrant incorporation that are truly at work. In sum, these three main points are integral to the analysis of Little Havana and the process of immigrant incorporation in place, and will be discussed further throughout the balance of the dissertation.

\section{The Neighborhood and 'Becoming American'}

The importance of the role of the neighborhood in the study of immigrant incorporation is rooted in the work of the world's first department of sociology, founded at the University of Chicago in 1892. This department acquired a paradigmatic status under the charismatic leadership of Robert E. Park, who, along with W. I. Thomas and Ernest Burgess, led the Chicago School's work on ethnicity and race, immigration, intergroup relations, incorporation into US society, and the social problems of urban areas, notably Chicago. Their dominance in the social sciences on these topics lasted until roughly 1940, although the contributions of these intellectual pioneers continue to be relevant today (Nichols Clark, 2008; Sampson, 2008; Dear, 2003; 2002; Lal, 2003; 1990; 1987; Abbott, 1997; Cortese, 1995; Kazal, 1995; Goist, 1971). 
Chicago School scholars lived at a time when tens of thousands of European immigrants were arriving to Chicago, as well as a large number of Southern blacks as a result of the country's mobilization for World War I and shifting regional geographies of labor. Robert Park used ecology - the study of plant and animal life - to convert the facts of city life into a model to explain urban processes. He employed the concepts of competition, invasion, dominance, and segregation as the basis of "human ecology," by which he expressed the bio-logic of the physical and social changes affecting Chicago. As he saw the city grow with the influx of new inhabitants and the relations that sprung from their interaction, Park identified the consequence of this rapid urbanization as "social disorganization" in which the city disrupted the modes of association to which those who arrived in the city were accustomed. It demanded that newcomers adjust their habits and communication to a new way of life, and fit into the city's teleological progress (Goist, 1993; Marcus, 1985; Goheen, 1974).

In line with their view of society as an organism and history as a process in which progress came through conflict and transformation, Park and his colleagues posited that the social disorganization experienced by immigrants upon their arrival to the city would ultimately result in their assimilation. Assimilation, however, did not mean societal homogenization, but rather a proliferation of diversity. Individuals would break free from their ethnic attachments and form new social groups and express of their collective distinctness. The key element in the process of assimilation was the structure of the city; Burgess described its organization as "a centralized decentralized system of local communities" (Park et al., 1984 [1925]: 53). Each neighborhood constituted an internal 
community and differed from all others adjacent to it; they were inclusive activity spaces where people lived, worked, and worshipped (Martin, 2003). ${ }^{9}$

The ecological view resulted in the most enduring of the Chicago School models: the zonal or concentric ring theory, an account of the evolution of differentiated urban social areas by E.W. Burgess (1984 [1925]; see also Dear, 2003). He described the city as comprised of zones of adjacent niches occupied by human groups in a series of concentric rings surrounding a central core (See Figure 2.1 below). The concentric rings designated both the successive zones of urban extension and the types of areas that would be differentiated in the process of expansion. Traveling away from a central business district, one passes through a deteriorating zone in transition, holding immigrant colonies; to a zone of workingmen's homes - an area of generally second-generation immigrant settlement; to a residential zone of middle-class housing; and finally a suburban commuters' zone. Each zone tended to extend its area by invading its outer neighbor in a process of succession. In Burgess' own words: "In the expansion of the city a process of distribution takes place which sifts and sorts and relocates individuals and groups by residence and occupation" (Park et al, 1984 [1925]: 54; see also Dear, 2003; Low, 1996a).

In Burgess' view, the process of neighborhood succession within the city caused a social and spatial disorganization that was followed by reorganization; this process was both normal and progressive. In effect it caused an efficient, although at times uncomfortable, spatial and cultural adjustment of immigrant individuals and groups.

\footnotetext{
${ }^{9}$ Perhaps the most exemplary work on neighborhoods as natural areas is Louis Wirth's (1964 [1928]) The Ghetto, which traces the history of the Jews and their eventual arrival and settlement in the United States, concretely in New York City.
} 
"Class, occupation, world view, and life experiences are coterminous with an inhabitant's location within these niches. Social change occurs through socioeconomic transitions, with each group replacing the next in an outward spiral" (Low, 1996a: 385).

\section{Figure 2.1: Burgess' Zonal or Concentric Ring Model}

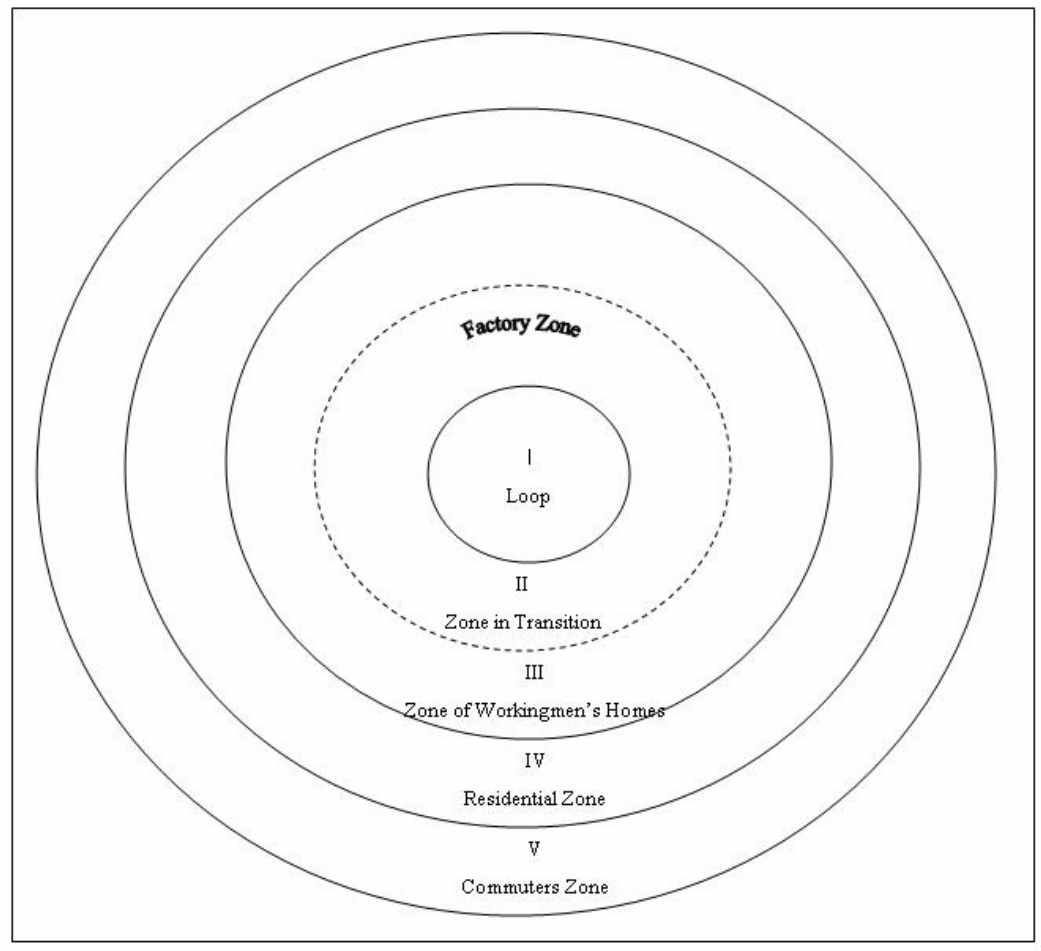

Source: adapted from Park et al., 1984 [1925], p. 51

For Chicago School scholars, the ethnic neighborhood was considered a 'natural area,' in that it served as a surrogate small town, similar to that from which the immigrant newcomer originated. Most of the immigrants at that time came from rural communities, where their lives were organized and prescribed through local institutions such as the extended family. According to Park, the 'natural area' was key for individuals to 
integrate into the life of a larger urban society. 'Natural areas' also provided a basis for association within the city, and thus a way for newcomers to reorganize. Through participation in immigrant organizations, the immigrant eased the reorganization of oldworld 'habits' into the new urban American context. These organizations - such as boarding houses, restaurants, and steamship, labor and real estate agencies - provided immigrants with collective support and allowed for new behavior appropriate to the circumstances of the receiving society; they also curbed the drift toward personal disorganization. In sum, 'natural areas,' full of institutional and associational life, bridged immigrants' past experiences with their new environment.

The cohesive community found at the localized scale in the 'natural area' further gave the immigrant group resources in its social conflict over status with other immigrant groups and American-born citizens. ${ }^{10}$ Indeed, the local (neighborhood) scale was crucial for Park and members of the Chicago School for understanding immigrant incorporation. "While Park recognizes other, non-spatial aspects of city life (e.g. public and political institutions - public schools - and social movements) which contribute to social reorganization, the starting point for understanding the dynamics of community in the large American city is the local (natural) areas" (Lal, 2003: 548).

Their work in Chicago further led members of the School to the finding that the development of parochial immigrant institutions and a strong cultural identity actually hastened the incorporation of minority groups into the mainstream of American life what has been called the 'ethnic paradox' (Lal, 2003; Wood, 1992; Cazenave, 1991).

\footnotetext{
${ }^{10}$ Note that according to Lal (2003), Park and Thomas believed that the root of social conflict of immigrant groups with other immigrant groups and with American-born citizens was largely about socioeconomic status, not ethnicity per se.
} 
Ethnic relationships are especially useful to economic success and in that sense incorporation into US society. "[T]he immigrant uses the distinctiveness of the ethnic culture to build sufficient personal confidence to face the difficulties of assimilation into the larger society and participation in the capitalist economy" (Wood, 1992: 55).

In sum, for Park and others of the Chicago School, ethnicity was the lynchpin of understanding and explaining immigrants' neighborhood selection, community creation, and ultimately their assimilation. Ethnic neighborhoods were populated by families that shared common cultural backgrounds, where economic insecurities - particularly in working-class areas - led people to rely upon one another for mutual assistance. The assistance was given due to shared bonds and obligations based on ethnic ties. These ties declined, however, as households developed greater economic independence, or, at least, as interactions among households decreased with growing distances traveled to work, greater use of telecommunications, and greater access (and attachments) to people living in other locations (Martin, 2003; see also Cox, 1982).

Politically speaking, ethnic neighborhoods were also crucial in that they served as the crux of immigrant political incorporation because they forged the primary ties and loyalties upon which the political machines of American cities were built. As Hunter (1979) points out, the ethnic political machines have in general declined over the course of the $20^{\text {th }}$ century because of successful immigrant incorporation. That is, as immigrants incorporated, they achieved greater social mobility accompanied by greater spatial dispersion and weaker ethnic identity due to the lack of daily reinforcement of the communal ethnic culture found in ethnic neighborhoods. This resulted in a weaker or 
disappeared dependence on the benefits that ethnic political machines could offer them (Conzen, 1979).

Chicago School scholars and their theoretical contributions to the social sciences shaped the understanding of neighborhood life and immigrant incorporation throughout the $20^{\text {th }}$ century and beyond. Their insights into the role of socio-spatial form and the management of difference are significant, as are the contributions made by more recent scholars who have critiqued and advanced their work. Caution at applying Chicago School principles to the analysis of urban life and immigration in the $21^{\text {st }}$ century is in order. This is especially the case in light of the discussion above on the dangers of conflating neighborhood and community, as was the tendency of Chicago School scholars. To what extent neighborhoods exist today as communities or 'natural areas' is an empirical question.

\section{Beyond the Chicago School}

The Chicago School's ecological models have been criticized from a variety of perspectives. Demographers, for example, have challenged the inevitability of racial transitions, especially as they pertain to Latino settlement. White flight does not automatically ensue with the mere entry of a minority group; rather it is related to factors such as the type of housing, distance from established minority neighborhoods, and the present of other minority groups in the neighborhood (Denton and Massey, 1991; Bean and Tienda, 1987). Other critics fault ecological theory's focus on individual decisions and behavior, and emphasize how urban settlement is shaped by political and cultural 
factors, including the state's role in the production of space (Gottdiener and Feagin, 1988).

Other critics argue that the ethnic and racial structure of neighborhoods and neighborhood transitions are often a product of larger political and economic forces that circumscribe the housing choices of those who are politically and economically vulnerable. More broadly, they take issue with ecological theory's assumption of eventual spatial assimilation and maintain that the Latino residential experience, much like that of African Americans, is characterized by a long history of exclusion and discrimination (Nagel, 2009; Betancur, 1996; Rodriguez, 1991). Ecological theory has been found less useful in explaining the African American experience because of the strong effects of white prejudice and institutional discrimination on their experiences in the housing market (Massey and Denton, 1993). Critics argue that these factors also explain why Latino settlement is characterized by segregation in neighborhoods with the poorest housing (Lobo et al., 2002).

Other recent scholarship primarily by sociologists has explored bonds and ties based on ethnicity in the body of ethnic economy literature known as the ethnic enclave, and present a more mature understanding of the way that neighborhood and community can overlap (Peach, 2005; Zhou, 2004; Light and Gold, 2000; Portes and Jensen, 1987; Sanders and Nee, 1987; Portes and Manning, 1986; Wilson and Portes, 1980). In this model, ethnic entrepreneurs consist mainly of those who are bounded by coethnicity, coethnic social structures, and location. The ethnic enclave economy refers to a specific phenomenon, one that operates within an identifiable community and is embedded in a system of community-based coethnic social relations and observable institutions. The 
ethnic enclave provides more than just a way for the disadvantaged who are forced to become entrepreneurs or work in low-wage jobs for owners of businesses of their own ethnicity. Rather, it allows for the potential development of a distinct structure of economic opportunities as an effective alternative path to social mobility (Zhou, 2004). The immigrant neighborhood populated by coethnics has been the physical locus of the "bounded solidarity" and "enforceable trust" that are a necessary part of the social relations that make up the ethnic enclave (Portes and Sensenbrenner, 1993; Portes and Zhou, 1992). Classic examples of this set of social-economic relations are Miami's Little Havana, New York's Chinatown, and Los Angeles' Koreatown ${ }^{11}$ (see Min Zhou, 2004; Yu Zhou, 1998; Portes and Manning, 1986; Wilson and Martin, 1982).

The ethnic enclave approach has been critiqued in part because it relies on a more static understanding of ethnic solidarity, rather than considering it as a dynamic social system that adapts to changes in the contexts in which it is embedded (Alberts, 2005; Menjivar, 2000; Friedman-Kasaba, 1996). This static perspective contrasts with the work of other scholars who emphasize that ethnic networks change over time (e.g., Hagan, 1998; Mahler, 1995a; Boyd, 1989; Granovetter, 1985). One alternative approach, the mixed-embeddedness approach, was developed by Robert Kloosterman, Joanne van der Leun, and Jan Rath to explain the entrepreneurial activities of immigrants in the Netherlands (Kloosterman et al., 1999). In this model, entrepreneurs are embedded in a number of different contexts, such as the economic structure of the area in question, state policies toward ethnic entrepreneurship, and the ethnic composition of a given area. These contexts operate at different geographical scales and interact with one another to

\footnotetext{
${ }^{11}$ For an analysis of Korean ethnic entrepreneurs in Atlanta, see Yoo (1998).
} 
produce a specific set of conditions in a particular place at a certain point in time

(Alberts, 2005; Mitchell, 2000).

\section{The Los Angeles School of Urbanism}

The most widespread critique of the work of the Chicago School has come from the more recently formed, so-called Los Angeles (LA) School of urbanism. ${ }^{12}$ Their theory of 'postmodern urbanism' contradicts many of the precepts of the Chicago School (Dear, 2003). "We assert that the tenets of modernist thought have been undermined and that in their place, a multiplicity of ways of knowing have been substituted; and analogously, in postmodern cities the logics of previous urbanisms have evaporated, and, absent a single new imperative, multiple forms of (ir)rationality have clamored to fill the vacuum" (Dear, 2002b: 423). In other words, the modernist logic of the Chicago School itself, along with its associated teleological, racial, and conceptual notions, has come under attack by the LA School.

The Los Angeles School emerged during the 1980s when professionals and scholars across the disciplines, including urban planners, geographers, architects, sociologists, and political scientists in Southern California began to examine the Los Angeles region as the possible new paradigmatic city where the broader socio-geographic transformation taking place within the US as a whole was concentrated (Dear and Flusty,

\footnotetext{
${ }^{12}$ There have been, and continue to be, debates around the existence of a Los Angeles School, though there are enough convincing arguments for this author to believe in its existence. The leaders of the LA School of urbanism argue that there is an urgent need to re-think and revise urban theory, and that Los Angeles/Southern California is a prototypical example on which to base this effort (see Dear 2002a; Dear et al., 2008; Dear, 2003; Shearmur, 2008; Davis, 1990). Dear and Flusty $(1998 ; 1996)$ attribute the vitality of the LA School to the coincidental intersection of scholars examining Los Angeles, the completion of their empirical research during a common time frame, and the designation of the region as the global capital of the postmodern era.
} 
1998). A re-formulation of urban theory with Los Angeles as the suggested multidimensional prototype of the postmodern city is invoked by Dear and Flusty (1998) using comparative analysis based in other metropolitan areas of the world. Scott and Soja (1996a; 1996b) call for more systematic and insightful understanding of the issues and problems in the postmodern era. Some of these include transportation policy, economic restructuring and development, the history of local urban planning, homelessness, immigration, and political history (Engh, 2000).

Raymond Rocco's (1996) work is an illustration of the LA School's attention to Latino communities. He analyzes the transformation of Latino community boundaries using the UCLA study, 'Latino Community Formation in Los Angeles.' Rocco explores the demographic change in Los Angeles' population base, by which the Latino population has shifted from a predominance of Mexican origin in the 1960s to a significantly more diverse population, including large numbers of immigrants from Central American countries. Rocco demonstrates the establishment of spatially overlapping social networks that contribute to a larger sense of community among Latino groups. At the same time, the latinization of Los Angeles has led to the emergence of new Latino communities and the transformation of older ones, resulting in a fragmented, rather than an integrated, panethnic Latino community. In direct contrast to the Chicago School, Rocco emphasizes that "the tendency to identify communities primarily or only in terms of physical spatial boundaries is of limited value. Rather, it is cultural space that seems to form the basis of community networks" (368). This work emphasizes the need to re-think the definition and meaning of neighborhood and community, as well as the ways that ethnic groups incorporate into their local surroundings. 
In conclusion, the empirical, conceptual, and theoretical foundations about neighborhood, community, and immigrant incorporation set by the Chicago School of Sociology, along with the critiques and advances made by more recent scholars, including the LA School of Urbanism, offer myriad ways to understand and explain if and how Latin American immigrants are incorporating into life in the US. This dissertation explores to what extent Little Havana and its residents fits into the previously discussed formulations. Perhaps a 'Miami School,' including this work on one local neighborhood, could arise, illustrative of our search for 'template' cities in understanding the socio-spatial dynamics of urban transformation.

\section{Placing Little Havana}

\section{An Introduction to Little Havana}

The theoretical and conceptual discussion above is crucial to understanding various aspects of the research project upon which this dissertation is based. The neighborhood is the scale at which this dissertation analyzes immigrant incorporation with respect to ethnic and racial identity, trust and community, and civic engagement. This section discusses various aspects of Little Havana, beginning with the definition of the neighborhood. Next, the history of the area is considered with careful attention paid to the social, economic, and political dynamics over the past 50 years. In keeping with the theoretical discussion about neighborhood in part one of this chapter, these aspects of Little Havana are considered 'in context,' that is, with an eye to Little Havana as a neighborhood embedded in the larger city, metropolitan area, and region. The final 
portion of this section gives the most current snapshot of the basic demographic profile of this neighborhood using survey data and other sources.

\section{Bounding Little Havana}

Little Havana is a vernacular ${ }^{13}$ neighborhood, not an official municipal entity, located just west of Miami's downtown area (see Figure 2.2 below), and occupies the same area formerly known as Riverside (George, 2006; Portes and Stepick, 1993; Boswell and Curtis, 1984). For administrative purposes, Little Havana forms part of the City of Miami, Miami-Dade County's largest municipality. ${ }^{14}$ To the north it borders the predominantly African American community of Overtown, one of Miami's oldest and poorest neighborhoods (see Dluhy et al., 2002; Dunn, 1997). To the South and East, respectively, Little Havana abuts the wealthy residential neighborhood of Coral Gables, and the expensive high-rises of Brickell and Miami's increasingly upscale downtown district. As a vernacular neighborhood, Little Havana's boundaries are approximate and blurry, but are generally understood to be the Miami River and SR 836/Dolphin Expressway (north), SW $9^{\text {th }}$ Street between $12^{\text {th }}$ and SW $22^{\text {nd }}$ Street, and SW $11^{\text {th }}$ Street East of SW $12^{\text {th }}$ Avenue to Interstate 95 (south), SW $22^{\text {nd }}$ Avenue (west) and Interstate 95/4 ${ }^{\text {th }}$ Avenue (east) (see Figure 2.3 below; http://www.miamigov.com/NETS/pages/LittleHavana/havananet.asp, accessed May

\footnotetext{
${ }^{13}$ The distinction between the vernacular and the official in landscapes, and by extension neighborhoods, was made by J.B. Jackson (1984) in Discovering the Vernacular Landscapes.

${ }^{14}$ The name of the county was changed from "Dade County" to "Miami-Dade County" in November 1997. Miami-Dade County contains thirty-five incorporated municipalities plus a huge unincorporated area. For more information, see Miami-Dade County Office of Zoning and Planning (http://www.miamidade.gov/planzone/home.asp).
} 
2010; see also Iber, 2005; Price, 2005). Figure 2.2 below shows Little Havana's position vis-à-vis downtown Miami and as part of Miami-Dade County (inset).

Figure 2.2: Map of Little Havana, Miami

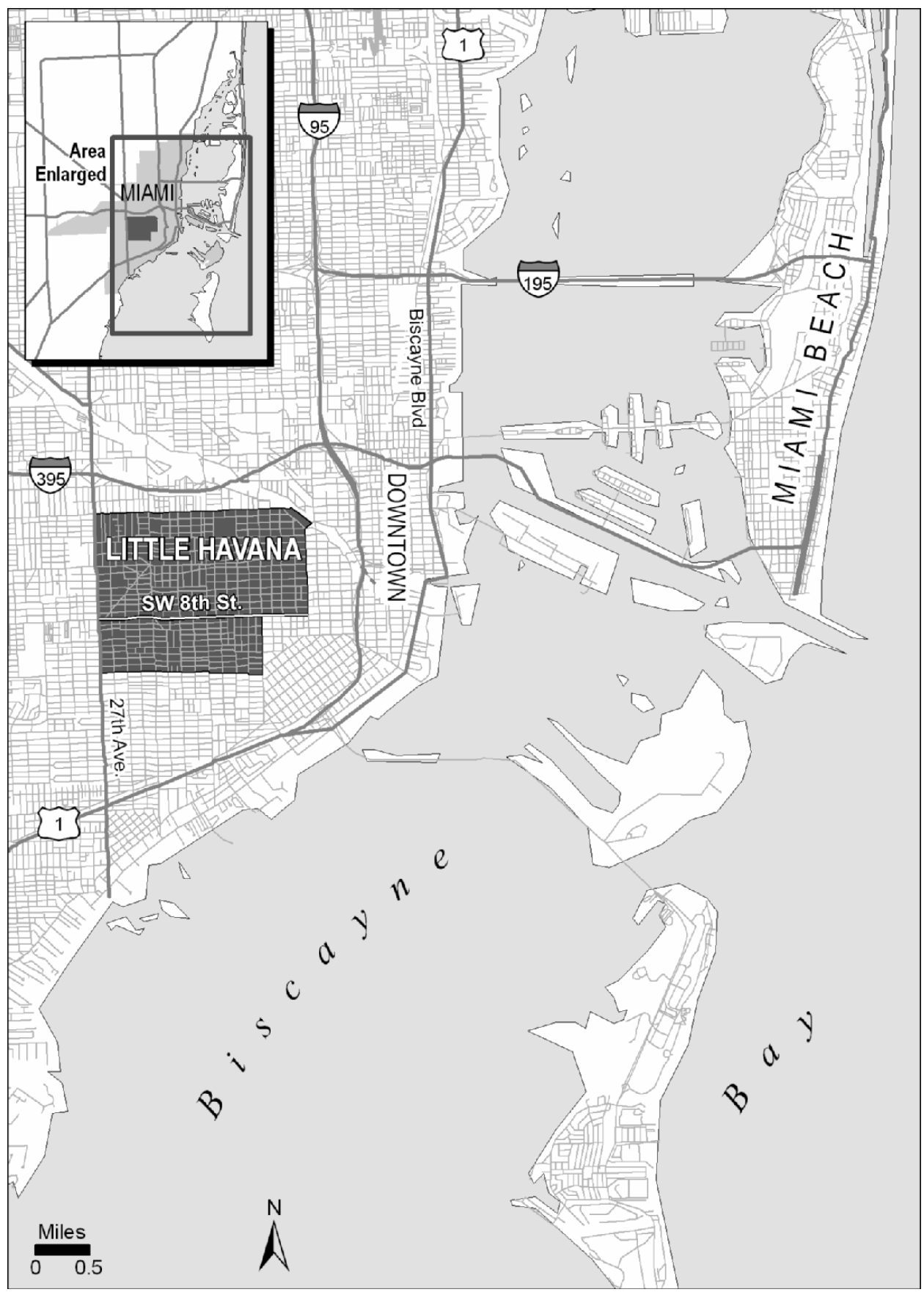

Courtesy of Chris Lukinbeal, School of Geographic Sciences, Arizona State University 
Figure 2.3: City of Miami Neighborhood Enhancement Team Neighborhoods Map

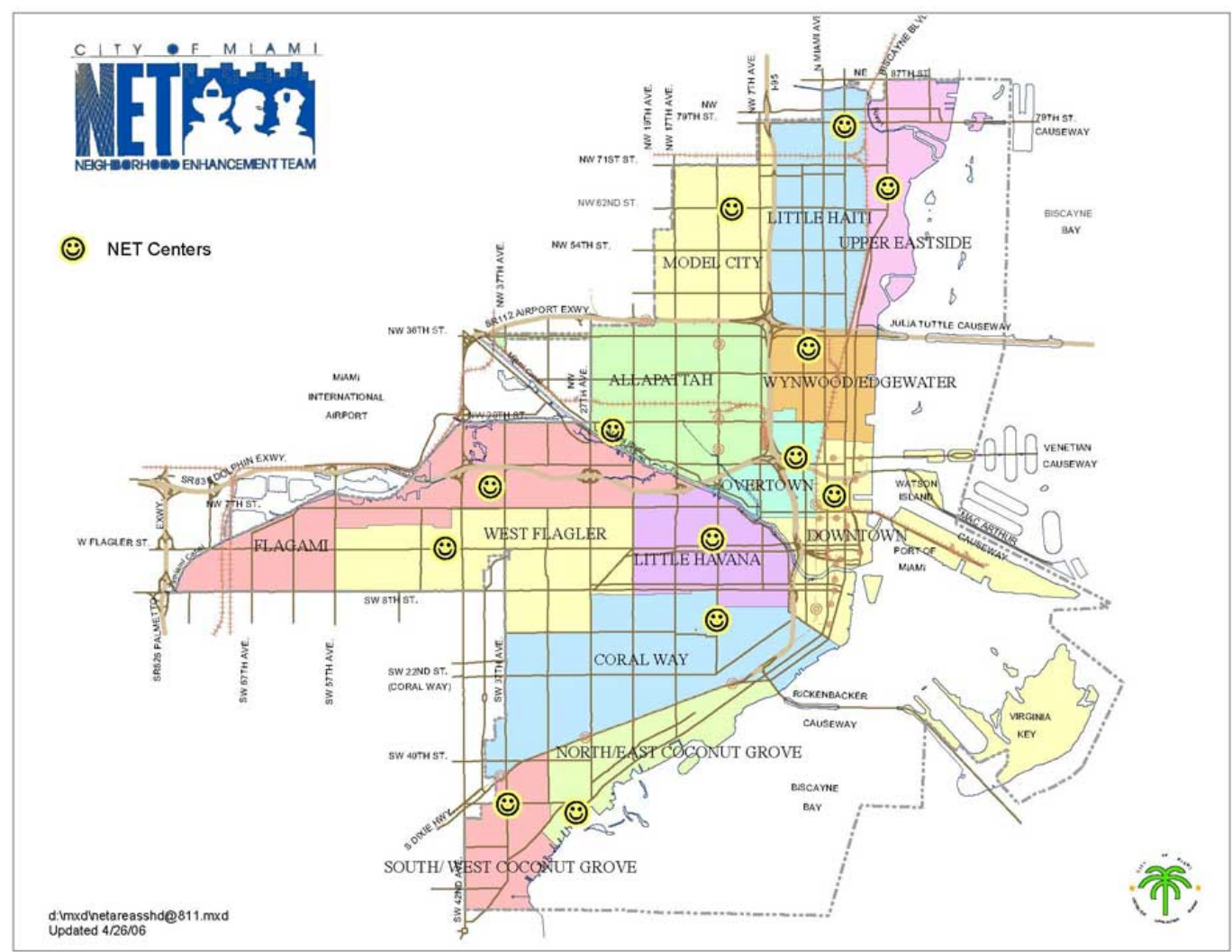

Source: City of Miami, Neighborhood Enhancement Team at http://www.miamigov.com/NETS/pages/LittleHavana/havananet.asp Accessed May 2010

Little Havana's informal designation lends itself to diverse interpretations of its status and boundaries, perhaps even contradiction and confusion, by individuals and groups, both from within and from without. In their 'Visitors' Guide,' for example, the Greater Miami Convention \& Visitors Bureau lists Little Havana as neighborhood along with various independent municipalities in Miami-Dade County, such as Aventura and Hialeah (see http://www.miamiandbeaches.com/visitors/neighborhoods.aspx, accessed May 2010). This implies some sort of conflation between the vernacular designation of Little Havana as a neighborhood with the official designation of the other municipalities 
(cities) in Miami-Dade County with which it is compared. The East Little Havana Community Development Corporation, a 501(c)(3) organization founded in 1984 with the mission "to revitalize the East Little Havana Neighborhood" (www.eastlittlehavanacdc.com, accessed July 2009), does not specify the boundaries of East Little Havana at all. The fuzziness of the boundaries of Little Havana goes to show how difficult it is to pin down in practice neighborhoods that are firmly rooted in geographical imaginaries at various scales.

Confusion also arises when Little Havana is considered vis-à-vis Shenandoah, another one of Miami's neighborhood. Shenandoah, whose boundaries fall within the borders of the vernacular neighborhood of Little Havana, also exists as an independent vernacular area; the boundaries of this area, however, have been established by the Shenandoah Homeowners' Association. The very existence of the Shenandoah Homeowners' Association distinguishes the area from Little Havana. In fact, there are other concrete differences between Shenandoah and the rest of Little Havana: Shenandoah is comprised of large, well-kept, single-family homes, forming a gentrified enclave of sorts. Some of these homes are, in fact, large and luxurious. In general, the housing stock and conditions found in Shenandoah contrast with those found in the rest of Little Havana (described below). In short, Shenandoah has a more upscale feel. In addition to the existence of the homeowner's association, Shenandoah's neighborhood identity is further buttressed by the existence of various city and county facilities which bear Shenandoah's name. These include a large City of Miami park including a swimming pool facilities (Shenandoah Park and Pool), a Miami-Dade County elementary and middle school (Shenandoah Elementary and Middle Schools), as well as 
a branch of the Miami-Dade Public Library System (Shenandoah Branch Library). The distinction between Shenandoah and Little Havana is surely made as an attempt by Shenandoah homeowners to maintain higher property values by differentiating themselves from the deteriorated condition of much of the housing stock and commercial spaces in Little Havana and commonplace perceptions of Little Havana as a dangerous or undesirable area of the city. Thus claims to name, here at the neighborhood level, are often grounded in broader claims to space and power.

For the research project upon which this dissertation is based, Little Havana was operationally defined as a 300-square block area with the boundaries on the north by NW $7^{\text {th }}$ Street, east by $8^{\text {th }}$ Avenue, south by SW $16^{\text {th }}$ Street, and west by $27^{\text {th }}$ Avenue; these boundaries generally coincide with nine US Census tracts (see Figure 2.4 below). ${ }^{15}$ In this dissertation, therefore, when referring to Little Havana, it is the area demarcated by these boundaries with the acknowledgement that the social, political, and economic dynamics of Little Havana are not formally bounded by these borders.

The blurriness of Little Havana's boundaries and the concomitant neighborhood identity surfaced in the research data. Survey respondents were asked "What is the name of your neighborhood?” (Q\# 10) ${ }^{16}$. Out of the 384 responses $^{17}, 25$ discreet responses were given. Little Havana/La Pequeña Habana received the highest percentage $(63.6 \%)$, followed by 'I don't know' (11.5\%), Shenandoah (6.0\%), and the Southwest (5.7\%). The

\footnotetext{
${ }^{15}$ The US Census tracts used to delineate Little Havana are 52.01, 52.02, 53.01, 53.02, 54.01, 54.02, 64.01, 64.02 , and 64.03 .

${ }^{16}$ The author uses this annotation system to specify the number of the survey question. The original surveys are included as Appendix A (English) and Appendix B (Spanish).

${ }^{17}$ Survey data include only those respondents that were categorized as Latino by the surveyors in Q\# 9-A.
} 
plethora of answers reveals that many of the residents in Little Havana perceive and name their neighborhood in a different way. The lack of consensus might also point to a lack of neighborhood identity and the lack of identification of residents with their immediate surroundings, and a limited sense of belonging. Or, it could point to the fine tapestry of belonging and naming that exists even within already-local entities such as neighborhoods. Regardless, as will be shown later, understanding belonging is crucial to understanding immigrant incorporation as far as ethnic and racial identity, trust, and civic engagement are concerned. ${ }^{18}$

Figure 2.4: Map of Little Havana Census Tracts

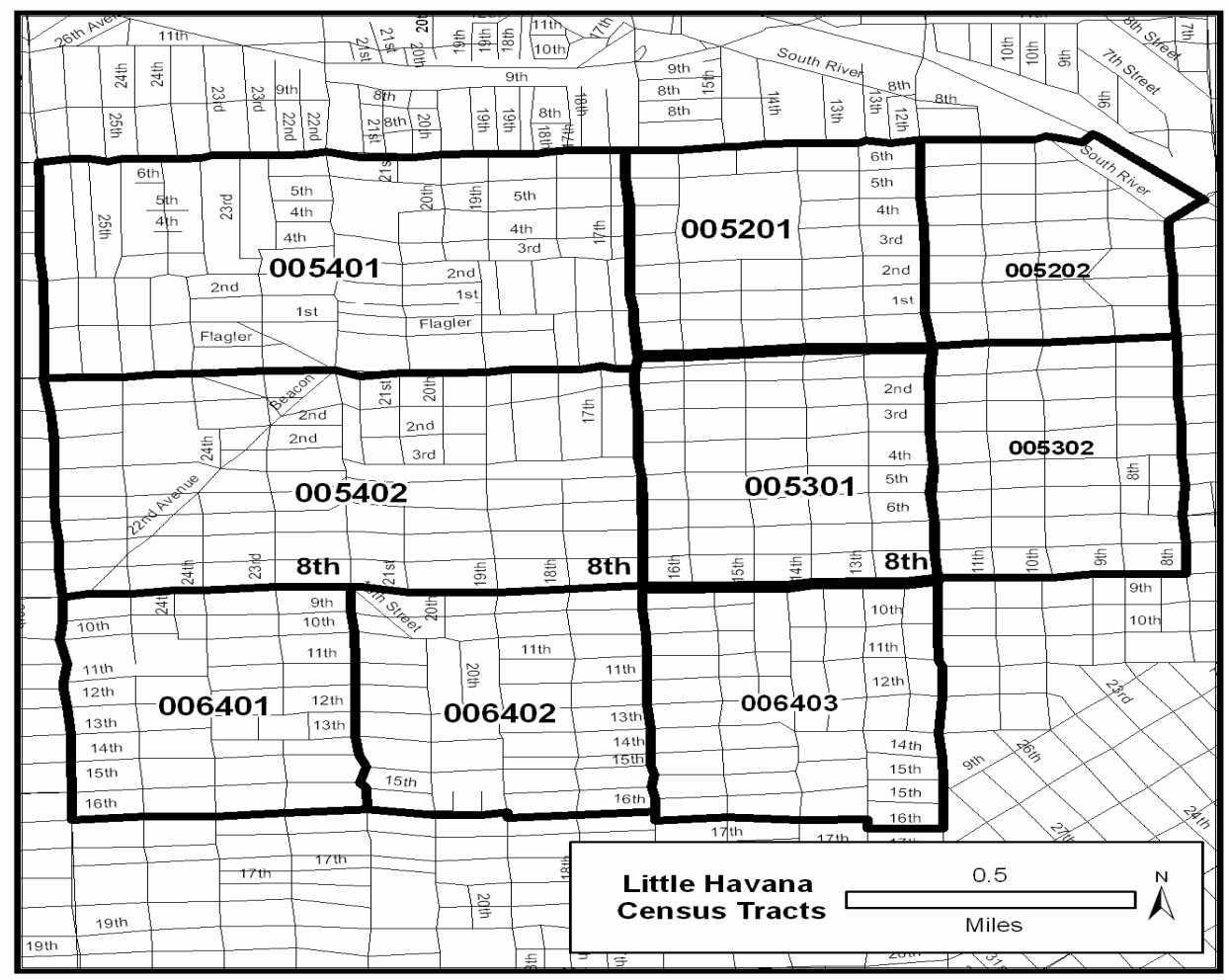

Courtesy of Chris Lukinbeal, School of Geographical Sciences, Arizona State University

\footnotetext{
${ }^{18}$ For a recent discussion of the role of language, identity, identifications and belonging, see Meinhof and Galasiński (2005).
} 


\section{Defining Little Havana}

In the absence of some sort of official designation, and in the face of the empirical evidence that residents do not unanimously share the notion that they in fact live in a place called Little Havana, what other factors might define Little Havana as a neighborhood? The constitution of Little Havana as a neighborhood has been determined by the social, economic, and political dynamics over the course of the past 50 years; and these dynamics have been shaped by the waves of immigration from Latin America, especially Cuba, beginning in 1959. In 1959, as a result of the political revolution in Cuba, thousands of exiles began to arrive to Miami, many of whom took up residence first in the declining neighborhood then known as Riverside, a predominantly Jewish neighborhood at the time (George, 2006; Alberts, 2005; Portes and Stepick, 1993; Boswell and Curtis, 1984). As the concentration of Cubans in this neighborhood grew and their presence was increasingly felt, the neighborhood acquired the informal, colloquial name of Little Havana.

With the passing years and the continued tension between the US and Cuba, Miami became the seat of the Cuban exile community, and Little Havana more specifically became the symbolic capital of Cuban exile. Named after the capital city of the island from which most of the neighborhood residents originated, Little Havana also became a Cuban cultural and business hub (Price, 2007; 2005; Alberts, 2006; 2005; 2003; Portes and Stepick, 2003; 1993; Nijman, 2000; Garcia, 1996; Sassen and Portes, 1993; Boswell and Curtis, 1984). By the 1980s, however, the neighborhood fell into disrepair, with low rents and high crime rates. The conditions and safety in one section of the Little Havana was so bad during one period (1980s-1990s) that one resident referred to it as 
'Little Vietnam' to describe the danger and destruction in Vietnam during and after the war there.

The cultural influence of Cuban immigrants was felt strongly, and the latinization of the Miami area was viewed with some trepidation in the popular press (e.g., Burkholz, 1980; New York Times, 1973). The burgeoning cultural diversity and inter-group power dynamics resulted in tensions and sometimes even violence (Grenier and Castro, 1999; Dunn, 1997; Portes and Stepick, 1993; Mohl, 1988). This has been attributed to a variety of causes, including differences surrounding special immigration policies for Cuban refugees, ${ }^{19}$ the group's rise to economic and political dominance in the metropolitan area, and ethnic and racial conflicts. Cubans, in fact, have arrived and settled in a manner distinct from other ethnic groups in the area. At least during the 1960s, members of the Cuban exile population actively organized to overthrow Fidel Castro and his Communist regime, and return to the island. When efforts made to topple the Castro regime failed, Cubans situated in Miami realized that their return to the island might be postponed. They settled into life in Miami and fostered the economic development of the city by establishing lively and intense economic activity, thanks in part to the benefits and significant aid provided to them by the American government, most notably the Cuban Refugee Program (Price, 2009; Alberts, 2006; 2005; Portes and Stepick, 2003; 1993;

\footnotetext{
${ }^{19}$ Cubans were declared political refugees by American President Dwight Eisenhower in 1960, and in 1966 the Cuban Refugee Adjustment Act was passed and still remains in effect today. The law distinguished Cubans from other groups by allowing undocumented Cubans who manage to arrive in US to stay be eligible for permanent residency just one year after arrival. The law applied regardless of whether a Cuban arrived with or without proper immigration documentation. As a matter of policy, but not law, the U.S. Department of Justice with almost no exceptions paroled Cubans who arrived without proper immigration into the U.S. which meant that Cubans did not have to struggle to obtain a legal immigration status and could readily become first permanent residents and then, if they wished, naturalized citizens. Nevertheless, as of 1994, the US has had a "wet foot-dry foot" policy. Those Cubans who make it to shore (touch US soil with their feet) are granted asylum. Those who are caught at sea (with wet feet), on the other hand, can be returned to Cuba. For more, see Blue (2005); Pérez (1999).
} 
Reiff, 1999; Torres, 1999; García, 1996; Masud-Piloto, 1996; Fernández, 1987; PedrazaBailey, 1985).

The settlement process took place in various aspects of life. Socially and economically, Cubans established a vibrant ethnic economy, including the unique characteristics of an enclave economy which are based on bonds of solidarity and obligation (Alberts, 2006; 2005; 2003; Zhou, 2004; Portes and Stepick, 1993; Portes, 1987; Portes and Jensen, 1987; Portes and Manning, 1986; Bonacich, 1980; 1973; Wilson and Portes, 1980). Cubans became active in the political process, and have obtained offices on all levels of government. In general, Cubans immigrants and their descendants have transitioned from the practice of exile politics to immigrant or ethnic politics (Fernandez, 2001; 1987; Grenier and Castro, 1999; Torres, 1999; 1998; Croucher, 1997; Masud-Piloto, 1996; Moreno and Rae, 1992; Mohl, 1988; Pedraza-Bailey, 1985).

The arrival of hundreds of thousands of Cubans into the city of Miami has embossed the politics of the city (Grenier and Perez, 2003; Portes and Stepick, 2003; 1993; Dluhy and Frank, 2002; Reiff, 1999; 1993; Torres, 1999; García, 1996; Moreno and Rae, 1992; Mohl, 1988; Fernández, 1987; Pedraza-Bailey, 1985). The first wave of Cubans who settled in Miami considered themselves exiles or refugees. Exile politics had a bifocal perspective - Havana and Washington - the two capitals where the exiles' fate would be determined. Like other exile groups, Cubans were generally rather myopic to the local issues of their neighborhoods (Mohl, 1988). Anti-communism, the toppling of the Castro regime, and the desire to return to a free Cuba were the banners for political mobilization, and dozens of organizations emerged in exile, many of them headquartered in Little Havana. These had a twofold agenda: combating communism in Cuba through 
political organizations and defending Cuban national identity in the diaspora through cultural associations. By 1980 the most powerful political organization, the Cuban American National Foundation (CANF), epitomized the Cuba- and Washington-centric focus of Cuban collective action (Fernández, 1987). The CANF successfully lobbied both sides of the aisles in Congress and found common ground with President Reagan in standing up to worldwide communism, but did little to increase the time or energy spent on civic engagement at the neighborhood scale on neighborhood issues within Miami.

Demographically, the concentration of Cubans in Little Havana was a result of Cubans moving in and also of non-Cubans moving out (Shoer Roth, 2008; George, 2006). In Miami-Dade County generally, a process of so-called 'white flight' has been the subject of much speculation. The 'whites' referred to in this expression are more properly non-Latino, US-born whites, also known as 'Anglos' in South Florida. With the devastation wrought by Hurricane Andrew in 1992, many Miami-Dade residents received substantial insurance payouts on their destroyed dwellings. Anecdotal evidence claimed that Anglos were leaving Miami-Dade County for points north, particularly adjacent Broward County, for a variety of reasons: frustration with Miami's worsening traffic congestion, poor public schools, unaffordable housing, and - most saliently here discomfort with the latinization of Miami's linguistic and cultural landscape (Croucher, 2002; Booth, 1998; McHugh et al., 1997). Analysis of Census data reveals that for every immigrant arriving in the Miami-Dade County in recent years, an Anglo has left the county (Booth, 1998), though a direct causal relationship has yet to be proven.

Though the Cubans were the first group to cause a cultural change in the neighborhood, they were not the only group. Beginning in the late 1970s, the 
demographic profile of Miami and Little Havana changed once again as new immigrants from Central America, especially Nicaragua, began to arrive because of political, economic, and social turmoil in Central America. In Nicaragua, the Sandinista Revolution provoked successive waves of Nicaraguan immigrants to South Florida, beginning in the late 1970s and continuing throughout the 1980s (Cervantes-Rodriguez, 2006; Portes and Stepick, 1993). ${ }^{20}$ More recently, large numbers of Hondurans and Guatemalans have arrived following natural catastrophes in those countries. In general, the economic decline in many Central and South American countries has been a motivating factor for citizens of these countries to migrate to the United States, many of them to South Florida. Some of these new arrivals settle first in Little Havana because it is still (comparatively) inexpensive to live there, in addition to the fact that it is a traditional Latino immigrant gateway neighborhood. In fact, since its founding Miami has constituted a gateway city, particularly for Caribbean immigrants (Lin, 1998; Boswell et al., 2001; Skop and Menjívar, 2001). Although Little Havana was once a Cuban ethnic enclave neighborhood, the ethnic profile of the neighborhood looks much different today as continued and diversified flows of immigrants from Latin America arrive (Iber, 2005).

In more recent years, the influx of immigrants from other countries from all parts of Latin America has continued to change not only the demographic landscapes, but also the relations among the various racial and ethnic groups, the dynamics of power and influence throughout the greater city of Miami, and the cultural expressions of the people who make Miami their home (Stepick et al., 2009; Price, 2007; Portes and Stepick, 2003; 1993; Garcia, 1995). Heike Alberts (2006; 2005; 2003) has even argued that the social

\footnotetext{
${ }^{20}$ To read more on cases and contexts of US-bound Nicaraguan migration since the late 1970s, see Robinson (2003); Rodriguez (1999); Fitzgerald (1987; 1985); Aguayo (1985).
} 
relations and ties that bind (solidarity) within the Cuban American community have changed, such that the enclave no longer exists due to the passage of time and differences between immigrants during the different waves, among other reasons.

\section{Little Havana Today}

As per the 2000 US Census, the tracts comprising Little Havana counted 54,646 residents; $79 \%$ of this population was foreign-born and $92 \%$ was Latino or Hispanic (see Table 2.5 below). Cuban-born immigrants made up less than half—47\%—of the Latino/Hispanic population, followed by over one quarter of residents (26\%) hailing from Central America (primarily Nicaragua and Honduras). A growing number of residents (4\%) were from South America, 2\% Puerto Rican, and less than 2\% Mexican and Dominican respectively. A notable portion (18\%) does not identify primarily by national origin but rather as "other Hispanic or Latino" (US Census, 2000).

$\underline{\text { Table 2.5: Basic Demographic Profile of Little Havana }}{ }^{21}$

\begin{tabular}{|l|c|}
\hline Total population & 54,646 \\
\hline Hispanic or Latino & $92 \%$ \\
\hline Total population 18 years and over & 42,695 \\
\hline Foreign-born & $79 \%$ \\
\hline Percent below poverty level, 1999 & $33 \%$ \\
\hline Average median household income & $\$ 19,957$ \\
\hline Renter-occupied housing & $82 \%$ \\
\hline
\end{tabular}

Source: US Census, 2000

Survey data from 2005 shows that the Latino composition of Little Havana is even greater now than in 2000 when recorded by the Census ( $96 \%$ versus $92 \%$, respectively). Cuban-born immigrants still make up the largest foreign-born population in

${ }^{21}$ Data tabulated from US Census 2000 SF1 and SF3. See footnote 14 for list of census tracts used to define Little Havana. 
the neighborhood with $48.7 \%$, followed by $34 \%$ identifying as originally from countries in Central America, and 5.9\% from South American countries (see Table 2.6 below).

These shifts mean that the Cuban demographic presence in Little Havana has been diluted, a trend that accelerated by the notably older profile of Cuban ancestry residents of Little Havana (see Table 2.7 below). Thus Little Havana can thus most accurately be described as a multi-ethnic Latino neighborhood where the historic demographic dominance of one ancestry group - Cubans - is on the decline. ${ }^{22}$

Table 2.6: Countries of Origin of Little Havana's Latino Survey Respondents

\begin{tabular}{|c|c|}
\hline Country of Origin & $\mathbf{\%}$ \\
\hline Cuba & 48.7 \\
\hline Nicaragua & 20.8 \\
\hline Honduras & 9.9 \\
\hline United States & 8.3 \\
\hline Colombia & 2.6 \\
\hline Guatemala & 2.3 \\
\hline Mexico & 1.6 \\
\hline Argentina & 1.3 \\
\hline Dominican Republic & 1.3 \\
\hline Uruguay & 0.8 \\
\hline Costa Rica & 0.5 \\
\hline El Salvador & 0.5 \\
\hline Chile & 0.3 \\
\hline Ecuador & 0.3 \\
\hline Peru & 0.3 \\
\hline Spain & 0.3 \\
\hline Venezuela & 0.3 \\
\hline
\end{tabular}

${ }^{22}$ Mid-decennial Census counts, however, reveal that growth of the Cuban population of Miami-Dade has grown since 2000 has outpaced growth in non-Cuban Latinos, such that 54\% of Miami-Dade County's Latinos population is Cuban as of 2007, compared to $50 \%$ in 2000 (Shoer Roth, 2008). 
$\underline{\text { Table 2.7: Age Breakdown by Cuban vs. non-Cuban Respondents (Recoded) }}{ }^{\underline{23}}$

\begin{tabular}{|c|c|c|}
\hline Age categories & \% Cuban, & \% Non-Cuban, \\
\hline $18-25$ & 3.4 & 15.9 \\
\hline $26-35$ & 8.1 & 22.8 \\
\hline $36-45$ & 10.1 & 19.0 \\
\hline $46-55$ & 13.5 & 20.7 \\
\hline $56-65$ & 8.8 & 9.9 \\
\hline $66+$ & 56.1 & 11.6 \\
\hline
\end{tabular}

Economically, Little Havana is in general an impoverished neighborhood. The inflow of mostly poor immigrants into Little Havana regularly infuses the neighborhood with a low socioeconomic population, which acts to maintain the overall low socioeconomic profile of the neighborhood (McHugh, 1997; see Tables 2.8 and 2.9 below for distribution of education and income, respectively). The overall economic profile of Little Havana shows it to be a poor neighborhood set in a poor city. To put Little Havana in perspective, the median household income in 2000 was lower than the median for Miami: \$19,957 versus \$23,314. In 2000, 25\% of Little Havana’s labor force worked in service occupations, $39 \%$ in construction and transportation, $23 \%$ in sales and office. Some $12 \%$ worked in management and professional occupations. Little Havana is indeed distinguished by its overall poverty.

${ }^{23}$ Derived from Q\# 4, “In what year were you born?” by subtracting from 2005 , year of survey. Ages were then put into the six categories found in the table. See Appendix E for the age distribution of the overall population. 
Table 2.8: Breakdown of Income of Respondents (Recoded) ${ }^{24}$

\begin{tabular}{|l|c|c|}
\hline \multicolumn{1}{|c|}{ Annual household income } & $\mathbf{\%}$ & Valid \% \\
\hline Less than $\$ 10,000$ & 26.8 & 28.2 \\
\hline$\$ 10,000-\$ 24,999$ & 37.5 & 39.5 \\
\hline$\$ 25,000-\$ 49,999$ & 20.1 & 21.1 \\
\hline Over $\$ 50,000$ & 10.7 & 11.2 \\
\hline NR & 4.9 & - \\
\hline
\end{tabular}

$\underline{\text { Table 2.9: Breakdown of Level of Education of Respondents (Recoded) }}{ }^{25}$

\begin{tabular}{|l|c|}
\hline \multicolumn{1}{|c|}{ Level of Education } & \% \\
\hline Did not complete High School & 44.0 \\
\hline Complete High School & 23.7 \\
\hline Complete High School and Beyond & 32.3 \\
\hline
\end{tabular}

In recent years, the economic profile of the Miami metropolitan area is one where residents have faced significant economic challenges. For several years in a row in the early 2000s, Miami ranked first on the roster of poorest large cities in the US. It was replaced by Cleveland in 2005 and by Detroit in 2006; as of late 2007 Miami ranked number three (Arthur, 2007). High poverty rates, low median incomes, and some of the nation's highest median housing prices, as well as property taxes and insurance, have combined to make life very expensive for most Miamians (Tompkins, 2007). When the median cost of a home in Miami-Dade County peaked in 2007 (\$370,000), it was almost double the national median, and the tax rate was almost one-third higher. Although the economic recession starting in 2008 and continuing into 2009 caused the median home price to drop as of March $2009(\$ 205,000)$, housing still remains out of the grasp of even skilled workers like police officers and teachers (Andron, 2009).

\footnotetext{
${ }^{24}$ There were seven income response categories on the survey Q\# 55. These categories were collapsed into three categories for statistical analysis: $<\$ 10,000, \$ 10,000-\$ 24,999, \$ 25,000+$. Those who did not respond to the question were excluded from statistical analysis.

${ }^{25}$ There were 16 education response categories on the survey Q\# 50 (see Appendix A \& B). These categories were collapsed into three categories for statistical analysis.
} 
In general the economic panorama in Florida, Miami-Dade County, and the City of Miami has become bleaker in the past few years. The worldwide recession and economic crisis has hit the local area hard, resulting, for example, in the largest home foreclosure crisis in history. Property values have plummeted by $25 \%$ during the recent housing bust; residents have been hit a rise in property taxes, and a spike in hurricaneinsurance premiums and electricity rates. In short, Miami continues to be known for its low levels of income and high cost of living (Padgett, 2009).

\section{Little Havana as Hub of Culture and Activity}

Little Havana has been one of, if not the, main neighborhoods where collective action occurs, in the form of both cultural celebrations and protests. Public events provide a means through which neighborhood residents and others come together to celebrate aspects of their culture, and at the same time participate in the civic life (Price, 2007; Hebbert, 2005; contributors to Arreola, 2004; Flores and Benmayor, 1998; Low, 1996b; Jacobs, 1992 [1961]). In Little Havana, these have included events like the annual Carnavales celebration organized by the Kiwanis Club of Little Havana in March (www.carnavalmiami.com/home.html) for 30 years, the Three Kings Day Parade and Festival organized by Univision Radio in January for $35+$ years, and the arts and culture festival Viernes Culturales (Cultural Fridays) every last Friday of the month for the past few years (www.viernesculturales.org). The first two of these three events began as celebrations of aspects of the Cuban culture that predominated in the neighborhood and the city; the third began after this mixed demographic panorama had appeared. All three events are now marketed and celebrated in an explicit way for and with the mixed and 
diversified local Latin American population. Such events are manifestations of collective panethnic identity, solidarity, and collective action and reinforcing them at the same time. $^{26}$

Little Havana has also served as the main meeting place for civic events, such as protests, and other explicitly political events, though many of these have been motivated by Cuba-specific issues. Some events, such as the series of activities surrounding Elián González $^{27}$ in 2000 , have included members of other national origin groups besides Cubans (De La Torre, 2003; Stepick et al., 2003; Acosta, 2001). The small protest marches that took place in Little Havana against the proposed immigration reform by the US Congress in 2006 were led by mostly non-Cuban organizations and organizers, including Latin American and other immigrant groups. ${ }^{28}$ An estimated 7,000 people attended a march and rally in Little Havana in April 2006, comparatively few when compared to others larger marches, e.g., in Dallas where an estimated 500,000 people marched (McFadden, 2006). Much more recently, in late March 2010, thousands of Cubans and others marched along Calle 8 in Little Havana in support of Las Damas de Blanco, the ladies in white, a group of peaceful dissidents comprised of wives and mothers of Cuban political prisoners who oppose the Castro regime, and who were

\footnotetext{
${ }^{26}$ See Dávila (2001) for a discussion of how marketing and commercial interests, such as those that partially underlie the cultural celebrations mentioned, have served to create and consolidate a panethnic Latino/Hispanic identity and by extension a feeling of solidarity.

${ }^{27}$ In November 1999, a raft carrying a group of Cubans attempting to cross the Florida Strait capsized. The raft capsized and only three survived, including Elián González, a five-year-old boy. He was rescued and brought to Miami where he was placed in the custody of Miami relatives. Elián was eventually sent back to Cuba to live with his father. The events surrounding Elián spurred much controversy locally and elsewhere. For in-depth discussions of this case from a variety of perspectives, see Price (2009; 2004); D'Arcus (2006); Banet-Weiser (2003); Stepick et al., 2003; Hernández-Truyol (2001).

${ }^{28}$ The proposed legislation was entitled the Border Protection, Anti-terrorism, and Illegal Immigration Control Act, otherwise known as the 'Sensenbrenner Bill,'
} 
attacked the week prior to the march by government security forces in Havana (Cassola, 2010; Yanez et al., 2010). While some of the public manifestations deal with panethnic or Latino issues, the majority continue to be Cuba-specific; furthermore, though solidarity is shown by other national and ethnic groups, these events are, for the most part, organized by Cubans for a Cuban constituency.

The established cultural and commercial presence of a diversified Latin American immigrant neighborhood composition is reflected in some aspects of the physical landscape in Little Havana as well. This is part and parcel of the building of a panethnic, ethnic neighborhood (see Price, 2007; Arreola, 2004; Chacko, 2003). The Cubandominated landscape had begun to give way to one of mixed Latin American nationalities by the mid-1980s and has continued ever since. Along major thoroughfare, like Calle Ocho (see Figure 2.2 above), for example, store fronts display colors and symbols (especially flags) of many Latin American, especially Central American, countries. A small section of Little Havana was even renamed 'Latin Quarter' in 1984 by the Miami City Commission to recognize the increased multi-cultural and -national space shared by residents and commerce there. There have been efforts, often fervently opposed by residents and others in the neighborhood, to expand the boundaries of the 'Latin Quarter' designated area, especially by local merchants in the decades since, who are organized in the Latin Quarter Association (De Valle, 1997; Goldfarb, 1990; Rimer, 1990; Blanchard, 1982). ${ }^{29}$ Nevertheless, monuments, such as those found on Cuban Memorial Way,

\footnotetext{
${ }^{29}$ The designation of part of Little Havana as 'Latin Quarter' never been completely accepted by many, especially Cubans, and has arisen as a point of contention. In any case, the area is still mostly commonly referred to as Little Havana.
} 
continue to represent and depict Cuba-relevant aspects of the neighborhood's history (Price, 2007).

In conclusion, Little Havana has gone through two major demographic transitions in the past 50 years, although symbolically the area remains the Cuban cultural capital in exile. Although the vernacular designation of the neighborhood contributes to confusion around the neighborhood borders as well as to a lack of consensus around neighborhood identity by residents, ethnic cohesion as evidenced through social and economic relations and political collective action have contributed to a neighborhood definition, despite the diversification of Little Havana residents.

\section{Research Design, Methodology, and Data Analysis}

\section{$\underline{\text { Introduction }}$}

The research upon which this dissertation is based was carried out as part of a larger comparative research project entitled 'Comparative Civic and Place Engagement in Three Latino Enclave Neighborhoods in Transition' from January 2005 through December 2006. This was a large, inter-disciplinary, team-based project with three study areas: Pilsen in Chicago, IL; Little Havana in Miami, FL; and Garfield in Phoenix, AZ. The research team consisted of two principal investigators in each site and spanned the disciplines of political science, geography, and anthropology. Each research team also included a group of graduate and undergraduate students that aided in carrying out field research, data entry, and various aspects of data analysis.

The research project sought to allow a systematic, comparative assessment of how individuals and groups interact with one another civically through organizations to shape 
their physical surroundings, and how these surroundings in turn foster or hinder belonging and exclusion. The three main research questions were:

1. Does pan-ethnic solidarity, or 'latinismo,' exist amongst Latinos? If so, what forms does it take and how is it enacted on different scales, in different cities, and in different situations? What are the implications of civic coalitions that transcend, and perhaps reshape, prior bases of identity and activism such as national or ethnic identifications?

2. What aspects of the built environment of cities promote divisiveness and lack of civic engagement amongst neighborhood residents, and what aspects promote solidarity and civic engagement? What are the similarities and differences in different cities?

3. How do established inner-city Latino residents negotiate challenges posed both by new Latino immigrant diasporas, and by gentrifiers who are economically empowered by changes in the global economic environment?

As a graduate assistant for the Miami research team, the author participated in various aspects of the research project. These included background research, design of the field data collection instruments (survey, interview, and focus group questionnaires), instrument testing, conducting surveys and interviews, quantitative and qualitative data entry and quality control, and data analysis. Data used in this dissertation were gathered in a series of three phases that incorporated a combination of quantitative and qualitative 
approaches. Methodological triangulation, or the use of multiple research methods, such as that used in this study, allows for the strengths of diverse methods to complement one another and provide greater coverage, validity, reliability, and robustness (Alberts, 2003; Hakim, 2000; Denzin, 1978). The collection and analysis of qualitative data on the topics to be addressed in this dissertation, especially trust and civic engagement, have usually been studied quantitatively, and more qualitative work needs to be done to gain a greater understanding of these phenomena (Stepick et al., 2009; Orosco, 2007; Marschall and Stolle, 2004; Mohan and Mohan, 2002; Edmondson, 2001; Waters, 1993). In what follows, the research design for Phase 1 (survey) and Phase 2 (interview) is described, followed by a discussion of data analysis. ${ }^{30}$

\section{$\underline{\text { Research Design }}$}

Phase 1: Survey

This descriptive phase was carried out from June through August 2005, and served to provide an overview of the current demographics of neighborhood residents, quantity and type of neighborly interaction, levels of trust, and civic and place engagement. The survey questionnaire covered various topics, including basic demographics; ethnic and racial identification; ethnic solidarity; sociability; trust; civic and political engagement; and use of and satisfaction with neighborhood spaces. See Appendix A and Appendix B for the final versions of the survey instrument in English and Spanish, respectively.

The survey sampling frame encompassed adults residents (18 and older) within the area geographically defined by census tracts as the boundaries for the neighborhood

\footnotetext{
${ }^{30}$ Phase 3 (focus group) is not described or discussed as the data from Phase 3 were omitted from this dissertation.
} 
as mentioned above (see footnote 12 above), using a modified area probability random sampling procedure to generate demographically and spatially representative samples at a 95\% confidence interval (Fowler, 2002; Golledge and Stimpson, 1997). The neighborhood was stratified by census tracts and was randomly sampled proportionate to its population size (deVaus, 1991). To enhance probability sampling in the stratified areas, parcel data were geo-referenced to each census tract using the appropriate State Planes Coordinate System. Parcels were assigned a unique identification number and a randomization algorithm selected parcels for the survey sample. To compensate for anticipated response rates lower than $100 \%$, to account for the fact that some selected parcels would be commercial rather than residential, and to insure a 95\% confidence interval of the Latino population, a randomly-selected parcel list that was three times larger than the target sample size for each tract was generated. The master list was then randomly sub-divided into three lists and mapped onto three parcel maps of the study area.

Within each identified block, the survey questionnaire of approximately 30 minutes duration was administered by three teams of researchers. Each team began at the northwest corner of their assigned census tract, proceeding east on one side of the street and west on the other side, until all randomly-selected parcels were visited. If the team could not conduct the target number of surveys for the tract from their first parcel map, they moved on to the second, and in rare cases the third, parcel map. One adult per selected household was surveyed and rotation for age and gender of respondent was utilized to minimize bias. Face-to-face surveys were used to minimize distrust and thus maximize response rate, which averaged $65 \%$ across sites, above and beyond what 
telephone or mail survey would have yielded (Bernard, 2006; Babbie, 2005; Halbrook et al., 2003; Sheshkin, 1985). Survey teams were bilingual and survey instruments were available in both English and Spanish, utilizing back translation and extensive bilingual pilot testing. Verbal informed consent was obtained.

Phase 2: In-depth interviews

The purpose of this phase was explanatory and was meant to uncover individuals' rationales, decisions, perceptions, and visions. This phase lasted from March through September 2006, and involved ethnographic techniques that complemented the descriptive survey conducted in Phase 1 in several ways (McTavish and Loether, 2002; Coffey and Atkinson, 1999; Weiss, 1994).

During the course of survey administration in Phase 1, interview candidates were identified drawing directly on cases and snowball cases derived from these. A stratified sample achieved a fair cross-section of respondents across national origin, time of arrival, socio-economic class, age, and gender. Forty individuals (roughly $10 \%$ of the survey size) were interviewed to allow ample latitude for distinguishing sub-groups and specific patterns or clusters of attitudes, perceptions, and behaviors (Hakim, 2000: 35-6). Interviews were conducted by teams of two researchers and were audio recorded using digital recorders. Interviewees signed a written consent form before the interview and were awarded a token for participation valued at $\$ 10$ at the end of the interview.

The interviews employed an open-ended, semi-structured questionnaire that was tested and adapted such that average interview length was 60 minutes. See Appendix C and Appendix D for the final versions of the interview instrument in English and Spanish, 
respectively. The topics addressed in the interviews included reactions to the neighborhood and local physical spaces; ethnic identification/solidarity; civic engagement at the neighborhood level; civic awareness about public services and elected official; personal networks; sense of community, connection to local places, and the notion of 'home'; and changes in physical space/gentrification. Following these questions, an array of photographs taken from study areas that document contested aspects of the visual landscape was employed to illicit responses. Photo elicitation is a projective technique long used in qualitative research (El Guindi, 1998). It was useful for eliciting discussion on sensitive topics (Hakim, 2000), and, more broadly, "to discover how members of a society experience, label, and structure the world in which they live" (El Guindi, 1998: 475; see also Rose, 2007). A base map of the designated neighborhood and surrounding areas was the last component the interview; it was given to interviewees to complete as a cognitive mapping exercise. ${ }^{31}$

\section{Data Analysis}

Statistical analysis was performed by members of the Miami research team along with consulting help from Florida International University's (FIU) Statistical Consulting staff (www.fiu.edu/ statcon/) using the statistical package SPSS. Chi-square was utilized as the measure of significance, except for data for which a meaningful mean value could be calculated (or proxied), in which case the Kruskal-Wallis test was used for significance. Significance $(*)$ was defined at the conventional level of $<0.05$, with 'very significant'

\footnotetext{
${ }^{31}$ Data from the cognitive mapping portion of the interview were not used in this dissertation, therefore a detailed discussion of that methodology is omitted.
} 
$(* *)$ indicating $<0.01$ and 'highly significant' $(* * *)$ indicating $<.001$. Analysis output appears throughout the dissertation in tabular format.

Statistical analysis was performed only on those residents who were classified as Latino by members of the research team in the surveying process ( $\mathrm{Q} \#$ 9-A). The three sets of dependent variables on identity, trust, and civic engagement are presented and discussed in Chapters Four, Five, and Six, respectively. Thirteen independent variables (IVs) were used consistently for each data set (see Table 2.10 below). These IVs were separated in two major groups: dichotomous and continuous. The eight dichotomous variables are: US citizenship, gender, home ownership (rent/own), domestic partnership status (currently partnered vs. currently unpartnered) ${ }^{32}$, nativity (US-born vs. foreignborn), the presence of children $(<18)$ in the household, English language ability (Spanish monolingual vs. some level of bilingualism), and dominant-subordinate national origin group (Cuba-born versus all other Latinos; see Chapter Four for a detailed explanation). The five continuous IVs are: education, income, age, years lived in Little Havana, and years lived in the US (for immigrants only). ${ }^{33}$ Responses for education (Q\# 50) and income (Q\# 55) were both categorical and ordinal and thus have been proxied as continuous. Age, years lived in Little Havana, and years lived in US were open-ended questions whose responses have been placed in ordinal categories. Descriptive data tables for each of the independent variables used are found in Appendix E. The statistical

\footnotetext{
${ }^{32}$ Domestic partnership is at times abbreviated as DP in this dissertation.

${ }^{33}$ In this dissertation, I have termed these variables as 'continuous' to distinguish them from the dichotomous variables. Nevertheless, it is rather a misnomer. Education and income are in fact multicategorical variables that were collapsed upon analysis, while age, years lived in Little Havana, and years lived in the US were proxied as categorical.
} 
analysis performed for each question was determined by the nature of both the IV (dichotomous or continuous) and the DV (dichotomous or continuous).

Table 2.10: List of Independent Variables and Type of Variable

\begin{tabular}{|l|c|}
\hline Citizenship & Dichotomous \\
\hline Gender & Dichotomous \\
\hline Rent/own & Dichotomous \\
\hline Domestic partnership status & Dichotomous \\
\hline Nativity & Dichotomous \\
\hline Children in household & Dichotomous \\
\hline Language ability & Dichotomous \\
\hline Dominant-subordinate & Dichotomous \\
\hline Education & Continuous \\
\hline Income & Continuous \\
\hline Age & Continuous \\
\hline Years in Little Havana & Continuous \\
\hline Years in US & Continuous \\
\hline
\end{tabular}

Recordings of interviews with Latino residents of Little Havana were transcribed, edited for quality controlled, coded, and analyzed by the author (see Ryan and Bernard, 2003; Coffey and Atkinson, 1999; Miles and Huberman, 1994, especially Chapter 4; Silverman, 1993). Computer-assisted qualitative data analysis software (NVIVO) was utilized to store, organize, and code qualitative data. Such software encourages analytical rigor, allows for standardizing and sharing large amounts of qualitative data among research sites, and automated coding, text search and retrieval, response association, and pattern discernment (Johnston, 2006; Lewis, 2004; Seale, 2002). All interviewees were assigned aliases that are used throughout this dissertation. The author performed all translations from the original Spanish that appear in this dissertation. Since the vast majority of the interviews were performed in Spanish, only those quotes taken from interviews performed in English are noted in the text. 
In conclusion, the research upon which this dissertation is derived, through its multiple phases and methods, acts as a lens to view a complex problematic. As discussed above, Little Havana is a neighborhood facing many changes and challenges, as are its diverse residents. Latin American immigrants and American Latinos who reside there negotiate various aspects of their local, everyday existence and incorporation into life in the US on a daily basis. The conclusions that are drawn throughout this dissertation are based equally on quantitative and qualitative data and offer a new understanding of the ways that ethnic and racial identities, trust and community, and civic engagement are lived and negotiated in Little Havana, Miami. 


\section{Becoming American: Placing Assimilation, Identity, Trust, and Civic Engagement}

Cultures are continually co-produced in the interactions I call 'friction': the awkward, unequal, unstable, and creative qualities of interconnection across difference.

- Anna Tsing, Friction (2005)

Why should the Palatine boors be suffered to swarm into our settlement, and, by herding together, establish their language and manners, to the exclusion of ours? Why should Pennsylvania, founded by the English, become a colony of aliens, who will shortly be so numerous as to Germanize us, instead of our Anglifying them, and will never adopt our language or customs any more than they can acquire our complexion?

- Benjamin Franklin, Observations Concerning the Increase of Mankind, People of Countries, etc. (1706-1782)

In recent decades, it has become apparent that ethnicity and race are among the most common categories that contemporary human beings use to organize their ideas about who they are, to evaluate their experiences and behavior, and to understand the world around them. In some societies, of course, ethnic and racial categories and ties are more salient than in others. It is increasingly evident nevertheless that ethnicity and race are among the fundamental organizing concepts of the contemporary world.

- Stephen Cornell and Douglas Hartmann, Ethnicity and Race: Making Identities in a Changing World (2007) 
The United States... has historically been a high-trust, group-oriented society, despite the fact that Americans believe themselves to be rugged individualists.

- Francis Fukuyama, Trust (1995)

[I]nhabitants of diverse communities tend to withdraw from collective life, to distrust their neighbors, regardless of the colour of their skin,...to volunteer less, to register to vote lesss...Diversity, at least in the short run, seems to bring out the turtle in all of us. - Robert Putnam, E Pluribus Unum: Diversity and Community in the Twentyfirst Century (2007) 


\section{Introduction}

Much of the academic research on South Florida and Miami has focused on aspects of political, economic, and social life of the various immigrant groups that now live there. Topics include urban and labor market segregation (Stepick, 1991; Wilson and Portes, 1980), cultural, linguistic, and education norms and adaptation of second and third generation immigrant children (Rumbaut, 2005; Stepick et al., 2003; Alba et al., 2002; Boyd, 2002; Perez, 1994; Rumbaut, 1994), and the dynamics of ethnic and racial identities and intergroup relations (Croucher, 2002; Grenier and Castro, 1999; Portes and Stepick, 1993). The common ground of this Miami-focused scholarship with other scholarship on immigrants is that they attempt to understand and explain the ways that newer immigrants and immigrant groups incorporate themselves into life in the US, i.e., how immigrants as individuals and in groups 'become American,' and how life in the US is itself transformed via the process of accommodation that takes place. For decades, the most influential paradigm to explain immigrant incorporation into American life has been assimilation, the process by which members of diverse ethnic groups come to share a common culture with and gain equal access to opportunities in society to native-born Americans.

This dissertation contributes to the understanding of how immigrants 'become American' with respect to three areas: identity, trust, and civic engagement. Chapter Three consists of four sections which address the following topics, in turn: 1) an overview of the assimilation paradigm, its critiques, and alternative models of immigrant incorporation; 2) a discussion of ethnicity and race in the United States, including the development of these concepts, their relevance in immigrant incorporation, and the 
panethnic Latino group; 3) an explanation of trust, including operationalizing the term, major theories of trust formation, and the role of trust in civic life in the US; and 4) a discussion of the place of civic engagement in the US discourse of citizenship and immigrant relations, the major models used to explain mass participation, and differences between ethnic and racial groups. The literature discussed in the following four sections lays a foundation to understand the empirical data on identity, trust, and civic engagement presented and discussed in Chapters Four, Five, and Six, respectively.

\section{Assimilation}

Scholars have explained the process of immigrant incorporation in a variety of ways and from different perspectives. The most influential of the theoretical foundations for understanding how immigrants become a part of their adopted society in the United States - assimilation - is rooted in the work of the Chicago School of sociologists discussed in Chapter Two. In short, these scholars stressed the role of the city and urban spatial dynamics in the experiences of European immigrants and described their patterns of settlement, including the cultural and spatial components (Waters and Jimenez, 2005; Lal, 1990; Lieberson, 1980; 1963). Their ideas culminated in Milton Gordon's (1964) Assimilation in American Life: The Role of Race, Religion, and National Origins, in which he viewed assimilation as the natural consequence of the immigrant experience in America. Milton separated the process of assimilation into two stages (cultural and structural) and created a typology of seven dimensions of assimilation: cultural, structural, marital, identificational, attitude receptional, behavior receptional, and civic. Cultural assimilation (also known as acculturation) is the first stage, and occurs when 
immigrants replace their native language and view of the world with the English language and an American outlook. For Gordon, acculturation was a necessary precondition for structural assimilation to take place. The second phase, structural assimilation, consisted of deepened interaction with other established resident Americans, first as friends and close associates, and eventually marriage partners (Gordon, 1964; see also Alba and Nee, 2003; 1997; Stepick et al., 2003; DeWind and Kasinitz, 1997; Kazal, 1995; Morawska, 1994).

Social scientists have used four primary benchmarks to measure immigrant incorporation following the classic assimilation model outlined above: 1) socioeconomic status (SES); 2) spatial concentration; 3) language assimilation; and 4) intermarriage. In both scholarly discussions and in the popular American expectations, progress is not only expected in all these areas, but also seen as normatively good. The patterns of assimilation are as follows:

1) Socioeconomic status ${ }^{34}$ improves. Immigrants arrive uneducated and poor, mostly from rural areas. They work in factory jobs to support their families. Later generations obtain higher levels of education and pay in the US than their parents.

2) Spatial concentration decreases. Newly-arrived immigrants settle in enclave neighborhoods found in the central city and populated with co-ethnic kinsman. The ethnic neighborhood allows new arrivals to speak and read in their native language, eat traditional food, maintain or build new social relations with other from their own country

\footnotetext{
${ }^{34}$ Socioeconomic status is usually a composite measure of three components: educational attainment, income (parity in earnings), and occupational specialization. See Brady et al. (1995); Verba et al. (1993); Verba and Nie (1978). Occupation is not considered as an independent variable in this dissertation, although data on occupation was collected on the survey (Q\# 6).
} 
or region, and find cheaper housing prices. As SES improves either in the first or second generation, ethnics move outside of the city center, eventually into the suburbs. ${ }^{35}$

3) Language acquisition and assimilation occur such that members of the second generation are English dominant, though they maintain the parents' native language. By the third generation, the grandparents' native language is lost, though some words and phrases continue to be used in a symbolic fashion. ${ }^{36}$

4) Intermarriage. Immigrants will marry co-ethnics, but subsequent generations will marry outside of their ethnic or racial group. When this occurs, full assimilation will have been achieved. ${ }^{37}$

Across the four major indicators above, the key variable used to measure assimilation is generation. The first generation, or foreign-born generation, is expected to be less assimilated and exposed to American life than their American-born children, or second generation. The grandchildren of immigrants, or third generation, are expected to resemble the core American mainstream much more so than their parents (Waters and Jimenez, 2005: 106). The phrase "straight-line assimilation" was popularized by Gans (1973) and Sandberg (1973) to describe this linear notion of assimilation (see also Lieberson, 1973).

\footnotetext{
${ }^{35}$ This is defined in terms of dissimilarity in spatial distribution and of suburbanization.

${ }^{36}$ This indicator is defined in terms of English language ability and loss of mother tongue.

${ }^{37}$ Inter-marriage is considered primarily as marriage across races or between Latinos and non-Latinos.
} 


\section{Critiques of the Assimilation Paradigm}

Assimilation theory was based upon empirical evidence and analysis of the lives of immigrants who arrived to and settled in Chicago during the first great wave of immigration between 1890 and 1920. With the Johnson-Reed Immigration Act of 1924, Asian immigrants were excluded and the entry of southern and eastern European immigrants was restricted through a national origins quota system. Only after the passage of the Hart-Cellar Immigration Reform Act of 1965, which abolished the quotas system and established preference categories based on family reunification and professional skills, did large-scale immigration begin again (Lee, 2005; Alba and Nee, 2003; Joppke and Morawska, 2003; King, 2001; 2000; Joppke, 1999). ${ }^{38}$

One of the main differences between these two major waves of immigration is that the world region and country of origin of the newcomers changed. Whereas in the first wave the majority of immigrants were southern European (especially Italian) and Eastern European (especially Jewish), in the second wave the vast majority of immigrants hail from Asia and Latin American. Many of the newcomers from these regions are visibly different from the white majority in the US, and would fall into ethnic and racial minorities. Because of these differences, the process of accommodation might be more difficult than for the European immigrants of the first wave who have, for the most part, been absorbed into the white majority. This is due, in large part, because the definition of

\footnotetext{
${ }^{38}$ This piece of legislation was multi-faceted and has had various effects. It abolished the national-origins (quota) system of 1924 that gave preference to European immigrants and established source-country universalism in the admission of immigrants. It thus opened the door for large-scale immigration from Asia and Africa. It also has given preference to immigrants with higher levels of 'professional skills.' It has caused a drastic shift in the racial and cultural composition of immigrants; post-1965 legal arrivals have been, on average, more educated and held more prestigious occupations than both earlier immigrants and other native-born populations. Higham (1963) and Reimers (1985) remain the standard works on the 1924 and 1965 Immigration Acts, respectively. For more, see Lee (2004); Pierre (2004); Model (1997); Fortney (1972).
} 
'white' - which excluded Irish and Italians and Jews - was itself expanded, such that these southern and eastern Europeans became unproblematically white because the category expanded to include them, over time (Nagel, 2009; Kasinitz, 2004; Jacobson, 1998; Roediger, 1991; Anderson, 1987; see also Sibley, 1995).

The result of the immigration laws that sharply ended the entrance of new immigrants in the 1920s was to isolate individuals and groups from their countries of origin and curtail the extent of cultural infusions from the immigrants' homelands. It was in this context of immigrant settlement that scholars established the use of 'generation' in measuring assimilation. In the current wave of immigration begun in 1965, however, immigrants continue to arrive, thus refreshing and adding to existent populations. Ties between country of origin and adopted country often remain strong and many immigrants and their offspring lead transnational lives. To what extent 'generation' continues to serve the key variable in understanding immigrant incorporation has been questioned (Waters and Jiménez, 2005).

By the mid-1960s and through the mid-1980s, the standard assimilation paradigm had fallen prey to much criticism. Critiques targeted a number of aspects of the theory, as well as public and political policies and practices that both were reflected and justified by such theory, such as the increasingly nativist Americanization movement after World War I (Brubaker, 2001; Gleason, 1980). One of the most common critiques of the early formulation of assimilation theory discussed above was its insistence on analytical and normative Anglo-conformity: immigrant assimilation was both necessary and good. Furthermore, assimilation entailed giving up other ethnic traits and ideas and conforming to the white Protestant 'core culture.' These beliefs in assimilation pre-dated assimilation 
theory as articulated by the Chicago School and Gordon, as seen in the epigraph by Benjamin Franklin at the beginning of this chapter, and certainly informed their theorizations. They also provided a basis for government programs that put assimilation policy into practice. One of the most glaring and abhorrent ways that such beliefs in assimilation manifested was enacted on Native (indigenous) Americans beginning in the late nineteenth century. The General Allotment (Dawes) Act of 1887, which established a new system of land allocation, employed an assimilationist logic. It was accompanied by an 'Americanization' program meant to "Americanize Native American children into the US identity and way of life through education and, at times, removal from their families" (King, 2001: 154; see also Hoxie, 1989; Prucha, 1984, volume 2). Thus the normative face of assimilation meant that it was not a process that just happened; instead it was considered an inevitable and normatively good process that should, and in some cases was forced to, happen.

Other critics of the assimilation paradigm have argued that while assimilation into the "melting pot" was possible for some individuals and groups, it has been impossible for others, namely visible minorities. Scholars have argued that members of these ethnic and racial groups have not been allowed to melt. This critique points out structural factors - prejudice, discrimination, and for many years direct policy (slavery, segregation) - that have impeded visible minorities, especially blacks, from being equal and 'becoming American' (Nagel, 2009; Du Bois, 2007 [1889]; Pierre, 2004; Stepick et al., 2003; Brubaker, 2001; King, 2000; Alba and Nee, 1997; Nagel, 1994; Massey and Denton, 1993; Waters, 1990; Hirschman, 1983; Glazer and Moynihan, 1970 [1963]; Shibutani and Kwan, 1965). 
Yet another critique of the assimilation paradigm emphasizes the lack of clarity as to the content of the 'core group' or 'mainstream' into which immigrants are supposed to incorporate. In effect, critics ask the question: Of what does American culture consist? For Gordon (1964) and most others, 'core society' referred to middle-class, white, Protestant Americans, and the cultural patterns of this group as the 'core culture' (73-74; see DeWind and Kasinitz, 1997: 1097). ${ }^{39}$ This definition has proven too monolithic in recent decades, especially in urban areas. It does not take into account the diversity of cultures present in the US (Fainstein, 2003; Amin, 2002; Alba and Nee, 1997), the power of cultural changes, e.g., through globalization and cultural transfer (Sharp, 2007; Benton-Short et al., 2005; Robinson, 2004; Purcell, 2003; Santana, 2002; Mayo, 2000; Lin, 1998; Low, 1996), the ambivalence around a multi-cultural country and society (Ley, 2004; Mitchell, 2004; Frazier and Margai, 2003; Kymlicka, 2003; Amin, 2002; 1999; King, 2000; Hollinger, 1995), and the rapidly and drastically changing demographic landscape of the United States (Iceland, 2009; Odem and Lacy, 2009; Manter, 2008; contributors to Massey, 2008; contributors to Goździak and Martin, 2005; Reisinger and Tettey-Fio, 2003; Stepick et al., 2003; Iceland et al., 2002; Lobo et al., 2002; contributors to Suárez-Orosco and Páez, 2002; Suárez-Orosco and Singer, 2002; Suro, 1998; Portes and Rumbaut, 1990; McHugh, 1989), especially since the 1965 immigration laws changed. As will be discussed below, this criticism has resulted in a more nuanced, although not unproblematic, variation in the assimilation paradigm that

\footnotetext{
${ }^{39}$ In his much criticized work, Huntington $(2004 ; 1997)$ employs this same framework in discussing immigration and the impending culture clashes, especially between the core group and Latino and Arab immigrants and their descendants. He considers the 'core' as an uncomplicated, monolithic group and culture. Milton (1964), writing almost 40 years before, recognized the nuances of the core group and culture by explicitly acknowledging subsociety and subculture.
} 
takes into account cultural diversity and the possibility of incorporation as a variegated process. $^{40}$

\section{Alternative Approaches to the Assimilation Paradigm}

Alternative approaches to assimilation through the 1960s, 1970s, and 1980s included “ethnic retention," cultural pluralism, and "bumpy line" theories (see Gans, 1997; 1979; Gibson, 1988; Lieberson and Waters, 1988; Yancey et al., 1985; Glazer and Moynihan, 1970 [1963]). In these views, scholars argue that recent waves of immigrants retain more characteristics of their native culture and have assimilated less than the linear assimilation model allows. Assimilation is instead embedded within a multi-cultural society in which conflict, especially of the sort predicted by the Chicago School in their ecological model, did not occur. These models were rather optimistic and removed the normativity inherent in the assimilation paradigm for immigrants and their descendants that chose to retain immigrant cultural characteristics (Iceland, 2009; Nagel, 2009; Alba and Nee, 2003). Thus the teleological linear progression from 'immigrant' to 'native' was challenged by these models.

The "segmented assimilation" approach also arose as an alternative variation to assimilation (Waldinger and Feliciano, 2004; Perlmann and Waldinger, 1997; Zhou, 1997; Rumbaut, 1994; Portes and Zhou, 1993; Gans, 1992). This modified version of the assimilation paradigm emphasizes that assimilation is, for many immigrants, a variegated process. One of the assumptions in the assimilation model is that the socioeconomic

\footnotetext{
${ }^{40}$ See Touraine (2000 [1997]) for in-depth discussions about equality and difference in an age of shifting notions of modernity, globalization, and culture, and how they intersect with social movements, multiculturalism, democracy, and other topics.
} 
status (measured by educational attainment, occupational specialization, and parity in earnings) of immigrants improves from the first generation (foreign-born) to the second and third generation. It also assumes that English language proficiency improves and use increases. Work by some researchers has shown that this is not the case for some immigrants. Rather, the socioeconomic level of some immigrants over generations has either stayed the same or gone down. The causal factors of this phenomenon found in the neighborhoods where immigrants settle, the schools they attend, and the people with whom they socialize. In essence, immigrants and their offspring who do not follow the 'straight-line' of assimilation settle in poorer, lower class neighborhoods, attend inferior schools, and culturally take on both attitudes and behaviors of those (ethnic and racial minorities) with whom they live. These circumstances then reproduce a sort of 'immigrant underclass,' the opposite of the predicted and desired assimilation effect according to the mainstream model (Plaza, 2006; Perlmann, 2002; Alba and Nee, 1997; DeWind and Kasinitz, 1997; Portes and Zhou, 1993). ${ }^{41}$

Further critiques to the classic assimilation paradigm are based on discoveries about more recent social and spatial phenomena and patterns identified by social scientists over the past few decades; these apparently "correct" some of the mistakes made by proponents of standard assimilation theory. The work of various scholars (e.g., Guarnizo, 2001; Morawska, 2001; Mahler, 1999; 1998; 1995b; Guarnizo and Smith, 1998; Laguerre, 1998; Basch et al., 1994; Massey et al., 1994; Glick-Schiller et al., 1992), for example, has emphasized the extremely transnational attitudes and behaviors

\footnotetext{
${ }^{41}$ The underachieving, unassimilating groups are often juxtaposed against those who progress at an expected pace as well as some Asian groups that progress much more rapidly and drastically than might be predicted.
} 
of more recent immigrants. For them, ties between country of origin and host country are deeper, transportation is cheaper and more accessible, and communication has become faster and more economy. Transnational literature "emphasizes the persistent links between migrants and their homelands, the embeddedness of migrants in cross-border 'social fields,' and the complexity and fluidity of social boundaries in the face of globalization" (Nagel, 2009: 400; See also Basch et al., 1992). These factors have created conditions that allow immigrants to live their lives between the two countries. ${ }^{42}$

Immigrant settlement patterns described and predicted by both the Chicago School and those proponents of the ethnic enclave discussed in Chapter Two have become increasingly divergent from today's patterns, although immigrants still continue to be most highly concentrated in certain urban areas throughout the country (Iceland, 2009; contributors to Massey, 2008; contributors to Frazier and Margia, 2003; Reisinger and Tettey-Fio, 2003; Skop, 2008; Brettell, 2003). Many immigrants, however, arrive to the US and do not settle in traditional enclave neighborhoods within or near the central business district, or even in the cities proper; they instead bypass the urban core and move directly into the suburbs. In addition, some are moving to more rural areas and to states and regions that are not typical gateway or immigrant cities, largely in response to the location of employment opportunities (Price, 2010; contributors to Jones, 2008; contributors to Price and Benton-Short, 2008; contributors to Singer et al., 2008; Skop and Menjívar, 2001; Lin, 1998).

Ethnic neighborhoods themselves also appear to be going through changes (Alberts, 2005; 2003; Brettell, 2003). Zelinsky and Lee (1998), for example, propose a

\footnotetext{
${ }^{42}$ For critiques of the transnational literature from a feminist perspective, see Pratt and Yeoh (2003) and Mahler and Pessar (2001).
} 
model that supplements and partially replaces the older assimilationist and pluralist models. Heterolocalism describes an ethnic group that arrives to a metropolitan area, and instead of concentrating in one area, disperses residentially. Nevertheless, co-ethnics remain cohesive, forming "communities without propinquity." Another new model is the ethnoburb (Li, 1998; also Skop and Li, 2003) which describes certain ethnic clusters in Los Angeles. Rather than the traditional inner-city ethnic enclave neighborhood, ethnic neighborhoods are suburban in location. The ethnoburb hub is mostly commercial, and a place where immigrants go to interact, meet, exercise their ethnic identity, and shop. Ethnic community is built and maintained around the commercial area, without a high residential spatial concentration, and through the use of the internet, creating in effect cyber-communities from which thick social relations spring forth. ${ }^{43}$

\section{Ethnic and Racial Identity}

Considering how and why ethnic, racial, and panethnic groups are formed, maintained, and transformed over time speaks to the complex dynamics of identity formation, power, and collective action. Ethnicity and race "have to do with fundamental group processes: how human beings come to see themselves and others in particular ways, how they come to act on those perceptions, and how their understandings and actions are shaped by social and historical forces" (Cornell and Hartmann, 1998: 12). In recent years, scholars in the social sciences have argued, and to some extent agreed, that ethnicity and race are social constructions shaped by historical, cultural, and place-specific practices (Prewitt,

\footnotetext{
${ }^{43}$ For a discussion on political action, community formation, and changing identities in urban public space, see Crang (2000). See Ley (2004) for a discussion of transnational space, the global-local interconnection, and work on transnational businessmen and cosmopolitanism.
} 
2006; Hale, 2004; King, 2000; Mayo, 2000; Sollors, 1996; Nagel, 1994; Gupta and Ferguson, 1992; Omi and Winant, 1986). Empirical research has shown ethnic and racial identities and identifications to be fluid, situational, multiple, and dependent.

A common image used in the discussion of ethnicity and race is the boundary, a reference to the literal and figurative line that separates one grouping of people from another (Sibley, 1995; Waters, 1990; Barth, 1969). ${ }^{44}$ Boundaries create insiders and outsiders; they bind those found inside the demarcation line and exclude those outside of it. They can also give shape for solidarity and by extension collective action. This dissertation explores the possibility that ethnic and racial boundaries in the US, and the notion of inside and outside, are being challenged by the influx of Latin American immigrants and their offspring.

\section{Ethnicity and Race in the United States}

Concerns over ethnic and racial identity vis-à-vis the incorporation of immigrants in the US go far back; in fact, they pre-date the founding of the independent US nation. They are rooted in the perceived need to maintain the integrity of American society and culture, and emanate from the question of national identity and the threats posed to this identity by immigrants and immigrant-derived ethnic and racial groups. The assumption, indeed obligation, that immigrants adopt the identity of their host nation can be traced to one of the most famous and influential personalities of the US-independence period: Benjamin Franklin. As seen in the epigraph at the beginning of this chapter, Franklin reaffirmed the core English nature of American society, feared a non-Anglo demographic

\footnotetext{
${ }^{44}$ For a comparative discussion of boundaries vis-à-vis assimilation and exclusion, see Alba (2005).
} 
change, and denounced immigration and ethno-linguistic enclaves (Fraga and Segura, 2006; Smith, 1997; Fuchs, 1990).

John Hector St. John de Crèvecoeur, a French-born scholar/politician who immigrated to North America, on the other hand, believed in the capacity of the United States to melt immigrants from all nations into a new race of men; this capacity was for him at the foundation of the US national identity. "[T]he most important element of American identity was its capacity to be built through the successful synthesis of people with nationally diverse origins into a new American identity. There is no sense of threat posed by immigrants, provided they leave old customs and beliefs behind and embrace a 'new' American identity'” (Crèvecoeur, 1981 [1782], from his Letters from an American Farmer; quoted in Fraga and Segura, 2006: 280; italics in the original). Thus the debate over national identity vis-à-vis immigrant incorporation is an old one.

The concerns discussed above have continued since Franklin's time, and appear in government and popular discourse as well as in academia. A manifestation of these concerns and fears surfaced as one of the seven dimension of assimilation proposed by Gordon (1964). His identificational assimilation is the third of seven subprocesses required for the full assimilation of immigrants to take place. Identificational assimilation is "the development of [a] sense of peoplehood based exclusively on [the] host society" (71). ${ }^{45}$ Despite the challenges to the assimilation paradigm, the identificational subprocess continues to occupy a place in the lives of both descendants of European

\footnotetext{
${ }^{45}$ Though Gordon's (1964) view has been criticized because it seems absolute and like a one-sided process, he does acknowledge in a footnote that "ethnic identification in a modern complex society may contain several 'layers"' (77, footnote 28). He points out that some groups (e.g., black Americans, Jews, and Catholics) think of themselves as American while also having an inner layer peoplehood which is black, Jewish, or Catholic that differs from that of the white, Anglo-Saxon, Protestant core society.
} 
immigrants and new (post-1965) immigrant groups. Alba and Nee $(2003 ; 1997)$ point out that Gordon's concept of identificational assimilation was overly demanding because it required the extinction of all other forms of ethnic identity and their replacement by an exclusively national, American identity. Empirically, however, studies have shown that most Americans also identify with some non-American ethnic ancestry (Lieberson and Waters, 1993; Lieberson, 1985). As other scholars (Alba, 1990; Waters, 1990; Gans, 1979) have pointed out, however, this ethnic identification is often only symbolic.

\section{Theorizing Ethnicity and Race in the United States}

Ethnicity in the United States first arose by juxtaposing it to race. Race groups people according to processes of external ascription and internal identification by variations routed in genetic makeup and emphasizes phenotypical differences. Of these, skin color is the primary, but not the only, feature used to differentiate and order races in a social hierarchy. In the $18^{\text {th }}$ and $19^{\text {th }}$ centuries, many scholars focused on studying race by identifying, classifying, and ranking variations in humankind (Visweswaran, 1998; Sollors, 1996; Sanjek, 1994; Wolf, 1994; Isajiw, 1974; Van den Berghe, 1967). The work of Franz Boas $(1940 ; 1922 ; 1912 ; 1906)$ was crucial to refuting this 'scientific' racism (eugenics was one of its manifestations); he began the move toward understanding race as a variable shaped by broader societal forces. Though a complete consensus has never been reached, most social scientists reject the biological understandings of race and consider at least certain aspects of race to be socially constructed.

Ethnicity provided an alternative to race; it shifted the paradigm of study. Whereas race had been understood based in biology, ethnicity, in general, marks 
processes of external ascription and internal identification based in non-biologicallybased traits, e.g., culture, language, religion, or national origin (Mayo, 2000;

Visweswaran, 1998; Sollors, 1996; Sanjek, 1994; Jackson, 1987; Van den Berghe, 1967). ${ }^{46}$ According to Cohen (1999):

for traditional liberal thinkers race was still a bad item because it constituted a fixed quasi-biological essence operative only within scientific or popular racism; race meant defining people by the colour of their skin, the size of their skull, or the shape of their nose; ethnicity, however, was good (or at least better) in so far as it offered a more permeable and open-ended account of identities in which language, culture and religion all played their part in making or marking forms of historical individuality (2).

As with the concepts and realities of neighborhood and community as discussed in Chapter Two, debates abound over the exact 'stuff' of ethnicity. Scholars that consider ethnicity are usually drawn into two groups: those who consider ethnicity as an objective phenomenon and those who adopt a more subjective approach. ${ }^{47}$ Members of the former group, commonly known as primoridalists, share a fixed notion of ethnicity whereby inclusion in an ethnic group is determined by common ancestry or kinship and is rooted in unchangeable circumstances of birth. In this formulation, ethnicity has a fundamental, intractable power, much as with the notion of race. The latter group, the constructivists,

\footnotetext{
${ }^{46}$ Sollors (1996) points out that 'race' was discredited by the emergence of fascism, especially Nazi Aryanism.

${ }^{47}$ Isajiw (1974) acknowledged that some authors use a combination of the objective and subjective approaches in their works, suggesting that the dichotomy of understanding and explaining ethnicity is more of a continuum.
} 
on the other hand, takes ethnicity as a process in which people self-identify with a group, are identified by others as belonging the group, or both. In this formulation, one's own perception and the perception of others are key because they allow ethnic groups to be subjectively (re)defined. ${ }^{48}$ Ethnicity in this view is malleable and flexible, as well as subject in some measure to personal choice (Cornell and Hartmann, 2007; 2004; 1998). ${ }^{49}$

More recently, Hale (2004) has teased out additional aspects of the primordialist and constructivist views on ethnicity. For primoridalists, according to Hale, extended kinship relations hold ethnic groups together and imbue them with emotive power. Furthermore, ethnic groups have "particular constitutive features (cultures, traditions, histories, physical traits, language, repertoires, religion, etc.) that also do not change and that tend to be quite consistently distributed within the group" (460). For constructivists, on the other hand, what defines and differentiates ethnic groups are not the particular elements of culture or kinship, but rather that boundaries distinguishing groups from each other are created and persist. Though the constituent factors of an ethnic group may change over time, ethnic identity endures once it is created because the boundaries themselves are durable (ibid: 461; see Geertz, 1996). Following Geertz (1973), Hale (2004) posits feelings of group membership along a spectrum of 'thick' and 'thin.'

\footnotetext{
${ }^{48}$ Max Weber's understanding of ethnicity, as for so many topics in the social sciences, has been central to many subsequent definitions, although many in the social sciences have abandoned his definition. Weber defines ethnic groups as "those human groups that entertain a subjective belief in their common descent because of similarities of physical type or of customs or both, or because of memories of colonization and migration...Ethnic membership (Gemeinsamkeit) differs from the kinship group precisely by being a presumed identity...” (Weber, 1968 [1922], Chapter 5; italics in the original). Weber's notion of ethnicity is so subjective that belonging based on shared origins in largely, if not wholly, fictitious. For more, see Stone (2003); Cornell and Hartmann (1998); Isajiw (1974).

${ }^{49}$ For classic examples of early subjective approaches to ethnicity, see Cohen (1978); Cohen (1974); Barth (1969); Weber (1968 [1922]).
} 
"Personal points of reference or categorizations...become 'thicker' when they come to have greater importance in people's lives..." (468). Ethnic identity (ethnicity) is one such set of personal points of reference.

Hale (2004) points out that although primordialism and constructivism are usually posited dichotomously, these two views actually have much in common: they both see identities as constructed; symbolic content of ethnic groups can vary to some degree over time; there is at least some variation in the intensity or nature of group identification across members; and group identities tend to be quite stable once created. Hale thus renames the groups instrumentalists and perdurabilists according to the one factor that truly differentiates them: the real debate lies between those who view "the possibility of instrumentally altering individual ethnic identities within constraints... and [those] who cast individual-level ethnic identities as highly durable (perdurable) once constructed" (462). A person identifies with a category when he or she feels like a member of that category, i.e., when he or she has a "reference point in common with others to some aspect of the social world" (ibid: 468).

Joane Nagel (1994) focuses on the 'construction' of ethnicity which "stresses the fluid, situational, volitional, and dynamic character of ethnic identification, organization, and action..." (58). The ontological and epistemological approach taken by Nagel is very much based on the work on boundaries mentioned above. For Nagel, "[e]thnicity is constructed out of the material of language, religion, culture, appearance, ancestry, or regionality. The location and meaning of particular ethnic boundaries are continuously negotiated, revised, and revitalized both by ethnic group members themselves as well as by outside observers" (ibid: 58). Nagel agrees with Barth (1969) that boundaries can be 
crossed, although she stresses that the degree of difficulty of crossing varies according to the individual and the ethnic group. She further emphasizes that boundaries are constantly in flux, and are continually being (re)negotiated by insiders and outsiders. This is because the 'stuff' of ethnicity is culture; culture dictates the norms - e.g., linguistic, religious, artistic, musical, - of a group, and culture is always changing. ${ }^{50}$

Mary Waters' $(1996 ; 1990)$ work on optional ethnicities echoes Nagel's emphasis on fluid identities. Her key insight is that while some individuals and groups have the option to select their ethnic identities as they please, others do not. She shows how this is particularly the case for black Americans in the United States. ${ }^{51}$ More specifically, Waters speaks to the use and deployment of ethnic identifications. Her empirical work with English-speaking black Caribbean immigrants in New York and London led her to conclude that ethnic identifications are situational. Some individuals and groups, e.g., Americans of European descendent, have the option of identifying themselves ethnically in a number of ways. They can be white, or American, or a hyphenated American; often they choose one of their various European ancestry groups to identify with rather than another. For other groups, particularly those who are visibly different and thus defined in US society, e.g., blacks, it is much harder or impossible to choose an ethnic identity because their racialized ancestry is what has been defined as essential.

In other work, scholars have emphasized the place-specific nature of ethnic identity formation. In Becoming Americans, Becoming New Yorkers, Kasinitz, Mollenkopf, and Waters $(2004 ; 2002)$ argue that the dense and diverse immigrant and

\footnotetext{
${ }^{50}$ See Sibley (1995) for more discussion of boundaries.

${ }^{51}$ See Plaza (2006) for a similar discussion of Indo-Caribbean and African Caribbean Canadians.
} 
minority population of New York City forces second generation immigrants to negotiate their ethnic identities vis-à-vis other second generation immigrant groups and local native minorities. This context gives youth a different set of possibilities than youth who must negotiate ethnic boundaries with a core group of white Americans. This work is important because it speaks to the way that local context, in this case on the scale of the city, influences the way that assimilation takes place.

\section{Latino Ethnicity and Race in the United States}

Though scholars in some disciplines reject the notion of race outright (e.g., the American Anthropological Association's Statement on Race, 1998) and advocate for the use of ethnicity instead, other scholars insist that the negotiation of race and ethnicity forms an integral part of the incorporation experience for immigrants (Price, 2009; Foner, 2005; Foner and Frederickson, 2004; Kasinitz et al., 2004; 2002; King, 2000; Waters, 1999; 1994; 1990). ${ }^{52}$ This debate is pertinent for Latinos in the US, who have oscillated historically between being racialized and merely being categorized as an ethnic population, both by the general society and by the legal system (Price, 2009). De Genova and Ramos-Zayas (2003), in fact, insist that work on Latinos in the United States reminds us that any discussion of ethnicity without the consideration of race is incomplete. "[M]any of the prominent contributions to the Latino Studies scholarship opt instead to rely upon the analytic categories of 'culture' or 'ethnicity' in order to specify and theorize 'Latino' identity and community formations, and thus evade the question of 'race' and racialization altogether" (De Genova and Ramos-Zayas, 2003: 3).

\footnotetext{
${ }^{52}$ For a discussion of the race problematique in anthropology, see Visweswaran (1998).
} 
Choosing not to consider race when discussing Latin American immigrant incorporation obscures important aspects of the history of these ancestry groups in US history that have influenced the ways that Latino identity is perceived and expressed today. For example, Mexican Americans are a group whose history in the US dates back over 150 years to the annexation of what is now the American Southwest as a result of the Mexican-American War (Arreola, 2004). For decades, this population was forced to fit into what Latino/a critical (LatCrit) scholars call the 'black-white binary,' the socially constructed distinction between blacks and whites that has long informed both policy and scholarship on race in the US (Price, 2009; Gualtieri, 2001; Perea, 1998; Haney López, 1996), although post-1965 waves of immigration appear to have softened the black-white divide (Iceland, 2009). DeWind and Kasinitz (1997) point out that "[a]lthough in reality the United States has always been a multiracial rather than simply biracial society, American social thought has usually understood race in bi-model, black or white, terms" (1106).

The political activism of the 1960s and 1970s, rooted in the civil right movement, gave impetus to established Mexican American groups, along with the more recently established population of Puerto Ricans in the Northeast and Midwest US, to fight for recognition and rights. In response, the federal government began to experiment with various panethnic labels, in what was ultimately an effort to erase the unique histories of these two groups and thereby challenge their activist movement. In fact, many scholars agree that what we now see as the homogenization of distinct Latin American groups in the US was a result of the implementation of a pan-Latino label on official forms by the 
government (Dávila, 2008; 2004; 2001; Tienda and Mitchell, 2006; De Genova and Ramos-Zaya, 2003; Portes and Rumbaut, 1996; Calderon, 1992; Omi and Winant, 1986).

The growing number of Latin American immigrants and the proliferation of their offspring since the mid-1960s, together with the developing saliency of ethnicity in American society and the concept's prominence in American academia, seem to have opened up a space for a more complex and complete consideration of identity and identifications for Latin American immigrants to the US and their American-born offspring. In short, the lines between ethnicity and race, especially when considering this population, have begun to blur. However, the liminal space in which ethnicity and race are blurred has tended to homogenize all Latin American immigrants and their descendants into the panethnic categories Latino or Hispanic (Price, 2009; 2007; Arreola, 2004; Foner and Frederickson, 2004; De Genova and Ramos-Zayas, 2003; see also Espiritu, 1992). "Culturalist explanations of intra-Latino 'ethnic' identifications tend to presuppose substantive, if not essentialized, commonalities internal to groups with origins in Latin America, and thereby also take for granted their a priori status as groups" (De Genova and Ramos-Zayas, 2003: 2; italics in the original).

The ethnic characteristics that to a greater or lesser extent are shared by Latin American cultures are rooted in Spanish-speaking countries' shared colonial history; they commonly include 'traditional' foods, music, family values, and folkloric displays, and the Spanish language. These characteristics are used from within and without the panethnic boundary to homogenize Latinos into a panethnic group (Arreola, 2004; Foner and Fredrickson, 2004; Dávila, 2001). A shared language among Latinos is one of the main differences between the Latino and the Asian panethnic groups, both of which have 
been 'constructed' in the US. In her work, Espiritu (1992) draws attention to the political aspect of panethnicity - that is, the struggle for power and resources inside and outside the community. Panethnicity is thus instrumentalist in that it promotes group unification and mobilization. As such, the construction of panethnicity entails at least one of the same conceptual characteristics as the construction of ethnicity: facilitating members to view themselves as part of the group or inside the boundary.

As mentioned above, the homogenization of Latin American groups in the United States is seen to have been has been inextricably connected to the formulation of panethnic labels (e.g., Latino, Hispanic) by the US federal government. The homogenized Latino 'ethnic' construct has since been produced and disseminated through various means, including educational curricula as well as the mass media (Dávila, 2008; 2001; De Genova and Ramos-Zayas, 2003). The mass media and commercial markets have been a particularly influential factor in the diffusion of the homogenized Latino identity, through the construction of the 'Latino audience' for advertising purposes. The result has been "a largely undifferentiated or massified notion of Latinos as a discrete and unitary racialized market, notably conflating racial nonwhiteness with a presumed dominance of Spanish language that served as a proxy for 'low' socioeconomic status" (De Genova and Ramos-Zayas, 2003: 5; see also Rodríguez, 1998). Latinidad ${ }^{53}$, a homogenized concept rooted in shared cultural traits by all Latin American immigrants and their descendants, thus became both depoliticized and marketable (Dávila, 2008; 2001).

\footnotetext{
${ }^{53}$ Latinidad refers to a pan-Latino identity, whereas Latinismo refers to the strategic deployment of Latino or Hispanic identity. See De Genova and Ramos-Zaya (2003); Price (2007).
} 
Despite the creation of the panethnic label and group Latino and its initial positioning non-racial, they nonetheless act as a race (Campbell and Rogalin, 2006; Tienda and Mitchell, 2006; Foner and Frederickson, 2004; Dávila, 2003; De Genova and Ramos-Zaya, 2003; Cornell and Hartmann, 1998; Jackson, 1987). This has led to an ambiguity by which, for example, the terms are often used alongside black and white in an enumeration of racial categories. The elision occurs vernacularly, as well as in policyrelated discussions. Indeed, the mere designation of Latinos as a minority population and their inclusion in affirmative action qualifies them, at minimum, as a racialized minority (Campbell and Rogalin, 2006; De Genova and Ramos-Zaya, 2003). "Latinos straddle the divide, between being both a race, in some common understandings, and an ethnic group" (Cornell and Hartmann, 1998: 33; see also Price, 2009; 2007). Some scholars argue that ethnic and racial identifiers draw strength and salience as they are employed oppositionally against the prevailing structural and popular identifiers (Waters, 1996; 1990). Work on black immigrants (Africans, Black English-speaking Caribbeans, and Haitians) has shown that many members of those groups prefer ethnic labels to describe themselves rather than the racial identifier 'black' because of negative connotations that being 'black' (i.e., African American) has to them and to outsiders (Stepick et al., 2003; Stepick and Stepick, 2002). ${ }^{54}$

The discussion above points to the power of social, political, economic, cultural, and place-specific factors in shaping ethnic and racial identities and identifications. ${ }^{55}$

\footnotetext{
${ }^{54}$ These complicated and confusing dynamics leave black Latinos in a doubly difficult definitional situation.

${ }^{55}$ See Cornell and Hartmann (2007), Prewitt (2006), Levine (1999), Sibley (1995) for discussions of the role of power in constructing ethnicity and race.
} 
Individual and group agency would seem limited or non-existent. Certainly structure e.g., in the form of racial and ethnic census categories - constrains the breadth of possibilities. For example, respondents to the US Census "might provide racial and ethnic identifications that merely fit the format of the questions, regardless of whether those identities are particularly salient" (Campbell and Rogalin, 2006: 1031). For immigrants to the United States, the ethnic and racial structure is particularly relevant, as ideas and understandings of race are place- and context-dependent. This is because the social construction of race in general, and whiteness in particular, is highly place-specific and "has constituted a relatively porous social formation, if variously so over time and place (Price, 2009: 18; Oberle and Arreola, 2008; Martínez, 2000; Almaguer, 1998). Latin American immigrants arrive to the United States with one notion of ethnicity and race, but are confronted with and expected to adapt to a different understanding (Campbell and Rogalin, 2006; contributors to Arreola, 2004; Foner and Frekerickson, 2004; Gualtieri, 2004; Dávila, 2001; King, 2000; Radcliffe, 1999; Omi and Winant, 1986). The tension that surfaces is found in empirical evidence in which "many Latinos reject the United States' emphasis on black-white dichotomies and choose ethnic and cultural descriptors instead" (Campbell and Rogalin, 2006: 1033; Prewitt, 2006).

Those scholars who emphasize the structural pressures imposed by the US government to establish the Latino panethnic group often de-emphasize the intentional and instrumental aspect of the unification of various groups into one larger group to seek access to resources and power (Orosco, 2007; De Genova and Ramos-Zaya, 2003; Dávila, 2002; Haney López, 1996; Calderon, 1992; Espiritu, 1992). They also overlook the mobilization of members of diverse Latin American country of origin groups, races, 
and socio-economic backgrounds under a collective banner, utilizing their shared cultural characteristics and history as a base to fight for rights denied to them. The construction of the Latino panethnicity thus was not just a product of structural forces, but rather a process simultaneous to the agency-filled and intentional mobilization of disparate actors to mobilize within the boundary. As such, members of various Latin American origin groups also exercised agency in the creation of, participation in, and promulgation of the Latino panethnicity. The negotiation of identities and identifications, however, is an ongoing process. Where this process will lead Latin American immigrants and American Latinos is unknown. Indeed, as DeWind and Kasinitz (1997) point out, "[p]erhaps in the next $\left[21^{\mathrm{st}}\right]$ century the ties of language will make of the children of Colombians, Ecuadorians, Cubans and Mexicans (along with the grandchildren of Puerto Ricans and the great, great, great grandchildren of southwestern Hispanos) a single, quasi-racial 'Latino' group. But this is hardly the only possible outcome, or even the most likely one" (1100).

What Campbell and Rogalin (2006) point out in their analysis of 2000 Census data, however, is that agency on the part of respondents does exist and is, in fact, exercised in defining and re-defining ethnic and racial identities and identifications. "Many Latinos do not feel that the 'standard' racial categories provided on most surveys describe them adequately, and therefore turn to the 'other race' category. Virtually all (97\%) of those respondents who identified as 'some other race' on the 2000 Census were Latino, and $42 \%$ of Latinos chose 'some other race' as their racial identification" (1032). The negotiation of race and ethnicity can thus be considered in terms of the quote at the 
beginning of this chapter - as friction - "the awkward, unequal, unstable, and creative qualities of interconnection across difference.” (Tsing, 2005: 4).

Studies such as those mentioned above (e.g., Kasinitz et al., 2002; Nagel, 1994; Waters, 1990) are valuable because they show the changing perceptions of ethnic and racial identity and point to the fluidity within them. However, these studies do not necessarily show if or how ethnic and racial identities translate from sentiment into action. In some cases, as with studies of the Cuban ethnic enclave in Miami, research has shown the ways that ethnic ties can bind people together to the benefit of both individuals and the larger community (Zhou, 2004; Portes and Stepick, 1993; Portes and Manning, 1986) ${ }^{56}$ However, less work has been done on the ways that panethnic Latino identity transforms into a sense of generalized trust and civic engagement. These two topics will be dealt with below, in turn.

Trust

$\underline{\text { Introduction }}$

Trust is the second aspect of immigrant incorporation that will be considered in this dissertation. Trust has constituted an important part of the social fabric of the US since the founding of the nation (Paxton and Mughan, 2006; Paxton, 2005; 2002; 1999) and is relevant in the discussion of immigrant incorporation because the United States has been a high-trust, group-oriented society since early in the country's history (Herbert, 2005; Putnam, 2000; Fukuyama, 1995; Tocqueville, 1973 [1840]). As such, the well-being of

\footnotetext{
${ }^{56}$ For a discussion on localized attempts in San Francisco to create at least temporary panethnic solidarity through cultural performance, see Sommers (1991). This article explores the role of public fiestas in the creation of emergent panethnic Latino culture and consciousness.
} 
the nation's democracy has been thought to hinge on rich and healthy relationships of trust between citizens. There has been research over the past decade or so, however, indicating that levels of trust in the US are declining (Robinson and Jackson, 2001; Paxton, 1999; Rahn and Transue, 1998). Putnam (2000; 1999; 1995), for example, has shown a decline in the percentage of Americans that demonstrate generalized trust, from $56 \%$ in 1960 to $43 \%$ in 1976 to $34 \%$ in 1999 , while others have found a drop in the size of core discussion networks and a shift away from neighborhood and community ties toward those with close kin (McPherson et al., 2006).

These findings are troubling because trust occupies an important place in recent and current discussions in the social sciences. The field that has most explored the effects of (dis)trust of different groups since the mid-20 $0^{\text {th }}$ century has been social psychology through its work on intergroup contact (e.g., Pettigrew and Tropp, 2006; 2000; Pettigrew, 1998; 1971; Allport, 1954; Watson, 1947; Williams, 1947), although this area has also been of particular interest to sociologists (Glanville and Paxton, 2007; Paxton, 2007; 2006; 2005; 2002; 1999) and political scientists (Putnam, 2007; 2000; Uslaner and Conley, 2003; Uslaner, 2002; 1999). The intergroup contact field of study surfaced in social psychology in part due to the atrocities of World War II and the extreme feelings of hate that manifested mostly atrociously in the Nazi movement to extinguish Jews in Europe. More recently, scholars have posited trust's foundational role in overcoming problems of collective action and in fostering productive social exchanges ${ }^{57}$ (Cook, 2005; Arrow, 1974), democratic governance ${ }^{58}$ (Paxton, 2002; Uslaner, 2002; 1999; Putnam,

\footnotetext{
${ }^{57}$ Not all discussions of cooperation and collective action include discussions of trust. See Olson (1965) for an example of a non-trust based approach.
} 
2000), economic development ${ }^{59}$ (Knack and Keefer, 1997; Fukuyama, 1995), and as an essential component of social capital (Putnam, 2000; Paxton, 1999). This last area is the latest refinement of classical sociological ideas such as Gemeinschaft (Tönnies, 1963 [1887]), civil society (Calhoun, 1993), and civic culture (Almond and Verba, 1963). Immigration and trust are intricately intertwined because the post-1965 wave of immigration has brought new and different immigrants and thus further diversified the ethnic, racial, and cultural panorama in the US. Ethno-racial diversity has been posited by some (Putnam, 2007; Fukuyama, 1995) to be an obstacle to building trust; implying that the absence or opposite of difference, i.e., sameness or homogeneity, breeds trust. ${ }^{60}$ Difference is thought to cause feelings of skepticism, doubt, anxiety, and prejudice, feelings that can manifest in concrete effects. Spatially, these include segregation; ${ }^{61}$ socially, they include discrimination. Fukuyama (1995) posits that trust is a cultural characteristic inherent in society. For there to be trust, however, members of the group must share understandings and behaviors. "Trust is the expectation that arises within a community of regular, honest, and cooperative behavior, based on commonly shared norms, on the part of other members of that community" (Fukuyama, 1995: 26). Thus,

\footnotetext{
${ }^{58}$ Trust in government means that individuals are at least minimally willing to place political power in the hands of 'the people' (Paxton, 2007; 2002).

${ }^{59}$ Fukuyama (1995) argues that strong relationships of trust are at the root of economically successful countries whereas weak or non-existent relationships of trust have proven detrimental a country's economic success.

${ }^{60}$ See Nagel (2009) for a discussion of assimilation as a process of the making of 'sameness' and 'difference.'

${ }^{61}$ Segregation is not directly addressed in this dissertation. There is a copious literature in the social sciences on this subject, however. See, for example, Iceland (2009); Johnston et al. (2009); Goldberg (1998); Massey et al. (1996); Massey and Denton (1993); Denton and Massey (1991); contributors to Jackson (1987).
} 
increased diversity spawned by immigration could be considered potentially detrimental to the integrity of the American social fabric.

The 'similarity versus difference' argument congeals around the growing ethnic and racial diversity in the US as a result of immigration as an inhibitor of the formation of common culture and by extension the formation of trust as argued by Fukuyama and others (see Huntington, 2004). ${ }^{62}$ These arguments are aligned with findings from some cross-national studies that have shown that the highest levels of trust are found in the relatively ethnically and socioeconomically homogenous, egalitarian and well-to-do Scandinavian countries ${ }^{63}$, whereas the lowest are found in South America, Africa, and some parts of Asia (see Dehley and Newton, 2005; Newton, 2004; Rothstein and Uslaner, 2005). ${ }^{64-65}$ These findings are in line with work by other scholars that has found lower levels of trust among minorities and with low-income people, as well as studies demonstrating that economic inequality has also been shown to be a factor in lower levels of trust (Uslaner, 2002; Woolcock, 1998). In short, those who are less-trusting are people who are vulnerable and disadvantaged in certain ways, and who probably find it riskier to trust because they are less able to deal with the potential consequences of misplaced trust (Glanville and Paxton, 2007). This is often the case with immigrants, especially new

\footnotetext{
${ }^{62}$ Durkheim (1984 [1893]) employed the same terminology in his The Division of Labor in Society in arguing for the importance of both similar and different social bonds to exist in order for society to exist.

${ }^{63}$ This work generalizes about homogeneity and egalitarianism, and could make these countries seem perfect. The work of Allan Pred $(2004 ; 2000)$ is helpful in balancing out the view of Sweden, where he worked and documented the existence of racism and prejudice, as well as tracing its historical trajectory.

${ }^{64}$ The United States figures in the upper middle range of the trust index. See Dehley and Newton (2005); Rothstien and Uslaner (2005); Newton (2004).

${ }^{65}$ See Paxton (2007) and contributors to Dekker and Uslaner (2001) for more on variations between countries. Paxton (2007) finds, on the contrary, that association membership does not always increase generalized trust in her study of thirty-one countries.
} 
immigrants that are less familiar with and have adopted less the values of the larger society. Many immigrants to the US do not see themselves as sharing a common culture with other Americans, though there are exceptions (Uslaner and Conley, 2003; see de la Garza et al., 1996).

\section{Operationalizing Trust}

Scholars generally agree on a simple definition of trust: the expectation of good will in others (Glanville and Paxton, 2007). Trust involves believing in the honesty, integrity and reliability of others, that they will honor their commitments and avoid harming others; it is a "faith in people" (Taylor et al., 2007: 1; Wuthnow, 1998; Yamagishi and Yamagishi, 1994; Barber, 1983). Giddens (1990) pointed out that trust is possible in face-to-face contexts as well as in situations in which direct contact with another individual does not occur.

Trust is usually divided into two types: personalized ${ }^{66}$ or localized trust, and generalized trust. ${ }^{67}$ Personalized trust is embodied through face-to-face interactions and is based on specific and concrete experiences an individual has with another resulting in a favorable or successful interaction. Local groups through which a person usually forms personalized trust include family, neighborhoods, co-workers, and voluntary associations. In this formulation of trust, the setting and origin of trust formation are specified. Generalized trust, on the other hand, goes beyond the boundaries of direct contact and specified settings and extends to people one has never met; it transcends the boundaries

\footnotetext{
${ }^{66}$ This kind of trust is also called particularized trust. See Uslaner and Conley (2003).

${ }^{67}$ See Yamagishi and Yamagishi (1994) on distinctions between general trust and knowledge-based trust. See Uslaner (2002) for empirical investigations.
} 
of kinship, friendship or even acquaintanceship. Yamagishi and Yamagishi (1994) call it general because it reflects "a belief in the benevolence of human nature in general" (139). People form a 'standard estimate' of the level of trustworthiness of the average person someone who is not a friend, not even an acquaintance (Robinson and Jackson, 2001). It is this generalized trust - not personalized trust - that has been considered a prerequisite for the attainment of goals through collective action.

The basic questions to measure trust quantitatively were formulated by Rosenberg (1956) and continue to be used in current studies (Paxton, 2007). These questions are: 1) Would you say that most of the time people try to be helpful, or that they are mostly just looking out for themselves?; 2) Do you think most people would try to take advantage of you if they got the chance, or would they try to be fair?; and 3) Generally speaking, would you say that most people can be trusted or that you cannot be too careful in dealing with people? These questions were used as a basis to formulate the questions about trust in the study upon which this dissertation is based, and will be discussed further in Chapter Five.

\section{Major Theories on the Formation of Trust}

Scholarship on trust has in general paid more attention to explaining the effects of generalized trust and less attention on identifying its sources (Marschall and Stolle, 2004;

Alesina and La Ferrara, 2000; however, see Hooghe and Stolle, 2003; Wuthnow, 1998). ${ }^{68}$ There are two primary perspectives to explain sources of trust. The first is called the psychological predisposition perspective and it posits that humans tend to trust because

\footnotetext{
${ }^{68}$ The source of personalized trust, on the other hand, seems to be inherent in its definition. In other words, people acquired personalized trust through direct, personal interactions with others.
} 
the propensity to trust other people is innate or formulated early in life (e.g., Uslaner, 2002; 1999; Becker, 1996; Jones, 1996; Wrightsman, 1992). People then have a largely unwavering tendency to trust, one that does not vary according to specific actors and is not based on experiences shared with others. ${ }^{69}$

The opposing perspective is the social learning perspective, which posits that people extrapolate from localized experiences to produce their estimates of generalized trust (e.g., Yosano and Hayaski, 2005; Hardin, 2002; Burns and Kinder, 2000; Offe, 1999; Rotter, 1971). According to this perspective, humans develop trust with particular groups of people, such as family, neighbors, and fellow voluntary association members and then use it to form a more generalized sense of trust. Furthermore, the interactions and opportunities offered by different settings, e.g., family and workplace, allow individuals to develop different levels of trust. Trust built in localized settings, therefore, augments generalized trust (Glanville and Paxton, 2007; Rotter, 1971).

The latter perspective on generalized trust formation relates to the body of literature known as intergroup contact theory mentioned above. In general, intergroup contact theory posits that exposure to and contact with dissimilar groups fosters understanding between individuals and groups. The fear and skepticism of one group that manifests in stereotypes, feelings of prejudice, and discrimination can be overcome if certain conditions are met. Allport's (1954) pioneering intergroup contact hypothesis asserted that positive effects could occur only in situations that were characterized by four key conditions: equal group status within the situation; common goals; intergroup

\footnotetext{
${ }^{69}$ See Jones (2004), however, for how this varies in the case of extremely traumatic experiences such as being the victim of rape or terrorism.
} 
cooperation; and the support of authorities, law, or custom. Other work posits that four interrelated processes operate through contact and mediate attitude change: learning about the out-group, changing behavior, generating affective ties, and in-group reappraisal. Pettigrew (1998) adds a fifth condition to the latter group: "[t]he contact situation must provide the participants with the opportunity to become friends" (76; italics in the original). Contact, then, is considered to involve both cognition (that which one knows) and affect (that which one feels).

Intergroup contact theory has both strengths and weaknesses. One of its strengths, for example, is its recognition that situations are embedded in institutions and societies whose norms structure the form and effects of contact situations (Kinloch, 1991; 1981). Historical institutions in the US, such as slavery and segregation, and their accompanying norms, are understood to have framed contact between black Americans and white Americans since the founding of the nation. A weakness of intergroup contact theory, on the other hand, is its limited focus on the dichotomous racial categories of black-white. Much less work has been done that substantially looks into relations between other ethnic groups or within panethnic groups.

Another limitation of this work is the lack of clarity with respect to who belongs inside of the group (in-group) and who is outside of the group definition or boundary (out-group). The boundaries seem to fall along the lines of what is known as primary group and primordial ties. These concepts have been talked about on various scales throughout the $20^{\text {th }}$ century. Edwards Shils (1957), for example, observed that there was a connection among members of one's primary group, the family, and that this attachment was due to extensive contact with family members as well as a sense of a significant 
relationship based on blood. As was discussed above, blood ties are considered by some as one of the foundations for the formation of ethnic groups, albeit on a scale that transcends the family. For Geertz (1994), who also employed the concept of primordial ties, group loyalties are based on:

an attachment that stems from the subject's, not the observer's, sense of the 'givens of social existence - speaking a particular language, following a particular religion, being born into a particular family, emerging out of a particular history, living in a particular place; the basic facts, viewed again from the actor's perspective, of blood, speech, custom, faith, residence, history, physical appearance, and so on (6; underlining in the original).

These are the ties that create boundaries, define in-groups and out-groups, and can end up positioning out-group members as 'other.'

Understandings on both the origins and effects of the ties that bind individuals together and trust have also surfaced from work on social capital. Social capital theory can be classified under two major formulations: the more recent political science formulation (Paxton, 2002; 1999; contributors to Dekker and Uslaner, 2001; Putnam, 2000; 1993) and its previous sociological formulation (Portes, 1995; Coleman, 1988; Bourdieu, 1983). Both schools of thought have placed the weight of emphasis for the formation of generalized trust on formal social interactions (e.g., through formal organizations and networks). ${ }^{70}$ Nevertheless, some of this work, as well as that done by

\footnotetext{
${ }^{70}$ The sociological formulation differs in many ways with Putnam and others' formulations. Coleman (1990; 1988), for example, saw social capital as a relational good that inheres in relations between individual or very small group actors. He, along with Bourdieu (1983), take a much more utilitarian view of
} 
other scholars (e.g., Marschall and Stolle, 2004; Laurier et al., 2002) has begun to pay more attention on informal interactions and activities (e.g., neighborly conversations) as sources of trust.

The most influential work on trust and social capital in the past decade and a half is that of Robert Putnam $(2007 ; 2000 ; 1993)$. Putnam sees trust as both a positive consequence of and a prerequisite for the existence and exercise of social capital. ${ }^{71} \mathrm{He}$ defines social capital as "the features of social life - networks, norms and trust - that enable participants to act together more effectively to pursue shared objectives" (Putnam, 1993: 664-665). He distinguishes between two important dimensions of social capital: bonding and bridging. Bonding social capital exists between people with similar characteristics, such as ethnicity, gender, religion, and class. This form of social capital is "inward looking and tend[s] to reinforce exclusive identities and homogeneous groups" (Putnam, 2000: 22). Bonding social capital appears to happen effortlessly because it exists between people who have things in common; the dense networks found in ethnic enclaves are an example of how this trust manifests.

Bridging social capital, on the other hand, is found in "networks [that] are outward looking and encompass people across diverse social cleavages" (Putnam, 2000: 22). These relations are thought to be 'less natural' than those found with bonding social capital precisely because they must cross lines of basic difference and be constructed

social capital in that their formulation incorporates the notion that individuals join and participate in groups in order to reap potential benefits that such membership and association could bring. Putnam, on the other hand, views social capital of a group resource and a normative good for society.

${ }^{71}$ For a complete discussion of the theoretical origins of social capital, see Portes (1998); for critiques of Putnam's formulation of social capital, see Holt (2008), Durlaf (2002), Mohan and Mohan (2002), Sobel (2002); Foley and Edwards (1999); for an example of a new formulation, see Stepick et al., (2009). 
upon other foundations. Often the moorings of trust and bridging social capital are shared political, economic, or other interests; such relations have resulted in the civil rights movement, youth service groups, and ecumenical religious organizations. ${ }^{72}$

In sum, there are various theories and perspectives on how trust is formed, but no clear or overwhelming consensus exists. Empirical work on this topic elucidates various nuances of how trust works on a variety of scales and is discussed below.

\section{Major Findings on Trust}

Some researchers have measured trust and found relationship between levels of trust and certain demographic variables. For example, the Pew Research Center (Taylor et al., 2007) performed a telephone survey of three questions of trust on a nationally representative sample of 2,000 adults and searched for associations with demographics, including ethnicity and race, age, domestic partnership status, income, education, and occupation. Statistically significant relationships were found between many of the variables and trust. ${ }^{73}$ For example, white, higher income, better educated, and married, middle aged and elderly people are more trusting than blacks or Latinos, low-income, less educated, single, and young people, respectively. Gender, political party, and religious affiliation do not have any relationship with levels of trust. ${ }^{74}$ For Americans on

\footnotetext{
${ }^{72}$ Bonding and bridging social capital parallel closely what Granovetter $(1985 ; 1983 ; 1973)$ termed 'strong' and 'weak' ties. For Granovetter, the 'weak' ties that link someone to more distant acquaintances who move in different circles are more valuable and efficient in helping to get a job than the 'strong' ties one has with relatives and close friends. Thus Putnam's 'bridging' social capital is akin to Granovetter's 'weak' social ties both in with whom they are made and the effects they have.

${ }^{73}$ The three questions asked in the survey were: 1) Generally speaking, would you say that most people can be trusted or that you can't be too careful in dealing with people?; 2) Do you think most people would try to take advantage of you if they got the chance, or would they try to be fair?; and 3) Would you say that most of the time people try to be helpful, or that they are mostly just looking out for themselves?
} 
the whole, however, the results are basically split fifty-fifty, with roughly half of the population exhibiting a trusting attitude and the other half not. ${ }^{75}$ These results have fluctuated very little in the 40 years, although there was a drop in the 1990s. The survey did not delve into the motivations for why people do or do not trust, which is in keeping with the general lack of qualitative data on this subject.

The findings of the Pew Research Center show that age group is a serious factor to consider when discussing trust. Similar to Putnam (2000), Pew found that younger adults are less trusting than those who are middle aged or older. A few explanations for this finding have been posited. First, the life cycle effect theory posits that with more exposure, contact, and interaction with others, people become more trusting over time. Second, the generational effect, popularized by Putnam in the 1990s, posits that people who came of age at a time when social mores and historical events provided a more fertile seed bed for social trust are themselves more trusting. Putnam concretely posits that those born before 1930 are more trusting and civic-minded because of their common coming-of-age experience (World War II), while successive generations are less trusting as a result of their shared cultural experiences.

Other work has explored how ethnicity, race, and trust inter-relate. Marschall and Stolle (2004), for example, discuss how racial context and social interaction work to shape an individual's propensity to trust. Their study reveals that individuals who live in more racially diverse neighborhoods show higher levels of generalized trust than those

\footnotetext{
${ }^{74}$ Results from this survey also found that those who live in urban areas are also less trusting than those who live in suburban or rural areas, even when controlling for ethnicity and race and income.

${ }^{75}$ The question asked was "Generally speaking, would you say that most people can be trusted or that you can't be too careful in dealing with people?" The exact breakdown was $45 \%$ agreed with the former part of the questions (thus trusting) and 50\% agreed with the second half of the questions (not trusting).
} 
who live in more racially homogeneous neighborhoods (139). When they parsed out their data, however, Marschall and Stolle found that trust development works differently for blacks and whites. For whites, both racial attitudes and educational achievement are strong predictors of generalized trust. For blacks, on the other hand, racial context and the density of informal neighborhood social interaction matter most. These findings support the intergroup contact theory mentioned above (e.g., Bobo, 1988), which posits that social interactions among heterogeneous individuals and groups and positive cooperative experiences are more conducive to the development of trust that includes members of the out-group. Contact with or sustained knowledge about individuals of different racial, ethnic, or class backgrounds has therefore been shown to break down prejudices that are themselves based on inaccurate and rigidly held stereotypes. In addition, the findings highlight the importance of the neighborhood scale of social interaction for the formation of trust amongst racialized minorities.

The finding is bolstered by work by Putnam (2007) from his Social Capital Community Benchmark Survey (SCCBS), in which a series of questions was asked regarding generalized trust. Putnam first found a strong positive relationship between inter-racial trust and ethnic homogeneity, and that greater ethnic diversity seems to breed less trust in people who are racially and ethnically different. Putnam's conclusions echo research done by economists (e.g., Alesina and La Ferrara, 2000) that showed a negative connection between ethnic and racial heterogeneity and generalized trust. Putnam also found, however, a positive relationship between intra-racial trust and ethnic homogeneity, such that "in more diverse settings, Americans distrust not merely people who do not 
look like them, but even people who do" (ibid 148; italics in the original). He concludes that as far as trust is concerned, diversity causes anomie or social isolation.

Glanville and Paxton (2007), using data sets from the Pew Research Center's (1998) Social Trust Survey (STS) and the national component of the Social Capital Community Benchmark Survey (Roper Center for Public Opinion Research, 2000), tested the sources of generalized trust. They juxtaposed the two major source paradigms in the social sciences, the psychological predisposition and the social learning perspectives mentioned above. They asked if trust is more of a fixed predisposition as proposed by the psychological predisposition perspective or if it is based on extrapolations from experiences in localized interactions as posited by the social learning perspective. Their findings showed that trust in the localized domains of family, neighbors, church members, and club members should be treated as causal indicators of generalized trust. "[P]ositive trust experiences in localized settings have a powerful influence on generalized trust" (Glanville and Paxton, 2007: 238). Furthermore, they find that controlling for socio-demographic factors including education, income, race, and gender does not appreciably alter these results. In fact, trust in neighbors stands out as one of the domains that consistently have statistically significant positive influences on generalized trust across all of the samples" (238). ${ }^{76}$ "Trust experiences in neighborhoods are particularly important in the formation of generalized trust. Positive interactions with neighbors are a way of increasing generalized trust, while negative interactions with neighbors could undermine generalized trust" (Glanville and Paxton, 2007: 238; Yosano

\footnotetext{
${ }^{76}$ Trust in store workers also follows this same trend.
} 
and Hayishi, 2005). This means that trust in small groups and at the local scale can foster generalized trust.

These findings, however, contradict Stolle (2001) in that members of organizations characterized by high in-group trust express lower levels of generalized trust. In general, Glanville and Paxton's findings contradict the notion that strong trust in any one domain hinders the establishment of more generalized trust; on the contrary, trust in any one or various particularized domains may bolster generalized trust.

The above discussion points to the need for continued work on the sources of generalized trust. Conflicting accounts reflect the uncertainty around the role of ethnic and racial difference, socioeconomic demographics, and social milieu on trust. They also reflect the dearth of work on the role of racialized difference on trust that goes beyond the black-white racial divide; more in-depth and nuanced work that addresses trust focusing on the growing Latino population is greatly needed, especially given that membership in a minority ethnicity (e.g., being black or Latino) has now been posited as one of the strongest predictors of low levels of trust (Putnam, 2007). Furthermore, when considering immigrant incorporation into life in the US and the changing parameters of diversity this has occasioned, a US host society rich in trust into which immigrants would incorporate can no longer be taken for granted.

\section{Civic Engagement}

\section{$\underline{\text { Introduction }}$}

Civic engagement, like identity and trust, holds an important place in the US as both a state and as a nation. It has been considered a hallmark of life and society and a key 
factor in the country's democratic tradition ${ }^{77}$ (Fraga and Segura, 2006; Lee et al., 2006; Sawyer, 2005; Huntington, 2004; 1997; Paxton, 2002; Gerstle and Mollenkopf, 2001; Putnam, 2000; Tocqueville, 1973 [1840]; Almond and Verba, 1963). When civic engagement is addressed as an aspect of immigrant incorporation (i.e., participation by members of immigrant populations) as it is in this dissertation, it overlaps with the traditional concerns of studies of immigrant incorporation, or assimilation. In general, civic engagement speaks to the process of being a part of or belonging to a community and participating in a polity; for immigrants, it is a question of becoming part of and gaining a place of belonging on various scales, including the nation-state - i.e., citizenship broadly put (Stepick et al., 2008; Reed-Danahay and Brettell, 2008; Lee et al., 2006; Alba and Nee, 2003; 1997; Joppke and Morawska, 2003; Joppke, 1999)

Many of the same fears and concerns over the incorporation of immigrants vis-àvis identity mentioned above surface also vis-à-vis immigrant civic and political incorporation. For example, Thomas Jefferson worried that immigrants and their ethnic descendants would not incorporate into the political mainstream. According to Jefferson, the civic and political principles that immigrants brought from their home country could water down, warp, and bias American principles; if such an influence or infusion of these foreign principles into the polity occurred, the United States would become "a heterogeneous, incoherent, distracted mass" (as quoted in Fuchs, 1990: 12-13).

Similar concerns are voiced today by politicians and scholars. Latinos, especially Mexicans and Mexican Americans, have been the group of greatest concern in recent years (de la Garza et al., 1994; 1992; see Huntington [2004] for a particularly vitriolic

\footnotetext{
${ }^{77}$ For a critique of this theoretical approach to participation, see Hero (2000). He argues that the inequality for ethnic and racial minorities in the United States has made for an inegalitarianism.
} 
and ethnocentric perspective). ${ }^{78}$ Pundits express doubt that Latinos as a culturally distinct group will be able to adopt values seen as central to American political culture such as patriotism (de la Garza, 1982) and economic self-reliance (Romano-V., 1973). The adoption of American civic values by immigrants has come into relief because of findings that civic engagement, like trust, in the United States has declined overall ${ }^{79}$ (Putnam, 2007; 2000; 1995; Paxton, 1999; Uslaner, 1995; Teixeira, 1992). In some cases, negative feelings and hostile attitudes toward immigrants have arisen, culminating in legislation financing the construction of a wall along the extent of the border between Mexican and the United States.

Contrary to the criticism and ill-will of some pundits and academics, there is evidence that Latinos are successfully incorporating into civic and political life ${ }^{80}$ Their presence and participation have long affected various aspects of life in the United States, most recently and visibly in the political realm in congressional apportionments, electoral contests, activism in policy debates such as immigration reform, and daily social and economic relations as local residents and consumers at the state and local levels. The participation of Latinos at all level of government suggests a step toward civic and political maturation of the group overall (Fraga and Segura, 2006; Lee et al., 2006). Some

\footnotetext{
${ }^{78}$ There is often a slippage in these discussions between Latin American immigrants to the United States and US-born Latinos, which are both included under the panethnic label Latino. The broader tendency is to assume that Latinos are immigrants. As discussed in Chapter Three, panethnic labels hide a great deal of diversity within the collective, including nativity. Although many of those who are classified under the Latino label are immigrants, there is a sizable US-born Latino population, many of whom trace residence in the US many generations. The slippage reflects the enduring qualities of ethnic and racial stigmatization and points to the possible 'un-meltability' of Latinos in the US.

${ }^{79}$ Though there are a number of scholars who argue that civic engagement has declined, there are also many other who posit that civic engagement is in a process of change. See Olander (2003); Lopez (2002); Youniss et al., (2002); Youniss et al., (2001); Youniss and Yates (1997).

${ }^{80}$ This is also the case for other immigrant and ethnic groups, including Asians.
} 
studies, in fact, have shown that ethnicity and culture do not impede civic incorporation. De la Garza et al., (1996), for example, commenting on the case of Mexican Americans, have shown that ethnic characteristics may actually enhance civic engagement because "ethnic differences strengthen support for mainstream political values" (348).

\section{Operationalizing Civic Engagement}

In order to empirically study civic engagement, it must be operationalized in some fashion. Defined narrowly, civic engagement refers to participation in formal civic organizations, e.g., sports teams, professional groups, religious congregations, and volunteer organization. In this dissertation, a broader perspective of civic engagement is employed, and includes participation in public and community life through activities such as signing a petition or participating in a protest. This perspective takes into account the individual's relationship with both the state well as with the broader society. This can be understood as being (or in the case of immigrants, becoming) part of a polity. The civic engagement that is being discussed here, then, can include formal political (electoral) participation, participation in established clubs and associations, as well as activities that occur through social networks that extend beyond one's family (Stepick et al., 2008; Hyman, 2002; Flanagan and Faaison, 2001; Flanagan and Sherrod, 1998).

Civic engagement is essentially a question of behavior and is measured by participation in a number of activities. These activities include, for example, voting, signing petitions, participating in protests, attending religious services, playing on a sports team, contacting public officials, and volunteering, among others. There are various frameworks to group these activities (see Hero, 2007; Ramakrishnan and 
Baldassare, 2004; Andolina et al., 2003; Grootaert et al., 2003; Putnam, 2000; 1995).

Keeter et al. (2002) divides his list of 19 core behavioral indicators of civic engagement into three major categories: electoral, political, and civic voice. Electoral engagement includes registering to vote, voting, and being actively involved in political campaigns. Political engagement addresses taking an active role in expressing opinions to the media, politicians, organizations, or the general public. Civic engagement includes (nonpolitical) volunteering, active group membership, and participation in charity work along with efforts to solve community problems.

In their study of South Florida immigrant youth, Stepick, Dutton Stepick and Labissiere (2008) use Keeter et al.'s (2002) schema as a base but modify it into a 4category schema. Their political category includes the same activities as Keeter et al. (2002), but extends to include discussing politics, attending a demonstration, and seeking information on current events through newspapers or the Internet. The other categories are civic, expressive, and social. Civic includes activities in formal service organizations and programs, from holding a leadership positions (e.g., club officer) to being a volunteer or performing community service. Following Kirlin (2003), the authors distinguish between expressive group membership, which includes athletics, ethnic, and hobby organizations, on the one hand, and social activities, which include both helping one's family and others from the broader community, e.g., friends and acquaintances of a church congregation. The kind of activities that are included in this last category is important because informal social activities received less attention but have been theorized to have an intimate connection with participation in the other civic engagement categories. 


\section{$\underline{\text { The Socioeconomic Model of Civic and Political Engagement }}$}

Scholars have spent much time and energy studying and explaining mass participation in civic life in the United States. The most influential model to explain civic and political participation is socioeconomic status (SES). This model posits that individuals with high levels of socioeconomic resources (i.e., education, income, occupational status) are more likely to participate in the political system and other civic activities. Its validity has been bolstered by the work of many scholars who have shown that individuals with higher SES vote more, contact more, organize more, and campaign more than those with lower levels across the SES-related attributes (Putnam, 2007; 2000; Leighley and Vedlitz, 1999; Verba et al., 1995; 1993; Kenny, 1992; Leighley and Nagler, 1992a; 1992b; Conway, 1991; Leighley, 1990; Nie et al., 1988; Wolfinger and Rosenstone, 1980; Verba and Nie, 1972; see also Leighley [1995] for a review of these studies). Socioeconommic status has also been seen as the primary factor for variations in participation rates between ethnic and racial groups (e.g., Putnam, 2007; 2000; Verba et al., 1995). ${ }^{81}$

The SES model suffers from at least five major problems or limitations when considering Latin American immigrants and their children in the United States with regards to political and civic engagement. First, there is little empirical knowledge about minority groups compared to what is known about white Americans. The bulk of the minority-specific work has studied African Americans, although there is some work that

\footnotetext{
${ }^{81}$ The SES model of immigrant incorporation basically posits that socioeconomic incorporation happens first and civic incorporation follows; therefore, the patterns used to explain civic incorporation are indistinguishable from those that explain socioeconomic incorporation. This means that the civic behavior of immigrants and their descendents has been understood to flow from their economic incorporation, with few or no other paths considered possible. For further discussion, see Leighley and Vedlitz (1999); Fuchs (1990).
} 
has addressed Latino political involvement (see, for example, DeSipio, 2006; García Bedolla, 2006; Arvizu and Garcia, 1996; Diaz, 1996; Hero and Campbell, 1996; Wrinkle et al., 1996). For the most part, then, scholars have relied on findings about white Americans and extended them to Latinos under the assumption that SES works in the same way for all minority groups. The political and civic behavior of African Americans has been unreflexively generalized to other minority and ethnic groups (Leighley and Vedlitz, 1999). ${ }^{82}$

Second, the little existing work by various scholars on minority group civic and political engagement has presented mixed results. Lien (1994), for example, showed that education is significant for participation by Mexican Americans, but not Asian Americans. The inconsistent, often only occasional, relationship of education and income to participation among African Americans has been shown by Harris (1994), Tate (1993; 1991) and Dawson et al. (1990). These studies point to an argument made by SánchezJankowski (2002) in which he challenges the traditional notion that there is just one civic culture in the United States. ${ }^{83}$ Instead, he believes that civic culture and associated forms of civic engagement emerge from group history, social class, and social order. As such, the civic engagement of Latinos' as a group will mostly likely vary from that of other large ethnic or panethnic groups in the US. This argument not only challenges the existence of one civic or political mainstream, it furthermore lends itself to the possibility that within the Latino panethnic category there are in fact other groups, e.g., national groups, that might participate civically in different ways.

\footnotetext{
${ }^{82}$ See Pinderhughes (1987, especially Chapter 4) for reasons why generalizing between minority groups is not a good option. Reasons include groups' diverse historical experiences, cultures, and political goals.

${ }^{83}$ This argument resonates with the segmented assimilation literature mentioned earlier.
} 
Third, it is difficult to make comparisons across minority groups due to differences in the timing and sampling of minority populations. The tendency in the social sciences has been to use white Americans as the yardstick against which to measure minority groups, meaning that blacks and Latinos are compared separately to white Americans and their behavior judged accordingly. In many large study samples, however, minorities are not represented sufficiently; the minority subsamples are inadequate to compare the groups. Furthermore, Latino-specific data sources are few, another aspect of the dearth of work on Latinos mentioned above. Researchers thus have limited their analyses between whites and blacks, and whites and Latinos, but have not been able to compare whites to Latinos and blacks, or blacks and Latinos to one another. $^{84}$

Fourth, mass civic engagement, especially political participation, has mostly been studied by political scientists using disciplinary tools and lenses of analysis, although sociologists and psychologists have also made significant contributions. In geography, John Agnew (1996; 1994; 1993; 1987), a political geographer who employed the concept of 'geographical context' to focus on the spatial situatedness of individuals and social relations of human action, is one notable exception.

[C]ontext refers [to] the hierarchical (and non-hierarchical) 'funnelling' of stimuli across geographical scales or levels to produce effects on politics and political behavior. These effects can be thought of as coming together in places where micro (localized) and macro (wide-ranging) processes of social structuration are

\footnotetext{
${ }^{84}$ Leighley and Vedlitz (1999), Verba et al., (1995) and Uhlaner et al. (1989) are notable exceptions.
} 
jointly mediated. As a result, politics can be mapped not simply as the geographical outcome of non-spatial processes of political choice, but as a spatialized process of political influence and choice (Agnew, 1996: 132).

This dissertation is an attempt to 'place' civic engagement empirically and thus correct some of the above-mentioned limitations.

Fifthly and finally, an overall paradox exists in the study of civic and political behavior using the SES model: why is it that as levels of education and income in the United States have increased in the last four decades, levels of participation have decreased (Putnam, 2000; Paxton, 1999; Brody, 1978)? The five critiques explained above highlight various flaws with the SES model for explaining immigrant civic and political incorporation, and lead the way into other theories that explain engagement. Other Theories of Civic and Political Engagement

Other theories of mass participation opt for non-SES approaches to explaining levels of participation between ethnic and racial groups in the US. The psychological resources model, for example, emphasizes certain psychological orientations - political interest, political efficacy, trust in government, and sense of civic duty - as major determinants of participation (e.g., Aldrich, 1993; Rosenstone and Hansen, 1993; Texeira, 1992; Conway, 1991; Abramson and Aldrich, 1982). Other scholars explain participation using the individual's relationship to the larger society in what is known as the social connectedness model. In this model, the more connected individuals are to each other and 
to society, the more they participate. ${ }^{85}$ Concepts that have been used to describe social disconnect include anomie, alienation, lack of trust, estrangement, prejudice, and apathy (e.g., Pettigrew, 1964; Reisman, 1956; Allport, 1954; Lane, 1954; Durkheim, 1984 [1893]).

Putnam (2007; 2000; 1995), Uslaner (1995), and Teixeira (1992) all belong to the social connectedness model tradition and have argued that the deteriorated social fabric among individuals and between individuals and the larger political and social community is at the heart of the decline in political and civic participation in the US over the past thirty years. However, few studies focusing on ethnic groups have found social connectedness to be related to political activity. Research on the black church's crucial role in mobilizing black political participation (e.g., Harris, 1994; Verba et al., 1993; Vedlitz et al., 1980) and voluntary associations' crucial role in mobilizing AfricanAmerican and Latino civic participation, including voter turnout (Barreto et al., 2009; Benjamin-Alvarado et al., 2008; Jones-Correa and Leal, 2001; Diaz, 1996; Barker and Jones, 1994; Rosenstone and Hansen, 1993, chapter 6; Hero, 1992, chapter 4; Carton, 1984) has shown instead that ethnicity-based institutional resources are often more important for minorities than attachment to the community at large.

Other research from political science, psychology, and sociology has extended the two models discussed above and demonstrated the importance of group identity or consciousness as a factor influencing individual political behavior (e.g., Junn, 2006; Sanchez, 2006; Stokes, 2003; Jones and Vedlitz, 1994; Hardy-Fanta, 1993; de la Garza et al., 1992; Tate, 1991; Shingles, 1981; Gurin et al., 1980; Verba and Nie, 1972; Olsen,

\footnotetext{
${ }^{85}$ See Sawyer (2005) for a discussion of the role of socialization in building civil society.
} 
1970) ${ }^{86-87}$ The overall results, however, are contradictory. Although some studies have found that group consciousness is associated with participation for blacks, women and the poor (e.g., Wilson and Gomez, 1990; Miller et al., 1981), group identity is not consistently related to participation when estimated separately for other ethnic groups (e.g., Lien, 1994; Uhlaner et al., 1989).

In general, the research on civic engagement shows that levels of participation for ethnic minority groups are lower than those of the non-Latino white cohort and the national average. A study performed by Ramakrishnan and Baldassare (2004) for the Public Policy Institute of California analyzed civic engagement in light of the state's rapidly changing demographics. ${ }^{88}$ Their study corroborated findings by others that there are sizeable differences in participation associated with race and ethnicity. It further showed significant differences between first-generation immigrants and those in later immigrant generations, as well as between English-speaking and Spanish-speaking Latinos. The latter inequalities in participation, however, were generally smaller than those found for ethnicity and race.

\footnotetext{
${ }^{86}$ Various alternative theories to the SES model focus on African Americans. For example, both group identity or consciousness and compensatory theories (e.g., Guterbock and London [1983]; Williams et al., [1973]; Verba and Nie [1972]; Olsen [1970]); Bobo and Gilliam's (1990) placed the utmost importance of minority political empowerment (i.e., black officeholding) in local politics, while Cohen and Dawson (1993) considered the effects of the local social environment on black political involvement. In general, however, these alternative explanations have been criticized for their limited empirical bases and have failed to present truly compelling challenges to SES.

${ }^{87}$ This model of political and civic behavior is consistent with group conflict theory, which was developed in several social science disciplines. Group conflict theory posits that conflict is an inherent part of the historical and current social relations between both individuals and the groups to which they belong (and/or with which they identify). Some of the roots of this conflict are (real or symbolic) resources, struggle over political power, or differences over fundamental cultural values like religion. For more, see Pettigrew (1999); Tajfel and Turner (1986; 1979).

${ }^{88}$ California is now a majority-minority state, along with New Mexico, Hawai'i, and California, as well as numerous cities, like Miami, throughout the nation (Lee, et al., 2007).
} 
Verba et al. (1993) applied a resource model to the analysis of racial and ethnic difference in civic and political activities, including registering to vote, voting, participating in a protest, and contacting a public official. They also took into account social institutions not associated with economic position, e.g., voluntary associations and religious institutions that could provide resources that facilitate activities. They concluded that Latinos, in general, participate less than either non-Latino whites or African Americans. When the data for Latinos were parsed out according to ancestry group, however, important differences became apparent. For example, “Americans of Cuban origin, on average, engage in about as many political acts as the national average" (461). An integral aspect of their analysis was to differentiate between civic and political activities vis-à-vis the types and amounts of resources needed to participate. Verba et al.'s analysis showed that Latinos are only slightly less likely than non-Latino whites to have participated in a protest, but substantially less likely to report having contacted a government official. In addition to the conclusion that a group's level of participation depends upon the availability of resources derived from economic and social institutions, the authors show that "aspects of ethnicity itself - in particular, language and patterns of religious affiliation - also confer resources that facilitate political action” (458).

All of the models used discussed above provide a platform upon which to understand civic and political engagement in the US. They also serve as a lens through which to view the civic and political life of residents of Little Havana. In Chapter Six, these models will be used as a basis for interpreting survey and interview data, paying special attention to the role that SES and ethnicity play in the process. 


\section{$\underline{\text { Immigrant Incorporation and Civic Engagement }}$}

The process of immigrant incorporation is complex and multi-faceted, and involves the dynamics of a changing civic panorama in the US. Some recent research has revealed nuances to civic engagement in immigrant communities. For example, Uslaner and Conley (2003) found that people with strong ethnic identifications and who associate primarily with people of their own ethnic group will withdraw from civic participation or will belong only to organizations made up of their own nationality. In this case, those people with strong ethnic identifications are also those who exhibit high levels of particularized trust and remain with other members of their in-group. On the one hand, complete withdrawal from civic life would not be a good thing; on the other hand, active participation in ethnic groups could not be viewed exclusively in a negative light. In fact, participation in ethnic groups was considered by early immigration scholars (e.g., Park et al., 1984 [1925]) as a fast track into American civic life. Uslaner and Conley equate such participation in ethnic community as leading away from civic engagement in the larger community. These considerations might be attenuated, however, if they were studied over time or in light of generalized trust as mentioned above.

Other scholars have focused on religious life as a prism through which to understand immigrant civic engagement (Stepick et al., 2009; Jones-Correa and Leal, 2001). Although participation in religious congregations is a standard indicator in civic engagement questionnaires (Grootaert et al., 2004; Andolina et al., 2003; Putnam, 2000), its importance in the consideration of the ways that immigrants incorporate into their receiving society in the US is obscured as it is viewed as similar or equal to any other indicator. Many immigrants are highly religious, however, and as Stepick et al., (2009) 
point out, "religion is central to immigrants' personal and communal identity and their social orientation in a new land" (8; see also Stepick, 2004). Hirschman (2004) affirms that "[j] ust as many immigrants come to learn that they are ethnics in the United States, a significant share of immigrants also 'become American' through participation in the religious and community activities of churches and temples" (1207). As such, considering religion is important for understanding how immigrants incorporate into their host country. ${ }^{89}$

Religion has been shown to have a strong connection to civic and political engagement, especially with regards to immigrants. Research has demonstrated that various aspects of religion serve to shape and promote civic engagement among immigrants $^{90}$ (Stepick et al., 2009; Chang, 2005; Marquardt, 2005; Leonard, 2002; Rey, 2002; Stepick, 1998; Hammond, 1993; Nackerud, 1993; Aguilares, 1985) and also serves in the functioning of social capital ${ }^{91}$ (Stepick et al, 2009; Sikkink and Hernández, 2003; Wuthnow, 2002; Kim and Kim, 2001; Suh, 2001; Chai, 2000, Ebaugh and Chafetz, 2000; Min, 2000; Yoo, 1998; Kwon et al., 1997; Hurh and Kim, 1990). Various studies have shown that the more people attend church, the more likely they are to engage in civic activities, both inside and outside the church (Park and Smith, 2002; Brooks and Lewis, 2001; Smidt, 1999; 1987; Wuthnow, 1999). Data specific to Latinos are sparse yet

\footnotetext{
${ }^{89}$ Putnam's (2007: 160) findings, in fact, suggest religious identity is more important to them than their ethnic identity; however the salience of religious difference as lines of social identity has sharply diminished.

${ }^{90}$ Many churches actively promote civic engagement through activities like soup kitchens and other charitable work.

${ }^{91}$ An example of these functions is supplying information about jobs and housing.
} 
consistent, and studies show that church is often the primary, if not only, civic association to which Latinos belong (e.g., Jones-Correa and Leal, 2001) ${ }^{92}$.

Some of what is known about immigrant incorporation with respect to civic and political engagement has been discovered in studies of immigrant youth, although there is dearth of youth civic engagement literature. ${ }^{93}$ In general among immigrants, higher levels of socialization and acculturation translate into more participation, especially for voter registration and turnout at the polls. Members of the later generations have been shown to be more politically active than the first generation (e.g., Hill and Moreno, 1996; Lamare, 1982; Kellstedt, 1974). Part of this difference might be explained by studies that show that the educational system in the United States fosters participation in civic activities such as sports (Stepick et al., 2003; Stepick, 1998; Greenfield, 1997) and community service $^{94}$ (Kleiner and Chapman, 2000).

In his civic engagement study, Maxwell (2004) draws a link between neighborhood characteristics and the political expressions of Dominican youth. Maxwell shows that Dominican youth manifest politically in a different way depending on the demographics of the neighborhood in which they live. Why this happens is linked to questions of identity. Those who live in the majority Dominican neighborhood of Washington Heights have a specifically Dominicanized American political identity; they engage in an intra-ethnic politics with other Dominicans as their principal base of

\footnotetext{
92 Jones-Correa and Leal (2001) based this finding on data from the 1989-1990 Latino National Political Survey and the 1990 American National Elections Studies.

93 See Stepick and Dutton Stepick (2002) for a literature review on youth civic engagement.

${ }^{94}$ Note that the community service discussed by Kleiner and Chapman (2000) is a requirement for high school graduation.
} 
support. This group differs substantially from those Dominicans who reside in the ethnically mixed neighborhood of Brushwick-Williamsburg where Dominicans are a minority. In this setting, Dominicans engage in multi-racial, multicultural, ethnic politics. In sum, scholars have shown the importance of taking into consideration certain aspects of immigrants' lives and culture, including religion. Studies on youth civic participation engagement have been helpful in teasing out nuances to engagement, especially the role of ethnic and racial identities, as well as the place-specific aspects of solidarity and action.

In conclusion, Chapter Three has explored various aspects of four major topics addressed in this dissertation: assimilation, ethnic and racial identities and identifications, trust, and civic engagement. Each topic was operationalized, its theoretical and conceptual paradigms, debates, and limitations were explained, and relevant empirical findings were presented. This chapter lays the groundwork for interpreting and explaining these topics with respect to residents of a Miami neighborhood in the chapters that follow. In the balance of this dissertation, empirical data gathered from surveys and interviews in Little Havana will be used to answer the research questions outlined in Chapter One. They will be used to answer the specific questions about the incorporation process vis-à-vis identity, trust, and civic engagement. Overall, this dissertation provides a nuanced view of how Latin American immigrants and American-born Latinos are 'becoming American.' 


\section{Placing Ethnicity and Race in Little Havana}

This will give [you] proof [that all the various national groups in Little Havana get along]. Everybody's dancing, having a good time, eating, and there aren't any problems [at the Calle 8 festival]. If one million-plus people can get together [for a festival] and there aren't any fights or anyone dead, that's a big success.

- Felisa, 60 year-old Cuban-born resident of Little Havana for 39 years

It's pride. I feel very proud of where I come from, and...I read the statistics. Cubans are like the Latin community that has...succeeded [most] since they came to the United States of America and the hard work or small businesses, you know, we've made Miami basically. I'll be honest with you. One of the things that bothers me about these other communities is that they come here, they work here and...they send all their money...over to their country. They don't see it as, like, when we [Cubans] got here...We feel like we're Americans. This is our new nation...There's a lot of these South American and...Central America[ns] they still feel like they're...sending everything over there 'cause they always feel like they want to return some day. I feel like it's kind of raping this country. ${ }^{95}$

- Daniel, 37 year-old Cuban-born resident of Little Havana for 28 year

\footnotetext{
${ }^{95}$ English in the original.
} 
Recently some African-Americans, to be PC [politically correct], moved into that building over there, that big building over there...I don't mind because I grew up in Carol City and I was a Marine so...to me you're either light green or dark green; there is no color barrier in the Marine Corps. There's light green and dark green. And I grew up in Carol City so I've been around blacks all my life so it doesn't, personally, it doesn't affect me but it does affect the property values... Because once you have, you know, birds of a feather flock together, so once you get one apartment in there, then more will come in and that would definitely drop the property value...All the Nicaraguans came in [to Miami] and they're all in Sweetwater and Westchester. You tend to be around your own kind. It's natural, you know? Natural selection. ${ }^{96}$

- Gonzalo, 42 year-old Cuban-born long-term resident of Little Havana

\footnotetext{
${ }^{96}$ English in the original.
} 


\section{Introduction}

Sooner or later, immigrants to the United States are expected to modify their ideas on ethnicity and race, conform to and adopt the place-specific versions of these in the adopted land, and employ certain Americanized identifications. Furthermore, immigrants to the US were historically expected (and in some cases, forced) to renounce their allegiance to their countries of origin and adopt American ideology and identity when citizenship was granted to them. This process of ethnic and racial identity shifting is most probably incremental, both over the course of an immigrant's life as well as over generations, and perhaps in most cases, never complete. Indeed, the existence and employment of additive, syncretic, or hyphenated identities, (e.g., Italian-American) even after 100 years and three or more generations, suggests the lingering quality of ethnicity despite the clear move toward Americanization.

The sentiments expressed in the epigraphs above reveal the complex and nuanced ways in which ethnic and racial identities and identifications in the lives of Latin American immigrant and American Latino residents of Little Havana. Chapter Four explores these identities and identifications using quantitative and qualitative data gathered in the neighborhood. Many residents of Little Havana in general appear to have already adopted and currently employ certain Americanized forms of ethnic identification while at the same time holding on other forms of identification, including country of origin. There is a large portion, almost half, of Little Havana residents who employ panethnic labels racially, indicating an understanding of the racial structure in the US and their willingness to use their agency to challenge it. Conversations with residents, however, reveal that while the belief in a monolithic and harmonious panethnic group is 
common, it is also incorrect. The diversity that exists within the panethnic group serves as a boundary that collective panethnic labels have yet to erase between groups; axes of difference include many factors, including country of origin, color, and cultura and educación.

Chapter Four is structured in the following way. First, the changing neighborhood demographics and the dominant-subordinate variable are explored. Data are displayed and findings are discussed on the following four topics, in turn: primary identifications, panethnic identification, panethnic solidarity, and racial identifications. A discussion that synthesizes research findings follows. The chapter concludes with five conclusions regarding ethnic and racial identities and identifications in Little Havana.

\section{Changing Neighborhood Demographics}

As discussed in Chapter Two, Little Havana is a neighborhood populated primarily by Latin American immigrants. Surveyors categorized 96\% of Little Havana residents as Latino, revealing a higher concentration for these census tracks than that reported by the 2000 US Census (92\%); of these Latinos, almost 92\% were born in a Spanish-speaking country Latin American country. ${ }^{97}$ The breakdown of surveyees' countries of origin is diverse and includes 16 different countries (refer back to Figure 2.6); its distribution is also quite uneven. Cuban-born residents predominate in Little Havana at $48.7 \%$, with Nicaraguan-born (20.8\%) and Honduran-born (9.9\%) making up the second and third largest national origin groups, respectively. The next largest group is American-born Latinos (8.3\%); as a result of survey limitations, it cannot be determined for all of these

\footnotetext{
${ }^{97}$ Survey data also reveal that the neighborhood has a overall higher percentage of foreign-born residents than reported by the 2000 Census data, $88 \%$ versus $79 \%$ respectively.
} 
respondents the country(ies) of origin of their ancestors or what generation they are. For political, economical, social, and cultural reasons, this group is considered a distinct national origin group (Price, 2009; Skop, 2008; García, 2007; Hernández-Truyol, 2001; Reiff, 1999 [1987]; Fox, 1997). None of the other 12 national groups represented in survey sample reaches $3 \%$; the percentage of these 12 groups together add up to just shy of $12 \%$ of the total.

Little Havana is thus even more densely populated by Latinos and by foreign-born residents (first generation immigrants) than previously reported by the 2000 US Census. However, no one national origin group holds a statistical majority. Despite its name, Little Havana is no longer exclusively a Cuban ethnic neighborhood, at least when speaking in strictly demographic terms. Instead, the statistical plurality of country of origin groups reflects the shift toward Latin American diversity in Little Havana, a notable change since the 1970s and early 1980s when the overwhelmingly Cuban composition occasioned the neighborhood's colloquial designation of Little Havana. Nevertheless, Cubans continue to outnumber any other single national group in the neighborhood. When percentages of Latino residents born in Spanish-speaking Latin American countries other than Cuba are added together with those born in the US, the aggregate percentage is roughly on par with Cubans in terms of population $-48.7 \%$ Cuban vs. $52.3 \%$ other Latino ${ }^{98}$ (see Table 4.1 below). These two groups - Cubans (dominant) and all other Latinos (subordinate) - can be used as independent variables as mentioned in Chapter Two. This dominant-subordinate variable reflects the historic

\footnotetext{
${ }^{98}$ All those American-born Latinos were placed in the other Latino (subordinate) group, even though many of them were probably of Cuban descent. One reason for this is that the survey did not allow for this information to be clearly ascertained in all cases. A second reason is that this group grew up and was socialized in very different circumstances in the US than those born abroad.
} 
demographic and cultural dominance of Cubans in the neighborhood and takes into account differences and tensions that might arise as a result. ${ }^{99}$

Table 4.1: Percentages Countries of Origin of Survey Respondents Collapsed into Dominant-Subordinate Groups

\begin{tabular}{|l|l|}
\hline Cuba (dominant) & 48.7 \\
\hline Other Latino (subordinate) & 52.3 \\
\hline
\end{tabular}

Residents overwhelmingly realize, acknowledge, and accept the above-mentioned ethnic diversity in the neighborhood. In other words, residents know that Little Havana is no longer in its majority populated by Cubans, but rather contains a rich mix of almost exclusively Latin Americans immigrants and American-born Latinos. A few neighborhood residents, like Felisa, a 69 year-old ${ }^{100}$ Cuban-born woman who has lived in the neighborhood for almost 40 years, considers it more a "little Latin America." This sentiment is echoed by Remedios, a 75 year-old long-time Little Havana resident originally from Cuba. She says: “That's not Little Havana any more. That's more like Little Latin America because there are Latin Americans from everywhere, especially Central Americans...Nicaraguans, Hondurans, Salvadorans. Those [are the nationalities] that are mostly found there."101 Neither Felisa's nor Remedios' words or tone indicate disdain or sadness about these changes; rather they expresses a practical acceptance of the neighborhood's changed demographics.

Surveyees also overwhelming know that the majority of Little Havana residents are immigrants and that there are very few Anglos currently residing in Little Havana.

\footnotetext{
${ }^{99}$ For a discussion of dominant-subordinate ethnic group relations that was used as the basis for this distinction, see Doane, Jr (1997). See also Hooker (2009).

${ }^{100}$ The ages of respondents reflects their age as of 2005, the time survey was taken.

${ }^{101}$ All translations have been performed by the author.
} 
This undergirds the neighborhood's ethnic-ness, a reality in which more than one resident finds great comfort, as well as a sense of protection and security. The presence of stores that sell Latin American foods and the omnipresence of the Spanish language are attractive neighborhood characteristics. Daniel, for example, a 37 year-old Cuban-born man who came to Miami as a child and has lived in Little Havana for 28 years, says: "[Little Havana] is like a different country... every store you go here, everybody speaks Spanish. There are a lot of little stores that were in Cuba before...It's just staying with your culture, you know? It's different, like I said, you go to Kendall or up north Florida and it's like you get a lot of [anti-Latino] racism..."102

Most Little Havana residents interviewed also believe that the neighborhood is overall very quiet (tranquilo) and that members of the various ancestry groups present get along well. A common response was that most fellow neighbors were decent people (buena gente); nevertheless, Little Havana residents commonly acknowledged that there were some problematic residents. The following comment made by Consuelo, a 50 yearold Guatemalan-born woman who has lived in the neighborhood for 6 years, sums up this sentiment: “...You know that in every nationality there are good people and bad people...that's the way it is in every country." In general, however, relations between members of the various national origin groups, at least on the surface, are considered agreeable; Little Havana residents say that tensions do not exist between national origin groups. As will be seen below, however, the dynamics of these relations are more complex and nuanced than residents readily admit.

\footnotetext{
${ }^{102}$ English in the original.
} 
The cultural transition of Little Havana from a Cuban ethnic neighborhood to a mixed Latin American ethnic neighborhood has, however, met with some resistance and displeasure on the part of more than one Cuban-born resident. Reinaldo, for example, is a 53 year-old Cuban-born male who arrived in Miami and moved directly into Little Havana when he was 11 months old. When he refers to the growth of the non-Cuban Latin American population in Little Havana, particularly on and around Calle 8, he does so in a manner that expresses a sense of both nostalgia and threat. "When I was a kid, there was a very ethnic joke amongst the Americans that: 'Will the last American bring the flag when you leave Miami?' And now it's: 'Will the last Cuban bring the flag when you leave Miami [and Little Havana],' 'cause you know...now we're the minority. We're the ones being pushed out." 103

The transition to which Reinaldo is referring also plays out in the physical landscape, and creates a certain dilemma for the diverse Little Havana population. The continued use of the colloquial designation Little Havana and the fixed monuments, concretely those erected on Cuban Memorial Way (SW $15^{\text {th }}$ Avenue between $8^{\text {th }}$ Street and $10^{\text {th }}$ Street), reflect and represent only Cuban history, culture, and interests. It is clear that none of the non-Cuban residents of Little Havana identify whatsoever with the monuments that stand there, although none of them dislike or disdain their presence. Carla, a 42 year-old Nicaraguan-born immigrant who has rented her apartment in the neighborhood for the past 5 years, does not know what historical acts or people the monuments commemorate or feel any feeling toward the them, but she says: "Well, I guess for Cubans it is nice because they remember their country, their origins..." When

\footnotetext{
${ }^{103}$ English in the original.
} 
asked if she'd feel different if the flags in the photo elicitation exercise were Nicaraguan, she emphatically responds: "Of course! Yes! Because we would know we were recalling them [the Nicaraguan people] too!" On the other hand, the commercial landscape along the main thoroughfares, including Calle 8 , reflects and represents the mixed, especially Central American, demographic residential presence in the neighborhood. Many restaurants and stores are owned, operated, and marketed to this demographic using relevant images and symbols

Some residents, especially some Cubans who have lived in the neighborhood for many decades, reject the demographic shift toward diversity changes in certain ways. Teodoro, a 75 year-old Cuban-born male who has lived in Little Havana for over 40 years, is an example of this attitude. Although he recognizes that immigrants of other (non-Cuban) nationalities have moved into the 'greater' Little Havana area, he does not seem willing to grant them access to his immediate space; they reside in other parts of the neighborhood. He distances them geographically when he refers to these other nationalities "they're down that way" (están allá abajo"), i.e., not in his immediate vicinity. He refers to the distance again later in the interview, revealing the nuanced social distance he wants to create, mirrored by the spatial distance he places between himself and his immediate Cuban neighbors and the other Latin American residents. "People live here [in Little Havana] however they want. Those people from Central America over there ( $p a^{\prime}$ allá), principally Mexicans, they send all there money back there [to their home countries]. They live here just to drink beer." In addition emphasizing the non-Cubans' geographic placement denoted through the use of "pa'allá" (over there, not here), Teodoro also minimizes their contribution to both the quality of life in the 
neighborhood and in the country; his tone is vitriolic and his insults generalize against other nationalities, including Central American and Mexican immigrants. Nevertheless, Teodoro's comments are not quite accurate in that Mexicans are not a sizable national group in the neighborhood as corroborated by census data and survey results (less than $2 \%)$.

Although some neighborhood residents seem agreeable to, and even welcoming of diversity, it is clear that accommodating and adapting to diversity, here intra-Latino diversity, can be a complicated process for many neighborhood residents, and one that reveals a multitude of ethnic and racial positions adopted in Little Havana. In the next sections, results from a series of questions on ethnic and racial identity and identification are presented and discussed. The responses to these questions reveal interesting trends about how Latin American immigrants and American Latinos exercise, conform to, and challenge current norms and structures.

\section{Primary Identifications}

In a series of survey questions related to ethnic and racial identity, researchers asked respondents to state their primary identification. The responses were varied and for analytical purposes have been collapsed into twelve principal categories (see Table 4.2 below). The data reveal a plurality of primary identifications: country of origin (37.8\%) proves to be the most common primary identification for Latinos in Little Havana, followed by a panethnic label (Latino or Hispanic - 28.9\%). Color-oriented identifications (e.g., white, black - 11.2\%) are followed closely by hyphenated identifications (e.g., Cuban-American - 10.7\%). 


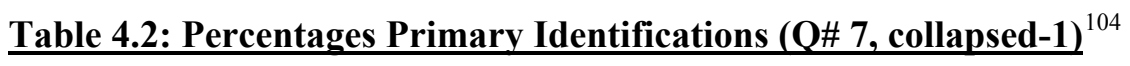

\begin{tabular}{|l|c|}
\hline Country of Origin & 37.8 \\
\hline Panethnic & 28.9 \\
\hline Color & 11.2 \\
\hline Hyphenated & 10.7 \\
\hline World region & 3.9 \\
\hline Country of Origin - US & 2.9 \\
\hline Other & 1.3 \\
\hline I'm not sure & 0.8 \\
\hline No Response & 0.8 \\
\hline Mixed & 0.5 \\
\hline Native/Indigeous & 0.3 \\
\hline US state & 1.0 \\
\hline
\end{tabular}

As discussed in Chapter Three, theorists and others have placed notable importance on identificational assimilation as an aspect to immigrant incorporation. The ways that immigrants and others choose to identify themselves are circumscribed by a number of factors. For first-generation immigrants, the amount of time spent in the US is key in shaping their identities and allowing for or facilitating a feeling of belonging. Other research has shown that later generation Americans do indeed choose an American primary identification; many, however, have the option of employing an ethnic identifier if and when they choose (Kasinitz et al., 2002; Morawska, 2001; Waters, 1990). Some other immigrants, e.g., Haitian and Black Caribbean youth, have been found to express their ethnic and racial identity in opposition to other groups, opting to distinguish themselves culturally and linguistically (Stepick et al., 2003; Stepick and Stepick, 2002; Waters, 1994). The above-mentioned data on primary identification can thus be collapsed to understand it more clearly in terms of identificational incorporation.

\footnotetext{
${ }^{104}$ Figure 4.2 shows percentages of responses to the open-ended question into first-round aggregate categories determined by the author along with other researchers.
} 
Further collapsing the categories is helpful to distinguish the extent to which immigrants and US-born Latinos are adapting to and adopting American forms of identifications, what might be considered identificational assimilation or 'becoming American' (see Table 4.3 below). ${ }^{105-106}$ Residents of Little Havana that identify according to non-US country or region of origin (43.7\%) continue to hold on to nonAmerican identifications, suggesting a lack of identificational incorporation into American life; these immigrants are referred to as 'non-assimilated.' Respondents who identify with panethnic labels, hyphenated national adjectives, and US country of origin (44.5\%), on the other hand, reflect a move toward incorporation or assimilation, adopting the North American adjectives and ethnic monolithic group identifications; this group is referred to as 'assimilated.' As the statistics below demonstrate, these two groups are almost even, suggesting that as many Latin American immigrants and American Latinos are, in fact, assimilating identificationally to American culture and society as those who are not. At the same time, there is a notable percentage of Little Havana residents $(11.7 \%)$ for whom color is the most important primary identification for them.

Table 4.3: Percentages Primary Identifications (Q\# 7, collapsed-2)

\begin{tabular}{|l|l|}
\hline Non-assimilated & 43.7 \\
\hline Assimilated & 44.5 \\
\hline Color & 11.7 \\
\hline
\end{tabular}

When the dominant-subordinate variable is used to tease out how Cubans and all other Latinos express their primary identification, we see significant differences emerge

\footnotetext{
${ }^{105}$ In the second round of collapsing, the following responses were discarded because they did not fit into either one of the three new categories: I'm not sure; mixed; native/indigenous; other; US state; no response.

${ }^{106}$ For more on assimilated identities, see Lee et al., (2006); Prewitt (2006); Foner and Frederickson (2004); Kasinitz (2004); Rumbaut (1994).
} 
between the two groups (see Table 4.4 below). Cubans, the dominant group in the neighborhood, express a primary identification that is statistically significantly less assimilated than the minority group; they also express their primary identification statistically significantly more in terms of color. In the subsection below on race, further nuances of these differences will be discussed.

Table 4.4: Percentages Primary Identifications ( $Q \# 7$, collapsed-2) Cuban vs. Other Latino

\begin{tabular}{|l|c|c|}
\hline & \% Cuban & \% Other Latino \\
\hline Non-assimilated & 48.3 & 39.3 \\
\hline Assimilated & 33.9 & 54.8 \\
\hline Color & 17.8 & 5.9 \\
\hline
\end{tabular}

Statistically significant at $.000 * * *$

\section{Panethnic Identifications}

Neighborhood residents were also asked if they identify as Latino, Hispanic, both, or neither. This question in effect measures the salience of panethnic identifiers for Latin American immigrants and American Latino residents of Little Havana. The statistical distribution is found below (see Table 4.5). The vast majority of respondents (71.4\%) identify as both 'Hispanic' and 'Latino,' while less than 10\% do not identify as either one. It is of note that of those identifying with only one the terms, Hispanic (17.2\%) was more popular than Latino (11.5\%). For the purposes of this analysis, the distinction between Latino and Hispanic is not as important as the fact that neighborhood residents are choosing to employ at least one of them. ${ }^{107}$

\section{Table 4.5: Percentages Identification with Latino/Hispanic Panethnic Labels} Do you identify yourself as Latino/Hispanic? (Q\# 8)

\footnotetext{
107 The author acknowledges the unique histories of Latino and Hispanic, but has opted not to analyze this aspect of the data. See Chapter One, footnote 2.
} 


\begin{tabular}{|l|c|}
\hline No $^{108}$ & 8.3 \\
\hline Hispanic only & 17.2 \\
\hline Latino only & 11.5 \\
\hline Both Hispanic and Latino & 71.4 \\
\hline
\end{tabular}

In order to understand the extent to which Little Havana residents are adapting an American or assimilated form of identification, the panethnic categories - Hispanic only, Latino only, and both Hispanic and Latino - were collapsed into one category (see Table 4.6 below). Results indicate that panethnic identifiers are overwhelming salient for residents of Little Havana. As discussed in the previous subsection, panethnic identifiers were the preferred primary identification for only around $30 \%$ of residents; nevertheless, when asked if they identify using a panethnic label, almost $92 \%$ are willing to selfidentity as Latino and/or Hispanic in one situation or another. In contradiction to DeSipio and Henson (1997), this finding demonstrates the overwhelming extent to which the vast majority of Latin American immigrants and US-born Latinos adopt the American panethnic concept.

Table 4.6: Percentages Identification with Latino/Hispanic Panethnic Labels Do you identify yourself as Latino/Hispanic? ( $Q \# 8$, collapsed)

\begin{tabular}{|l|c|}
\hline No & 8.3 \\
\hline Yes & 91.7 \\
\hline
\end{tabular}

These data are also noteworthy for a discrepancy that they reveal. While $96 \%$ of neighborhood residents were categorized by researchers as Latino, only $92 \%$ selfidentified using a panethnic label. Portes and Rumbaut (1996) argue that "contemporary Latin American immigrants are told - in no uncertain terms - that despite their ancestral differences, they are all 'Hispanic'” (137). Some Little Havana residents (roughly 4\%),

\footnotetext{
108 The 'no' category is composed of those respondents who answer 'no' along with those who answered 'I'm not sure.' The same goes for Tables 4.6, 4.7, and 4.8.
} 
however, did not participate in the panethnic collective identity. The discrepancy suggests that residents of Little Havana are exercising agency to identify ethnically, only they are doing so in a surprising way, i.e., choosing not to identify as Latino or Hispanic. Overall, however, we see that the Latino/Hispanic labels are sticking, and in an important way.

The dominant-subordinate analysis helps decipher where the above-mentioned discrepancy lies. Cubans choose to identify as Latino or Hispanic statistically significantly less than non-Cuban Little Havana residents; conversely, non-Cubans identify significantly more than Cubans as both Latino and Hispanic (see Table 4.7 below). When the categories of Latino only, Hispanic only, and both Latino and Hispanic are collapsed into the panethnic dependent variable and tested against the dominantsubordinate independent variable, the difference between the two groups comes into greater relief (see Table 4.8 below). More Cubans choose not to adopt the panethnic identifier than non-Cubans, suggesting perhaps a resistance to adopting Americanconstructed panethnic labels or becoming part of the Latino collective in the US. This finding presents a curious contradiction given that Cubans and Cuban Americans have been considered by the US government and scholars alike as a model immigrant community, assimilating successfully into US society and achieving the American dream. This group also tends to have achieved greater socioeconomic standing than all other Latin American origin groups, another indication of successful assimilation (Portes and Shafer, 2006; Alberts, 2005; 2003; Pedraza-Bailey, 1985; Wilson and Portes, 1980).

Table 4.7: Percentages Identification with Latino/Hispanic Panethnic Labels Do you identify yourself as Latino/Hispanic? (Q\# 8)

Cuban vs. Other Latino 


\begin{tabular}{|l|c|c|}
\hline & \% Cuban & \% Other Latino \\
\hline No & 14.5 & 2.5 \\
\hline Hispanic only & 8.0 & 9.6 \\
\hline Latino only & 12.8 & 10.2 \\
\hline Both Hispanic and Latino & 64.7 & 77.7 \\
\hline
\end{tabular}

Statistically significant at $.001^{* *}$

Table 4.8: Percentages Identification with Latino/Hispanic Panethnic Labels Do you identify yourself as Latino/Hispanic? (Q\# 8, collapsed) Cuban vs. Other Latino

\begin{tabular}{|l|c|c|}
\hline & \% Cuban & \% Other Latino \\
\hline No & 14.4 & 2.5 \\
\hline Latino and/or Hispanic & 85.6 & 97.5 \\
\hline
\end{tabular}

Statistically significant at $.000^{* *}$

At the scale of the neighborhood, the place-specific power dynamics of Cubans might be used to understand the differences between the dominant and subordinate groups with respect to the acceptance and adoption of the panethnic labels. As discussed in previous chapters, 'neighborhood' and 'identity' are co-constituted phenomena. The neighborhood and the identity of its residents influence and constitute each other; as such, the firm Cuban cultural and symbolic characteristics of the neighborhood might act to reinforce Cuban identity, just as the firm Cuban identity of the residents perpetuates the existence of the Cuban ethnic neighborhood. Living in Little Havana, despite the demographic changes through which the neighborhood has gone through in the past decades, may act to reinforce Cubans' identities as belonging to their national origin group, as opposed to melting into the panethnic Latino collective. At the same time, the latinization (versus previous Cubanization) of the neighborhood might contribute to the willingness on the part of most Little Havana residents in accepting the panethnic identifiers; furthermore, a firm identification with panethnic labels could contribute to a more Latinized ethnic place. 
Nuances of the ways that panethnic identifications are employed by residents of Little Havana were revealed by the interview data. As mentioned above, most respondents claim say that members of the various national origin groups get along well and that tensions do not exist. Many respondents, especially female respondents, attest to the good relations between national groups embodied through friendship with people from other nationalities. Consuelo, mentioned above, for example, says: "I have [female] friends from Guatemala, Nicaragua, Colombia, Honduras... I get along with [people] from anywhere."

Antonio, a 79 year-old Cuba-born man who has lived in Miami since 1959 and in Little Havana almost since he arrived to the city, says “of course! (¡cómo no!) he feels affinity with other non-Cuban Latinos. He sees no cultural difference between Cubans and other Latin American nationalities; he, in fact, invokes a universalizing ideology: "For me, everyone is equal" (Para mí, todas las personas son iguales)." Antonio claims not to discriminate against those from other countries, although he notices that others $d o$ discriminate against Cubans. Careful to make it clear that he wishes not to offend anyone, he states: "Cubans have 'made' Miami. Miami was made by the Cubans. Cubans have a way that is not like other countries, so if you are from Nicaragua, you don't see Cubans in a positive light." So while Antonio personally claims not to discriminate against other ethnicities, he acknowledges that inter-ethnic relations are fraught with tension. He even goes so far as to say that other Latinos discriminate against Cubans: "They feel hatred toward Cubans." On a personal level, though, the only thing that Antonio says he judges a person by is how he or she acts and how he or she treats him. 
The anti-Cuban sentiment described by Antonio is echoed by Daniel, mentioned above. The source of the tension is envidia (envy or jealousy) of Cubans felt by members of the other national groups because of the special political and economic privileges that the former group has enjoyed as an exile group in the US. His words also point to a tension between feelings of superiority and envy in how Cubans explain others' feelings toward them as Cubans. Daniel says:

There's like a lot of Cuban, anti-Cuban [sentiment] 'cause we've gotten so many privileges, like to come into the United States and then the Haitians, you know, they don't get the same privileges... But those countries don't realize that we came because of oppression, you know?...The Cubans are always getting all the benefits and...they treat us, you know, weird...especially other Latinos. 'Cause they feel like, 'Oh man, we gotta go through all things to get our green card, this and that and you all just automatic [get it when] you come...' So it's envy. There's a lot of envy and we feel it, it's something that we can feel. ${ }^{109}$

Other lines of fragmentation are discussed by Mercedes, a 23 year-old Nicaraguan-born woman who has lived in the same house in Little Havana since her family immigrated to the US 22 years ago. Mercedes thinks that a great sense of community exists among Cubans, but that the same kind of sense of community does not exist among Latinos in general. Instead members of different national origin groups think

\footnotetext{
${ }^{109}$ English in the original.
} 
and speak badly about members of other groups, impeding an overall sense of panethnic community. She says:

I think that...the Cuban community is really close and when they want something they get it. I think that if that could be expanded to include everyone, of course I think that everyone would benefit from that. But, it's like, God, it's too fragmented at times. Colombians, and Cubans and sometimes you hear comments about Hispanics [by other Latinos] that, 'I don't like that person of El Salvador,' or 'I don't like Cubans' or 'I don't like Puerto Ricans,' or I don't like... ${ }^{110}$

The intra-Latino prejudice based on country of origin described by Mercedes is illustrated by the comments of Javier, a 66 year-old Cuban-born man who has lived in Little Havana for 8 years. He echoes the anti-Mexican sentiment seen above in Teodoro's statement when he gives the example of cultural differences between national groups. "From childhood, I learned and understood, and from experience have seen, that Mexicans, many of them, are not grateful for anything you do for them." Though he claims to not want to generalize ("no quiero generalizar"), he does, in fact make sweeping generalizations about other ethnic groups. "There is a percentage, not only me, but many people, from other countries too, that say 'Be careful of the Mexicans.' [But] I don't have anything against them; I [even] have Mexican members of my family."

Both Mercedes' and Javier's comments speak to the inter-group relations, primordial ties, and bridging and bonding social capital discussed in Chapter Three

\footnotetext{
${ }^{110}$ English in the original.
} 
(Stepick et al., 2009; Cheong et al., 2007; Uslaner and Conley, 2003; Putnam, 2007; 2000). Similarities between people, here residents of Little Havana, such as country of origin, appear to function as bonds, which as will be seen in the following chapters, provide a platform for sociability, trust, community, and collective action. On the other hand, for residents from different countries, national origin as a fundamental difference is a chasm over which a bridge must be built for the bonds of trust to take root. Indeed, evidence from this study suggests that national origin trumps panethnic identification as a foundation for sentimental bonds, and as will be seen later, continues to provide a sound base for productive social relations for Cubans in Little Havana.

The neighborhood is at the same time a place where ethnic distinctions are played out on a daily basis. Javier continues: "In this neighborhood - Hondurans, Guatemalans, Argentineans - [they] all live in this neighborhood. Each one looks for his own group [by country of origin]. They are not like us [Cubans]. We open our hearts and arms to any country." Overall, he characterizes the neighborhood as one of fragmentation. Fragmentation along lines of country of origin is not due to Cubans, according to Javier, but rather to the attitudes and actions of the other Latin American national groups.

Emilia, a 23 year-old American Latina born in Miami, expressed a point of view in opposition to that of Mercedes' above. She believes that a universal sense of community, a union among Latin American national groups, exists. "I know there's like stereotypes and things like that but, you know [what] people say about people, but for the most part I think people, if you're Latin, you kind of stick together in a sense...I think 
now-a-days it's just everybody. It's not a Cuban thing anymore. It's just everybody." "111 For Emilia, the importance of the national origin for most people seems to have faded away to the panethnic Latin category.

The opinions of Roberto, a 69 year-old Cuban-born resident of Little Havana for over 20 years, reinforce the dynamics of difference between national origin and panethnic identification. Though he believes that neighbors from different countries have things in common, he points out certain 'cultural' differences. "They don't greet each other like we Cubans do, because they have their system (way of doing things), and they don't adapt to ours. They are sloppy, I mean, if they have an empty soda can they just throw it on the ground. They're not respectful like Cubans are. It's not that we want to think we're better than anybody, but we know how to behave and be respectful." Despite these comments, Roberto claims not to be prejudiced against anyone, from any country. "What I do acknowledge, and it must be acknowledged, is that they are not the same as us [Cubans]. They have their way of being, and they don't have any proper upbringing (cultura $)^{112}$."

In sum, the collective panethnic 'Latino' identification is seen to be complex, fraught with tensions perceived by members of both members of the Cuban dominant group as well as the members of the other national origin groups. The fragmentation is often rooted in feelings of difference of cultura or educación, and in other cases envidia (envy); these difference parallel differences of country of origin. Nevertheless, the data

\footnotetext{
${ }^{111}$ English in the original.

${ }^{112}$ Cultura and educación are tricky words to translate from Spanish into English. Cultura can express the sentiment as culture does in English; likewise educación can be translated as education in the sense of schooling. These terms also can be used to mean upbringing or refinement, as they have been translated above. These words often have race and class undertones when used in the later sense.
} 
above suggest that identities based on country of origin and panethnic labels can and do exist simultaneously. In fact, the vast majority of Little Havana residents negotiate between multiple identifications. They maneuver between one label or another due to do the place-specific aspects of ethnicity and race, as well as scale. Within Little Havana and surrounded by other Latin American immigrants, residents choose to employ certain labels which change as they move throughout the city, county, state, or country.

\section{Panethnic Solidarity}

Little Havana residents were asked if they feel solidarity with other Latinos in the United States. This question probes the extent to which panethnic identifiers reflect and/or act to create a sense of commonality and collective identity; this can also be seen as group consciousness, and has been considered a building block for civic and political action (Barreto et al., 2009; Hooker, 2009; Cheong et al., 2007; Junn, 2006; Sanchez, 2006; McBride, 2005; Stokes, 2003; Segura et al., 2001; for counter argument, see Uslaner and Conley, 2003). The overwhelming majority of respondents (87.6\%) do indeed attest to feeling solidarity with other Latinos (see Table 4.9 below). ${ }^{113}$

Table 4.9: Percentages Solidarity Do you feel solidarity with other Latinos in the US? (Q\# 8-A)

\begin{tabular}{|l|l|}
\hline No & 12.4 \\
\hline Yes & 87.6 \\
\hline
\end{tabular}

The relationship between identification and solidarity mentioned above, however, does not follow a linear path. The propensity not to identify shown by Cubans does not hold true for feelings of solidarity; Cubans actually claim to feeling more solidarity with

\footnotetext{
${ }^{113}$ This percentage consists only of those who answered 'yes' to question \#8. Those who answered 'I'm not sure' to Q\# 8-A were placed in the 'no' category.
} 
Latinos in the United States than members of the minority group, despite the fact that members of the former identify less with the panethnic label as seen above (see Table 4.10 below). This inconsistency puts in doubt the presumed relationship between the need to self-identify as part of a panethnic group in order to feel a sense of commonality and collectivity represented through the feeling of solidarity.

Table 4.10: Percentages Solidarity

Do you feel soldarity with other Latinos in the US? (Q\# 8-A) Cuban vs. Other Latino

\begin{tabular}{|l|c|c|}
\hline & \% Cuban & \% Other Latino \\
\hline No & 7.4 & 16.7 \\
\hline Yes & 92.6 & 83.3 \\
\hline \multicolumn{2}{|c|}{ Statistically significant at $.009^{* *}$} \\
\hline
\end{tabular}

Further comments from Roberto, mentioned above, help to elucidate how solidarity based on panethnicity might work. According to Roberto, despite the diversity based on national origin and cultura between neighbors, he would help anyone out, no matter what country they are from. In his own words: "I'll help anyone who needs it. I don't care what country they come from, only that they are someone who needs help." Chapter Five explores aspects of collective identity and solidarity further, specifically in regards to trust and community.

Racial Identifications 
Little Havana residents were also about asked in an open-ended question to identify their race $(\mathrm{Q} \# 9) .{ }^{114}$ The survey answer key to this question was patterned after the $2000 \mathrm{US}$ Census and employed the following categories: White, African-American/Black, American Indian/Alaskan Native, and Asian/Pacific Islander; a fifth option for the surveyor to record responses was 'other.' If a respondent self-identified racially as 'other,' then the surveyor followed up with 'what other race?' If they responded to the question directly with an 'other' race, the surveyor checked the 'other' box and filled in the blank without further follow-up. The responses in their raw form by percentage are found in Table 4.11 below; these responses were then collapsed into 'white' vs. all other racial responses (see Table 4.12 below). ${ }^{115-116}$

\section{$\underline{\text { Table 4.11: Percentages Racial Identification (Q\# 9) }}$}

\begin{tabular}{|l|c|}
\hline White & 50.0 \\
\hline African-American/Black & 2.1 \\
\hline American Indian/Alaskan Native & 1.0 \\
\hline Asian/Pacific Islander & 0.0 \\
\hline Other & 46.6 \\
\hline No response & 0.3 \\
\hline
\end{tabular}

Table 4.12: Percentages Racial Identification (Q\# 9, collapsed-1)

\begin{tabular}{|l|l|}
\hline White & 50.1 \\
\hline Other categories combined & 49.9 \\
\hline
\end{tabular}

\footnotetext{
${ }^{114}$ The English version of this question (Q\# 9) was "What race do you consider yourself to be?" The Spanish version was "De qué raza se considera Ud.?"

115 'No response' $(0.3)$ from the pre-collapsed categories was discounted from the analysis. It was programmed as a missing value.

${ }^{116}$ This collapsing appears not to be very important here, as 'other' constitutes approximately $95 \%$ of the non-white respondents. Its relevance becomes clear below, however, when it is associated with the dominant-subordinate independent variable.
} 
The breakdown of responses shows that the vast majority of Little Havana residents consider themselves to belong to one of two racial categories: white (50.0\%) or other (46.6\%). These findings are not surprising given other similar work on the subject. For example, Campbell and Rogalin (2006) similarly found in their analysis of US Census data that $48 \%$ of the Latino population chose 'white' as their race, $2 \%$ chose a 'black,' and the remaining 50\% chose 'other' (1033).

When we look at the way respondents who did not identify according to a standard pre-established US Census racial category but rather chose 'other,' the fluidity, malleability, and place-specificity of the notions of ethnicity and race come into focus. The universe of responses was both large and varied, containing 29 distinct responses and including answers as diverse as Cuban, Central American, mixed, human, and cobrizo (copper-colored). Three of the responses predominate however: Hispanic (32\%), Latino $(12 \%)$, and mestizo $^{117}(11 \%)$. For analytical purposes, the universe of 'other race' responses were collapsed into 10 categories (see Table 4.13. below). ${ }^{118}$

Table 4.13: Percentages Voluntary 'Other' Responses for Race (Q\# 9, collapsed-1)

\begin{tabular}{|l|c|}
\hline Color & 6.9 \\
\hline Country specific - US & 0.6 \\
\hline Country specific - non US & 6.3 \\
\hline None (I have no race) & 5.1 \\
\hline I don't know/I'm not sure & 2.9 \\
\hline Mixed & 17.1 \\
\hline Native and/or Indigenous & 5.1 \\
\hline Other & 4.6 \\
\hline Panethnic & 50.3 \\
\hline World region & 1.1 \\
\hline
\end{tabular}

\footnotetext{
${ }^{117}$ This word in Spanish refers to the mixing of European, most often Spanish, and indigenous blood.

${ }^{118}$ Those who choose not to answer an 'other' race (no response) have been excluded from this analysis.
} 
The various 'other' race responses were then collapsed again into more parsimonious categories (see Table 4.14 below). Data show that $25 \%$ of Little Havana residents sampled consider themselves to be of the Latino/Hispanic race. As discussed in Chapter Three and hinted at above, considering the complexities around Latino ethnicity and panethnicity in the US is incomplete without considering the dynamics of 'Latino' as a racialized ethnicity and the analytical distinction between the two. Aggregate data show that panethnic labels are salient not only as ethnic identifiers for the vast majority of Little Havana residents (in some cases even as their primary identification), but that they are also actively employed for racial identification as well. The finding that almost half of Little Havana residents chose not to identify as one of the established US Census racial categories, but rather to fill in their own, parallels the findings of and claims by other scholars that Latino/Hispanic have already begun to emerge as a race (Campbell and Rogalin, 2006; Committee on Transforming our Common Destiny, 2006; Amaro and Zambrana, 2000). There is also talk by some scholars (Dávila, 2003; De Genova and Ramos-Zaya, 2003; Haney Lopez, 2000) of how Hispanic/Latino should be analytically treated as a race. The slippery line of distinction between ethnicity and race thus comes into relief, especially with respect to how it is defined, interpreted, and expressed by immigrants to the United States (see, for example, Lancaster, 2003; Gualtieri, 2001). In sum, Little Havana survey data can be used to answer the question posed by Campbell and Rogalin (2006) - "For these groups, does the choice of a Latino label and a racial label have meaning?" (1033) - with a resounding yes.

$\underline{\text { Table 4.14: Percentages Voluntary 'Other' Responses for Race }}$ 
$\underline{(Q \# \text { 9, collapsed-2) }})^{119}$

\begin{tabular}{|l|c|}
\hline Color & 6.9 \\
\hline Place of Origin & 8.0 \\
\hline Mixed & 17.1 \\
\hline Panethnic & 50.3 \\
\hline Other & 17.7 \\
\hline
\end{tabular}

As with the data on primary identification, panethnic identification, and solidarity discussed above, the ways that Cubans self-identify racially prove to be significantly different than the ways other Latin American immigrants and American Latinos express their racial identity (see Table 4.15 below). Cubans identify their race statistically significantly more as 'white' (69.5\%), while an almost identical percentage of non-Cuban Little Havana residents (68.4\%) identify as some race other than 'white.' This finding mirrors that of the Committee on Transformation our Common Destiny (2006) in their analysis of the 2000 US Census data where Cuban-ancestry individuals were three times as likely to claim 'White alone' as their race than other Latin American-ancestry individuals. One explanation of these data is that Cubans are choosing to identify racially with the Anglo-Protestant, English-speaking majority group in the United States and not with the Latin American individuals and groups. A second explanation is the racialized way that the Cuban diaspora's geography plays out, while still another is the fact that Afro-descent Cubans form a significant percentage of the Cuban population, unlike many other Latin American countries. None of these explanations is mutually exclusive, but

\footnotetext{
119 'Color' contains all the answers that were color-oriented. 'Place of Origin' contains country specific-US and Country specific-non-US and World Region. 'Mixed' includes answers such as mestizo, criollo, and mixed that refer to combinations. 'Other' contains all miscellaneous responses. This analysis does not include those who responded with any of the specific Census category races or those who did not respond ('no response').
} 
rather allow for a fuller understanding of the nuances to the dynamics of race between various Latino national groups.

Table 4.15: Percentages Racial Identification (Q\# 9, collapsed-2) Cuban vs. Other Latino

\begin{tabular}{|l|c|c|}
\hline & \% Cuban & \% Other Latino \\
\hline White & 69.5 & 30.5 \\
\hline All Other Responses Combined & 31.6 & 68.4 \\
\hline
\end{tabular}

Statistically significant at $.000^{* * * *}$

When the other' racial responses are analyzed using the dominant-subordinate variable, more nuanced differences between the groups become clear (see Table 4.16 below). Cubans who racially identify as 'other' and then filled in the blank chose a mixed (e.g., mulatto) racial category statistically significantly more than other Latinos; they also identify their race using a panethnic identifier significantly less. Cubans, then, identify both ethnically and racially as panethnic significantly less than other Latinos in Little Havana.

Table 4.16: Percentages Voluntary 'Other' Responses for Race (Q\# 9, collapsed-2) Cuban vs. Other Latino

\begin{tabular}{|l|c|c|}
\hline & \% Cuban & \% Other Latino \\
\hline Color & 6.3 & 7.1 \\
\hline Place of Origin & 12.5 & 6.3 \\
\hline Mixed & 29.2 & 12.6 \\
\hline Panethnic & 35.4 & 55.9 \\
\hline Other & 16.7 & 18.1 \\
\hline \multicolumn{2}{|r|}{ Statistically significant at $.037^{* 120}$}
\end{tabular}

The results of these questions reveal interesting aspects of the racial perceptions and expressions of Little Havana residents as a whole and when broken down into dominant-subordinate groups. Race, as discussed in Chapter Three, is now generally

\footnotetext{
${ }^{120}$ The answers are non-ordinal, i.e., categorical, and therefore a non-parametric test cannot be done on them. Note that 2 cells $(20.0 \%)$ have expected count less than 5 , where the minimum expected count is 3.29 , in the cross tabulation. The norm for taking this coefficient as valid is that $20 \%$ or less of the cells are violated and the expected count is greater than 1 (Pallant, 2007: 214).
} 
accepted by social scientists as a social construct; work by geographers has shown that a key factor in understanding the social construction of whiteness by Latinos is place (Price, 2009; Oberle and Arreola, 2008; Winders et al., 2005; Winders, 2005; Arreola, 2004; Radcliffe, 1999). As Price (2009) points out, the case of Cubans in Miami is exemplary to understanding the way race, specifically whiteness, is constructed and defined. "Because of their demographic presence and socio-economic power - in other words, their occupation of space - Cubans in Miami have great power to define locally what constitutes 'white', and who will be included and excluded from membership" (18). To what extent scale plays here, i.e., race in the neighborhood, cannot be easily teased out using the quantitative above.

Qualitative data from the interviews, however, reveal some facets of how race is perceived and expressed by Little Havana residents. As was demonstrated using the quantitative data above, the content of 'race' is often unclear and interpreted in a variety of ways. When asked about race (raza in Spanish), interviewees, especially non-Cubans, referred first to country of origin, delineating national origin group (read: 'people' or pueblo in Spanish) as the stuff of race. When asked what race her neighbors are, Berta, a 60 year-old Honduran-born woman who has lived in Little Havana for a year and a half, responded: "Around me there's a little bit of everything...Nicaraguans, Hondurans... I think that most of us are Honduran."

Notions of race were not just limited to color, as is commonly the case in the United, or country of origin, but also included world region, ethnicity, and panethnicity; this was the case with Cubans and non-Cubans alike. Edgar, a 23 year-old Nicaraguanborn man who has resided in Little Havana since he was 7 years old, says that all of his 
neighbors are of the same race as himself. "We are all Central American and we all belong to the same race, each of us, there's no difference [between us]." These data suggest two things: 1) the content race is indeed fluid and place- and context-dependent, and is interpreted and expressed differently by individuals; and 2) the boundaries between the social formation of ethnicity and race are very blurry, perhaps more so when the ethnic group combines many different cultures and countries of origin as the Latino panethnicity does in the United States.

Overall, however, the most common reaction when asked about race was a liberal, politically-correct discourse of equality. Javier, a 66 year-old Cuban-born man mentioned above, for example, believes “of course we are all children of God, all of us. I don't look at white or black. I wasn't raised that way... What I don't like and what does mortify is bad upbringing (or bad manners; educación in Spanish) and lack of consideration [for others]." At least one interviewee, however, expressed explicitly racist sentiments. This was 67 year-old Cuban-born Alejandra, who has lived in Little Havana for 24 years. Curiously and contradictorily, Alejandra begins her interview by stating, "Race is not important, it's the upbringing (educación) [of a person] that matters [to me]." Minutes later, however, she says:

The Chinese have to stick with the Chinese. The whites have to stick with the whites. The blacks with the blacks. The mulattos with the mulattos. [Racism] is not an American thing or a Cuban thing... Now I personally would not like for a black or a mulatto person to move here [into my neighborhood]. [It should be] someone the same as you, right? [It goes] the same for a black 
neighborhood. I'm not gong to live in a black neighborhood. Of course not...Americans want to be with Americans. It's logical. I'm Cuban, I want to live with Cubans; they are not inferior to me, right? It goes the same with South Americans...I'm not going to look for a South American [person or neighborhood].

The direct and vitriolic ethnocentrism and racism expressed by Alejandra in the quote above shines light on the tension that exists within the neighborhood. It also highlights again how common the blurring boundaries between race, ethnicity, panethnicity, and national origin group can be. It further sheds doubt on the validity and sincerity of the liberal, politically-correct discourse expressed by many Little Havana residents vis-à-vis intergroup relations. Is Alejandra an exception to the 'we are all equal' rule? Is she the lone bigot in a neighborhood of an otherwise open-minded and accepting people? Or might others who also initially claim to believe 'all races are equal' or that all people belong to the same race, be thinking similar sentiments but hiding them?

One resident who believes that skepticism based on race has a negative effect on neighborhood relations is Rodrigo, a 24 year-old American Latino who has lived in Little Havana for 16 years. He lives on a street with a few other Cuban American families, but for the most part his neighbors are quite diverse - Nicaraguans, Hondurans, Mormons, Haitians - but according to Rodrigo, no one talks to anyone. He attributes the lack of social interaction to differences in race. "They're from Nicaragua and these [other neighbors] are Haitians. They [my family and friends on the block] feel like just because they can't, you know, because they're black, 'oh, they're bad.' They're not bad 
people...[I]t's the skin color thing. They're not bad, they're very nice people. Or at least these [who live in the house across the street].

Yolanda, a 35 year-old woman who has lived in neighborhood for one year, is from Mexico and has felt the prejudice and attests to having suffered discrimination from Cubans based on her nationality. "I get along with, I try to get along [with Cubans], but I know they are a little racist...not a little, very racist...against everyone, especially Central Americans." According to Yolanda, she was not able to enroll her daughter into daycare because it was run by Cubans, and they gave preference to other Cubans; hence her nationality worked to her disadvantage. She confirmed this discrimination because her husband, who is Cuban, returned on a separate occasion to enroll their daughter and indeed, the little girl was granted admission. In general, however, Yolanda stands up for herself and members of other, non-Cuban nationalities when she is confronted with insulting or derogatory comments by Cubans. She says:

I don't stay quiet...If they start speaking badly about people [of other nationalities], I tell them, 'Give thanks that the [American] government is there [to help you]. That is why you are [in such a good position]. If [the government] gave a work permit to the other people, the Mexicans, Hondurans, or Central Americans, if it gave them that opportunity, they wouldn't be [in such a bad position].

In conclusion, the data discussed above reveal interesting aspects of the ways that Little Havana residents perceive and express ethnicity and race. Latin American immigrants and American Latinos are in some cases adopting North American forms of ethnic and racial identification and in other ways challenges these concepts and the 
boundaries denoted and connoted by them. The panethnic labels Latino and Hispanic are overall popular, accepted, and salient ways to identify. As far as race is concerned, on the other hand, about half of Little Havana residents chose not to identify as one of the established US racial categories, but rather to define their own race. This finding supports work by other researchers that Latino/Hispanic is emerging as a race, bolstering the insistence by many scholars that Latino is a racialized ethnicity. When put into the agentstructure framework, these findings suggest that while Latin American immigrants are in the process of accommodating to the structure of ethnic and racial identification in the US, they are also challenging it and contributing to its modification.

The accompanying qualitative data show that respondents often express the sense of common cultural elements - e.g., language, culture, food - as sources of mutual cultural bonding and the potential basis for feelings and practices of collective identity. At the same time, many Little Havana residents draw boundaries around themselves using country of origin, color, cultura or educación. and race. These findings demonstrate that identification with both country of origin and with a Latino panethnicity are possible. In the section that follows, the complexities of ethnic and racial identity are revealed through an analysis of frictions and tensions.

\section{Discussion}

Though the panethnic identifiers of Latino/Hispanic are both popularly and widely employed, these labels cover up cleavages that exist between those who use them. In other words, panethnic labels must continue to be problematized for what this category hides, despite its salience among Latin American immigrants and American Latino in the 
US. Interview data reveal that intra-Latino relations are actually fraught with tension. At the beginning of the interview, most respondents expressed an agreeable attitude and generic sense of unity, as expressed in the phrase 'we are all equal' (todos somos iguales). However, upon further questioning and discussion, many respondents revealed that they did, in fact, feel very different from other Latinos, and in some cases even discriminate against them. There were, for example, country-specific discriminatory comments made, e.g., from various Cuban Little Havana residents about Mexicans. The basis of division or distaste for others include region of origin, e.g., against Central Americans; differences in economic and political power; time of arrival (e.g., recently arrived immigrants versus more established ones); and cultura and educación.

The anomalous finding over the discrepancy between the self-identification of Little Havana residents as Latino/Hispanic and the identification of respondents as Latino/Hispanic by researchers discussed above suggests that further work on the optional and situational aspect to ethnic identities and identifications must be done. Under what circumstances is the Latino/Hispanic identifier used? Why? Theorizing about optional and situational ethnicities has been carried out with Black immigrants and their second-generation offspring. Might there be similar differences between Latinos and other groups? If so, upon what are they based? Generally speaking, Latinos differ from black Caribbeans in that the former span the gamut of phenotypical characteristics where as the latter do not. Might this make a difference?

The above finding also points to methodological and meta-theoretical weaknesses that permeate the study of ethnic and racial groups in the US: the problem of the positionality of the researcher to his 'interest' in the topic matter. The comparison made 
above pre-supposes the validity of the percentage of Latino respondents as identified by the surveyors, i.e., "I identify you as..." The classification of respondents by researchers is supposedly not subjective, but rather based on a set of objective characteristics (including place of birth and language). As such, the classification seems to relegate the self-identification of the subject to a different (read: inferior) category or 'kind' of data. Although anthropologists in the US have dealt with knowledge creation and cultural interpretation vis-à-vis the study of 'tribes' in other countries, there has not been enough methodological or meta-theoretical discussion as to the study of ethnic groups, specifically Latinos, within the national context. Future work on Latino/Hispanic race/ethnicity/panethnicity should address the subject-object divide because studies such as this one are the basis upon which knowledge is created.

Furthermore, the findings on the primary identification of respondents discussed above pose problems to the theoretical position that identities are fluid, situational, and dependent. If identities do indeed pause and flow, shifting according to circumstances, then does a primary identification really matter at all? If so, the nuances of why one label or another sticks as primary seems to be much more valuable than which one it is. Henry Hale's (2004) notion of ethnic identity firmly places ethnic identity into the framework of a constellation of shifting thick and thin identities that manifest through myriad identifications. This formulation offers more potential for a meaningful analysis than classifying identities and identifications hierarchically.

The limitation of Hale's (and most others') notion of ethnicity is how, when, and why Latino identities and identifications translate from sentiment to action. Extensive work has been done on ties that bind ethnic groups along lines of national origin in the 
US (e.g., Cuban Miami as an ethnic enclave). However, as panethnic labels stick and Latin American immigrants and native-born Latino incorporate (though they act to change it as well) into civic life in the US, there is not enough theoretical work as to how ‘becoming Latino, becoming American’ occurs.

\section{Conclusion}

Latin American immigrants and American Latinos are maneuvering the structure of ethnic, racial, and panethnic identifications and categories in ways that show both adaptation (accepting the given ethnic/racial categories) and creative struggle (Latino as race - 'other') to describe and express themselves in a culturally-relevant way. The empirical evidence discussed above reflects these processes and supports the theoretical and conceptual arguments in the social science that ethnicity and race are social constructions, fluid, and mutable. It also points to the shift of Latino/Hispanic from solely ethnic/panethnic label in the United States toward a race. Such a change is the result of a dialectical relationship between the governmental and social structures in the United States and the agency of those who choose to identify themselves as Latino/Hispanic. Whether used as a ethnic or racial identification, Latino/Hispanic indicates a level of Americanization as well as a foundation upon which the 'in' group can base feelings of solidarity. Such an infrastructure of sentiment can serve as the basis for collective action.

Discussions such as these are important for many reasons. Prejudice and violence based on racial and ethnic difference stain the history of the United States, as in many other countries around the world. Though laws and norms have changed dramatically over the past 100 years to protect minority populations from discrimination, injustice 
continues in present social relations. The backlash to diversity in and from some segments of the population is clear, as are the attempts to fortify borders and refine boundaries. Miami is one place where such tensions are high and violence has erupted between ethnic and racial groups. Understanding the complexities and nuances that are part and parcel to the construction of boundaries between groups could help to prevent similar outbreaks of racial and ethnic clashes in the future.

The above analysis leads to five conclusions about Latino ethnicity and race in Little Havana. First, when talking about ethnicity and race, it is useful to draw a theoretical distinction between identity and identification. As discussed in Chapter Three, if identity is the complete set of personal reference points that a person uses as social radar, than identifications are the individual points. Ethnicity is a dimension of identity that can encapsulate many ethnic identifications simultaneously. Discussions of ethnicity and race should be framed in terms of identification, rather than identity, in order to acknowledge that change in any one of those points can and does happen, and that the shifting of identifications can take place without destabilizing a person's 'complete' sense of self or identity.

Second, a taken-for-granted Latino panethnic identity is more complex and nuanced than often thought or admitted. Cultural differences based on country of origin sometimes result in cleavages or prejudices. The plurality of answers for various ethnic and racial identifications that Little Havana residents feel and employ is evidence of cultural diversity. In fact, there are significant tensions expressed by residents, usually falling along the lines of country of origin. Third, these tensions can be interpreted as discriminations, often cloaked in terms of group or national culture as well as upbringing 
or refinement, expressed in Spanish as cultura and educación. The leap between ethnic and panethnic identifications, therefore, is problematic.

Fourth, despite existing tensions (read: discrimination) between groups, Latino/Hispanic is a salient race in the eyes of many (roughly 25\%) Little Havana residents. This finding supports arguments already made by scholars in the social sciences that Latino has already, and should, emerged as a race. Interestingly, however, Latino as a racial categorization in Little Havana appears to be based on real or imagined linguistic, cultural, and geographic similarities, and not necessarily on the basis of color. Finally, place matters. Foner and Frederickson (2004) point out "the need to explore the differences among local communities, cities, and regions - specifically, to assess how the construction of race, ethnicity, and intergroup relations has been shaped over time by the unique characteristics of particular places and their distinctive immigration flows" (17; see also Price, 2009; Kasinitz et al., 2008; 2004; 2002; Arreola, 2004; King, 2000). Little Havana residents engage in close interaction and shared residential space inside the neighborhood with other residents from a variety of cities, regions, states, and countries. Such an environment could contribute to both the sense of panethnic collective identity as evidenced by the data presented in this chapter, as well as the differences and discriminations mentioned above. The overwhelmingly high concentration of Latin American immigrants and American Latinos who share aspects of a common colonial cultural and linguistic heritage could be an important factor in the production of their racial, ethnic, and panethnic identifications and identities. 


\section{Placing Trust and Forging Community in Little Havana}

Sometimes I feel like I don't belong, and I'll tell you why. I wasn't born here, but I wasn't raised where I was born, so, you know...I always have to be explaining [my situation] to people. Sometimes I wish I could say 'I was born in Miami, I'm American.' In that sense sometimes I feel in the larger sense sometimes I feel excluded by the overpowering sense of community of the Cuban community, and I feel that most groups are left out... ${ }^{121}$

- Mercedes, 23 year-old Nicaraguan-born resident of Little Havana for 22 years

I've seen it [solidarity among the Latino residents in her neighborhood] ... if you look at when there are hurricanes and all that. As they say, 'when bad things happen to you, look to your good neighbors.'

- Consuelo, 50 year-old Guatemalan-born resident of Little Havana for 6 years

No way [is there solidarity between Latinos]. There is a lot of egotism, the worse defect in people. Some, at least the Argentineans, think that they are better than everyone. Hondurans, Nicaraguans, and Guatemalans are pretty humble, but not everyone. There are those [Central Americans] that you ask, 'hey, are you Nicaraguan?' and they tell you 'no!' and they try to speak like a Colombian or a Venezuelan, or like someone from any other country besides Nicaragua or whatever country they're from. I met this one

\footnotetext{
${ }^{121}$ English in the original.
} 
Nicaraguan girl and I asked her, 'you're Nicaraguan, no?' 'No," she told me, 'I'm from Colombia.' But from the way she pronounced a few words, I knew she was Nicaraguan.

- Rodolfo, 26 year-old Nicaraguan-born resident of Little Havana for 1 month 


\section{Introduction}

As demonstrated in the previous chapter, Latin American immigrant and American-born Latino residents of Little Havana are actively participating in the employment of a panethnic collective identity. In this respect, they are moving toward the adoption of Americanized or assimilated forms of identification. Though nuanced, this trend suggests that residents of Little Havana are on their way to 'becoming American.'

Shared identification is an important part of collective consciousness. Collective consciousness has been found to be one of the foremost and important building blocks of trust, the second aspect of assimilation considered in this dissertation. This chapter uses quantitative and qualitative data to examine trust in Little Havana and relate it to community, an important concept in the study of immigrant incorporation as seen in Chapters Two and Three. Together, trust and community have been understood to be key aspects of incorporation. Trust has been viewed as a cornerstone in the foundation upon which successful democratic practices are built. Immigrants have been found to group with others like them (usually co-nationals) in various ways, including geographically in ethnic neighborhoods, sentimentally through identification and trust, economically in enclaves, and politically in ethnic politics. Bonds of trust based on ethnicity have been implicitly understood as 'natural' or primordial, springing forth more or less organically, aided in part by the contact facilitated by co-residence in ethnic neighborhoods. Thus trust has an explicitly geographic dimension. Trust among coethnics and the feeling and exercise of community that result have allowed many, though not all, immigrant and ethnic groups to find a place in the social, political, and economic panorama of the larger 
society in the US. Trust and community, then, are considered hallmarks of the process of 'becoming American.'

But what does establishing trust and creating community mean for a population that comprises many nationalities, diverse peoples, and a wide range of races, ethnicities, cultural particularities, national origins, and socioeconomic profiles, under the banner of a panethnicity? Do Latinos, as members of a panethnic group, trust each other? Is there a general sense of community? Are they becoming Americans in this way? These are the questions that will be addressed in Chapter Five.

Various aspects of sociability, trust, and community in Little Havana are explored below. In addition to basic description, the quantitative analysis looks for the relationship between the independent variables (IVs) presented and discussed in Chapter Two and sociability and two series of dependent variables (DVs) of trust. Quantitative data are considered first for Latino respondents as a whole, and then are broken down by the dominant-subordinate group variable presented and used in Chapter Four. Qualitative data are employed to offer depth to the way that trust and community work in Little Havana.

Chapter Five is organized in the following way. First, sociability is explored as a possible source and way of understanding trust and community. Then the dependent variables used to measure trust in the quantitative analysis are explained. Findings on the first group of variables - neighborhood trust - are discussed, followed by a discussion of the second group of quantitative variables - ethnic trust. These are complemented by an exploration of qualitative data. The chapter concludes with a discussion of what sociability, trust, and community mean for becoming American in Little Havana. 


\section{Sociability}

As discussed in Chapter Three, contact and sociability have shown to serve as foundations for trust, which might then lead to a sense of community. One quantitative indicator of sociability is the number of times that a resident converses with his or her neighbors (Q\# 17; see Table 5.1 below). Many Little Havana residents converse with their neighbors frequently: 4 out of 10 residents attest to conversing more than 5 times per week; another $15 \%$ converse about every other day with their neighbors.

Table 5.1: Percentages Sociability

In an average week, how many times do you converse with your neighbors? $\underline{(\mathrm{Q} \# 17)}$

\begin{tabular}{|c|c|}
\hline \# of times & \% \\
\hline 0 & 20.3 \\
\hline $1-2$ & 24.0 \\
\hline $3-5$ & 15.1 \\
\hline$>5$ & 40.6 \\
\hline
\end{tabular}

A similar question asked by the Saguaro Seminar $(2006 ; 2000)$ can be used as a close benchmark (see Table 5.2 below). If the above category ' $<5$ ' is equated to Saguaro's 'just about every day,' the differences between the two studies are quite remarkable and suggest that residents of Little Havana are quite conversant and sociable with their neighbors. Residents of Little Havana surpass all comparison populations overall, white, and Latino - by at least 17 percentage points. This seemingly extremely sociable portion of Little Havana's population contrasts with its rather large percentage (20.3\%) that never converses with neighbors. That one fifth of neighborhood residents never interact at all with their neighbors seems fairly bleak, especially when compared to results from the Saguaro Seminar in which only $9 \%$ of the overall population and $6 \%$ of the white population never converses with their neighbors. When compared to the Latino 
respondents in the Saguaro Seminar study that never interact (26\%), however, Little Havana residents' $20 \%$ does not seem so bleak.

Table 5.2: Social Capital Community Benchmark Survey Sociability Benchmark

\begin{tabular}{|l|c|c|c|c|}
\hline $\begin{array}{l}\text { How often do you talk with or } \\
\text { visit your immediate neighbors? }\end{array}$ & \multicolumn{3}{|c|}{2000} & 2006 \\
\hline & \% Overall & \% White & \% Latino & \% Overall \\
\hline Never & 9 & 6 & 26 & 9 \\
\hline Once a year & 4 & 3 & 4 & 5 \\
\hline Several times a year & 5 & 5 & 6 & 6 \\
\hline Once a month & 9 & 9 & 12 & 11 \\
\hline Several times a month & 19 & 20 & 14 & 21 \\
\hline Several times a week & 31 & 34 & 23 & 30 \\
\hline Just about everyday & 22 & 23 & 15 & 18 \\
\hline
\end{tabular}

Source: Saguaro Seminar, 2006; 2000

Analysis of the relationship between the sociability indicator above and independent variables thought to relate to it reveals no statistically significant relationship for gender, home ownership, nativity, language ability, or education (see Table 5.3 below). Citizenship, domestic partnership status, the presence of children in the household, income, age, years lived in Little Havana, and years lived in the US, on the other hand, all show statistically significant association. Those residents who are citizens have statistically significant higher levels of sociability than non-citizens, as do those who are not partnered as opposed to those who are partnered; those who do not have children in the household socialize significantly more than those who do. These findings are in keeping with previous knowledge on sociability. Findings about sociability's relationship to education, on the other hand, are surprising: residents belonging to the lower two income categories $(<\$ 10,000$ and $\$ 10,000-\$ 24,999)$ converse more than the higher two categories $(\$ 25,000-\$ 49,999$ and $\$ 50,000)$. Age also has a positive effect on sociability: the three oldest age groups $(46-55,56-65$, and $66+)$ have much higher levels 
of sociability than the youngest three, with the oldest age group conversing the most. For years spent living in Little Havana and years in the US, sociability also trends up as time increases, with particularly high percentages of conversation frequency for the $20+$ years category.

Table 5.3: Summary of Significance Independent Variables on Sociability (O\# 17)

\begin{tabular}{|l|c|}
\hline & Coefficient $^{\mathbf{1 2 2}}$ \\
\hline Citizenship & $.006^{* *}$ \\
\hline Gender & .214 \\
\hline Rent/Own & .078 \\
\hline Domestic partnership status & $.028^{*}$ \\
\hline Nativity & .698 \\
\hline Children in house & $.002^{* *}$ \\
\hline Language ability & .298 \\
\hline Education & .767 \\
\hline Income & $.004^{* *}$ \\
\hline Age & $.000^{* * *}$ \\
\hline Years in Little Havana & $.004^{* *}$ \\
\hline Years in US & $.000^{* * *}$ \\
\hline
\end{tabular}

The qualitative data complement nicely the quantitative discussion above and reveal many aspects and nuances of sociability in Little Havana. The extent to which many Little Havana residents claim to interact is limited in many cases to what in Spanish known as el saludo, or greeting; this simple and passing exchange consists usually of a 'buenos días' (good morning) or 'buenas tardes' (good afternoon). These hello- and good-bye-style interactions are not necessarily grounded in any interpersonal rapport and certainly not a sense of trust; they do not translate into conversation or dialoge. In most cases, they are exchanged due to custom and common courtesy. Various

\footnotetext{
${ }^{122}$ Mann-Whitney reported for all binary IVs, Kruskal-Wallis reported for all others.
} 
interviewees said they have one or two neighbors with whom they interact, maybe even trust, but again, in most cases, neighbors were almost strangers.

Yolanda, a 35 year-old Mexican-born immigrant who has lived in Little Havana for one year, for example, knows and trusts the apartment building property manager, who lives in the same building. He even has a key to her apartment, though this is due to the fact that he is the property manager. In any case, Yolanda believes that he is trustworthy; she has even asked him to enter her apartment in her absence to do some maintenance activities. Although Yolanda knows some of her other neighbors, she does not feel a sense of community with them or trust them. Like Yolanda, Maite, a 52 yearold Honduran-born immigrant who has lived in Little Havana for 15 years, only says 'hello' to her neighbors, except for one older Cuban lady who is basically home-bound and with whom she interacts and helps out on a regular basis.

Yolanda and Maite, like many Little Havana residents, live in very close proximity to their neighbors, in small apartment buildings with adjacent front doors and common walkways and staircases. This proximity, however, does not seem to contribute favorably to sociability in the form of conversation, though perhaps el saludo is more common for residents of such apartment buildings (Laurier et al., 2002). As far as Monserrat, a 43 year-old Nicaraguan-born immigrant who has lived in Little Havana for 10 years, is concerned, the design of the apartment building has nothing to do with sociability; rather, it is the personality and idiosyncrasy of the residents. She and her daughter in fact have lived in other apartment buildings with a similar design in the past where they knew many of their neighbors, conversed with them regularly, and had good relations with them. She says: 
I don't think that [the design of the building] has anything to do with [neighbor relations] because in some other places we used to live in a building, let's say, I live [on] the third floor or something and people from the first floor were, you know, our friends. So it doesn't have to do with the [way the apartment building is]...it's just [that] they're [the neighbors] are just like that, you know. You cannot change [them] if people [are] like that [anti-social]. ${ }^{123}$

Another theme that arose with respect to sociability is the lack of time and energy available to people because of their taxing work schedules. These circumstances were understood by many residents of Little Havana as 'the way things are in the US,' an 'all work, no play' lifestyle. The heavy demands on time and energy placed on individuals by their work, necessary to survive and pay the bills, do not permit for socializing. Maite (mentioned above) says that she would love to have a closer rapport with her neighbors, but people do not seem to have time. As she does not know them very well, she does not count on them for anything or in any deep way. Maite's feeling of social distance and disconnection is curiously contradictory to the American ideal of community, or the fostering of social ties through either informal or formal means. As such, such a perception inhibits the process of becoming American.

Perhaps as a result of work-related time constraints or for other reasons, there is a common perception that people, at least in Little Havana, are very independent, autonomous, and individualistic, acting as if getting to know neighbors and building community is not important. Justo, a 69 year-old Cuban-born immigrant who has lived in

\footnotetext{
${ }^{123}$ English in the original.
} 
Little Havana for 17 years, says: "Everyone lives very independently, you know? This is a country where you work a lot to survive, and then there is no time to interact with others very much." Edgar, a 23 year-old Nicaraguan-born man who has resided in Little Havana for 16 years, expresses the same sentiment as Justo: "I think that everyone here [in the US] is very independent." He is also rather pessimistic; for Edgar, being an immigrant means being making it on his own. In his case, Edgar has to work hard to make a living and survive; he is busy and therefore does not have a lot of time for socializing.

Monserrat, mentioned above, says that her neighbors, many of whom are from Central American countries like herself, are just not sociable people; most of them are in fact rude and seem not to care about each other at all. For Monserrat, it is hard to meet and inter-relate with neighbors, and cultural affinities based on country of origin are not enough to overcome these barriers. She says:

I don't know these people here. It's strange because, you know, you try, you even try to talk to them [and] they try to stay away from you. I just see them and I know they are my neighbors...But they almost never stay there [at home] because they work almost all the time, so it's hard to see them. And when they [are] here, I am not here because I work. It is mostly [that] we don't see each other. And I don't know why [it is], what was the difference because I'm from Central America and these people [are too]. ${ }^{124}$

\footnotetext{
${ }^{124}$ English in the original.
} 
For many residents who are immigrants from Latin America, the neighborhood culture found in Little Havana is very different from the neighborhood culture they knew, and liked, in their countries of origin. Isabel, a 37 year-old Nicaraguan-born immigrant woman who has resided in Little Havana for 4 years, compares life in Little Havana and life in the neighborhood where she lived in her native city of Managua. She feels like one has nothing to do with the other. She says that where she comes from, everyone knew each other, and could count on each other; there was a sense of trust and community. Isabel felt comfortable letting her children play outside because everyone knew the children and watched out for them. She gives the example of letting her children play outside. In Little Havana, on the other hand, "the most one can do is get to know the neighbor that lives right next door to you or across the hall."

Another factor that inhibits sociability, neighborhood relations, and trust is residential turnover. As seen through the quantitative data, the longer one lives in the neighborhood, the more frequently he or she converses with his or her neighbors. This is not always the case, however. The case of Octavio, a 75 year-old Cuban-born resident of Little Havana where he has lived in the same apartment for 22 years, provides a useful illustration of this point. Octavio has seen most of his very long-term neighbors move away, although he says that currently most of the people that live around him have been there for about 10 years. Nevertheless, he just greets them, and shares no feeling of friendship or trust with them. In his words: "We all get along and everything, but we do not share (compartir) in the sense of visiting each other at home; each one lives and stays in his or her own place." Octavio does have an extensive friend network that consists of co-nationals (Cubans) that meet daily at Domino Park, a neighborhood place on Calle 
Ocho where older gentlemen get together and play domino. These friends, in contrast to his neighbors, are like family to him. As will be seen later in the chapter, one of the saving graces of community is shared ethnicity, at least in the case of Little Havana's Cuban residents.

Overall the data discussed above clearly suggest that personal relations with neighbors that exist (or in this case, tend not to exist) influence a feeling of reliance, trust, and community with neighbors. The lack of extensive and broad networks of sociability and interaction in Little Havana results in a lack of trust and a weak sense of community.

\section{Trust Variables}

The dependent variables used to measure trust are separated into two groups because they measure different attitudes. The first set of trust indicators - referred to here as neighborhood trust - measures trust and perceptions of the trustworthiness of neighbors and is made up of three statements with which residents of Little Havana were asked to agree, disagree, or express no opinion (see Appendix A \&B: Q\# 20-A, 20-B, and 20-C). The statements are: 1) Most people in this neighborhood can be trusted; 2) Most people in this neighborhood will take advantage of you if you let them; and 3) Most people in this neighborhood do not trust each other.

These three questions are grouped together for three reasons. First, the questions are similar, though not identical, to questions asked in other studies on trust. Second, these questions are of a similar order; they fit together neatly conceptually. Third, all three of these questions inquire about trust on the same scale, i.e., in the neighborhood and about neighbors. Because of the scalar specificity of these questions, they contrast 
with the usually scale-less questions asked by other researchers. It is thus difficult to benchmark them with exactitude. Where possible, however, comparison is made between study data and other relevant sources. The scalar aspect to the neighborhood trust questions also makes it difficult to place them neatly into one or another of the two dominant trust categories (personalized and generalized) discussed in Chapter Three. In effect, these questions combine aspects of both kinds of trust: residents of Little Havana were asked about their neighbors' trustworthiness, some of whom they know personally and some of whom they have never met.

The second series of trust questions, on the other hand, is well placed in the generalized trust category. These questions ask about trust in members of certain ethnic, racial, and national groups; here they are referred to generally as ethnic trust (see Appendix A \& B: Q\# 21-A through 21-G). These questions are non-scalar, and as such do not combine the two types of trust in the way that the questions on neighborhood trust do.

\section{Neighborhood Trust}

The descriptive statistics for neighborhood trust indicators are found below (see Table 5.4). Overall, there is no majority opinion on trust for any of the three neighborhood trust questions. For Q\# 20-A, "Most people in this neighborhood can be trusted," the largest percentage of respondents agreed, though not a statistical majority (48.2\%), followed by those who disagreed (41.1\%). For Q\# 20-B, an almost identical percentage of residents believe that "most people in this neighborhood will take advantage of you if you let them" as those who do not (39.1\% and 39.8\%, respectively). The results from both 
Q\# 20-A and Q\# 20-B suggest that residents are just slightly more trusting than not. However, the percentage of respondents that agreed with Q\# 20-C, "most people in this neighborhood don't trust each other" was almost twenty points higher those who disagree (47.4\% and $28.6 \%$ respectively), suggesting a distrustful and pessimistic view of their neighbors.

Table 5.4: Percentages Neighborhood Trust (Q\# 20-A, 20-B, 20-C)

\begin{tabular}{|l|c|c|c|}
\hline & Agree & Disagree & No opinion \\
\hline 20-A: Most people in this NH can be trusted. & 48.2 & 41.1 & 10.7 \\
\hline $\begin{array}{l}\text { 20-B: Most people in this NH will take } \\
\text { advantage of you if you let them. }\end{array}$ & 39.1 & 39.8 & 21.1 \\
\hline $\begin{array}{l}\text { 20-C: Most people in this NH don't trust each } \\
\text { other. }\end{array}$ & 47.4 & 28.6 & 24.0 \\
\hline
\end{tabular}

When Q\# 20-A, 20-B, and 20-C are considered together, residents of Little Havana appear to be a somewhat skeptical lot. The notable percentage of residents for each question that had no opinion on the subject matter suggests, furthermore, an indifference toward or ignorance of their neighbors. ${ }^{125}$ These seemingly pessimistic findings can be put in perspective by comparing them, to the extent possible - to other sources of trust data: the Saguaro Seminar's Social Capital Community Benchmark Survey (SCCBS, 2006; 2000) ${ }^{126}$ and the Pew Research Center's Social Trends Report on Americans and Social Trust (Taylor et al., 2007). Data from these sources appear in Tables 5.5 and 5.6 below.

\footnotetext{
${ }^{125}$ The extent that skepticism or lack of trust in the researcher was felt by Little Havana residents is unknown. The author has wondered if it might have resulted in the high number of 'no opinion' responses.

${ }^{126}$ In the Saguaro Seminar $(2006 ; 2000)$ questions were asked about trust between official Census racial and ethnic groups, but not between various Latin American ancestry groups.
} 
Table 5.5: Social Capital Community Benchmark Survey Trust Benchmark

\begin{tabular}{|c|c|c|c|c|}
\hline \multirow{2}{*}{$\begin{array}{l}\text { Generally speaking, would you say } \\
\text { that most people can be trusted or } \\
\text { that you can't be too careful in } \\
\text { dealing with people? }\end{array}$} & \multicolumn{3}{|c|}{2000} & \multirow{2}{*}{\begin{tabular}{|c|}
2006 \\
$\%$ Overall
\end{tabular}} \\
\hline & $\%$ Overall & \% White & \% Latino & \\
\hline People can be trusted. & 47 & 54 & 23 & 44 \\
\hline $\begin{array}{l}\text { You can't be too careful in dealing } \\
\text { with people. }\end{array}$ & 46 & 40 & 68 & 52 \\
\hline It depends. (Volunteered response) & 7 & 6 & 9 & 4 \\
\hline \multicolumn{5}{|l|}{$\begin{array}{l}\text { How much can you trust people in } \\
\text { your neighborhood? }\end{array}$} \\
\hline & $\%$ Overall & $\%$ White & \% Latino & \% Overall \\
\hline Trust them a lot & 49 & 57 & 20 & 46 \\
\hline Trust them some & 34 & 32 & 38 & 35 \\
\hline Trust them only a little & 11 & 7 & 26 & 14 \\
\hline Trust them not at all & 6 & 4 & 13 & 6 \\
\hline
\end{tabular}

Source: Saguaro Seminar, 2000 and 2006

Table 5.6: Pew Research Center Trust Benchmark

\begin{tabular}{|l|c|c|c|}
\hline & $\begin{array}{l}\text { \% Most are } \\
\text { trustworthy }\end{array}$ & $\begin{array}{c}\text { \% You can't } \\
\text { be too careful }\end{array}$ & $\begin{array}{l}\text { \% Other/ } \\
\text { Depends/ } \\
\text { Don't know }\end{array}$ \\
\hline $\begin{array}{l}\text { Generally speaking, would you } \\
\text { say that most people can be } \\
\text { trusted or that you can't be too } \\
\text { careful in dealing with people? }\end{array}$ & 45 & 50 & 5 \\
\hline
\end{tabular}

Source: Taylor et al., 2007

Results from the question, "Generally speaking, would you say that most people can be trusted or that you can't be too careful in dealing with people?" from the Saguaro Seminar $(2006 ; 2000)$ give three measures: for the overall population, for white Americans, and for Latinos. When compared to these percentages, residents of Little Havana appear to be as trusting as the American population as a whole, somewhat less trusting than white Americans, and notably more trusting than the general Latino population. The SCCBS percentage for the overall population and the findings from the Pew Research Center similarly suggest that the majority of Americans are neither trusting 
nor do they believe their neighbors to be trustworthy. When using this question from the two complementary surveys as a point of comparison, residents of Little Havana do not fare too badly.

Comparisons with findings from the question "how much can you trust people in your neighborhood?" 127 (Saguaro Seminar, 2006; 2000), however, present a contradictory picture. In the Saguaro Seminar study, surveyees show much higher levels of trust in neighbors when compared to generalized trust. They also show much higher levels of trust in their neighbors than do residents of Little Havana. In short, the vast majority of people are more trusting than not. Similar to the trend above, white nonLatino Americans are more trusting than the general population, and the general population is more trusting than Latinos.

The three neighborhood trust indicators discussed above were analyzed statistically as dependent variables with the independent variables discussed in Chapter Two and above. Table 5.7 below shows the coefficients and statistical significance of the relationships. A number of findings are immediately apparent. Of the seven dichotomous variables, four - gender, domestic partnership status, nativity, and language ability - have no statistically significant relationship at all with the various forms of neighborhood trust. On the other hand, the remaining dichotomous variables - citizenship, home ownership, and children in the household - show a consistent statistically significant, often highly significant, association with neighborhood trust indicators. In general and according to the literature on trust, the expectation is that being a citizen, owning a home, and the

\footnotetext{
${ }^{127}$ This question was measured using a four-point scale: a lot, some, a little, none. Here, 'a lot' and 'some' where added together and reflect a trusting attitude. 'A little' and 'not at all' were added together and reflect a mistrusting attitude.
} 
presence of children in the household, should lead to higher levels of trust. These factors relate (not shown in table), for the most part, in the expected way in Little Havana.

Citizens are statistically significantly more trusting than non-citizens for all three of the trust questions; conversely, non-citizens are less trusting. Similarly, homeowners are significantly more trusting across the three indicators. In contrast with the previous two independent variables, the presence of children in the household has an inconsistent association with trust. Having children in Little Havana has a negative relationship with trust across the three indicators: parents, in other words, do not appear to be the most trusting. Residents who do not have children living in their households, on the other hand, appear to be trusting for Q\# 20-A and Q\# 20-B, but show less trust in Q\# 20-C.

Table 5.7: Summary of Significance

\section{Dichotomous Independent Variables on Neighborhood Trust} (Q\# 20-A, 20-B, 20-C)

\begin{tabular}{|l|c|c|c|c|c|c|c|}
\hline & Citizenship & Gender & Rent/Own & $\begin{array}{c}\text { DP } \\
\text { Status }\end{array}$ & Nativity & $\begin{array}{c}\text { Children in } \\
\text { Household }\end{array}$ & $\begin{array}{c}\text { Language } \\
\text { Ability }\end{array}$ \\
\hline 20-A & $.000^{* * *}$ & .186 & $.000^{* * *}$ & .660 & .151 & $.005^{* *}$ & .721 \\
\hline 20-B & $.000^{* * *}$ & .282 & $.000^{* * *}$ & .661 & .197 & $.002^{* *}$ & .952 \\
\hline 20-C & $.000^{* * *}$ & .120 & $.000^{* * *}$ & .823 & .058 & $.000^{* * *}$ & .112 \\
\hline
\end{tabular}

Results of statistical analysis on the set of continuous independent variables are rather surprising (see Table 5.8 below). Similarly to the dichotomous variables discussed above, some of the continuous independent variables have no effect on neighborhood trust (education and income) while others (age, years lived in Little Havana, and years lived in the US) are consistently statistically significant, and highly so. The most surprising finding is that education and income show no statistical significance for any of the neighborhood trust indicators considered here. This is contrary to the expected

\footnotetext{
${ }^{128}$ Abbreviation for domestic partnership.
} 
relationship, whereby socioeconomic status (SES) - usually a composite of education, income, and occupation - has been shown to have a statistically significant and positive correlation with trust; i.e., the higher the SES, the more trusting a respondent is. For residents of Little Havana, however, SES does not show any statistical significance whatsoever.

Table 5.8: Summary of Significance Continuous Independent Variables on Neighborhood Trust (Q\# 20-A, 20-B, 20-C)

\begin{tabular}{|l|c|c|c|c|c|}
\hline & Education & Income & Age & $\begin{array}{c}\text { Years in } \\
\text { LH }\end{array}$ & $\begin{array}{c}\text { Years in } \\
\text { US }\end{array}$ \\
\hline 20-A & .990 & .178 & $.000^{* * *}$ & $.001^{* * *}$ & $.000^{* * *}$ \\
\hline 20-B & .967 & .443 & $.000^{* * *}$ & $.002^{* *}$ & $.003 * *$ \\
\hline 20-C & .643 & .098 & $.000^{* * *}$ & $.001 * *$ & $.000^{* * *}$ \\
\hline
\end{tabular}

Findings for age, years lived in Little Havana, and years lived in the US are consistent and positive. As age increases, so do levels of trust. Similarly, as the years spent living in the neighborhood and living in the US increase, so too do levels of trust, though the percentage is somewhat smaller than that found for age. For years lived in the neighborhood, the greatest increase is seen for the group that has lived from 11-20 years and then again in $20+$ years. Residents who have lived in Little Havana for 20+ years are the most trusting. These data suggest that the longer an immigrant lives in his or her neighborhood, the more trusting he or she is. If being trusting means becoming American, then residents of Little Havana become better Americans as they spend more years in their neighborhood and in the country.

Similar to analysis performed in Chapter Four with regard to racial and ethnic identification, statistical analysis was done using a dominant (Cubans) and subordinate (non-Cuban Latinos) group variable on neighborhood trust (see Table 5.9 below). For all 
neighborhood trust indicators, the dominant-subordinate variable shows a highly statistically significant and consistent relationship: Cubans are more trusting than nonCuban Latinos. For Q\# 20-A and Q\# 20-B, the majority of the dominant Cuban group (65.2\% and 52.4\%, respectively) trust, while the percentage of Cubans in agreement with Q\# 20-C was notably less (41.2\%). Nevertheless, Cuban respondents expressed statistically significant higher levels of trust than members of the subordinate other Latino group for each of the three questions $(42.6 \%, 46.2 \%$, and $35.5 \%$ respectively).

\section{Table 5.9: Summary of Significance}

Dominant-Subordinate Independent Variable on Neighborhood Trust (Q\# 20-A, 20-B, 20-C)

\begin{tabular}{|l|c|}
\hline & Coefficient \\
\hline 20-A & $.000 * * *$ \\
\hline 20-B & $.000 * * *$ \\
\hline 20-C & $.000 * * *$ \\
\hline
\end{tabular}

Belonging to the dominant or subordinate group in the neighborhood, then, appears to have an important relationship to trust. Residents who belong to the dominant Cuban group are more trusting. One way to explain this difference is by considering the neighborhood dynamics discussed in Chapter Two. The role that the place-specific dominance of Cubans has played in Little Havana, their continued predominance as far as national group demographics, and the continued symbolic of Little Havana for Cubans might give them an increased sense of power and security, which serve as a platform to trust. If this is, in fact, true, then these findings may shed light on intra-enclave dynamics in other ethnic neighborhoods as well. 


\section{Ethnic Trust}

What is termed here ethnic trust is considered a form of generalized trust; it probes the extent to which Little Havana residents trust in groups of people beyond their personal acquaintance and to which they do not belong (Marschall and Stolle, 2004; Uslaner and Conley, 2003; Uslaner, 2000; Fukuyama, 1995; Yamagishi and Yamagishi, 1994). Residents of Little Havana were asked on a Likert scale from 1 (lowest) to 5 (highest) how much they trust in nine different ethnic, racial, and national groups most common in Little Havana. ${ }^{129}$ These groups were: Puerto Ricans, Cubans, Nicaraguans, Dominicans, Colombian, Mexicans, Americans (Americanos, or white non-Latinos), AfricanAmericans, and Hondurans. They were chosen because of their important presence in South Florida, in particular in Miami-Dade County, and because of their presence in the Little Havana. Generalized ethnic trust, however, is a rather understudied area, so the framework employed to understand neighborhood trust above is also used here for ethnic trust. The same relationships between neighborhood trust and the independent variables are assumed to exist for ethnic trust and the independent variables. Some scholarship, however, has pointed to factors that are not included in the generalized trust framework that effect the ways members of immigrant populations trust each other internally (e.g., the role of stigmatization among Colombian immigrants, see Guarnizo et al., 1999; the role of wave of immigration, race, and class among Cuban immigrants, see Alberts 2005; 2003; vis-à-vis social capital, see Stepick et al., 2009). More work needs to be done to

\footnotetext{
${ }^{129}$ Trusting was determined by summing the percentages from the categories of 'mostly' or 'completely' ( 4 and 5 on the 5 -point Likert scale); non-trusting was determined by summing percentages of 'not at all' and 'a little' ( 1 and 2 from the same Likert scale).
} 
better explain the nuances to the ways that generalized trust among intra- and inter-ethnic groups is explained.

In Little Havana, ethnic trust levels range from $24 \%$ at their lowest (of African Americans) to $45.6 \%$ at their highest (of white non-Latino Americans), followed closely by Cubans at $44.2 \%$ (see Table 5.10 below). Overall, then, less than half of Little Havana residents express generalized trust in any ethnic group. The majority of residents are either untrusting or indifferent of different ethnic groups. Nevertheless, relatively high levels of trust exist for both white non-Latino Americans and for Cubans, the only groups for which percentages surpassed $40 \%$.

Table 5.10: Percentages Ethnic Trust How much do you trust the following groups?

(Q\# 21-A through 21-G)

\begin{tabular}{|l|c|c|c|c|c|c|c|c|c|}
\hline & $\begin{array}{c}\text { Puerto } \\
\text { Rico }\end{array}$ & Cuba & Nica & $\begin{array}{c}\text { Dom } \\
\text { Rep }\end{array}$ & Col & Mex & $\begin{array}{c}\text { US } \\
\text { (Anglo) }\end{array}$ & $\begin{array}{c}\text { African } \\
\text { Amer }\end{array}$ & Hond \\
\hline Not at all & 8.9 & 7.6 & 9.1 & 7.8 & 8.6 & 13.3 & 5.7 & 15.9 & 8.3 \\
\hline A little & 3.4 & 4.9 & 9.9 & 6.0 & 4.2 & 6.5 & 4.2 & 9.1 & 10.7 \\
\hline Neutral & 53.6 & 43.0 & 44.9 & 55.7 & 54.2 & 52.9 & 44.3 & 49.7 & 49.5 \\
\hline Mostly & 13.5 & 15.6 & 14.6 & 13.3 & 13.8 & 11.7 & 19.3 & 11.2 & 12.5 \\
\hline Complete & 20.3 & 28.6 & 21.4 & 16.9 & 19.0 & 15.4 & 26.3 & 13.8 & 18.8 \\
\hline $\begin{array}{l}\text { No } \\
\text { response }\end{array}$ & 0.3 & 0.3 & -- & 0.3 & 0.3 & 0.3 & 0.3 & 0.3 & 0.3 \\
\hline
\end{tabular}

When analysis of the ethnic trust indicators and dichotomous independent variables is performed, various important points become clear. In contrast to results of the neighborhood trust analysis, few statistically significant relationships are found between ethnic trust and the independent variables; furthermore, those that are found are for the most part not consistent across the various ethnic groups (see Table 5.11 below). Nativity is not statistically significant for any group, gender and domestic partnership status are statistically significant for only one group, and home ownership for two groups. The absence of a clear pattern suggests that for ethnic trust in Little Havana, gender, home 
ownership, domestic partnership status, and nativity are not good predictors of ethnic trust. With the exception of home ownership, this finding parallels that of the neighborhood trust series.

The only two independent variables that prove somewhat consistently statistically significant are US citizenship (for three ethnic groups) and the presence of children in the household (for five groups). For all three of the ethnic groups with which US citizenship shows a statistically significant association with trust, citizens are, as expected, more trusting than non-citizens. Citizens, in general, are seen as being more settled and in a more secure position than non-citizens; a favorable and stable legal status provides residents a platform to trust. Non-citizens, on the other hand, are considered to be in a more precarious position, creating a more cautious and in some instances skeptical attitude toward others. The presence of children in the household - a circumstance that reflects a sense of security and settlement that allows for generalized trust - works contrary to what is expected. That is, in all five cases where the presence of children in the household shows a statistically significant relationship with trust in ethnic groups, neighborhood residents who do not have children in the household are more trusting than those who do. 
Table 5.11: Summary of Significance

Dichotomous Independent Variables on Ethnic Trust

(Q\# 21-A through 21-G)

\begin{tabular}{|l|c|c|c|c|c|c|c|}
\hline & Citizen & Gender & Rent/Own & $\begin{array}{c}\text { DP } \\
\text { Status }\end{array}$ & Nativity & $\begin{array}{c}\text { Children in } \\
\text { Household }\end{array}$ & $\begin{array}{c}\text { Language } \\
\text { Ability }\end{array}$ \\
\hline $\begin{array}{l}\text { 21-A } \\
\text { Puerto } \\
\text { Ricans }\end{array}$ & .062 & .837 & $.046^{*}$ & $.029^{*}$ & .145 & $.006^{* *}$ & .320 \\
\hline $\begin{array}{l}\text { 21-B } \\
\text { Cubans }\end{array}$ & $.006^{* *}$ & .074 & $.022^{*}$ & .165 & .495 & $.034^{*}$ & .826 \\
\hline $\begin{array}{l}\text { 21-C } \\
\text { Nicaraguans }\end{array}$ & $.019^{*}$ & .204 & .317 & .954 & .374 & $.003^{* *}$ & .668 \\
\hline $\begin{array}{l}\text { 21-D } \\
\text { Dominicans }\end{array}$ & .085 & .149 & .179 & .633 & .129 & $.002^{* *}$ & .208 \\
\hline $\begin{array}{l}\text { 21-E } \\
\text { Colombians }\end{array}$ & $.008^{* *}$ & .416 & .323 & .949 & .953 & .080 & .444 \\
\hline $\begin{array}{l}\text { 21-F } \\
\text { Mexicans }\end{array}$ & .271 & $.034^{*}$ & .773 & .606 & .160 & .263 & .155 \\
\hline $\begin{array}{l}\text { 21-G } \\
\text { Americans }\end{array}$ & .902 & .742 & .930 & .288 & .886 & .352 & $.029^{*}$ \\
\hline $\begin{array}{l}\text { 21-H } \\
\text { African } \\
\text { Americans }\end{array}$ & .091 & .064 & .415 & .398 & .895 & .622 & .344 \\
\hline $\begin{array}{l}\text { 21-G } \\
\text { Hondurans }\end{array}$ & .688 & .474 & .727 & .634 & .052 & $.047^{*}$ & $.019^{*}$ \\
\hline
\end{tabular}

The relationship between ethnic trust indicators and the continuous independent

variables present some surprising findings as well (see Table 5.12 below). One

independent variable, education, is unexpectedly not statistically significant for any of the groups. Education, as a measure of SES, is supposed to have a fortifying effect on trust, such that higher levels of education lead to higher levels of trust. In Little Havana, however, this relationship does not hold true. Language ability and years lived in Little Havana are statistically significant for only two groups each (non-Latino white Americans and Hondurans, and Puerto Ricans and Cubans, respectively). 
Figure 5.12: Summary of Significance

Continuous Independent Variables on Ethnic Trust

(Q\# 21-A through 21-G)

\begin{tabular}{|l|c|c|c|c|c|}
\hline & Education & Income & Age & $\begin{array}{c}\text { Years in } \\
\text { LH }\end{array}$ & $\begin{array}{c}\text { Years in } \\
\text { US }\end{array}$ \\
\hline 21-A Puerto Ricans & .608 & .289 & $.038^{*}$ & $.042^{*}$ & $.013^{*}$ \\
\hline 21-B Cubans & .891 & $.029^{*}$ & $.000^{* * *}$ & $.010^{*}$ & $.000^{* * *}$ \\
\hline 21-C Nicaraguans & .858 & .114 & $.009^{* *}$ & .062 & .184 \\
\hline 21-D Dominicans & .094 & $.037^{*}$ & $.005^{* *}$ & .084 & $.020^{*}$ \\
\hline 21-E Colombians & .622 & .135 & $.034^{*}$ & .164 & $.022^{*}$ \\
\hline 21-F Mexicans & .163 & .064 & .445 & .783 & .550 \\
\hline 21-G Americans & .284 & .993 & .743 & .681 & .826 \\
\hline 21-H African Americans & .849 & $.017^{*}$ & .504 & .137 & .092 \\
\hline 21-G Hondurans & .059 & $.012^{*}$ & .482 & .992 & .150 \\
\hline
\end{tabular}

Income, age, and years lived in the US, on the other hand, have a significant statistical association with more ethnic groups (4, 5, and 4 respectively); the statistical cross-tabulations (not shown here) show surprising findings. In general, higher income is expected to be associated with higher levels of trust. Income proves statistically significant vis-à-vis four ethnic groups (Cubans, Dominicans, African Americans, and Hondurans) but the relationship between income and trust is inconsistent, i.e., no clear pattern emerges. The only commonality is that levels of trust in for all categories within each group are under 50\%; the percentage of trust for all categories is highest in Cubans (between $37.7 \%$ and $49.5 \%$ ). Thus, it cannot be concluded, as would be expected, that higher income leads to greater ethnic trust. Instead, those who are expected to trust the most because of higher incomes in fact demonstrate the most distrusting attitudes.

The second continuous independent variable that showed consistent statistical significance - age - works somewhat differently for each of the five groups for which there is a statistically significant relationship (Puerto Ricans, Cubans, Nicaraguans, Dominicans, and Colombians), although a general pattern can be deciphered. The most 
apparent trend is that the oldest age group $(66+)$ is, in all cases, both the most trusting within each group and the least mistrusting. As far as levels of mistrust are concerned, however, there is a consistent decrease in levels of mistrust as age increases for four of the five ethnic groups (Puerto Ricans, Cubans, Nicaraguans and Dominicans); for Colombians, the levels of mistrust, in a similar fashion for trust in this group, vary unpredictably.

The association between ethnic trust and both years lived in Little Havana and years in the US is generally inconsistent. Residents who have lived less than one year in the US (very recently arrived and numerically very small) seem in general to be a rather trusting group, with a minimum of $42.9 \%$ for the statistically significant groups (Puerto Ricans, Cubans, Dominicans, and Colombians). Residents who have lived 20+ years in Little Havana also prove to be the most trusting in all ethnic groups, except in the case of trust in Cubans, in which the most recently arrived group of Cubans trust in their compatriots even more than long-term residents higher $(71.5 \%$ versus $56.0 \%$, respectively). Curiously, years lived in Little Havana and years in the US are each statistically significant only for trust in two of the same groups (Puerto Ricans and Cubans). Nevertheless, when considering trust in all the ethnic groups, there is an apparent trend that suggests that the more time an immigrant lives in the US, the more he or she trusts.

Finally, to consider the independent dominant-subordinate variable, the difference between Cuban-born residents of Little Havana and other Latinos is statistically significant for seven of the nine ethnic groups discussed (see Table 5.13 below). Statistical significance was not found for trust in Mexicans and white non-Latino 
Americans. In all cases where statistical significance between the dominant and subordinate group was found, Cubans were always more trusting, while members of the subordinate group were less trusting (see Table 5.14 below). Percentages for the three ethnic groups in which Cubans trust most all surpassed $40 \%$, and are in the following descending order: Cuba (57.2\%), Nicaraguans (42.3\%), and Puerto Ricans (40.6\%). These findings suggest that the dominant group trusts in its own group the most, and that contact with other groups in the neighborhood (as is the case of Nicaraguans) and at the larger scale of the city (as with Puerto Ricans, the second largest 'country of origin' group in the City of Miami), reinforce trust through exposure and contact.

Table 5.13: Summary of Significance Dominant-Subordinate Independent Variable on Ethnic Trust (Q\# 21-A through 21-G)

\begin{tabular}{|l|c|}
\hline & Coefficient \\
\hline 21-A Puerto Ricans & $.000^{* * *}$ \\
\hline 21-B Cubans & $.000^{* *}$ \\
\hline 21-C Nicaraguans & $.011^{*}$ \\
\hline 21-D Dominicans & $.001^{* *}$ \\
\hline 21-E Colombians & $.019^{*}$ \\
\hline 21-F Mexicans & .109 \\
\hline 21-G Americans & .997 \\
\hline $\begin{array}{l}\text { 21-H African } \\
\text { Americans }\end{array}$ & $.011^{*}$ \\
\hline 21-G Hondurans & $.049^{*}$ \\
\hline
\end{tabular}

Table 5.14: Percentages Ethnic Trust Dominant-Subordinate Independent Variable on Ethnic Trust in Cubans $\underline{(\mathrm{Q} \# \text { 21-B) }}$

\begin{tabular}{|l|c|c|}
\hline & \% Cuban & \% Other Latino \\
\hline Not at all & 3.2 & 11.7 \\
\hline A little & 3.2 & 6.6 \\
\hline Neutral & 36.4 & 49.5 \\
\hline Mostly & 18.2 & 13.3 \\
\hline Completely & 39.0 & 18.9 \\
\hline \multicolumn{2}{|c|}{ Significance: Mann-Whitney U: .000, *** } \\
\hline
\end{tabular}


These data suggest that the place-specific history and dynamics of Little Havana as a Cuban ethnic neighborhood influence the way groups overcome differences, at least in terms of ethnic trust. Little Havana, a historically Cuban neighborhood, facilitates members of the dominant group to trust members of their ethnic in-group, as well as members of out-groups, more. This also points to the strength of the symbolic influence of localized neighborhood culture, e.g., in the form of monuments, landscape, and civic action, to reinforce and cohere identity, trust, and community among and by Cubans, despite changing demographics.

These findings also point to ethnicity as a good predictor of levels of generalized trust in both in-groups and out-groups. Findings on ethnic trust parallel those on neighborhood trust and suggest that for many people, the neighborhood is a good place to build generalized trust. Residents who have frequent direct contact and interaction with their neighbors are having the kind of localized experience of personalized trust that can foster more generalized trust (Glanville and Paxton, 2007). At the same time, the rather large (one fifth) of Little Havana residents who never speak with their neighbors lack the same foundation for building trust.

The understanding that localized experiences of trust contribute to a greater sense of generalized trust is also one possible explanation for the generally low levels of trust in the Mexican national group. Mexicans are a comparatively small ethnic group in South Florida, although there is at least one concentration in and around Homestead in south Miami-Dade County, where a sizeable population is dedicated to the agricultural sector found there. Besides this concentration, there are very few Mexicans in Miami-Dade County, and even fewer in Little Havana (1.6\% of survey sample). Levels of trust in this 
group (27.1\%) are the second lowest of any group; furthermore, there is only one independent variable - gender - that shows a statistically significant association with trust in the Mexican group. Following the intergroup contact theory discussed in Chapter Three, the limited amount of exposure of Little Havana residents to Mexicans may shape their distrusting opinion of the group. In effect, the absence of Mexicans in the neighborhood (and at larger scales) inhibits the kind of personalized and localized experiences that contribute to a sense of generalized trust. Below qualitative data are discussed to elucidate further the nuances between neighborhood and ethnic trust and community.

\section{Neighborhood Trust and Community}

Interviews completed with neighborhood residents revealed interesting findings regarding trust and community in Little Havana. The caveat placed on conflating neighborhood and community in Chapter Two comes into sharp relief when the qualitative data is taken into account, exemplified by the general lack of feeling of belonging to an over-arching, Little Havana neighborhood. For decades, propinquity has been used to delineate, either rightly or wrongly, both neighborhood and community under the assumption that the kind of social relations and ties that constitute community 'naturally' exist among people who live close to each other. There is little evidence that a generalized sense of neighborhood community exists in the boundaries of Little Havana used in this study or among the majority of Latino neighborhood residents. Instead, the Little Havana community as a coherent, unified socio-spatial entity is more of an idea than a reality. In practice Little Havana is an internally fragmented neighborhood, fracturing along the same lines as 
those discussed in Chapter Four: national origin, cultural difference, and the often-related concepts of cultura and educación. The unity and cleavages that are based on ethnicity are explored in greater detail below. Nevertheless, the few respondents who affirm the existence of an overarching community in Little Havana are discussed in turn.

After living in Little Havana for only one month, Rodolfo, a 26 year-old Nicaraguan-born immigrant, is convinced that there is a very clear and defined sense of community in Little Havana, but it is one to which he does not belong. This is because community in Little Havana revolves around ethnicity, specifically being Cuban. The cultural dominance of Cubans in Little Havana prevents Rodolfo from feeling a part of a neighborhood community because he is not Cuban. He says instead that he feels more connection with the city of Miami than the neighborhood: "It would have to be Miami [that I identify with more], because with Little Havana, I just don't really [identify]. It's not that I don't like Cuban people, but I don't feel a part of the Cuban community...” When asked if Little Havana has a connection with the Cuban community, Rodolfo emphatically responded "Everything!"130

For another resident, community does exist, but not on the scale of the neighborhood; rather it is found on the sub-neighborhood scale of the block. Virginia, a 46-year old, US-born resident of Little Havana for the past 22 years, for example, does not feel any connection to Little Havana, though she does share some sense of community, "on the block, not past that, I don't think." ${ }^{131}$ She indicates that this is due to the fact that she knows personally and interacts regularly with the people in her

\footnotetext{
${ }^{130}$ The author has taken some poetical license in this translation, from the Spanish, ¡Demasiado!

${ }^{131}$ English in the original.
} 
immediate (block) vicinity, but not beyond. As discussed above, Virginia's comments underscore the importance of contact and sociability for trust building and community creation.

At least two Cuban residents of Little Havana emphatically affirm the existence of community in the neighborhood. Gonzalo, a 42 year-old man who moved to Little Havana directly from Cuba when he was 16 years old, says: "I feel like I belong to the [Little Havana] community; and I feel the community belongs to me." ${ }^{132}$ His conviction and sense of belonging run deep. Carla, on the other hand, is a 42 year-old immigrant from Nicaragua who has lived in the neighborhood for the past five years. She, like Gonzalo, attests to feeling a sense of community and solidarity in Little Havana. "There is a strong sense of union [in Little Havana], more so when there are hurricanes." For Carla, the unity she mentioned has even resulted, on occasion, in concrete benefits; her neighbors have helped her after the damaging effects of more than one hurricane. Benefits such as this one appear to be a positive manifestation of a sense of community, but they are mentioned by only a few interviewees, and therefore cannot be assumed to exist systematically throughout the neighborhood.

Emilia, now 26 years old, was born in Miami and has lived in the same house all her life. Her story offers more evidence of the importance of personal contact and sociability for fostering a feeling of community. Emilia attests to feeling very much a part of the community that is circumscribed by the informal boundaries of the Little Havana neighborhood. Her history is there, and that gives Little Havana a special meaning for her. The personal social connections that she and her family have established there have

\footnotetext{
${ }^{132}$ English in the original.
} 
resulted in a feeling of community. Emilia's father has owned a local barbershop for decades; he and his family members, including Emilia, know many of the father's clients. She says: "For sure, I'm part of this community when it comes to like, you know, growing up here... I'm telling you, my dad, like, I'll walk down the street and it's like 'That's so and so's daughter'..."133

The conviction felt and expressed by those few residents who feel and participate in community in Little Havana contrasts sharply with the sense of anti-community expressed by most residents, including Jaime, a 78 year-old Cuban-born immigrant and long-term resident of Little Havana for thirty years. Jaime emphasizes passionately that he does not belong to any community, either neighborhood- or ethnicity-based. He says: No, no, no, no, no, no, no! I don't belong to any community. It makes the same difference to me if I live here or in Hialeah, wherever I can fit, wherever I can live...If I were forced to live in a black neighborhood, as long as I could survive there, I wouldn't have any problem with it...I don't have any community, but I do seek out my nationality because I speak Spanish, with whichever nationality it is, Nicaraguan, Ecuadorian or whoever...I don't [feel a part of] Little Havana at all.

This Little Havana resident's complete rejection of community, no matter what the base, is rather perplexing and bitter. Jaime does mention, however, the importance of language, in his case Spanish, for getting along in his daily routine, a distinct benefit of living in a Cuban or Latino ethnic neighborhood. Nevertheless, Jaime's attitude reflects the

\footnotetext{
${ }^{133}$ English in the original.
} 
spectrum of 'pro' and 'con' sentiments that exist vis-à-vis community in Little Havana and the various ways that immigrants feel a sense of belonging or not.

Jaime's utter rejection of community was not the only seemingly negative attitude vis-à-vis community heard throughout the interview process. Various residents expressed a resistance or reluctance to admit to feeling or belonging to a specific community (e.g., national group) expressed by other Little Havana residents. The reluctance appears to be rooted in a perception that belonging is a bad or incorrect thing to do. Or perhaps it is akin to the concern underscored in Chapter Four that interviewees answered in certain ways because they want to give 'right answer' or be politically correct. Consuelo, a 50 year-old Guatemalan-born immigrant who has resided in Little Havana for 6 years, seemed confused and flip-flopped a number of times when asked if she belongs to a community. First she said she did not belong to any community, then she changed her mind and said that she felt a part of "the community here... of here, part of where I live; I feel like a part of here [her neighborhood]." There was a tone of uncertainty in her voice. When asked if she belonged to any ethnic or national (e.g., Latino, Latinos of Miami, Guatemalan, South Florida), she said, "no, no, I feel good, I feel good with all [the different] nationalities."

A trend that became evident when analyzing the qualitative data on community was the lack of comprehension by interviewees when asked about 'community' (comunidad, in Spanish). In designing the interview instrument, there was an implicit assumption that community would be an unproblematic word and concept, i.e., it would be easily understood by residents of Little Havana. Furthermore, the cultural relevance of the term and concept were not brought into question. Data suggest quite the opposite 
however. When asked about community, a number of interviewees simply drew a blank at first, i.e., had no idea what the term meant or how to respond to the question. In a number of cases, interviewees answered the question by interpreting community in their own ways, which were very different than the ways that researchers expected. This might have to do with the very understanding of the term, community, which might well help to explain some residents' ambivalence about belonging to a 'Little Havana community. ${ }^{، 134}$

The extent to which comunidad seemed to fall on deaf ears can be seen in the following interview with Berta, a 60 year-old Honduran-born immigrant who has lived in Little Havana for a year and a half:

Interviewer: Do you belong to a community?

Berta: $\quad$ Ummm...no.

Interviewer: Any kind of community.

Berta: What? What? Like what?

Interviewer: A community, say like the Honduran community of Miami...

Berta: Well, we...we...I'm going to explain it to you like this. We immigrants have something called TPS [temporary protected status]...But that is for [our legal] documents. I'm registered there. I'm registered.

\footnotetext{
${ }^{134}$ The author acknowledges the possibility of nuanced differences between the English word 'community' and the Spanish word 'comunidad.' The interview instrument, however, was designed by bilingual and bicultural members of the research team, and was then translated and back translated by out-sources. Any confusion over the denotation or connotation over community/comunidad was unanticipated.
} 
Interviewer: Do you feel any connection with other immigrants?

Berta: What?

Interviewer: Do you feel like part of the immigrant community?

Berta: $\quad$ The TPS organization...That's what I'm a part of...I belong to that [organization] because that's how I get my TPS and papers: work permit, social [security number], and everything.

In Berta's case, she appears to have no immediate comprehension of the word and concept community. She struggles to understand, and then does her best to give it a meaning on the spot. She related community to her temporary protected status (TPS), granted to her by the US government immigration services because of special economic, political, and social circumstances in her country of origin.

Another resident, Julia, a 57 year-old Cuban-born immigrant and long-time resident of Little Havana for 26 years, also drew a total blank when asked if she belonged to a community. When the concept was explored further, the most coherent way that Julia was able to give it meaning was by defining it as belonging to an association or club; once she established this meaning of community, she admitted to not belonging to any association. A similar interpretation of community as association or through an institution was offered by Felisa, another Cuban-born woman, 69 years old, who has lived in Little Havana for almost 40 years: "I belong, for example, to the parish of Saints Peter and 
Paul; that's been my parrish since I arrived [from Cuba] because I've always lived here [in this neighborhood]..."

Findings from the qualitative data discussed above serve as a caution to scholars and others who work with populations and on the topic of trust in the process of immigrant incorporation (Iceland, 2009; Fraga and Segura, 2006; Brettell, 2000; Croucher, 1997; Kazal, 1995). Ways that these terms and concepts are understood (or not) and interpreted by people are slippery and inconsistent. Community understood as a group of people who share sentimental and affective ties, feelings of connectedness and belonging to a collective based on certain characteristics cannot be taken for granted. Instead, the above underscores the need to recalibrate expectations; immigrants, and others, might not have any point of refer or resonance with community, at least in the way that it is commonly understood in the US. The various permutations of community (e.g., through a government designation, an association, religious congregation, or club) that arose from interviews allow for new and different explanations of how neighborhood residents form attachments to place and development networks, connections, and a sense of belonging. Likewise, expressions of resistance and reluctance to community, as in the case of Jaime, challenge researchers to explain why and how people choose not to belong and at the same time to temper or remove the normative aspect of belonging.

These findings give reason to proceed with caution as far as the meaning and reality of community in urban settings, in neighborhoods, and in immigrant populations. As Francis Fukuyama (1995) has shown, trust and community mean different things to people in different cultures; the contents and realities of trust and community vary from one culture to another. Understanding and interpreting community is not an automatic or 
natural thing. Instead it is also contingent of cultural, including linguistic, factors. The culturally- and place-dependence of trust and community could be an inhibiting factor in the creation and sedimentation of trust and community in Little Havana and other settings in the US.

\section{Ethnic Trust and Community}

The existence of a Cuban (not pan-Latino) community in Miami was identified by a number of Little Havana residents, both Cuban and non-Cuban alike. Previous work by social scientists has documented Miami's Cuban ethnic enclave, and Little Havana has been considered a hub of the social and economic relations that constitute the Cuban enclave economy (Portes and Shafer, 2006; Portes and Stepick, 1993; Portes, 1987). The strong and functional sentimental ties shown to exist between the early-arrived Cubans exiles were rooted in personal relationships and trust built in the homeland, and in many cases resulted in social, political, and economic success in South Florida. Recent research has pointed out that relations between Cubans in Miami have changed over time, and questions the quality and scope of the affective ties and transactions that were once considered paramount for the ethnic enclave (Alberts, 2005; 2003).

The above data suggest that a foundation of trust exists between Cubans, as well as a tendency for Cubans to be statistically significantly more trusting in other ethnic groups than members of the subordinate population in Little Havana. The existence of community was affirmed by many residents of Little Havana, but this community was not so much a generalized Latino community, but rather a Cuban community. What characterized the community was a perception that Cubans 'help each other out,' one of 
the basic tenets of the ethnic enclave theory. Ethnicity continues to be perceived and to act as social glue, for identity and trust, but also for action.

Monserrat, mentioned above, speaks of Cubans and the community she perceives to exist between them as an example to be followed. For her, they are a model ethnic and immigrant group. Cubans also contrasts starkly with Monserrat's Central American compatriots among whom she says no such unity exists. She admires Cubans because their ethnicity, rooted in their shared national origin, trumps other factors and serves to unite them as a group. Nevertheless, Monserrat sees what might be called ad hoc community materialize in other populations at specific moments; it comes in the form of solidarity and civic engagement when a specific topic or interest of the group is at stake. Monserrat's observations below regarding the issue-focused dimension of panethnic solidarity have been noted in work by other scholars (e.g., Alvarado et al., 2009; Barreto et al., 2009; Mayo, 2000; Diaz, 1996; Rosenstone and Hansen, 1993). She says:

I have seen the Cuban people get very, esos son bien unidos (they are very united), they help each other, and Chinese people, they help each other...but Central Americans, no. I don't know why it is, you know?...Just when they say ' $\mathrm{Oh}$, we have to fight for our green card or our permits to work,' then you see them all...Cubans no matter how bad they are between each other, they help each other...Almost they all help each other; they have a business and 
this and that but Central Americans, I don't know why, Central and South Americans, they're different. ${ }^{135}$

Ernesto, a 26 year-old Honduran-born immigrant who has lived in Little Havana for seven years, echoes Monserrat's belief that community in Little Havana is a rather spotty phenomenon, although he claims to feel a part of it. He participates in it and supports it when there is an activity or event that interests and benefits the group as a whole. Ernesto's comments reveal a rather pragmatic take on community; for him, Honduran ethnic community is utilitarian and event-oriented. Both Monserrat's and Ernesto's comments, however, provide one possible answer to the question posed above regarding the content of community. The existence of affective bonds and ties are one aspect to community; another aspect of community lies in action.

Daniel, a 38 year-old Cuban-born immigrant man who migrated to the US when he was 9 years old, is unwavering in his belief that community exists in Little Havana; like many interviewees, Daniel thinks this community is a Cuban one rather than a panethnic, Latino one. For Daniel, community is the manifestation of sentimental, affective, and emotional ties, but it also has concrete political and economic contours. On the one hand, the Cuban community exists because he feels it around him and feels a part of it. At the same time, the Cuban community gives Daniel a sense of belonging and serves as a source of pride. Community also fulfills another function: protection. It shields those within the boundary from attacks by those outside the boundary, in this case

\footnotetext{
${ }^{135}$ English in the original.
} 
from non-Cubans. "I sound like it's 'us' against the rest of the world...It's not like that. It's kind of, you know, we react to how it is they treat us..."136

Despite the common identification and active employment of panethnic identification by residents of Little Havana and their expressed feelings of solidarity explored in Chapter Four, there is no evidence for the existence of a 'Latino community.' Quite a few residents point to differences between national origin groups as an impediment to establishing and cultivating a more extensive and inclusive pan-Latino community. Residents' understanding of the tendency to separate along national lines, even in the case of Latin American immigrants who share certain cultural and linguistic origins, has a 'natural' undertone, very reminiscent of the work of Chicago School scholars. Daniel, for example, continues:

Yeah, well there's a lot of differences between different Latin communities. Sometimes I can't even understand what they're saying. To be honest with you. I might sound um, I'm not racist at all, but you know like, 'No, porque vos que tetetete (No, because you blah-blah-blah, mimicking an Argentine accent),' 'What, what, what you just, run that by me again?' So, you know, there is separation, and even with, you know...like cultural differences....that separate us...I see it more like every nationality has their own little community. You know, we could all say, 'Oh, we're all Latinos, you know.' Everybody more or less sticks with their own little [group], you have a lot of that here. There's is a lot

\footnotetext{
${ }^{136}$ English in the original.
} 
of separation in these little [national] communities, you know?

That's my opinion. ${ }^{137}$

The same sentiment of a strong bond with members of one's own national group was echoed by Octavio, mentioned above, who says he supports all the various communities, Honduran, Nicaraguan, Colombian, "even the Haitians, that come here in search of a better life. We have to give the Haitians an opportunity." Nevertheless, Octavio feels more a part of the Cuban community than the Latino community, even though he feels part of both, because "[other] Latinos are my neighbors and friends, [but] between Cubans we always share our way of speaking, our way of thinking. If I get invited to a BBQ, I go and I experience all that [common feeling, belonging] with the friends that I have who are also from Cuba."

The same differences mentioned in Chapter Four as the basis for tensions and cleavages between Little Havana residents in terms of identification reappear when discussing trust and community. Trusting across these differences and belonging to more than one community appear possible, as expressed by Octavio above, but for some, national origin trumps all. Javier, a 66 year-old Cuban-born immigrant who has only lived in Little Havana for two months, says: "I always trust in Cubans more than other people...Why? For the simple reason that when you help anyone, there are a lot of people that thank you for it, but there are others that do not..." This rather cryptic answer draws the lines of separation along national origin in a similar fashion to Daniel, above; nevertheless the differences revolve around what is considered upbringing, manners, refinement, or class (cultura and educación), and has undertones of cultural superiority.

\footnotetext{
${ }^{137}$ English in the original.
} 
The impetus for and facilitation of community when a critical mass of coethnics was present in close geographical proximity, e.g., in the neighborhood, was mentioned by one neighborhood resident as an explanation for the lack of a Honduran community. Esperanza, a 58 year-old Honduran-born immigrant who has resided in Little Havana for four years, says:

It appears [that there is Honduran community]...but they are spread out all over the place (regados), so I can't really say. For example, up there by Biscayne there are only Honduran people around...I used to go out on Sundays and meet up with my Honduran friends in a field on $12^{\text {th }}$ Street and $3^{\text {rd }}$ Avenue Northwest, but they got rid of that [space] and built houses there. Now I don't know where there's a field [to meet up in] or anything, so I stay here [at home]. I don't even have any days off.

Esperanza's comments point to the importance of ethnic neighborhoods as a locus for community creation, echoing the approach described and promulgated by the Chicago School scholar at the beginning of the $20^{\text {th }}$ century discussed in Chapter Two. It also emphasizes the importance of public spaces for congregating to facilitate and exercise community. Esperanza felt more connected, more part of a Honduran community, when she met up, congregated, and socialized with other Hondurans on a regular basis. These encounters used to take place in a local, public space. Due to time constraints and the erasure of that public space, the resultant disconnect from her co-nationals has dampened her sense of belonging to and participation in the Honduran community. This point echoes the discussion above on the positive effects that socializing has on community. 
The above data bolster the discussion in Chapters Two and Three about boundaries, in terms of ethnic identity, trust, and community. Boundaries along national lines continue to be salient for many residents of Little Havana. The boundaries that delineate in-group and out-group have positive aspects and benefits; they help to maintain community. They also have the negative effect of impeding to a greater or lesser extent the creation and nourishment of the panethnic, Latino community.

\section{Conclusion}

In contrast to the overall conclusions in Chapter Four that Latin American immigrant and American-born Latino residents of Little Havana are becoming American vis-à-vis their ethnic and racial identities, conclusions regarding sociability, trust, and its correlate concept of community are not as easy to make. Analyzing trust in Little Havana has presented a complex and variegated picture. When comparing levels of neighborhood trust in Little Havana to scale-less benchmarks from national studies, residents of Little Havana do not fare poorly. They have slightly lower levels than the overall population and white non-Latino sub-population, but are notably more trusting than the Latino subsample in the US. On the other hand, when compared to levels of trust in neighbors (Saguaro Seminar, 2006; 2000), residents of Little Havana are notably lower.

At the same time, the relationship between variables that have a longstanding conceptual link to trust also proves somewhat confusing. Some variables, such as gender, domestic partnership status, and nativity, have no effect on either neighborhood or ethnic trust. Of the two components for SES that are reported here, neither education nor income has any effect on neighborhood trust, while income does associate significantly with trust 
in some of the ethnic groups. Strong cases for the importance of trust with age and years lived in the neighborhood and in the US cannot be made, although data do indicate that there is a trend toward more trust as each of those three variables rise separately.

Meanwhile, what has been termed in this dissertation the dominant group in Little Havana - Cuban-born residents - do overall appear to be more trusting both in neighborhood trust and ethnic trust than non-Cuban Latino. One explanation for this is that the previous dynamics of the neighbor as an overwhelmingly Cuban ethnic neighborhood and its status as part of the Cuban ethnic enclave found in Miami provides a platform for Cuban residents to trust members of their in-group as well as members of the non-Cuban out-group. This suggests that in the face of diversity, members of a dominant group do not necessarily trust less, withdraw from community life, or pull back into their shell, as has been argued by some (e.g., Putnam, 2007). Conversely, members of the subordinate group - other Latinos - do trust significantly less than Cuban on both neighborhood and most ethnic trust indicators, and do not have the same instruments or ability to bridge differences. These findings give evidence to the argument that social relations, including trust and community, are place-specific.

Sociability and localized interactions appear to be key in building trust in Little Havana, although more precisely the lack of broad interaction with neighbors is impeding the establishment of more and deeper trust in the neighborhood. Though many residents have daily conversations with their neighbors, in general the number of neighbors with whom they interact is small. In other words, residents of Little Havana interact with a small handful of neighbors, albeit on an intimate level. They attest to trusting those with whom they have an intimate rapport, but again their social spheres of neighborhood 
intimacy are very small. Perhaps neighborhood residents are having too personalized experiences of trust for that trust to become generalized.

Research in Little Havana also offers a complicated and nuanced understanding of neighborhood and ethnic trust and community. Data suggest that community in Little Havana is formed to a greater or lesser extent on the basis of national origin, as has been show by previous work on the ethnic enclave (see Chapter Two). In the case of this neighborhood, however, the only national origin group that truly has a community, as attested to by both members of the in-group and out-group, are Cubans. Little Havana, as a diverse neighborhood populated by members of various Latin American-origin groups, has been superimposed on the pre-existing Cuban ethnic neighborhood and well-establish Cuban ethnic enclave mentioned above. As such, strong personal ties and networks existed, as well as trust, both personalized and generalized. A sense of community still remains. At the same time, other ancestry groups in the neighborhood appear to suffer from a dearth of community.

Although community is formed along the lines of national origin, there does seem to be some existence of pan-Latino community. These sentiments were expressed in terms of solidarity in Chapter Four, but rarely surface as part of dialogue around community during the interviews. Nevertheless, for some Little Havana residents, it is possible to feeling like a part of both communities, although most do not. Perhaps the existence of a Latino community is just too weak still to be identified with by neighborhood residents. In sum, there is only weak evidence of a pan-Latino community; instead, community, as in years past, continues to hinge on national origin. 
In part, this is because the content of community goes beyond just sentiment into the realm of action. Action is interpreted broadly, and can include social, civic, economic, and charitable activities. In other words, community can be built by 'doing' in a number of areas. In the case of Octavio mentioned above, 'doing' meant meeting up with his long-time friends from Cuban frequently at Domino Park to play domino. For many Little Havana residents, 'doing' took the form of helping friends and family members from their homes country accommodate upon arrival, including giving them (often in the form of 'hand-me-down's' clothes or furniture. After a hurricane, 'doing' means helping a neighborhood pick up debris from their yard or sharing an electric generator or canned food or water. As will be discussed more in the next chapter, 'doing' also takes the form of activism or participation in marches or demonstrations. Whatever form it takes, 'doing' is an essential piece of community and complements the identificational aspect of using a common label or the sentimental aspect of feeling like a part of a collective.

Finally, to the extent that the trust and community point to incorporation, assimilation does appear to be taking place, at least with the dominant ethnic group in the neighborhood. The neighborhood continues to be a place where exposure, contact, interaction, sociability, trust, and community are built, at least with some groups. This echoes work by the Chicago School where the neighborhood is the locus of becoming American, due in part to the neighborhoods ethnic characteristics and institutions that are found there. What this chapter shows is that the transcendence of the importance of national origin for trust and community has not occurred in Little Havana, and thus leaves open the question to what extent Latinos will build trust and community on a variety of scales. 


\section{Placing Civic Engagement in Little Havana}

I don't feel represented [by local politicians]. I really don't feel represented at all...

- Julia, 57 year-old Cuban-born resident of Little Havana for 25 years

I don't know the [elected] representatives and I don't have any major problems. I guess they're doing okay...We had some guy come by like six years ago. He was running for commissioner; he was already a commissioner and he was running for re-election. He came and went door to door. And I told him, 'I don't vote, I don't know who you are, 'but he sat there and talked to me for like fifteen to twenty minutes and told me, 'Well I've been working on this, and you don't know that we've done this and this, and we plan to do this.' And I was real[ly] impressed with him. Of course I don't know his name though. But I thought it was nice of him to come around door-to-door and to spend time talking to me after I told him I don't really vote for city commissioner...But he was from the neighborhood and I got the feeling that he really cared about the neighborhood; he wasn't, you know, a lawyer or something. ${ }^{138}$

- Virginia, 46 year-old US-born resident of Little Havana for 22 years

[My commissioner] has never responded to me at all. I leave messages with his secretary and nothing [happens]. Every time there is any problem here, I call him. I call the police, and nothing happens.

- Roberto, 70 year-old Cuban-born resident of Little Havana for 10 years

${ }^{138}$ English in the original. 
First and foremost, I don't have any time...Sometimes I leave home at 5 o'clock in the morning and I don't get home until 6:30 in the evening. I get home and I'm tired, I have to eat dinner and clean up. Then we go to church. There's no time left [for anything else]. -Mauricio, 55 year-old Nicaraguan-born resident of Little Havana for 16 years

I don't care if [the elected officials] represent me or not. That's my sincere opinion. I don't worry about that. I feel that [politicians] have to do their part, but I also have to do my part. And when I do my part and am responsible, then the rest is not my problem...I have to be a good citizen; if I am a good citizen, it would be difficult for me to cause some sort of problem that the [elected] officials would have to get involved in. I know that I am in a country made up of laws and I have to follow those laws. So I don't blame the elected officials for my errors because it is not their issue.

- Felisa, 69 year-old Cuban-born resident of Little Havana for 39 years 


\section{Introduction}

The third aspect of immigrant incorporation to be explored in this dissertation is civic participation. As discussed in Chapter Three, participation in civic life has been deemed important because participating signifies becoming part of the democratic process in the US. Some civic activities, e.g., voting, are available to immigrants only when citizenship is attained, making nativity, circumstances around migration, length of time lived in the US, and legal status of extreme importance. ${ }^{139}$ Other activities, such as signing a petition or playing on or coaching a team sport, on the other hand, are more accessible because they are not dependent on citizenship.

Chapter Six provides a snapshot of the civic landscape of Little Havana. Data collected with the survey instrument provide measures of activities commonly used as indicators of civic participation on a variety of scales. Meanwhile, qualitative data collected through interviews allow for a greater depth of understanding about how Latin American immigrant and American-born Latino residents of the neighborhood act collectively or not, and why. This chapter begins with a brief explanation of the variables used to measure levels of civic engagement. These are grouped into three categories neighborhood, associational, and political - and are discussed, in turn, using quantitative data. A section exploring neighborhood associations, politics, and impediments to civic participation in Little Havana using qualitative data follows. In sum, this chapter reveals some challenges to studying civic engagement, the role of ethnicity and neighborhood in civic life, and the articulation between identity, trust, and civic engagement.

\footnotetext{
${ }^{139}$ For much of American history, noncitizen voting in elections was both permitted and common. For a discussion of the importance of citizenship in political participation on a variety of scales, see Garcia Bedolla (2006); Hayduk (2002); Harper-Ho (2000); Raskin (1993).
} 


\section{Civic Engagement Variables}

As explained in Chapter Three, there are various ways to group civic indicators and engagement activities as well as frameworks used to understand them. In this dissertation, civic engagement indicators are placed into three categories: neighborhood, associational, and political. The four civic activities which comprise the category 'neighborhood' attending a public meeting, working with others to solve a problem, signing a petition, and participating in a protest or demonstration - are usually performed through social networks that extend beyond one's family but do not rely on direct participation or membership in a formalized club, group, or organization. ${ }^{140}$ Though these activities are de rigueur when considering civic engagement, the scale about which they were asked in this study makes them different. They are grouped under 'neighborhood civic engagement' because in this study, the questions were modified from their customary form and 'placed' on the scale of the neighborhood, i.e., each one of these activities was qualified by 'in the neighborhood' (e.g., "In the past two years, have you ever attended a public meeting about a problem in the neighborhood?"). The data collected therefore reflect not general, scale-less civic engagement, but rather a more specific engagement or activity about and in neighborhood life. The activities classified under 'associational civic engagement' - membership in a professional group, volunteering, and playing on a sports team - take place through established clubs, groups, or organizations, and imply a formalized associational participation. The third and final set of civic activities registering to vote, voting, and volunteering for a political party or candidate - explores

\footnotetext{
${ }^{140} \mathrm{Q} \# 36-\mathrm{B}$, "In the past year, have you been invited to attend a public meeting about a problem in your neighborhood?" was omitted from the analysis as it does not measure a civic activity, but rather is an ancillary question and possible explanation as to why people participate or not.
} 
formal political (electoral) participation and are grouped under the umbrella term 'political civic engagement.'

Attempts are made throughout the chapter to benchmark the findings; some of the questions about civic activities were close, but not identical, to those asked by other researchers. In this case, the closest comparisons are made for benchmarking. As with the trust data in Chapter Five, certain limitations exist. Most of the questions in the survey were qualified temporally by "in the past two years." This qualification was purposeful so as to measure recent engagement, not if a resident had ever done the activities in question at some point and time during their lifetime. In this respect, survey questions differ from some benchmark findings that ask about different time periods (e.g., 'in the past twelve months' as in the Social Capital Community Benchmark Survey [SCCBS]; see Table 6.2 below). In the balance of this chapter, where benchmarking is performed, the temporal differences are discussed. Scale is also a notable difference for the neighborhood civic engagement indicators. Whereas these activities are usually asked in a scale-less fashion, here they are considered at the scale of the neighborhood. While the scale-specificity of the indicators makes the comparison a bit more imprecise, it provides a new scalespecific benchmark for future research. Scale is not a problem for benchmarking associational or political civic engagement variables, however, as the questions used in this dissertation are asked at the same scale as those questions from other surveys to which they are compared.

Exploring levels of civic engagement and the factors (independent variables) that are thought to be associated with them provides a well-rounded view of civic participation in Little Havana. In particular, understanding engagement on the scale of the 
neighborhood about neighborhood issues provides an interesting look into the importance of 'the local' in the process of immigrant incorporation. The three dimensions of engagement - neighborhood, associational, and political - are explored below, in turn.

\section{Neighborhood Civic Engagement}

Descriptive statistics of the four neighborhood civic engagement indicators are found below (see Table 6.1). In the past two years, less than 10\% of Little Havana residents have participated in any of the civic activities: attendance at a public meeting, working together informally in a group to solve a neighborhood problem, signing a petition, and participating in a protest or demonstration.

Table 6.1: Percentages Neighborhood Civic Engagement "In the past two years, have you ever...?" (Q\# 36-A, 36-C, 36-D, 36-E)

\begin{tabular}{|l|c|c|}
\hline & No & Yes \\
\hline $\begin{array}{l}\text { 36-A: Attended a public meeting about a problem in } \\
\text { the neighborhood? }\end{array}$ & 90.6 & 9.4 \\
\hline $\begin{array}{l}\text { 36-C: Worked together informally with someone or } \\
\text { some group to solve a problem in your } \\
\text { neighborhood? }\end{array}$ & 91.1 & 8.9 \\
\hline $\begin{array}{l}\text { 36-D: Signed a petition about a problem in your } \\
\text { neighborhood? }\end{array}$ & 92.2 & 7.8 \\
\hline $\begin{array}{l}\text { 36-E: Participated or joined in a protest or } \\
\text { demonstration about a problem in your } \\
\text { neighborhood? }\end{array}$ & 96.6 & 3.4 \\
\hline
\end{tabular}

To put these percentages in perspective, findings are compared to the extent possible with closest comparable findings from the Social Capital Community Benchmark Survey (SCCBS; see Table 6.2 below), In all of the categories for which there is comparable data, Little Havana residents participate less than both the overall US population of SCCBS respondents as well as the subset of SCCBS Latino respondents 
(available only for the 2000 data set). Not only are most of the discrepancies large (e.g., as much as 27 percentage points between the overall US population of SCCBS respondents and Little Havana residents vis-à-vis signing a petition), but the SCCBS time period is half that of the Little Havana survey (one year and two years, respectively). ${ }^{141}$

Table 6.2: Social Capital Community Benchmark Survey ${ }_{\text {Percentage 'YES' on Neighborhood Civic Engagement }}{ }^{142}$ "In the past twelve months, have you...?"

\begin{tabular}{|l|c|c|c|c|}
\hline & \multicolumn{3}{|c|}{ 2000 } & 2006 \\
\hline & \% Overall & \% White & \% Latino & \% Overall \\
\hline Signed a petition? (Q\# 26A) & 35 & 40 & 19 & 35 \\
\hline $\begin{array}{l}\text { Worked on a community } \\
\text { project? (Q\# 26C) }\end{array}$ & 38 & 41 & 26 & 34 \\
\hline $\begin{array}{l}\text { Worked with others to get } \\
\text { people to fix or improve } \\
\text { something in the } \\
\text { neighborhood? (Q\# 52) }\end{array}$ & 32 & 32 & 26 & 32 \\
\hline $\begin{array}{l}\text { Participated in demonstrations, } \\
\text { boycotts, or marches? (Q\# 26D) }\end{array}$ & 7 & 7 & 7 & 7 \\
\hline
\end{tabular}

Source: Saguaro Seminar, 2000 and 2006

Table 6.3 below displays the significance, or lack thereof, of independent variables' effect on civic engagement behaviors in Little Havana. Looking down the columns of the table, it is clear that only three dichotomous independent variables are found to have repeated statistical significance across the neighborhood civic engagement: US citizenship status, home ownership, and English language ability. Gender and domestic partnership status, on the other hand, have no significant relationship with any of the activities, and nativity and the presence of children in the household are significant

\footnotetext{
${ }^{141}$ Levels of neighborhood and associational civic engagement in Little Havana are low as benchmarked by the other study sites for the greater comparative research project from which the data used in this dissertation are drawn, as well. See Price et al. (under review).

${ }^{142}$ For all of the SCCBS data referenced here, the 2000 data was parsed by race/ethnicity using the following three groups: white, black, and Latino; percentages for the overall sample, for the white, nonLatino subpopulation, and for the Latino subpopulation are provided as a point of comparison. Data from the SCCBS (2006), in contrast, were broken down into only two categories (white and non-white); the overall percentages are reported here.
} 
for only one indicator of civic participation. With respect to the significant relationships that exist between US citizenship, home ownership, and English language ability (not shown in the table), the results are predictably in-keeping with conventional wisdom and/or longstanding conceptual linkages. For instance, citizens were far more likely $(14.9 \%)$ than non-citizens $(4.4 \%)$ to have attended a public meeting about a problem in the neighborhood; monolingual Spanish-speaking residents of Little Havana, on the other hand, were far less likely $(2.9 \%)$ than those who have some level of English (10.6\%) to have signed a petition about a problem in the neighborhood.

Table 6.3: Summary of Significance Dichotomous Independent Variables on Neighborhood Civic Engagement (Q\# 36-A, 36-C, 36-D, 36-E)

\begin{tabular}{|l|c|c|c|c|c|c|c|}
\hline & Citizen & Gender & $\begin{array}{c}\text { Rent/ } \\
\text { Own }\end{array}$ & $\begin{array}{c}\text { DP } \\
\text { Status }\end{array}$ & Nativity & $\begin{array}{c}\text { Children in } \\
\text { Household }\end{array}$ & $\begin{array}{c}\text { Language } \\
\text { Ability }\end{array}$ \\
\hline 36-A & $.001^{* *}$ & .277 & .059 & .357 & .065 & .593 & .217 \\
\hline 36-C & $.049^{*}$ & .149 & $.030^{*}$ & .833 & .140 & .499 & $.001^{* *}$ \\
\hline 36-D & $.000^{* * *}$ & .948 & $.000^{* * *}$ & .976 & $.000^{* * *}$ & .184 & $.013^{*}$ \\
\hline 36-E & .438 & .372 & .327 & .074 & .296 & $.023^{*}$ & .476 \\
\hline
\end{tabular}

When the significance table above (Table 6.3) is analyzed, it becomes clear that some civic indicators are associated with notably more independent variables than are others. The civic participation activities that appear to be least affected by the dichotomous independent variables are attending a public meeting (Q\# 36-A) and participating in a protest or demonstration (Q\# 36-E), both of which are significantly associated with only one variable: US citizenship and the presence of children in the household, respectively. Working informally to solve a problem (Q\# 36-C), on the other hand, is significantly affected by three variables: US citizenship, home ownership, and English language ability. Finally, signing a petition (Q\# 36-D) appears to be the most sensitive civic activity, showing a significant relationship with four of the seven 
dichotomous variables: US citizenship, home ownership, nativity, and English language ability.

One way to understand these differences is according to the nature and intensity of the civic engagement in question, i.e., the amount of effort that each activity requires. The two least affected activities (attending a meeting and participating in a protest) require more than just interest or initiative, but also a notable amount of effort to get of the house or workplace and go to another location. They also require a certain amount of contact and interaction with other people. Working informally (Q\# 36-C) is a broad variable, and could span any activity from staying at home and writing a letter or doing research via computer, to raking leaves or cleaning out clogged sewers. Signing a petition (Q\# 36-D) is the activity affected by the largest number of dichotomous variables and is also the least labor- or effort-intensive, i.e., this activity usually occurs either when a volunteer or employee of an organization knocks on a door and asks the resident for a signature, or in other cases, approaches someone while they are performing a daily activity, e.g., walking in or out of the grocery store.

A second explanation uses Verba et al.'s (1995) resource model to explain Little Havana residents' low levels of participation. In this model, certain civic activities require a greater amount of knowledge and a higher level of skill than others; in essence the model underscores that uneven amounts of human capital influences who participates and how much they participate. As such, those who do not have the requisite skills (e.g., letter writing requires a minimum level of literacy and a way of accessing information regarding to whom to write regarding a certain issue or problem) are less prone to participate. Stores of human capital also tend to relate to socioeconomic (SES) levels, 
affirming the relevance of the SES model to explaining participation as discussed in Chapter Three. ${ }^{143}$ This explanation is especially pertinent when considering Latin American immigrant and American-born Latino populations, whose levels of human capital and SES are generally lower than the white, non-Latino and overall population in the US (Jones-Correa, 2001; Segura et al., 2001; Leighley and Vedlitz, 1999; Verba et al., 1993); furthermore, and as discussed in Chapter Two, Little Havana is a poor neighborhood in a poor city and as such SES levels are lower across the board. Using this explanation to interpret the above findings, however, contradicts expectations in that the least sensitive dependent variables are also those which require the least amount of human capital and know-how whereas the most sensitive requires some levels of education.

Relationships between neighborhood civic activities and the continuous independent variables are also revealing in a somewhat surprising way (see Table 6.4 below). Income and age have no effect on engagement while the number of years lived in the neighborhood is statistically significant only for signing a petition. Education and the number of years lived in the US, on the other hand, prove significant for two of the four civic behaviors: working together informally and signing a petition. Following the formulation of the SES model, the absence of influence on civic engagement by income and the inconsistent effect of education contradict what is expected. Nevertheless, in the two cases where education is significant (working informally [Q\# 36-C] and signing a petition $[\mathrm{Q} \# 36-\mathrm{D}])$, greater education does translate into higher levels are of

\footnotetext{
${ }^{143}$ Socioeconomic status is made up of three components - education, income and occupation - together in a single scale. See Brady et al. (1995); Verba et al. (1993); Verba and Nie (1978). Occupation is not considered as an independent variable in this dissertation, although data on occupation was collected on the survey (Q\# 6).
} 
participation, as expected. ${ }^{144}$ Furthermore, for those neighborhood residents who are immigrants, the more years lived in the US, the more they participate civically. ${ }^{145}$ The latter finding in particular serves as evidence that Latin American immigrant residents in Little Havana seem to be incorporating with respect to civic behavior, despite the fact that their overall participation levels are notably lower than those of 'mainstream' Americans.

Table 6.4: Summary of Significance Continuous Independent Variables on Neighborhood Civic Engagement (Q\# 36-A, 36-C, 36-D, 36-E)

\begin{tabular}{|l|c|c|c|c|c|}
\hline & Education & Income & Age & $\begin{array}{c}\text { Years in } \\
\text { LH }\end{array}$ & $\begin{array}{c}\text { Years in } \\
\text { US }\end{array}$ \\
\hline 36-A & .768 & 1.000 & .940 & .600 & .591 \\
\hline 36-C & $.004^{* *}$ & .100 & .858 & .309 & .134 \\
\hline 36-D & $.022^{*}$ & .147 & .816 & $.004^{* *}$ & $.050^{*}$ \\
\hline 36-E & 1.000 & .151 & .070 & .251 & $.011^{*}$ \\
\hline
\end{tabular}

When consideration is paid to the sensitivity of the continuous dependent variables with respect to this group of independent variables, it becomes clear once more that neighborhood civic activities are not all the same. Attending a public meeting $(\mathrm{Q} \#$ 36-A) is not associated with any of the continuous variables whereas working together informally $(\mathrm{Q} \# 36-\mathrm{C})$ and joining a protest or demonstration $(\mathrm{Q} \#$ 36-D) are only associated with one independent variable: education and the number of years in US, respectively. As in the discussion above, the least labor- and effort-intensive activity (signing a petition $[\mathrm{Q} \# 36-\mathrm{D}]$ ), which is the activity that requires the high level of human

\footnotetext{
${ }^{144}$ Wolfinger and Rosenstone (1980, chapter 2) demonstrate of the three components of the SES variable, education rather than occupation or income that drives electoral turnout. With respect to other civic activities, however, occupation and income play a complicated role. See Brady et al. (1995), Verba et al. (1993).

${ }^{145}$ Due to the overall low levels of participation, the 'years lived in US' categories had to be collapsed into two categories $(0-20$ years and $20+$ years) for the cross tabulations to produce a valid significance.
} 
capital of this group, is the most prone to interact significantly with the independent variables.

In contrast to the findings in Chapter Four vis-à-vis ethnic and racial identification and Chapter Five vis-à-vis trust, the dominant-subordinate variable is only significant for one neighborhood civic activity: participating in a protest or demonstration (Q\# 36-E) (see Table 6.5 below). Cubans participated significantly more in neighborhood civic activities than other Latinos (see Table 6.6 below). Considering the discussion in Chapter Two on the use of public space in the neighborhood and Little Havana as a symbolic center and a hub for Cuba-centered activity, this finding is not surprising. Nevertheless, the question of what kinds of protests and demonstrations residents participated in does arise. The question posed to survey respondents asked specifically about protests and demonstrations 'about a neighborhood problem.' However many of the organized protests and demonstrations that take place in Little Havana, like the Damas de Blanco (Ladies in White) event in late-March 2010, focus on issues that can be considered external to the neighborhood, especially having to do with Cuba, and therefore might not technically be seen as a neighborhood issue.

Table 6.5: Summary of Significance ${ }^{146}$ Dominant-Subordinate Independent Variable on Neighborhood Civic Engagement (Q\# 36-A, 36-C, 36-D, 36-E)

\begin{tabular}{|l|c|}
\hline & Coefficient \\
\hline 36-A & .245 \\
\hline 36-C & .508 \\
\hline 36-D & .367 \\
\hline 36-E & $.035^{*}$ \\
\hline
\end{tabular}

Table 6.6: Percentages Participation Dominant-Subordinate Independent Variable on Protest or Demonstration

\footnotetext{
${ }^{146}$ For the significance for the dominant-subordinate independent variable on all civic engagement dependent variables in this chapter, the Fisher's Exact Test (1-sided) was used.
} 


\section{$\underline{(\mathbf{Q \# 3 6 - E})}$}

\begin{tabular}{|l|c|c|}
\hline & \% Cuban & \% Other Latino \\
\hline 36-E & 5.3 & 1.5 \\
\hline
\end{tabular}

In conclusion, Latin American immigrant and US-born Latino residents of Little Havana appear to be incorporating into civic life in the United States to a limited extent. Levels of neighborhood civic engagement are overall low. The relationship between civic activities and the factors that have been theorized to determine behavior are also generally very inconsistent and support the argument that scholars must move beyond the SES model to understand engagement, especially when considering immigrant communities (Taeku et al., 2006; Jones-Correa, 2001; Jones-Correa and Leal, 2001; Segura et al., 2001; Leighley and Vedlitz, 1999; Verba et al., 1993).

\section{Associational Civic Engagement}

The three participatory activities categorized here as 'associational' are: membership in a professional group, volunteering with a non-profit or community organization, and playing on a sports team or in a sports league. Table 6.7 below presents levels of participation for the sample population of Little Havana residents. Percentages for two of the three activities (participation in professional group [Q\# 39] and sports team [Q\# 42]) are similar to levels of participation in the neighborhood civic activities discussed above: less than $6 \%$ of Little Havana residents engage through these activities. On the other hand, levels of volunteering (Q\# 40) surpass those of any other civic activity mentioned so far. Overall, and as with the neighborhood engagement indicators, associational civic engagement seems to be lacking in Little Havana. 
Table 6.7: Percentages Associational Civic Engagement ${ }^{147}$

"In the past two years, have you ever...?"

$(\mathrm{Q} \# 39,40,42)$

\begin{tabular}{|l|c|c|}
\hline & No & Yes \\
\hline $\begin{array}{l}\text { 39: Been a member of a professional group related } \\
\text { to your job? }\end{array}$ & 94.3 & 5.7 \\
\hline $\begin{array}{l}\text { 40: Volunteered with any non-profit or community } \\
\text { organization? }\end{array}$ & 85.9 & 14.1 \\
\hline 42: Participated in a sports team or league? & 94.5 & 5.5 \\
\hline
\end{tabular}

When benchmarked against the most comparable questions asked by the Saguaro Seminar (SCCBS, 2006; 2000; see Table 6.8 below), levels of participation in associational civic activities in Little Havana do indeed prove quite low; this is the case when compared to the overall US population as well as the white and Latino subpopulations. For example, 5.7\% of Little Havana residents were members of a professional group related to their job, whereas $25 \%$ of the overall SCCBS, $27 \%$ of the white sub-population, and $12 \%$ of the Latino sub-population participated in a professional, trade, farm, or business association. In short, Little Havana residents participate less than half as much as Latinos nationwide, a group that in the aggregate is under-participating. The case of playing on a sports team or league reveals a similar picture: $5.5 \%$ of Latinos in Little Havana play on a sports team or league whereas $18 \%$ of Latinos nationwide report participating in this civic activity according to the Saguaro Seminar (see Table 6.8 below).

Recent work by DeSipio (2006) serves as another close benchmark for data on volunteering. He conducted an analysis on engagement in civic voluntarism using data

\footnotetext{
${ }^{147}$ Other related survey questions that fall under this group are $\mathrm{Q} \#$ 37-A, 37-B, 38, 38-A, 38-B, 39-A, 40A, 40-B, 41, 41-A, 42-A, and 42-B. They are not reported at the discretion of the author for various reasons, e.g., some were spatial data; others do not lend themselves to statistical analysis as they are qualitative.
} 
from the September 2002 Volunteer Supplement of the Current Population Survey (CPS), which asks several detailed questions about the topic. Concretely, the results on the question, "Have you done any volunteer work in the previous 12 months?" can be compared to the survey findings here. DeSipio found that $31 \%$ of white respondents and $15 \%$ of Latino respondents had volunteered in the past year. ${ }^{148}$ Again, Latino residents of Little Havana appear to be low participators when compared to non-Latino, white Americans nation-wide, and just slightly less participatory when compared to other Latinos. Indeed, these results confirm findings by others that Latinos across the board are the racial and ethnic group that participate least in civic activities.

Table 6.8: Social Capital Community Benchmark Survey Percentage 'YES' on Associational Civic Engagement "Have you...?"

\begin{tabular}{|l|c|c|c|c|}
\hline & \multicolumn{3}{|c|}{ 2000 } & 2006 \\
\hline & \% Overall & \% White & \% Latino & \% Overall \\
\hline $\begin{array}{l}\text { Participated in a professional, } \\
\text { trade, farm, or business } \\
\text { association? (Q\# 33J) }\end{array}$ & 25 & 27 & 12 & 22 \\
\hline $\begin{array}{l}\text { Participated in a charity or } \\
\text { social welfare organization? } \\
\text { (Q\# 33H) }\end{array}$ & 32 & 34 & 21 & 34 \\
\hline $\begin{array}{l}\text { Participated in a sports club, } \\
\text { league, or outdoor activity } \\
\text { club? (Q\# 33B) }\end{array}$ & 21 & 21 & 18 & 21 \\
\hline
\end{tabular}

Source: Saguaro Seminar, 2000 and 2006

As in the discussion above on the relationship between the independent dichotomous variables and neighborhood civic behaviors, there is an inconsistency present between the independent dichotomous variables and associational civici activities (see Figure 6.9 below). Domestic partnership status and the presence of children in the

\footnotetext{
${ }^{148} 19 \%$ for blacks and $18 \%$ of Asians reported having volunteered in the past 12 months according to DeSipio (2006).

${ }^{149}$ No time period was specified for these questions.
} 
household have no significant relationship with any of the activities, while US citizenship, gender, and home ownership relate significantly to only one of the three (professional group [Q\# 39], sports team [Q\# 42], and professional group [Q\# 39], respectively). English language ability holds a significant relationship with two of the three (professional group [Q\# 39] and volunteering [Q\# 40]), while nativity is significant with all three associational civic behaviors. All of the significant relationships show results that are predictably in-keeping with conventional wisdom and/or longstanding conceptual linkages. For instance, home owners (10.6\%) join professional groups more than renters (3.7\%); Spanish-only speakers were far less likely (7.3\%) than those who also spoke some English (17.9\%) to volunteer; and males (10.3\%) were far more likely than females $(1.4 \%)$ to participate in a sports team or league.

Table 6.9: Summary of Significance Dichotomous Independent Variables on Associational Civic Engagement (Q\# 39, 40, 42)

\begin{tabular}{|l|c|c|c|c|c|c|c|}
\hline & Citizenship & Gender & Rent/Own & $\begin{array}{c}\text { DP } \\
\text { Status }\end{array}$ & Nativity & $\begin{array}{c}\text { Children in } \\
\text { Household }\end{array}$ & $\begin{array}{c}\text { Language } \\
\text { Ability }\end{array}$ \\
\hline $\mathbf{3 9}$ & $.007^{* *}$ & .275 & $.015^{*}$ & .245 & $.006^{* *}$ & 1.000 & $.014^{*}$ \\
\hline $\mathbf{4 0}$ & .989 & .359 & .844 & .217 & $.023^{*}$ & .069 & $.007^{* *}$ \\
\hline $\mathbf{4 2}$ & 1.000 & $.000^{* * *}$ & .408 & .929 & $.005^{* *}$ & .069 & .158 \\
\hline
\end{tabular}

When the statistical significance table (Table 6.9 above) is analyzed laterally, there is a notable difference in sensitivity to influence on civic behaviors by independent variables. The activity most prone to statistical significance is professional group membership (interaction with four IVs) whereas both volunteering and playing in sports interact significantly with only two IVs. In contrast to some of the neighborhood civic behaviors discussed above, all three associational activities require contact and interaction with others and a certain 'get up and go' spirit. With that said, the nature of 
each behavior is somewhat unique. Professional membership is work-related and therefore speaks to economic stability and type of livelihood. Volunteering, on the other hand, is a humanitarian effort and might be considered an activity of the heart. ${ }^{150}$ Finally, playing sports is a leisure activity, a pastime, or hobby. One possible explanation for the higher variability of participation in a professional group is that it is less optional than either volunteering or playing sports because it deals with one's survival rather than enjoyment.

As for the continuous variables, the number of years lived in the neighborhood shows no statistically significant relationship to associational engagement activities, both age and years lived in the US interact with one civic behavior (playing sports), and education and income with two (professional group and volunteering, and professional group and playing sports, respectively) (see Table 6.10 below). With respect to the directionality of the statistically significant relationships (not shown in Table 6.10), relationships are predictably in-keeping with conventional wisdom and/or longstanding conceptual linkages. For example, higher income leads to more membership in professional groups ${ }^{151}$ and playing sports ${ }^{152}$; higher levels of education lead to increased levels of volunteering. Another relationship of note, between playing sports and age, is highly significant and reflects the fact that older residents engage in sports less than

\footnotetext{
${ }^{150}$ This is not the case for volunteering that is court-ordered.

${ }^{151}$ Due to the overall low levels of participation, the 'income' categories had to be collapsed into two categories $(<\$ 24,999$ and $\$ 25,000+)$ for the cross tabulations to produce a valid significance.

152 Due to the overall low levels of participation, the 'income' categories had to be collapsed into two categories $(<\$ 24,999$ and $\$ 25,000+)$ for the cross tabulations to produce a valid significance.
} 
younger residents. ${ }^{153}$ In general, education and income have a more consistent effect on associational civic engagement activities than on neighborhood civic engagement, even though it is not across the board.

Table 6.10: Summary of Significance Continuous Independent Variables on Associational Civic Engagement (Q\# 39, 40, 42)

\begin{tabular}{|l|c|c|c|c|c|}
\hline & Education & Income & Age & Years in LH & Years in US \\
\hline $\mathbf{3 9}$ & $.000^{* * *}$ & $.000^{* * *}$ & .292 & .520 & 1.000 \\
\hline $\mathbf{4 0}$ & $.003^{* *}$ & .143 & .072 & .994 & .863 \\
\hline $\mathbf{4 2}$ & .737 & $.007^{*}$ & $.000^{* * *}$ & .167 & $.011^{*}$ \\
\hline
\end{tabular}

The dominant-subordinate variable reveals interesting findings that contradict those discussed in previous chapters on identity and trust, as well as those on neighborhood civic engagement (see Table 6.11 below). There are statistically significant differences between the dominant (Cuban) group and subordinate (other Latino) group for two of the three associational engagement variables. Surprisingly, it is the minority 'other Latino' group in the case of volunteering and playing sports that far surpasses the Cuban group in their levels of participation (see Table 6.12 below). Other Latinos volunteer more than twice as much as Cubans (18.7\% vs. $9.1 \%$, respectively). While this finding is noteworthy, the difference in playing on sports teams is even more extreme: $0.0 \%$ of the Cuban population participates on a sports team while $10.7 \%$ of other Latinos do. The difference between dominant and subordinate groups no doubt coincides with the fact that the majority (56.1\%) of Cuban residents of Little Havana are 66+ years old (see Chapter 2, Table 2.7).

\footnotetext{
${ }^{153}$ Due to the overall low levels of participation, the 'age' categories had to be collapsed into two categories (18-45 years old and 46+ years old) for the cross tabulations to produce a valid significance.
} 
Table 6.11: Summary of Significance

Dominant-Subordinate Variable on Associational Civic Engagement (Q\# 39, 40, 42)

Cuban vs. Other Latino

\begin{tabular}{|l|c|}
\hline & Coefficient \\
\hline $\mathbf{3 9}$ & .463 \\
\hline $\mathbf{4 0}$ & $.005^{* *}$ \\
\hline $\mathbf{4 2}$ & $.000^{* * *}$ \\
\hline
\end{tabular}

Table 6.12: Percentages Associational Civic Engagement (Q\# 39, 40, 42)

Cuban vs. Other Latino

\begin{tabular}{|l|c|c|}
\hline & \% Cuban & \% Other Latino \\
\hline $\mathbf{4 0}$ & 9.1 & 18.7 \\
\hline $\mathbf{4 2}$ & 0.0 & 10.7 \\
\hline
\end{tabular}

In conclusion, levels of associational civic engagement are in line with those of neighborhood civic activities discussed above. In the case of both categories of civic engagement, levels of participation are low in Little Havana. Factors (independent variables) thought to influence collective action are also inconsistent, although education and income do prove to be statistically significant for two of the three associational civic behaviors. In light of the previous discussion on Cubans and their incorporation trajectory, it is surprising to find that for associational civic engagement, those activities where dominant-subordinate ethnic group dynamics are statistically significant, Cubans are participate less than members of other national origin groups.

\section{Political Civic Engagement}

The final group of civic engagement behaviors considered in this chapter belongs to the formal political engagement category, and include registering to vote, voting in an election, and volunteering for a political party or candidate. In Little Havana, residents were asked if they had participated in any of these activities in the past two years. Table 
6.13 below displays the descriptive statistics for political civic activities. A distinct cleavage between behaviors is immediately apparent: whereas levels of participation in formal electoral activities (registering to vote and casting a ballot) are extremely high, the extent to which Little Havana residents volunteer their time for a political party or candidate is dismally low and more in line with levels of neighborhood and associational civic activities seen above. Nearly nine out of ten Little Havana residents who are eligible to register to vote have done so; of those who are eligible and registered, nearly $90 \%$ have cast a ballot in the past two years. Such high rates are surprising given that Latinos are known in general to have one of the lowest electoral participation rates of any group, in part because of noncitizenship and youth (DeSipio, 2005; Segura et al., 2001; Leighley and Vedlitz, 1999; Arvizu and Garcia, 1996; Verba et al., 1995; 1993; Verba and Nie, 1972).

Table 6.13: Percentages Political Civic Engagement (Q\# 43 through 45$)$

\begin{tabular}{|c|c|c|}
\hline & No & Yes \\
\hline 43: Are you registered to vote ${ }^{154}$ & 12.2 & 87.8 \\
\hline $\begin{array}{l}\text { 44: Have you voted in a US election in the last two } \\
\text { years? }{ }^{155}\end{array}$ & 11.3 & 88.7 \\
\hline $\begin{array}{l}\text { 45: Have you worked as a volunteer for a political party } \\
\text { or candidate in the past two years? }\end{array}$ & 97.4 & 2.6 \\
\hline
\end{tabular}

When compared to self-reported electoral participation by SCCBS (see Table 6.14 below), Little Havana's voter registration level (87.8\%) surpasses the overall population $(80 \%)$ as well the white, non-Latino (85\%) and Latino (48\%) sub-populations. The same is true for going to the polls: in Little Havana, $88.7 \%$ of registered residents compared to

\footnotetext{
${ }^{154}$ This is the sub-sample of the population of residents who are US citizens and thus eligible to register.

155 This is the sub-sample of the population who are citizens and who are registered to vote.
} 
$69 \%$ of the overall SCCBS sample, $75 \%$ of the white, non-Latino subsample, and $36 \%$ of the Latino subsample voted in the last presidential elections. ${ }^{156}$ This is also the case when Little Havana survey data are compared to those on 2006 mid-term voting provided by the Pew Research Center (2007), although the percentages of registration and voting turnout for Latinos in the Pew study (53\% and 58\% in 2002, and 54\% and 60\% in 2006, respectively) are somewhat higher than SCCBS levels (see Table 6.15 below). ${ }^{157-158}$

Table 6.14: Social Capital Community Benchmark Survey on Political Civic Engagement Percentage 'YES' Participation

\begin{tabular}{|l|c|c|c|c|}
\hline & \multicolumn{3}{|c|}{$\mathbf{2 0 0 0}$} & $\mathbf{2 0 0 6}$ \\
\hline & \% Overall & \% White & \% Latino & \% Overall \\
\hline $\begin{array}{l}\text { Are you currently registered } \\
\text { to vote? (Q\# 22) }\end{array}$ & 80 & 85 & 48 & 81 \\
\hline $\begin{array}{l}\text { Did you vote in the 1996 } \\
\text { presidential elections? (Q\# 23) }\end{array}$ & 69 & 75 & 36 & 74 \\
\hline
\end{tabular}

Source: Saguaro Seminar, 2000 and 2006

Table 6.15: Pew Research Center Electoral Benchmark

\begin{tabular}{|l|c|c|c|c|}
\hline & \multicolumn{2}{|c|}{2002} & \multicolumn{2}{c|}{ 2006 } \\
\hline & \% White & \% Latino & \% White & \% Latino \\
\hline Registered to vote & 69 & 53 & 71 & 54 \\
\hline Voted & 71 & 58 & 72 & 60 \\
\hline
\end{tabular}

Source: Taylor et al., 2007

\footnotetext{
${ }^{156}$ The statistics for Hispanics do not take into account eligibility, but rather reflect percentage of the totally Latino population. As citizenship is a requirement for voting, a small portion of the Latino population, which is composed of a large percentage of non-citizenship (both documented and undocumented), registers and votes. A large percentage of the Latino population in the US is under the age of 18. These two factors combined result in an extra low share of the total voter turnout.

${ }^{157}$ The statistical analysis performed by the Pew Research Center was based on data from a supplement of the Current Population Survey (CPS) that is conducted by the US Census Bureau every November of an election year.

${ }^{158}$ These numbers are directly comparable to Little Havana data. In both cases, statistical analysis for registration was performed only on the eligible population, i.e., citizens; analysis on turnout at the polls was calculated using those that were registered.

${ }^{159}$ In the Saguaro Seminar (2000 and 2006) questions were asked about trust between official Census racial and ethnic groups, but not between various Hispanic ancestry groups.
} 
Tables 6.16 and 6.17 below display the statistical interaction between the twelve independent variables and political engagement. None of the twelve variables show a consistent, significant effect on the three activities. This is interesting because, as discussed in Chapter Three, all of these variables have been conceptually, theoretically, and empirically linked to civic engagement activities, and especially to political (electoral) behavior. Of the dichotomous variables, home ownership, domestic partnership status, and nativity have no significant relationship with any of the three behaviors; gender, the presence of children in the household, and English language ability are only significant for one of the activities (voting, registering, and political volunteering, respectively) (see Table 6.16 below). Of the continuous independent variables, education, years lived in Little Havana, and years lived in the US have no significant relationship with political behavior; income and age is each associated significantly to voting (see Table 6.17 below).

Table 6.16: Summary of Significance Dichotomous Independent Variables on Political Civic Engagement (Q\# 43 through 45$)$

\begin{tabular}{|l|c|c|c|c|c|c|c|}
\hline & Citizen & Gender & Rent/Own & $\begin{array}{c}\text { DP } \\
\text { Status }\end{array}$ & Nativity & $\begin{array}{c}\text { Children } \\
\text { in } \\
\text { Household }\end{array}$ & $\begin{array}{c}\text { Language } \\
\text { Ability }\end{array}$ \\
\hline $\mathbf{4 3}$ & -- & .392 & .519 & .895 & .572 & $.005^{* *}$ & .245 \\
\hline $\mathbf{4 4}$ & -- & $.021^{*}$ & .201 & .906 & .001 & .510 & .160 \\
\hline $\mathbf{4 5}$ & .126 & .511 & .155 & .188 & .586 & .519 & $.011^{*}$ \\
\hline
\end{tabular}

\footnotetext{
${ }^{160}$ The variable 'citizenship' was omitted in the analysis of Q\# 43 and Q\# 44 because citizenship is a requisite for both activities and was thus built into the creation of the sub-population of residents to analyze. One does not have to be a citizen, however, to volunteer for a political party or candidate and thus citizenship was analyzed with that dependent variable.
} 
Table 6.17: Summary of Significance

Continuous Independent Variables on Political Civic Engagement

(Q\# 43 through 45)

\begin{tabular}{|l|c|c|c|c|c|}
\hline & Education & Income & Age & $\begin{array}{c}\text { Years in } \\
\text { LH }\end{array}$ & $\begin{array}{c}\text { Years in } \\
\text { US }\end{array}$ \\
\hline $\mathbf{4 3}$ & .231 & .808 & .124 & .166 & .061 \\
\hline $\mathbf{4 4}$ & .917 & $.006^{* *}$ & $.000^{* * *}$ & .081 & .237 \\
\hline $\mathbf{4 5}$ & .108 & .413 & .461 & .074 & .609 \\
\hline
\end{tabular}

As with the neighborhood and associational civic engagement activities discussed above, political civic activities were analyzed with the dominant-subordinate ethnic variable in search of a statistically significance relationship. Both registering to vote and turning out at the polls are significantly related to the dominant-subordinate variable; volunteering for a political candidate or campaign, on the other hand, is not influenced by this variable (see Table 6.18 below). Not surprisingly, members of the dominant Cuban group both register and vote significantly more than members of the subordinate group (see Table 6.19 below). The discrepancy between the two groups is most certainly caused in part by the array of legal and political privileges accorded to members of the dominant Cuban group as political refugees, including their facilitated path to residency and US citizenship. Members of the other national groups (with exception of the American-born cohort) experience greater difficulty in gaining access to US citizenship, a pre-requisite for registering and voting. The framework known as context of reception (Stepick and Stepick, 2009; Portes and Rumbaut, 1996; Portes and Borocz, 1989) is useful for explaining the difference between dominant and subordinate groups with respect to political civic engagement. 
Table 6.18: Summary of Significance

Dominant-Subordinate Independent Variable on Political Civic Engagement (Q\# 43 through 45)

\begin{tabular}{|l|c|}
\hline $\mathbf{4 3}$ & $.000 * * *$ \\
\hline 44 & $.000 * * *$ \\
\hline 45 & .592 \\
\hline
\end{tabular}

Table 6.19: Percentages Participation

Dominant-Subordinate Independent Variable on Political Civic Engagement $(\mathrm{O \#} \mathrm{43,44)}$

\begin{tabular}{|l|c|c|}
\hline & \% Cuban & \% Other Latino \\
\hline $\mathbf{4 3}$ & 61.0 & 24.4 \\
\hline $\mathbf{4 4}$ & 94.7 & 70.8 \\
\hline
\end{tabular}

In conclusion, as opposed to their limited participation in neighborhood and associational civic activities, Latin American immigrant and US-born Latino residents of Little Havana participate in electoral activities (both registering and turning out at the polls) at extremely high levels. In this sense, then, they appear to be incorporating into life in the US and 'becoming American' in an exceptional way. These findings underline the importance of separating civic engagement activities in frameworks such as those discussed in Chapter Three and the framework used in this chapter. Doing so reveals variegated paths of assimilation vis-à-vis civic engagement activities, as well as the importance of scale and neighborhood in the process of incorporation.

Beyond the Numbers: Understanding Civic Engagement in Little Havana Interviews with residents of Little Havana reveal many aspects of the various types of civic engagement discussed above. The majority of the qualitative data discussed below focuses on two aspects of civic engagement: participation in neighborhood associations and political activities. These topics were deemed relevant by researchers when 
developing the interview guide after phase I survey data were entered and preliminary analysis of these data was performed. The dynamics of 'neighborhood versus community' discussed in Chapters Two and Five, and of the qualitative data on neighborhood civic engagement above, were explored through discussion of neighborhood associations. All interview participants were asked about their ideas, opinions, and feelings on neighborhood, community, the various forms of civic engagement, and political behavior, including recognition of and contact with local politicians, and electoral activities. These topics are addressed below.

\section{Neighborhood Associations}

In Chapter Two, various facets of the political, economic, and social life of and in Little Havana were discussed. As mentioned in that chapter, many aspects of the neighborhood have been driven by the dominant Cuban group and their outward-looking, Cuba-focused activities. Time and energy dedicated to local issues, as far as they relate to everyday life in the neighborhood, have been comparatively little. The levels of neighborhood and associational civic engagement discussed earlier in this chapter serve as additional evidence that civic life on the local scale in Little Havana, when defined and measured by the classic indicators, is low in both absolute and comparative terms.

Although participation in a neighborhood association (e.g., homeowners' association) was not specifically asked about in the survey, it was discussed systematically with all interviewees in the qualitative phases of data collection. Had this question also been asked in the survey, it could have been classified either as a neighborhood civic activity or as an associational civic activity given how these 
categories were conceived in the framework (discussed above). Conversations with Little Havana residents about neighborhood associations during the interview phase offer a different perspective on civic participation.

This dissertation has presented and discussed research that largely confirms the suspicion that there is not a rich or complex fabric of civic engagement on neighborhood and associational indicators in Little Havana. There is a notable dearth of such civic life, in fact. One of the indicators of the scarcity of neighborhood civic life is the absence of what might be called a Little Havana Neighborhood or Homeowners' Association. Without a doubt, the boundaries of Little Havana are blurry and there are a notable number of renters who reside there. However, no organization where residents can meet to discuss and resolve neighborhood issues and problems exists. There are non-profit groups located in Little Havana that focus their efforts on helping those in the community through social services (e.g., Abriendo Puertas, a 501(c)(3) organization that offers a wide variety of services to Little Havana residents, including adult English and computer classes, and an afterschool program for children; see www.abriendopuertasfl.org) or economic and real estate development groups (e.g., the East Little Havana Community Development Group, founded in 1984 to revitalize the East Little Havana neighborhood; see www.eastlittlehavanacdc.com). It was argued in Chapter Two that the history and place-specific context of Little Havana is what constitutes it as a neighborhood, despite the fact that an official delineation does not exist. However, the evidence discussed in Chapter Five suggests that there exists little semblance of a 'Little Havana neighborhood identity' or a sense of community based on propinquity. When asked if a neighborhood or homeowners' association exists in Little Havana, most residents answered correctly 
that there is indeed no such organization, although some claimed not to know if there was one or not. For example, Carla, a 42 year-old Nicaraguan-born resident of Little Havana for the last 5 years, says: "I couldn't tell you if there is or not because... What do you mean association? Like a union?...I don't know if there is or not...I think there probably is...Honestly, I don't know if there is one or not... There might be one."

In discussing neighborhood associations with Little Havana residents, a number of themes became apparent and reveal perceptions of neighborhood associations as well as other civic groups and activities. Some of these coincide with themes that appeared in the discussions of identity and trust in previous chapters. In general, data point to the general lack of formal associational and institutional life in Little Havana around local issues.

Many Little Havana residents believe that they would like for a neighborhood association to exist in Little Havana for various reasons. One commonly cited reason is the lack of sense of community in the neighborhood discussed in Chapter Five, and the perceived benefits that such ties could bring. Fundamentally, this could be considered a desire for place-based social capital, or personal relations that result in the concrete benefits that social ties bring with them. Many residents lamented the lack of rapport with neighbors, echoing the sentiments of disconnect discussed in Chapter Five. They expressed a desire to meet their neighbors or to get to know them better. Residents perceived a possible increased sense of safety and security if such ties were formed.

Consuelo, for example, a 50-year old Guatemalan-born resident of Little Havana for the past 6 years, thinks: 
It would be nice [if there were a neighborhood association in Little Havana]. You would get to know people better, you know? It would be nice because, like in my case, [I don't know] how to meet people. You don't even know the person that lives across the street from you. I can't get a feel for what the person is like. With neighbors, you get to know them the more contact you have with them. You get to know what kind (clase) of people they are...

Similarly, Hugo, a 35-year old American-born Latino of Puerto Rican descent, bought a house in the Shenandoah section of Little Havana and moved in about 2 months ago. He has attended a couple of meetings of the Shenandoah Homeowners' Association and says that he will continue to attend. "It's nice to know the neighbors, not just your immediate neighbors..."161

Yolanda, a 35-year old Mexican-born immigrant who has resided in her apartment in Little Havana for one year, agrees. She talks about the various benefits that a neighborhood association would bring. She says:

First of all, so we [neighbors] all get along, respect each other. Keep things safe, quiet, united... [These aspect of neighborhood life] are important to me because I have a son. Right now, I feel very good [in my apartment complex] because everybody here knows my son, and if I'm inside cooking and he runs outside, the neighbor catches him and tells him to go upstairs. Or [the neighbors say,] 'hey, get down from there.' Or if someone strange

\footnotetext{
${ }^{161}$ English in the original.
} 
is talking to him, the neighbors would watch him, because we all know each other. I would do the same with another child being bullied or beaten up. I would also say something.

Marcos, a 58-year old Cuban-born immigrant who has lived in Little Havana for 18 years, thinks that "it would be nice if all the neighbors knew each other because sometimes someone needs help and you could give it to him, or if I needed some help too...I haven't ever needed any help, but you never know when I could." Roberto, a 70year old Cuban-born man who has lived in Little Havana for 10 years, says a formal association is needed "to meet once a month to evaluate what is going right and what is going wrong [in the neighborhood]." Rafael, a 50-year old Nicaraguan-born immigrant who has lived in Little Havana as a renter for 10 year, identifies other kinds of benefits that connection and unity between neighbors could bring. He says emphatically that he would participate in a neighborhood association if one existed in Little Havana, in order to make improvements. "More unity with neighbors [would be good] to eradicate the drugs, crime, prostitution [that go on here]."

In essence, the residents of Little Havana discussed above believe that if they know each other, i.e., have contact and cultivate connection with each other, they will watch out for each other's physical and material well-being. In sum, a neighborhood association could be an excellent venue to create a sense of community and build social ties. Despite the rather common desire for such an organization to exist, however, no interviewee expressed any interest in taking the initiative to research the existence of one or to start one up. This reflects both a lack of initiative and a lack of leadership from residents as one reason why such an organization does not currently exist. 
Some residents are skeptical that such an organization could exist in Little Havana and if it would be at all efficacious. They say they would participate in such an organization, however, once they saw that it was truly useful, i.e., once the organization had actually accomplished something. Rodrigo is a 24-year old American-born Latino of Cuban descent. He has lived in the same house his parents bought in Little Havana 16 years ago. He says: "What happens to the neighborhood, happens to the neighborhood. They [the neighbors] don't care. It's not like a gated community. There's no [condo] board, there's nothing here...If there was [a neighborhood association], I would participate and put as much effort to see if anything could get resolved. But I don't think it would happen any time soon."

Rodolfo, a 26 year-old Nicaraguan-born immigrant to the US who has lived in his rented apartment for 1 month, talks about what could motivate him to participate in a civic group like a neighborhood association. He says:

The same thing that would motivate anyone: common interests. When there are no shared interests, no one participates. That makes sense: if there is no common interest involved, you don't waste your time. No way. I have learned something here [in Miami]: everybody participates and joins when it is convenient for them, if there is going to be some kind of [material] benefit to them. If there are no benefits, they look at you like 'why waste my time and energy?'

\footnotetext{
${ }^{162}$ English in the original.
} 
The positive feelings and perception of a formalized neighborhood association are confronted by feelings and perceptions of other residents who are opposed to such an organization for a variety of reasons. These reasons range from an apparent cluelessness or ignorance of and general disconnect from civic life, to a lack of understanding about what such an organization would or could do, to fear about too much control of one's life.

For example, some residents are clueless or ignorant; they do not understand the terminology or concept of neighborhood association. This thread also appears in Chapter Four and Five, indicating a lack of information and understanding about various aspects of life in the US. In this case, neighborhood associations appear to be foreign and unknown. In the case of Justo, a 69 year-old Cuban-born man who has been a renting resident of Little Havana for 17 years, when asked if he knows of or is a member of a neighborhood association, he answers:

Well, I don't belong, so I can't tell you. Here [in Little Havana], there are many Cuban associations, you know? There are Nicaraguan associations too...There are associations of all kinds: religious, Nicaraguan, Cuban, all kinds of associations here. I don’t belong to any of them... because I like to be independent. And be freer, have more time.

Justo is not able to articulate what a neighborhood association is. Such ignorance might be interpreted as a lack of incorporation into life in the US.

Others, like Teodoro, a 72 year-old Cuban-born resident of Little Havana who has owned his home for the past 10 years, do not understand what good could come from neighborhood association or how they would benefit from one. They believe such an 
organization would be useless because there is no reason for them to exist, e.g., no problems or shared interests. When asked if he would like there to be a neighborhood association, he relies "it makes no difference to me" (me da igual). When asked directly if he thinks it would help to solve neighbor issues, he says: "There have never been any problems here. Never. None. No.” Teodoro does not see any reason for a neighborhood association to exist, or any potential benefit that might arise from having one.

Like Teodoro, Maite believes that a neighborhood association would be useless because there are no changes or improvements to be made in the neighborhood. "There are never any problems here. The only problem that we have had is when there is a hurricane, but that is normal in all cities." Maite did mention a problem in the recent past with a street light on the corner of her block. She says that the light was too dark, "so I called and they came out to fix it." She uses this example to underscore the lack of need of a neighborhood association: why have one when direct contact with city officials will solve problems? In the case of Edgar, a 23 year-old Nicaraguan-born man who has lived in Little Havana for 16 years, he feels like he was able to accomplish a goal - making his neighborhood safer - by contacting the police over and over again, and insisting that they send more patrol cars more frequently. He accomplished this goal with the help of other neighbors, who informally decided to pursue the same interest of increased safety and vigilance by local police through the same means. An association was not necessary for such an accomplishment to take place, so Edgar is not convinced that it would do any good.

Felisa, a 69 year-old Cuban-born resident of Little Havana since she bought her home 39 years ago, agrees with Edgar. She sees no need for a neighborhood association 
because the neighbors look out for each other. It would be superfluous because the informal organization that exists is sufficient; in fact, it is better than getting involved in a formal organization. Felisa places great importance on the personal ties she has with her neighbors. She says:

There is no need for a neighborhood association. There is unity [among the neighbors]. Not only for something like keeping the street clean. There is unity also in the sense that if I leave my patio light on accidentally, my back-door neighbor, Olga, will call me and say, 'Hey, Felisa, you left your patio light on...I have never asked Olga to call me to tell me that I left my light on. But I know that if a week passes and Olga doesn't open her kitchen door, I call her on the phone and say, 'Hey Olga, what's up? Is everything okay? I haven't seen you in a week'...This is neighborhood relationship, inter-relationship. It's not a committee [formal group]...There is no need for that.

While the efficacy of neighbors directly dealing with and resolving neighborhood issues discussed in the two examples above is uplifting, it also seems to be a rather rare occurrence based on the data. What happens in neighborhoods (or parts of neighborhoods) where such social ties do not exist or informal efforts and campaigns are not undertaken? How would residents address issues and solve problems? Perhaps a formalized neighborhood association could help, but according to Julia, a 57 year-old Cuban-born homeowner in the Shenandoah part of Little Havana for the past 26 years, it 
is not likely. She has seen firsthand the lack of results of the Shenandoah Homeowners' Association. She says:

I never go to the meetings anymore because I tried on various occasions to get them to help me resolve certain issues with the commissioners and politicians, but they didn't get anything done at all. Why am I going to go the meetings and waste my time? I get home from work tired, so why would I go to a meeting where they are not going to do anything?

A more extreme point of view is voiced by other neighbors who perceive organizations as expressively negative. Some, like Daniel, a 37 year-old Cuban-born immigrant who has lived in Little Havana since he came to the US as boy 28 years ago, are fearful that such organizations are going to raise his cost of living; he is not willing to pay money or increase his expenses in order to have neighborhood association.

According to Daniel, it would be okay if there were a neighborhood association, "so long as the associations don't start charging you money for this or that...you know, like when you buy in these [condo] associations. You gotta pay for the lawnmower man and this and that. They got different taxes and stuff like that, so no, I'm not all for associations. $" 163$

Others deem a neighborhood association a system of observation and control. Some residents fear that the neighborhood association would become too nosy or 'in their business' (metido); furthermore, the perception that neighborhood associations exercise too much authority (e.g., regulating which color a house can be painted) is prevalent.

\footnotetext{
${ }^{163}$ English in the original.
} 
Virginia, 46 year-old American-born woman who has lived in her home in Shenadoah with her husband since they bought it 22 years ago, illustrates this concern well (along with the cluelessness, indifference, and perceived lack of need mentioned above). She says:

I'm not sure [if the Shenandoah Homeowners' Association] still exists or not. I don’t know [if is a good thing or not.] I was never involved. I don't know what they're doing. [I think if it's a good thing or not] depends. Are they a regular sane group of people or are they people who just want to make up a whole bunch of different rules? You know, [like] in condos sometimes, you get fanaticism...It could get crazy like, 'We're only going to paint houses brown in this block.' I'm kinda of lazy. I mean, we don't have any major problems, so...if it's not broke, don't fix it.

Natalio and Romeo, 66 year-old Cuban-born twin brothers who bought their home in Little Havana 8 years ago, share Virginia's frame of mind. They say:

I'm not a big fan of associations. There is always a president, and then arguments. I think that there should be a box for suggestions, ideas, criticism, complaints - good and bad things. A politician should read the papers and give solutions, because that's their job. Whenever there is an association, as in condominiums, there are arguments because of this and that, because someone has a dog, or a cat. That doesn't lead to anything good. It's not good for anybody. I believe that you should live on your own property, 
interact with other people, not throw trash in your neighbor's yard, and that your neighbor should not throw trash in your yard, and you should not be nosy and gossipy (chismoso).

The most extremely negative perspective on neighborhood associations was offered by Jaime, a 78 year-old Cuban-born resident who has lived in various rented apartments throughout Little Havana for the past 30 years. He equates such a group with control and his previous cultural-political context under Fidel, and calls neighborhood organizations communist. When asked about a neighborhood association, he emphatically says that there is not one in Little Havana: "No! No! No! No!...That's communism. Unions and religion and all that is from communism."

In sum, qualitative data regarding neighborhood associations reveal a spectrum of attitudes - from positive to negative - regarding why and how Little Havana residents view and participate in that aspect of civic life. There is no neighborhood organization in Little Havana (or anything like one); nevertheless, many residents appreciate the benefits that could arise from the existence of one. Another portion of interviewees, however, disagree with such a notion for a variety of reasons.

\section{Discussing Politics}

Another means of gauging and understanding the civic attitudes and behaviors of residents of Little Havana is through discussions regarding politics and politicians on a variety of scales. These topics were explored first with open-ended questions and then 
later in the interview using photo elicitation. ${ }^{164}$ Interviewees were asked if they feel represented by local politicians and if they feel like their interests are being represented. The responses were varied, and included some very supportive comments of politicians, while others were rather negative and pessimistic. These data reveal general attitudes visà-vis civic, especially political, life in Little Havana.

When asked about their interests, some Little Havana residents presented the same clueless, uninformed, or apathetic opinions as when asked about inter-ethnic neighborhood dynamics, trust, community, and neighborhood associations. Maite, mentioned above, admits to being clueless. "The truth is that I know I am not wellinformed, so I can't answer your question.” The same is the case with Alejandra, a 67 year-old Cuban-born homeowner who has lived in Little Havana for 24 years. She gives a similar response as Maite's when asked about politics: “I don't know. I don't know. Don't ask me about politics... [I am] ignorant." On the other hand, Remedios, a 75 yearold Cuban-born woman who has lived in the neighborhood for 5 years, chooses not to be political. "We [my husband and I] stay at the margin of politics...I don't belong to any political or Cuban American group...I'm not [involved] with any of that...I don't need it...I don't want to belong."

Other residents reveal apathetic attitudes toward politics and participation in general. They either do not find the need to participate or have other, better, or more important things to do. When asked if they had attended the recent immigration protests

\footnotetext{
${ }^{164}$ An $8 \times 11$ paper with photos of politicians from various scales relevant to life in Little Havana were shown to interviewees and they were asked to discuss. The pictures include local County Commissioners, the mayor of the City of Miami, the mayor of Miami-Dade County, and a US congress-people from Florida.
} 
that took place in Little Havana just blocks away from their home, Natalio and Romeo ${ }^{165}$, mentioned above, said no and explained that:

I dedicate 24 hours a day to my friends, my work, and to art. I have my time limited for other things. I have a computer but I barely have time to use it. If I am doing something else, I'm out and about in the street...If I happen to be around Calle Ocho $\left(8^{\text {th }}\right.$ Street $)$ and there is a protest, I listen and [if] I am interested, I'll stay around, but I never search [something like that] out.

One possible interpretation of these data posits that lack of understanding or information surfaces from the way that the residents view themselves in the civic and political panorama at various scales, including the neighborhood. That is, perhaps they were not able to answer questions about interests because they in fact do not view themselves as stakeholders, as residents who are able to have interests. This could certainly be the case for those who are not permitted to participate because of legal status, including legal residents (e.g., green card holders) who cannot vote, as well as undocumented immigrants, for whom participating formally could lead to risk due to increased visibility (and thus being caught by the immigration authorities). Another interpretation posits that the uninformed and ignorant stance toward politics reflects a lack of incorporation in life in the US.

Among the majority of interviewees who did understand the interview questions on politics and politicians, a clear cleavage appeared. Some residents express negative

\footnotetext{
${ }^{165}$ The interview was performed with Natalio and Rome together. They are identical twin brothers who also sound remarkably similar. It was impossible for the author to distinguish the two voices on the digital recording or from the transcript. Therefore, though they are two people, they are grouped together as one.
} 
opinions of politics and politicians in general, while others think highly of elected officials, in some cases know them personally, and believe they are contributing to a better life in Miami. Still others are disillusioned by the actions, reputations, and history of corruption, inefficacy, and lack of responsiveness by politicians.

Regarding politicians, Consuelo, mentioned above, says:

Of course they represent my interests. They are the authorities in charge of making things better. The only thing that people have to do is communicate [their needs] to them, because [otherwise] they won't know. If you don't tell them, they won't know...but sometimes we [people] stay quiet, and no one will come [help us]. [I think they are doing a good job] because they are making Miami a better place. Look how pretty the city is. It is getting pretty. They are changing Miami.

Octavio, a 75 year-old Cuban-born man who has lived in Little Havana for 22 years as a renter, agrees with Consuelo. "I believe they are following through with their promises. It seems to me that they are all honest. It hasn't been proven that they have done anything [bad], or that they have cheated anyone, or done anything wrong. I think they are doing a good job.”

Many other residents, on other hand, do not believe that the elected officials are representing their interests. Gonzalo, a 42 year-old Cuban-born longtime resident of Little Havana, illustrates this opinion well. He says:

I don't think he [my commissioner] represents [my] interests. I think...basically politicians [are] just out for themselves 
unfortunately...I consider myself one of [my commissioner's] constituents because of where I live...He should represent my interests. He lives in the Roads ${ }^{166}$ [nearby neighborhood] so, you know, the Roads and Shenandoah [are] completely different. Once you cross $12^{\text {th }}$ Avenue, it's completely different. So you think he's gonna care about this area as much as [his own]? Have you seen what they've done in the Roads with all those traffic circles and everything? And they've done nothing here except put four-way stop signs... [T]hey don't put as much attention [on] this area as I feel they should. ${ }^{167}$

Hugo, mentioned above, agrees with Gonzalo. He says he would like to participate in the political process, but he says his commissioner is a "typical politician...He hears everybody and says 'yes, yes' and writes everything down." Rafael, mentioned above, expresses a similar attitude. According to him, the commissioners, "promise heaven and earth, but they don't even give you a piece of earth."

More negative opinions about politics in general and the Miami-Dade County commissioners in particular were expressed by Rodrigo, mentioned above. When asked if he knows his local commissioner and believes that his interests are being represented by him, he replies:

I really don't pay attention to it [politics and the commissioners] because I personally think that if you were to vote for a person,

\footnotetext{
${ }^{166}$ The Roads is an adjacent neighborhood to Little Havana.

${ }^{167}$ English in the original.
} 
you would never see that person. You always see that person at election [time]; I have never seen my commissioner. It's not like they come through here to the blocks; they don't care about the block. It's all a politics thing. I try to stay away from politics.

Monserrat, a 43 year-old Nicaraguan-born single mother who has rented various apartments in Little Havana for the last 10 years, echoes Rodrigo's sentiment above when she says that she does not feel represented because she does not believe that representatives really know what is happening where she lives.

I should [feel represented], but sometimes the mayor doesn't even know what our interests are. He just has his people who work for him, but they really don't come to the communities to see what's going on here. They [the mayor's people] could be the leaders of an organization here instead of [sitting at] their desks talking about 'we're going to improve this.' Why not come to the communities and see what's going on? ${ }^{168}$

A number of other neighborhood residents expressed disdain, disappointment, or disgust in politics and politicians. Julia, mentioned above, says she does not have any faith in politicians. She tells the story of a neighborhood campaign to get a stop sign on her street in which she participated, after which she was very disappointed and disillusioned because the stop sign was never put in. "We collected signatures, because we need a certain number of signatures, and nothing happened. There was no way to resolve the issue." Experiences such as this one have affected negatively her belief in

\footnotetext{
${ }^{168}$ English in the original.
} 
politics and politicians and have impacted her level of participation. She says she continues voting, "but less and less each year...I continue voting but mostly in the presidential elections...I used to vote more. I made more effort to vote and I would take the time to do it, but now I don't make such effort. I vote from time to time..."

Similar negative impacts were experienced by Maite, who has stopped voting entirely “because [politicians] don't solve any problem (no resuelven nada). They only make promise after promise. I already said that I am not going to vote for anyone again.” Daniel's is a similar story. He expresses a pessimistic attitude toward politicians.

They really don't respond quickly. So how long did it take...I know that [hurricane] Wilma was a horrible disaster, but there were more things that they could do with the type of money that they had. I really don't have a very good opinion about politicians. Politicians - that's why I don't vote. I used to vote all the time... ${ }^{169}$

The dynamics between what has been termed the dominant (Cuban) and subordinate (other Latino origin) groups in Little Havana also surfaced in the interviews when talking about politics. The perception that the elected officials, most of whom are Cuban American, cater largely to the interests of the Cuban and Cuban American community, is common. Daniel, mentioned above, speaks about Ileana Ros-Lehtinen, a Cuban-born US-congresswoman representing the $18^{\text {th }}$ district of Florida (south Florida area, including Miami-Dade County), whom he believes to be a good politician and whom he supports. He says:

\footnotetext{
${ }^{169}$ The issues addressed in this section are generally considered questions of political efficacy in political science literature.
} 
I guess I've been brainwashed by my father. She's really good with the Cuban community. She's always talking garbage about Fidel and what we got to do [vis-à-vis Fidel]. And then she talks a lot to the President and in favor of our community...She's not only here [in Miami]; she's always in Washington and stuff so she has a lot of pull. So I like her. ${ }^{170}$

Julia, mentioned above, also acknowledges the aid and support of politicians at various levels, including local commissioners, when there are problems with Cuba or that involve Cuban people. She says:

They try to help when there are problems with the Cuban people and things like that. They always try to stand up and represent (sacar la cara) and try to solve the problems with respect to Cubans. For that they deserve credit, don't you think? I don't know how it is with other countries [nationalities], but at least with Cubans they try to help.

While Daniel and Julia are sympathetic and grateful for the attention to Cuban constituents, others neighborhood residents are not. Maite, a native of Honduras, also perceives that Cuban elected officials put Cuban concerns first. "They [politicians like Ileana Ros-Lehtinen] take care of Cuban issues. They are the ones that take care of the Cuban issues. For other countries, no.” Rodolfo, a 26 year-old immigrant from Nicaragua, agrees with Maite. He explains:

\footnotetext{
${ }^{170}$ English in the original.
} 
They [the elected officials] represent, more than anything, the Cuban American community. The Cubans, because they are always, whenever something unfortunate happens to the Cubans, like for example out at sea, they [the politicians] are the first ones there [to respond]. But, for a Guatemalan, Honduran, or Nicaraguan...That is definitely the skill (don) that has to be recognized by the Cubans; they are, in their community, united. They are united among each other.

Maite's and Rodolfo's frustration and dissatisfaction arise out of a perceived bias on the part of the Cuban American elected officials for their Cuban and Cuban American constituents, along with a perceived lack of concern for other national groups' issues. At least one resident, however, believes that Miami's politicians at various scales are succeeding at representing and helping both Cubans and other Latinos. Marcos, mentioned above, is very supportive of the work of the various elected officials he mentions by name, and acknowledges the work they do for both for the Cuban American population as well as Latinos in general. He says: "I'll tell you...for me, [Tomás] Regalado is a great commissioner...He has always been a very respectable person. Ileana [Ros-Lehtinen], for our community, has been amazing, not just for the Cuban community, but for the Latino community, because she serves everyone.

\section{Impediments to Participation}

As was the case above with regard to political engagement, certain civic activities suffer from a lack of participation due to bad experiences by those who had once participated. 
Daniel, mentioned above, had previously participated in various civic activities. On one occasion, he circulated a petition in support of getting a stop sign installed on his block. The civic effort had a favorable end for Daniel and others requesting the stop sign; it was eventually installed. Daniel liked participating, but the bad attitudes of others discouraged him, and now he chooses not to participate any longer. He explains:

I noticed that people don't treat you the same way you treat them. I've always been like, you know, if I'm gonna do something, I'm gonna do it strongly. From the heart. And people don't respond the same way. You just eventually say, why even associate? Because you associate with someone that really [takes advantage of you] and you kind of like... you'd rather do it on your own. So I've kinda of backed off from [civic activities], I'm not involved anymore. ${ }^{171}$

Over the course of the interviews, it became clear that there are a number of other factors that impede Little Havana residents from civic engagement. For certain parts of the population, health and age serve as constraints that limit a residents' ability to participate. As discussed in Chapter Two, the population of Little Havana has a sizeable number of elderly residents, especially among the Cuban sub-population. Octavio, mentioned above, is 75 years. He says that he would not participate in a community or neighborhood association because of his age. "I'd have to go to different events and assemblies. I've had a prostate operation, a hernia, and I'm diabetic. That means I have to stick to a strict eating regiment and insulin shots at certain times. I couldn't see myself

\footnotetext{
${ }^{171}$ English in the original.
} 
participating for 4 or 5 hours. We don't even go to the beach..." Health issues also hold Gonzalo, mentioned above, from participating more actively in civic life: he is wheelchair-bound. "There's the matter of me being able to get there. My mobility is limited." 172

Another possible reason for lack of civic participation is the lack of communication by individuals, groups, and organizations about local civic activities, and their desire and need for residents to participate. Monserrat, mentioned above, says: "Especially here [in Little Havana], all the people, we try to keep working and sometimes we don't have time, but [if] somebody [would] send us flyer or something... [if] there's something, maybe if I have the time, I would go. But they never send anything.",173 Gonzalo echoes Monserrat's frustration at never been invited to participate. He says: No, I've never gone [to a meeting of the Shenandoah Homeowners' Association]. I would... [it's just a matter of] them inviting me over there. Finding out where the meetings are and all that...I just know they exist because I read about it in the paper...I don't think they make [an effort to get people involved]...because [otherwise] I would be involved. This is my neighborhood, you know? I see people throw stuff on the street and I tell them 'Hey pick that shit up!'...I just think they [local organizations] don't

\footnotetext{
${ }^{172}$ English in the original.

${ }^{173}$ English in the original.
} 
have the proper funding or the channels to reach out to everybody, you know? ${ }^{174}$

In addition to the uninformed and apathetic attitudes discussed in the above section, the most common reason why people claimed not to participate was time. Rafael, mentioned above, explains that he did not attend any of the immigration protests a month and a half before the interview because he comes home late in the evening from work. He claims work is the factor that stops him from participating in civic life. He explains:

If I don't work, there's nobody to pay for the telephone, the electricity, the rent. [I sympathize with the causes], but I don't have time...The issue of time here [in the US] is not like in Latin America where it's more laid-back. Here it is very serious...I just celebrated my $50^{\text {th }}$ birthday and I look like I'm 60 .

Mauricio, a 55 year-old Nicaraguan-gorn immigrant who has lived in Little Havana for 16 years, echoes Rafael's sentiment. "First and foremost, you know that here [in the US], he who doesn't work, can't pay his rent, can't pay his things...The economy comes first, then the community." So does Carla, a 42 year-old Nicaraguan-born resident of Little Havana for the past 5 years. She says: "I would like to participate, yes, but the problem is my job. Sometimes I don't have time... [I don't work] 24 hours a day, but sometimes I finish work exhausted (rendida), without energy (agotada)." Edgar, mentioned above, agrees with Carla. He says he would participate as well, but "time is

\footnotetext{
${ }^{174}$ English in the original.
} 
what kills you, you know? Because you get home basically to sleep. I spent more time at work than at home, and the weekend I use my time to do chores around the house, no?"

\section{Conclusion}

In Chapter Six, quantitative data measuring levels of three different categories of civic engagement in Little Havana were presented and discussed. Overall, findings reveal low levels of participation in neighborhood and associational civic activities, while registering to vote and turning out at the polls is practiced by extraordinarily high numbers of residents. The relationships between these civic indicators and the factors (independent variables) that are supposed to influence them, when statistically significant, are in keeping with previous conceptualizations and theories. The surprising finding is that many of the relationships that are conceptually and theoretically expected to exist, especially SES, do not hold in Little Havana.

The qualitative data discussed above reveal Little Havana residents' outlook on neighborhood associations and local politicians specifically, as well as opening the door to a more nuanced understanding of civic participation in general. Little Havana residents' attitudes on neighborhood associations and local politicians are roughly split down the middle between optimistic and pessimistic point of views and opinions. Many residents would like there to be a neighborhood association, and spell out concrete benefits that they believe such an organization would bring. The most important of these is the ability to foster more social relations and ties between neighbors: to build placebased social capital. As discussed in Chapter Five, the benefits of such ties are often numerous. In the case of Little Havana, where many residents spoke of crime and danger, 
an increased sense of security and safety could be a concrete outcome of closer social ties based on proximity. Despite their expressed willingness to participate, however, none of the interviewees express any interest in or enthusiasm for taking the initiative to start or lead such a group.

With respect to politics and politicians, many neighborhood residents were supportive of their elected representatives and believe in both their moral and ethical character as well as their efficacy in office. Many Little Havana residents, however, expressed negative attitudes towards politics and politicians, and were not shy about revealing them. They voiced feelings of disappointment, frustration, disgust, lack of representation, and in some cases, interviewees have stopped participating because of bad experiences or perceptions of having wasted their time in the past. Despite the notable negative sentiment, however, the vast majority of Little Havana residents participate in the voting process, and in this way, are actively engaging in civic life. 


\section{Conclusion}

This dissertation explores three aspects of immigrant incorporation - identity, trust, and

civic engagement - in a specific place. Little Havana is a neighborhood populated predominantly by Latin American immigrants and their American-born offspring.

Though the neighborhood might be considered by some as a Latino ethnic neighborhood, this study reveals the diversity that lies within the panethnic collective and some of the nuances around the employment of the panethnic label. Furthermore, it is argued that intra-Latino diversity does in fact have a concrete effect on the aspects of incorporation discussed throughout.

Assimilation is the paradigm through which immigrant incorporation has been understood by most scholars throughout the twentieth century, and the spatial dimension holds central importance to assimilation theory. The neighborhood has served as the key geographic dimension and scale of explaining how immigrants incorporate into US culture and society in urban settings. Some recent work (e.g., Li, 1998; Zelinsky and Lee, 1998) challenges the importance of the urban immigrant neighborhood for providing the tools for ethnic individuals and groups to incorporate, at least in the traditional sense. Many immigrants in the $21^{\text {st }}$ century are bypassing the downtown and heading directly for the suburbs, while others are bypassing urban areas entirely and heading for cities and states that do not have a recent history of immigrant reception and settlement.

This dissertation picks up the theoretical and conceptual foundations of assimilation and seeks to understand and explain incorporation within the urban context, at the scale of the neighborhood. Assimilation is not the only way of analyzing attitudes and behaviors of newcomers, but it is useful in that it has traditionally encompassed 
many different dimensions, of which three have been explored here. Since the founding of the nation, ethnic and racial identity in the US has been of utmost importance in discussion of incorporation. In essence, scholars and others have held the expectation that immigrants adopt an American identity, reflected in part in the use of labels. Studies have shown that for many, the Americanization of identity has never been complete, in that syncretic and hyphenated identities and identifications are more the norm than the exception. Nevertheless, the overwhelming trend is a move toward the adoption of at least a partially assimilated ethnic identity. Race, meanwhile, proves itself to be a malleable concept. Its boundaries of belonging - who fits 'in' one race or another - have been places of struggle and contention and the product of both complex cultural and legal processes. Race is a dialectical process between agency and structure.

In the case of Latin American immigrants and their American-born offspring, American identities $d o$ indeed appear to be developing. This is exemplified clearly by the adoption and exercise of US-formed panethnic labels, namely Latino and Hispanic. This phenomenon, though commonly understood as monolithic, is actually quite complex and nuanced; its contours surface in Little Havana around question of diversity. Diversity in this case includes country of origin and socioeconomic status, both of which revolve in part around concepts of cultura and educación, which reflect ancestral and class-based differences. Key variations were found, in fact, between the historically- and symbolically-dominant ancestry group in Little Havana - Cubans - and residents of other Latin American origins. Nevertheless, most neighborhood residents have assumed at least a partial place- and context-dependent Latino identity and attest to feelings of solidarity with and across the panethnic group. 
The same lines of cleavage that surface when considering identity also appear when considering the second aspect of assimilation, trust, and its correlate community. Country of origin and socioeconomic status are seen as major lines of division for both trust in neighbors as well as trust in ethnic groups. They also act as barriers to the creation of community, despite the common identificational factor of panethnicity. Ancestral boundaries have aided Cubans in the neighborhood in such a way that members of this group trust both other members of the Cuban ancestry group as well as members of the out-group more, a finding that underscores the importance of the local relations, at the scale of the neighborhood, in assimilation. Convincing evidence of trust and a community based on both affective ties and civic action is found in this research. It suggests, however, that immigrant incorporation can still best be understood along the lines of ancestry, not as a part of a panethnic monolith. Latinos, as members of a diverse group, face challenges that they have not yet succeeded in overcoming, to consolidate as an on-going cohesive ethnic group in the US, despite their propensity to identify as such.

As for civic engagement, residents of Little Havana appear notably less likely to participate civically when compared to the overall US population and other subpopulation on most measures. Again, the historical and symbolic dominance of Cuban immigrants in Little Havana has much to do with this phenomenon. Cubans, though touted for long and by many as an exemplary immigrant group, have also been very focused on issues outside of their local environment, namely the politics on and with their country of origin. Over time, members of this group have re-focused attention on the local and many have become successful in political, economic, and social arenas in South Florida. Second- and third-generation Cubans and other Latinos, nevertheless, have 
followed a similar path as previous immigrant groups in that their contact with, interest in, and cultural ties to their ancestors' homeland and language wane (Alba, 2005; Waters and Jiménez, 2005; Lopez, 1996; Portes and Rumbaut, 1996). Nevertheless, their levels of civic engagement in the local - in the neighborhood and regarding neighborhood life are low, as are those for all national origin groups in Little Havana.

Formal political engagement, however, is exceptionally high, surpassing rates of the overall US population and all subpopulations. At the same time, residents of Little Havana express both positive and negative attitudes about group, associational, institutional, and formal participation, as well as about political efficacy on multiple scales. This dissertation, then, serves as evidence of the need to re-think and problematize the study of civic engagement, especially with immigrant communities. How and why members of the various national origin groups that comprise the panethnic Latino group could be presenting a new way of civic participation as the incorporate into life in the US.

Overall, this dissertation highlights the need and continued value of understanding immigrant incorporation 'in place,' and argues that the neighborhood is still an important scale at which to consider assimilation. It is also argued that trying to evaluate assimilation for Latinos as a panethnic collective is not the best approach given the diversity within the panethnic group that has been shown here to inhibit trust, community, and civic action; instead, assimilation appears to be happening along the lines of country of origin.

By way of conclusion, some final thoughts on the assimilation paradigm, the importance of place, social capital, and conflicted incorporation will be addressed below, in turn. 


\section{Assimilation Theory}

It is common in the social sciences to understand the progression of knowledge according to the changing of paradigms; the validity and popularity of an accepted framework of study and explanation of social facts shifts or breaks as knowledge is gained about the phenomenon and a new framework takes its place (Kuhn, 1962). The most common and influential paradigm in explaining immigrant incorporation in the US has been, and continues to be, assimilation. This dissertation, though posited more generally as a study of immigration incorporation, does in fact depart from an assumption that immigrants will move in a certain direction toward 'becoming American.' But it, as many other works, seeks to understand if this same paradigm applies to the panethic Latino group, and if so, how? In essence, the findings presented here allow for broader and more nuanced understandings of the ways that members of panethnic groups incorporate vis-àvis identity, trust, and civic engagement.

Asians and Latinos, the two main panethnic groups in the United States, are compared and contrasted in many ways in academic literature. Whereas Asians are often viewed as a heterogeneous group that united strategically for mostly political reasons despite the national, ethnic, linguistic, religious, and other differences that exist between the individuals and groups that make up the panethnicity, Latinos' homogeneity has been essentialized, despite its own internal national, ethnic, linguistic, and cultural diversity. As such, cleavages within the Asian panethnic group have been more easily be understood and accepted compared to cleavages between the various peoples that make up the Latino monolithic panethnic group. The data discussed throughout this dissertation suggest that these conceptualizations are incorrect, and that the salience of national origin 
is of the utmost importance for understanding if and how Latinos incorporate. These findings then support the continued use of some fundamental aspects of assimilation theory to explain immigrant incorporation, especially national origin as the pivotal axis around which it occurs.

\section{The Importance of Place}

This dissertation presents data, findings, and conclusions based on one example of one neighborhood in Miami, Florida. This neighborhood, which has been constructed by the researchers and at the same time exists in the imaginary on many scales, is embedded in a larger political, socioeconomic, cultural, and place-specific set of processes that influences what 'becoming American' looks like and how it works. Becoming American in Little Havana, then, is part of what it means to become American on multiple scales; the city, county, and South Florida region in which the neighborhood is embedded, create dynamics that influence immigrant incorporation. Little Havana is part of a majority Latino city and county; it is surrounded by sharp contrasts between glamour and wealth on the one hand, and poverty and violence on the other; it is a tri- lingual and -cultural region; and it serves as a hub of transnational activities.

As demonstrated above, the neighborhood does figure importantly in the aspects of immigrant incorporation examined in this dissertation, especially vis-à-vis the formation and exercise of trust and the forging of community. The quantitative data, for example, bear this out in that when all relevant independent variables are controlled for, country of origin (here known as the dominant-subordinate group variable) is consistently highly significant as a predictor of trust for Cubans. This group has been historically 
dominant in the neighborhood and continues to be dominant symbolically in Little Havana, despite the demographic and cultural diversification that has taken place. In short, the neighborhood is still the place where trust and community are made, at least for the dominant national group.

The extent to which the neighborhood functions to overcome cleavages based on national origin remains in doubt however. Evidence presented above suggests that a sense of Latino community in Little Havana is lacking, despite the saliency of the Latino panethnic label and feelings of Latino solidarity for most neighborhood residents. Latino panethnic solidarity as sentiment and action remains strategic, ad hoc, and often uneven between groups.

\section{Social Capital}

The theoretical formulation of social capital that links identity, trust, and civic engagement conceptually has not been specifically used in this dissertation. These topics have instead been addressed here somewhat independently and from the perspective of immigrant incorporation. A few words about social capital are in order, however, given that the findings as a whole speak to this paradigm. Overall, this dissertation indicates that social capital is a valid and useful concept to discuss identity, trust, and civic engagement, although the usual linkages between these areas are placed in doubt. In other words, identity, trust, and civic engagement appear to be following different paths and the articulations between them are much blurrier than previously pointed out.

The presence of trust and existence of community, according to the social capital formulation, are viewed as a facilitator or sort of grease that lead more easily to collective 
action and civic engagement. In Little Havana, among those who are trusting and belong to a community - Cubans, generally speaking - civic engagement is equally as lacking as for members who are less trusting and do not belong to any community - other Latinos, generally speaking. The glue that binds communities together and spawns engagement is not working. Members of the former group indicate equally low levels on measures of engagement, as well as attitudes of ambivalence or resignation about participating in group, associational, institutional, and civic life as members of the latter group. Voter registration and turn out at the polls, two political behaviors practiced significantly more by Cubans, on the other hand, are most certainly in part a bi-product of their privileged refugee status that facilitates residency and by extension citizenship. Furthermore, the outward-looking primary concerns of this group vis-à-vis Cuba and the resultant activism has been well-documented, and coincides in a scalar fashion with their extremely high political participation. Civic engagement, then, and by extension social capital, is both place- and scale-sensitive and must be considered as such in discussions of immigrant incorporation in the US in the $21^{\text {st }}$ century.

\section{Conflicted Incorporation}

Perhaps the term 'conflicted incorporation' best characterizes the phenomenon described and analyzed in this dissertation. The empirical evidence presented throughout shows that within the Latino panethnic group, there is indeed conflict in a number of different senses, in both attitudes and behaviors. The process of incorporation as it pertains to the dimensions discussed above is not linear, coherent, or simple, but rather more like a broken line, patchy, and complex. Within the Latino panethnic collective, individuals and 
groups seem to assimilate in different ways and to different extents. Relations between residents of Little Havana, including those between national groups, are often fraught with either explicit or implicit tensions; conflict manifests in a variety of feelings and actions.

The evidence presented in this dissertation suggests that individuals and groups incorporate in certain ways according to their belonging to either the dominant or subordinate neighborhood group. In short, members of the dominant Cuban national group are in a more favorable position to assimilate than members of the subordinate, non-Cuban Latino group in the neighborhood. ${ }^{175}$ Data indicate that this is due to their place-specific prominence culturally, economically, and politically. The dominant group's prominence might be diminishing given the shifted demographics of Little Havana, but evidence suggests that for now Cubans' historic and symbolic importance remain in tact. For the dominant Cuban group, national identity proves to be both a bonding and bridging factor, while this is not the case for the second largest national group in the neighborhood, Nicaraguans. ${ }^{176}$ Bonding and bridging is certainly occurring in and with the dominant group vis-à-vis trust, i.e., their levels of trust in members of their own national group as well as in members of other national groups are significantly higher than those of the subordinate group. Bonding and bridging social capital in terms of trust and community appears to exist and practiced by members of the dominant group. Meanwhile, overall findings on civic engagement suggest that national origin makes little or no difference, except in two of the three expressly political engagement

\footnotetext{
${ }^{175}$ This same could also be argued at the city and county scales, but the data presented focuses on the neighborhood scale.

${ }^{176}$ The sample size of members of the other national groups is too small to draw a conclusion.
} 
activities. These findings present serious empirical and conceptual challenges to previous work on trust, community, civic engagement, and social capital (e.g., Putnam, 2007).

This dissertation also suggests that 'becoming American' has to be problematized. At least in an idealized form, incorporation (read: assimilation) means becoming a 'good American' and meeting general expectations regarding participation in the thoughts, feelings, and behaviors that are associated with identity, trust, and civic engagement. It is clear, however, that homogenizing Latinos is not a valid or effective way to "judge" the outcomes of the assimilation process because members of various national groups differ and vary in notable ways. In essence, such expectations set Latinos up for "failure," creating (or reinforcing) the paradigm that they will never become 'good Americans' and will only remain 'second best.'

It has been argued that visible minorities (especially shown with African Americans in the US) will never incorporate fully, basically because they are not allowed to do so by an inherently racist social structure in the US. For Latinos, many of whom are also visible minorities, this argument could be made as well. Visible difference, then, together with cultural and linguistic differences, might further make full incorporation impossible. This, like most questions, in the social sciences, is an empirical question that can only be answered with further investigation. 


\section{BIBLIOGRAPHY}

Abramson, Paul R. and John H. Aldrich. 1982. The Decline of Electoral Participation in America. American Political Science Review 76(3): 502-521.

Acosta, Ikam. 2001. Boy Exile Turned Saint: Elián González as a Contested ReligioIdeological Symbol among Cuban-American Catholics, unpublished M.A. thesis. Department of Religious Studies, Florida International University.

Affigne, Tony. 2000. Latino Politics in the United States: An Introduction. PS: Political Science and Politics 33(3): 523-527.

Agnew, John A. 1996. Mapping Politics: How Context Counts in Electoral Geography. Political Geography 15(2): 129-146.

Agnew, John A. 1994. The National versus the Contextual: The Controversy over Measuring Electoral Change in Italy using Goodman's flow-of-votes Estimates. Political Geography 13: 245-254.

Agnew, John A. 1993. Representing Space: Space, Scale and Culture in Social Science. In James Duncan and David Ley (eds), Place/Culture/Representation, pp. 251269. London, UK: Routledge.

Agnew, John A. 1989. The Devaluation of Place in Social Science. In John A. Agnew and James S. Duncan (eds), The Power of Place, pp. 9-29. Boston, MA: Unwin Hyman.

Agnew, John A. 1987. Place and Politics: The Geographical Mediation of State and Society. Boston, MA: Allen and Unwin.

Aguayo, Sergio. 1985. El éxodo centroamericano: Consecuencias de un conflicto. Mexico, DF: Secretería de Educación Pública.

Aguilares, Gilberto. 1985. The Roots of the Sanctuary Movement: Witness of Refugees. Church and Society 75(4): 7-15.

Airriess, Christopher A. and Ines M. Miyares. 2006. Exploring Contemporary Ethnic Geographies. In Christopher A. Airriess and Ines M. Miyares (eds), Contemporary Ethnic Geographies in America, pp. 1-26. Lanham, MD: Rowman \& Littlefield.

Aitken, Stuart C. 2000. Mothers, Communities and the Scale of Difference. Social and Cultural Geography 1:65-82. 
Alba, Richard D. 2005. Bright vs. Blurred Boundaries: Second-generation Assimilation and Exclusion in France, Germany, and the United States. Ethnic and Racial Studies 28(1): 20-49.

Alba, Richard D. 1995. Assimilation's Quiet Tide. The Public Interest 119: 3-18.

Alba, Richard D. 1990. Ethnic Identity: The Transformation of White America. New Haven, CT: Yale University Press.

Alba, Richard D., John Logan, Amy Lutz and Brian Stults. 2002. Only English by the Third Generation? Mother-tongue Loss and Preservation among the Grandchildren of Contemporary Immigrants. Demography 39: 467-484.

Alba, Richard D. and Victor Nee. 2003. Remaking the American Mainstream: Assimilation and Contemporary Immigration. Cambridge, MA: Harvard University Press.

Alba, Richard D. and Victor Nee. 1997. Rethinking Assimilation Theory for a New Era of Immigration. International Migration Review 31(4): 826-874.

Alberts, Heike. 2006. The Multiple Transformations of Miami. In Heather A. Smith and Owen J. Furuseth (eds), Latinos in the New South: Transformations of Place, pp. 135-151. Hampshire, UK: Ashgate.

Alberts, Heike. 2005. Changes in Ethnic Solidarity in Cuban Miami. The Geographical Review 95(2): 231-248.

Alberts, Heike. 2003. Rethinking the Ethnic Enclave Economy: Cubans in Miami, unpublished Ph.D. dissertation. Department of Geography, University of Minnesota.

Aldrich, Howard E. and Roger Waldinger. 1990. Ethnicity and Entrepreneurship. Annual Review of Sociology 16: 111-135.

Aldrich, John H. 1993. Rational Choice and Turnout. American Journal of Political Science 37(1): 246-278.

Alesina, Alberto F. and Eliana La Ferrara. 2000. The Determinants of Trust. NBER working paper series. Nr. 7621.

Allen, J.P. 2002. The Tortilla-Mercedes Divide in Los Angeles. Political Geography 21: 701-709.

Allport, Gordon W. 1954. The Nature of Prejudice. Reading, MA: Addison-Wesley. 
Almaguer, Tomás. 1998. The Master Narrative of White Supremacy in California. In Richard Delgado and Jean Stefancic (eds), The Latino/a Condition: A Critical Reader, pp. 165-179. New York, NY: New York University Press.

Almond, Gabriel A. and Sidney Verba. 1963. The Civic Culture: Political Attitudes and Democracy in Five Nations. Princeton, NJ: Princeton University Press.

Alreck, Pamela L. and Robert B. Settle. 2004. The Survey Research Handbook, $3^{\text {rd }}$ edition. Boston, MA: McGraw Hill Irwin.

Amaro, Hortensia and Ruth E. Zambrana. 2000. Criollo, Mestizo, Mulato, LatiNegro, Indigena, White, or Black? The US Hispanic/Latino Population and Multiple Responses in the 2000 Census. American Journal of Public Health 90(11): 1724-1727.

American Anthropological Association. 1998. Statement on Race, available at www.aaanet.org/stmts/racepp.htm [accessed September 2009].

Amin, Ash. 2005. Local Community on Trial. Economy and Society 34: 612-633.

Amin, Ash. 2004: Regions Unbound: Towards a New Politics of Place. Geografiska Annaler (series B) 86: 33-44.

Amin, Ash. 2002: Ethnicity and the Multicultural City: Living with Diversity. Environment and Planning A 34: 959-980.

Amin, Ash and Nigel Thrift. 2002. Guest Editorial: Cities and Ethnicities. Ethnicities 2(3): 291-300.

Andersen, Benedict. 1991 [1983]. Imagined Communities: Reflections on the Origins and Spread of Nationalism, Revised edition. London, UK: Verso.

Anderson, K. 1987. The Idea of Chinatown: The Power of Place and Institutional Practice in the Making of a Racial Category. Annals of the Association of American Geographers 77(4): 580-598.

Andolina, Molly W, Scott Keeter, Cliff Zukin and Krista Jenkins. 2003. A Guide to the Index of Civic and Political Engagement. CIRCLE: University of Maryland.

Andron, Scott. 2009. Homes out of reach for many, study finds. The Miami Herald 8 May: 3C.

Anisef, Paul and Michael Lanphier (eds). 2003. The World in a City. Toronto, Canada: University of Toronto Press. 
Anzaldúa, Gloria E. 1987. Borderlands/La Frontera: The New Mestiza. San Francisco, CA: Aunt Lute Books.

Archibold, Randal C. 2010. Arizona Enacts Stringent Law on Immigration. The New York Times, April 23, online edition, available at www.nytimes.com/2010/04/24/us/politics/24immig.html [accessed April 2010].

Arizona State Senate Fact Sheet for S.B. 1070. 2010. www.azleg.gov/legtext/49leg/2r/summary/s.1070pshs.doc.htm [accessed July 2010].

Arreola, Daniel D., Damián J. Fernández, Chris Lukinbeal, Patricia L. Price, Timothy Ready and Maria de los Angeles Torres. 2004. Comparative Civic and Place Engagement in Three Latino Enclave Neighborhoods in Transition. Unpublished grant proposal funded by the National Science Foundation Human and Social Dynamics Program.

Arreola, Daniel D. 2004. Introduction. In Daniel D. Arreola (ed), Hispanic Spaces, Latino Places: Community and Cultural Diversity in Contemporary America, pp. 1-12. Austin, TX: University of Texas Press.

Arreola, Daniel D. (ed). 2004. Hispanic Spaces, Latino Places: Community and Cultural Diversity in Contemporary America. Austin, TX: University of Texas Press.

Arrow, Kenneth. 1974. The Limits of Organization. New York, NY: Norton.

Arthur, Lisa. 2007. Hungry for Progress: Miami Remains Among the Nation's Poorest Large Cities. Miami Herald, no page given. 3 Nov, available at www.libertypost.org/cgi-bin/readart.cgi?ArtNum=205572 [accessed September 2009].

Arvizu, John R. and F. Chris Garcia. 1996. Latino Voting Participation: Explaining and Differentiating Latino Voting Turnout. Hispanic Journal of Behavioral Sciences 18(2): 104-128.

Babbie, Earl. 2005. The Basics of Social Research, $3^{\text {rd }}$ edition. Belmont, CA: Thomson Wadsworth.

Bach, Robert, Rodolfo de la Garza, Karen Ito, Louise Lamphere and Niara Sudarkasa. 1993: Changing Relations: Newcomers and Established Residents in U.S. Communities. New York, NY: Ford Foundation.

Bachelard, Gaston. 1994 [1958]. The Poetics of Space. Boston, MA: Beacon Press. 
Back, Les and Michael Keith. 1999. 'Rights and Wrongs': Youth, Community, and Narratives of Racial Violence. In Phil Cohen (ed), New Ethnicities, Old Racisms?, pp. 131-162. London, UK: Zed Books.

Banet-Weiser, Sarah. 2003. Elián González and 'the Purpose of America': Nation, Family and the Child-citizen. American Quarterly 55: 149-178.

Barber, Bernard. 1983. The Logic and Limits of Trust. New Brunswick, NJ: Rutgers University Press.

Bardach, Ann Louise. 2002. Cuba Confidential: Love and Vengeance in Miami and Havana. New York, NY: Random House.

Barker, Lucius J. and Mack H. Jones. 1994. African-Americans and the American Political System. $3^{\text {rd }}$ edition. Englewood Cliffs, NJ: Prentice Hall.

Barreto, Matt A., Sylvia Manzano, Ricardo Ramírez and Kathy Rim. 2009. Mobilization, Participation, and Solidaridad: Latino Participation in the 2006 Immigration Protest Rallies. Urban Affairs Review 44(5): 736-764.

Basch, Linda, Nina Glick-Schiller and Cristina Blanc-Szanton. 1994. Nations Unbound: Transnational Projects, Postcolonial Predicaments and Deterritorialized NationStates. Amsterdam, Netherlands: Gordon and Breach Science Publishers.

Basch, Linda, Nina Glick Schiller and Cristina Szanton-Blanc (eds). 1992. Toward a Transnational Perspective on Migration: Race, Class, Ethnicity, and Nationalism. New York, NY: New York Academy of Sciences.

Basso, Keith H. 1996. Wisdom Sites in Places: Landscape and Language Among the Western Apache. Albuquerque, NM: University of New Mexico Press.

Bauder, Harald. 2002. Neighborhood Effects and Cultural Exclusion. Urban Studies 39: 85-93.

Beach, Walter G. 1925. Levels of Immigrant Assimilation and the Community. Social Forces 4(2): 373-375.

Bean, Frank D. and Marta Tienda. 1987. The Hispanic Population of the United States. New York, NY: Russell Sage Foundation.

Becker, Lawrence C. 1996. Trust as Noncognitive Security about Motives. Ethics 10: 743-761. 
Bedford, Tracey and Jacquelin Burgess. 2001. The Focus-group Experience. In Melanie Limb and Claire Dwyer (eds), Qualitative Methodologies for Geographers: Issues and Debates, pp. 57-72. New York, NY: Oxford University Press.

Bell, Wendell and Maryanne T. Force. 1956. Urban Neighborhood Types and Participation in Formal Associations. American Sociological Review 21(1): 25-34.

Benitez, Cristina. 2007. Latinization: How Latino Culture Is Transforming the U.S. Ithaca, NY: Paramount Market Publishing.

Benjamin-Alvarado, Jonathan, Louis DeSipio and Celeste Montoya. 2009. Latino Mobilization in New Immigrant Destinations: The Anti-H.R. 4437 Protest in Nebraska's Cities. Urban Affairs Review 44(5): 718-735.

Benton-Short, Lisa, Marie Price and Samantha Friedman. 2005. Globalization from Below: The Ranking of Global Immigrant Cities. International Journal of Urban and Regional Research 29(4): 945-959.

Bernard, H. Russell. 2006. Research Methods in Anthropology: Qualitative and Quantitative Approaches. Lanham, MD: AltaMira Press.

Berry, Kate A. and Martha L. Henderson. 2002. Envisioning the Nexus Between Geography and Ethnic and Racial Identity. In Kate A. Berry and Martha L. Henderson (eds), Geographical Identities of Ethnic America: Race, Space, and Place, pp. 1-14. Reno, NV: University of Nevada Press.

Beyerlein, Kraig and John R. Hipp. 2005. Social Capital, Too Much of a Good Thing? American Religious Traditions and Community Crime. Social Forces 84(2): 9951013.

Blanchard, Brian. 1982 (December 23). Miami Refines Latin Quarter Concept. The Miami Herald.

Blue, Sarah A. 2005. From Exiles to Transnationals? Changing State Policy and the Emergence of Cuban Transnationalism. In Damián J. Fernández (ed), Cuba Transnational, pp. 24-41. Gainesville, FL: University Press of Florida.

Boas, Franz. 1982 [1940]. Race, Language, and Culture. Chicago, IL: University of Chicago Press.

Boas, Franz. 1922. Report on an Anthropometric Investigation of the Population of the United States. Journal of the American Statistical Association June.

Boas, Franz. 1912. The History of the American Race. Annals of the New York Academy of Sciences 21: 177-183. 
Boas, Franz. 1906. The Measurement of Differences Between Variable Quantities. New York, NY: The Science Press. (Online version at the Internet Archive)

Bobo, Lawrence. 1988. Group Conflict, Prejudice, and the Paradox of Contemporary Racial Attitudes. In Phyllis A. Katz and Dalmas A. Taylor (eds), Eliminating Racism: Profiles in Controversy, pp. 85-114. New York, NY: Plenum Press Books.

Bobo, Lawrence and Franklin D. Gilliam, Jr. 1990. Race, Sociopolitical Participation, and Black Empowerment. American Political Science Review 84(2): 377-393.

Bohon, Stephanie. 2001. Latinos in Ethnic Enclaves: Immigrant Workers and the Competition for Jobs. New York, NY: Garland Publishing.

Bonacich, Edna. 1980. Middleman Minorities and Advanced Capitalism. Ethnic Groups 2: 211-220.

Bonacich, Edna. 1973. A Theory of Middleman Minorities. American Sociological Review 38: 583-594.

Booth, William 1998. A White Migration North From Miami. Washington Post, November 11 , online edition, available at www.washingtonpost.com/wpsrv/national/longterm/meltingpot/melt1109.htm [accessed May 2010].

Borjas, George J. 1994. The Economics of Immigration. Journal of Economic Literature 32(4): 1667-1717.

Boswell, Thomas D. and Terry-Ann Jones. 2007. Caribbean Hispanics: Puerto Ricans, Cubans, and Dominicans. In Ines M. Miyares and Christopher A. Airriess (eds), Contemporary Ethnic Geographies in America, pp. 123-150. Lanham, MD: Rowman and Littlefield.

Boswell, Thomas D., June Nogle, Rob Paral and Richard Langendorf. 2001. Facts About Immigration and Asking "Six Big Questions" for Florida and Miami-Dade County. Gainesville, FL: Bureau of Economic and Business Research, University of Florida.

Boswell, Thomas D. and Angel David Cruz-Báez. 1997. Residential Segregation by Socioeconomic Class in Metropolitan Miami: 1990. Urban Geography 18(5): 474496.

Boswell, Thomas D. and James R. Curtis. 1984. The Cuban-American Experience: Culture, Images, and Perspectives. Totowa, NJ: Rowman and Allanheld. 
Bourdieu, Pierre. 1983. The Forms of Capital. In John G. Richardson (ed), Handbook of Theory and Research for the Sociology of Education, pp. 241-258. New York, NY: Greenwood Press.

Bourne, Larry S. 2008: On Schools of Thought, Comparative Research, and Inclusiveness: A Commentary. Urban Geography 29(2): 177-186.

Boyd, Monica. 2002. Educational Attainments of Immigrant Offspring: Success or Segmented Assimilation? International Migration Review 36(4): 1037-1060.

Boyd, Monica. 1989. Family and Personal Networks in International Migration: Recent Developments and New Agnedas. International Migration Review 23(3): 638-670.

Brady, Henry E., Sidney Verba, and Kay Lehman Schlozman. 1995. Beyond SES: A Resource Model of Political Participation. APSR 89: 271- 294.

Brehm, John and Wendy Rahn. 1997. Individual Level Evidence for the Causes and Consequences of Social Capital. American Journal of Political Science 41: 9991023.

Breiger, Ronald and Philippa Pattison. 1978. The Joint Role of Structure of Two Communities' Elites. Sociological Methods and Research 7(2): 213-226.

Brenner, Neil and Nik Theodore. 2002. Cities and the Geographies of Actually-existing Neoliberalism. Antipode 33: 349-379.

Brettell, Caroline B. 2003: Bringing the City Back In: Cities as Context for Immigrant Incorporation. In Nancy Foner (ed), American Arrivals: Anthropology Engages the New Immigration, pp. 163-195. Santa Fe, NM: School of American Research.

Brettell, Caroline B. 2000. Theorizing Migration in Anthropology. In Caroline B. Brettell and James F. Hollifield (eds), Migration Theory: Talking Across Disciplines, pp. 97-135. New York, NY: Routledge.

Brettell, Caroline B. and James F. Hollifield. 2000. Introduction. In Caroline B. Brettell and James F. Hollifield (eds), Migration Theory: Talking Across Disciplines, pp. 1-26. New York, NY: Routledge.

Brewer, Marilynn. 1981. Ethnocentrism and Its Role in Interpersonal Trust. In Marilyn B. Brewer and Barry E. Collins (eds), Scientific Inquiry and the Social Sciences, pp. 345-359. San Francisco, CA: Jossey-Bass Publishers.

Brody, Richard A. 1978. The Puzzle of Political Participation in America. In Anthony King (ed), The New American Political System, pp. 287-324. Washington, DC: American Enterprise Institute. 
Brooks, A.C. and G. B. Lewis. 2001. Giving, Volunteering, and Mistrusting Government. Journal of Policy Analysis and Management 20(4): 765-769.

Brubaker, Rogers. 2001. The Return of Assimilation? Changing Perspectives on Immigration and Its Sequels in France, Germany, and the United States. Ethnic and Racial Studies 24(4): 531-548.

Buck, Nick. 2001. Identifying Neighborhood Effects on Social Exclusion. Urban Studies 38: $2251-2275$.

Burkholz, Herbert. 1980. The Latinization of Miami. The New York Times Magazine. 21 September: pp. 45-46, 84-88, 98-99.

Burns, Nancy and Donald Kinder. 2000. Social Trust and Democratic Politics. Report to the National Election Studies Board. Based on the 2000 NES Special Topic Pilot Study.

Cain, Bruce E., D. Roderick Kiewiet and Carole J. Uhlaner. 1991. The Acquisition of Partinsanship by Latinos and Asian-Americans. American Journal of Political Science 35(2): 390-422.

Calderón, José. 1992. "Hispanic" and "Latino": The Viability of Categories for Panethnic Unity. Latin American Perspectives 19(4): 37-44.

Calhoun, Craig. 1993. Civil Society and the Public Sphere. Public Culture 52: 67-80.

Cameron, Jenny. 2000. Focussing on the Focus Group. In Iain Hay (ed), Qualitative Research Methods in Human Geography, pp. 116-132. Oxford, UK: Oxford University Press.

Campbell, Angus, Philip E. Converse, Warren E. Miller and Donald Stokes. 1960. The American Voter. New York, NY: Wiley.

Campbell, Mary E. and Christabel L. Rogalin. 2006. Categorical Imperatives: The Interaction of Latino and Racial Identification. Social Science Quarterly 87(5): 1030-1052.

Cassola, Jose. 2010. Doral, Sweetwater, West Miami show support for Ladies White. The Miami Herald March 28: NW6.

Carton, Paul. 1984. Mobilizing the Black Community: The Effects of Personal Contact Campaigning on Black Voters. Washington, DC: Joint Center for Political Studies. 
Castells, Manuel. 1977. The Urban Question: A Marxist Approach. Cambridge, MA: The MIT Press.

Castles, Stephen and Mark J. Miller. 2003. The Age of Migration: International Population Movements in the Modern World. Basingstoke, UK: Palgrave MacMillan.

Cervantes-Rodriguez, Ana Margarita. 2006. Nicaraguans in Miami-Dade County: Immigration, Incorporation, and Transnational Entrepreneurship. Latino Studies 4: 232-257.

Chacko, Elizabeth. 2003: Ethiopian Ethos and the Making of Ethnic Places in the Washington Metropolitan Area. Journal of Cultural Geography 93: 21-42.

Chai, Karen Jun Won. 2000. Protestant-Catholic-Buddhist: Korean Americans and Religious Adaptation in Greater Boston, unpublished Ph.D. dissertation. Department of Sociology: Harvard University.

Chang, Derek. 2005. "Brought Together upon Our Own Continent": Race, Religion, and Evangelical Nationalism in American Baptist Home Missions, 1865-1900. In Karen I. Leonard, Alex Stepick, Manuel A. Vásquez, and Jennifer Holdaway (eds), Immigrant Faiths: Transforming Religious Life in America, pp. 39-65. Walnut Creek, CA: AltaMira Press.

Cheong, Pauline H., Rosalind Edwards, Harry Gouldbourne and John Solomos. 2007. Immigration, Social Cohesion and Social Capital: A Critical Review. Critical Social Policy 27: 24-45.

Cho, Wendy K. Tam. 1999. Naturalization, Socialization, Participation: Immigrants and (non)Voting. Journal of Politics 61(4): 1140-1155.

Chomsky, Aviva. 2007. "They Take Our Jobs!” and 20 Other Myths About Immigration. Boston, MA: Beacon Press.

Clark, Terry Nichols. 2008. Program for a New Chicago School. Urban Geography 29(2): 154-166.

Clark, William and Sarah Blue. 2004. Race, Class, and Segregation Patterns in U.S. Immigrant Gateway Cities. Urban Affairs Review 39(6): 667-688.

Coffey, Amanda and Paul Atkinson. 1999. Making Sense of Qualitative Data: Complementary Strategies. London, UK: Sage.

Cohen, Abner. 1974. Introduction: The Lesson of Ethnicity. In Abner Cohen (ed), Urban Ethnicity, pp. ix-xxiv. London, UK: Travistock. 
Cohen, Cathy J. and Michael Dawson. 1993. Neighborhood Poverty and AfricanAmerican Politics. American Political Science Review 87(2): 286-302.

Cohen, Phil A. 1999. Through a Glass Darkly: Intellectuals on Race. In Phil Cohen (ed), New Ethnicities, Old Racisms?, pp. 1-17. London, UK: Zed Books.

Cohen, Ronald. 1978. Ethnicity: Problem and Focus in Anthropology. Annual Review of Anthropology 7: 379-403.

Coleman, James S. 1990. Foundations of Social Theory. Cambridge, MA: Harvard University Press.

Coleman, James S. 1988. Social Capital in the Creation of Human Capital. American Journal of Sociology 94: 95-120.

Committee on Transforming our Common Destiny: Hispanics in the US, and National Research Council. 2006. Multiple Origins, Uncertain Destinies: Hispanics and the American Future. Washington, DC: National Academies Press.

Conroy, Stephen J. and David M. Heer. 2003. Hidden Hispanic Homelessness in Los Angeles: The "Latino Paradox" Revisited. Hispanic Journal of Behavioral Sciences 25(4): 530-538.

Conway, M. Margaret. 1991. Political Participation in the United States. Washington, DC: Congressional Quarterly Press.

Conzen, Kathleen N. 1979. Immigrants, Immigrant Neighborhoods, and Ethnic Identity: Historical Issues. The Journal of American History 66(3): 603-615.

Conzen, Michael P. and Richard P. Greene. 2008. Introduction: All The World Is Not Los Angeles, Nor Chicago: Paradigms, Schools, Archetypes, and the Urban Process. Urban Geography 29(2): 97-100.

Cook, Karen S. 2005. Networks, Norms, and Trust: The Social Psychology of Social Capital: 2004 Cooley Mead Award Address. Social Psychology Quarterly 68: 414.

Cooley, Charles H. 1918. Social Process. New York, NY: Charles Scribner's Sons.

Cooley, Charles H. 1909. Social Organization: a Study of the Larger Mind, New York, NY: Charles Scribner's Sons

Cooley, Charles H. 1922 [1902]. Human Nature and the Social Order, New York, NY: Charles Scribner's Sons. 
Cornell, Stephen F. and Douglas Hartmann. 2007. Ethnicity and Race: Making Identities in a Changing World. $2^{\text {nd }}$ edition. Thousand Oaks, CA: Pine Forge Press. Chapter 1, "The Puzzle of Ethnicity and Race" (pp. 1-14), Chapter 2, "Mapping the Terrain: Definitions" (pp. 15-38), Chapter 3, "Fixed or Fluid? Alternative Views of Ethnicity and Race" (pp. 39-71).

Cornell, Stephen F. and Douglas Hartmann. 2004. Conceptual Confusions and Divides: Race, Ethnicity, and the Study of Immigration. In Nancy Foner and George M. Frederickson (eds), Not Just Black and White: Historical and Contemporary Perspectives on Immigration, Race, and Ethnicity in the United States, pp. 2341. New York, NY: Russell Sage.

Cornell, Stephen F. and Douglas Hartmann. 1998. Ethnicity and Race. Thousand Oaks, CA: Sage.

Crang, Mike. 2001. Filed Work: Making Sense of Group Interview. In Melanie Limb and Claire Dwyer (eds), Qualitative Methodologies for Geographers: Issues and Debates, pp. 215-233. New York, NY: Oxford University Press.

Crang, Mike. 2000. Public Space, Urban Space and Electronic Space: Would the Real City Please Stand Up? Urban Studies 37(2): 301-317.

Crèvecoeur, John Hector St. John de. 1782. Letters from an American Farmer: Describing Certain Provincial Situations, Manners, and Customs, Not Generally Known; and Conveying Some Idea of the Late and Present Interior Circumstances of the British Colonies of North America.

Croucher, Sheila. 2002. Miami in the 1990s: 'City of the Future' or 'City on the Edge'? Journal of International Migration and Integration 3(2): 223-239.

Croucher, Sheila. 1997. Imagining Miami: Ethnic Politics in a Postmodern World. Charlottesville, VA: University of Virginia Press.

CRUSADA (Center for Research on US Latino AIDS/HIV and Drug Abuse). 2007. Miami Dade County. Miami, FL: Florida International University, available at http://crusada.fiu.edu/AB miamiDoc.cfm [accessed September 2009].

D’Arcus, Bruce. 2006. Boundaries of Dissent: Protest and State Power in the Media Age. Abingdon, UK: Routledge.

Dasgupta, Partha. 1988. Trust as a Commodity. In D. Gambetta (ed), Trust: Making and Breaking Cooperative Relations, pp. 46-72. New York, NY: Basil Blackwell.

Dávila, Arlene. 2008. Latino Spin: Public Image and the Whitewashing of Race. New York, NY: New York University Press. 
Dávila, Arlene. 2004. Barrio Dreams: Puerto Ricans, Latinos, and the Neoliberal City. Berkeley, CA: University of California Press.

Dávila, Arlene. 2001. Latinos, Inc. The Marketing and Making of a People. Berkeley, CA: University of California Press.

Davis, Mike L. 2000. Magical Urbanism: Latinos Reinvent the U.S. City. London, UK: Verso.

Davis, Mike L. 1990. City of Quartz: Excavating the Future in Los Angeles. New York, NY: Verso.

Dawkins, Casey J., Michael Reibel and David W. Wong. 2007. Introduction: Further Innovations in Segregation and Neighborhood Change Research. Urban Geography 28(6): 513-515.

Dawson, Michael C., Ronald E. Brown and Richard L. Allen. 1990. Racial Belief Systems, Religious Guidance, and African-American Political Participation. National Political Science Review 2(1): 22-44.

De Genova, Nicholas and Ana Y. Ramos-Zayas. 2003. Latino Crossings: Mexicans, Puerto Ricans, and the Politics of Race and Citizenship. New York, NY: Routledge.

de la Garza, Rodolfo O. 1992. Latino Politics: A Futuristic View. National Political Science Review 3: 137-144.

de la Garza, Rodolfo O. 1982. Chicano-Mexican Relations: A Framework for Research. Social Science Quarterly 63: 115-130.

de la Garza, Rodolfo O. and Louis DeSipio (eds). 1999. Awash in the Mainstream: Latino Politics in the 1996 Elections. Boulder, CO: Westview Press.

de la Garza, Rodolfo O., Angelo Falcon and F. Chris Garcia. 1996. Will the Real Americans Please Stand Up: Anglo and Mexican Support of Core American Political Values. American Journal of Political Science 40: 335-351.

de la Garza, Rodolfo O., Martha Menchaca and Louis DeSipio (eds). 1994. Barrio Ballots: Latino Politics in the 1990 Elections. Boulder, CO: Westview Press.

de la Garza, Rodolfo O., Louis DeSipio, F. Chris Garcia, John García, and Angelo Falcon. 1992. Latino Voices: Mexican, Puerto Rican, and Cuban Perspectives on American Politics. Boulder, CO: Westview Press. 
De La Torre, Miguel A. 2003. La Lucha for Cuba: Religion and Politics on the Streets of Miami. Berkeley, CA: University of California Press.

De Oliver, Miguel and Teresa Dawson-Muñoz. 1996. Place-not-race? The Inadequacy of Geography to Address Racial Disparities. The Review of Black Political Economy 25(2): 37-60.

De Valle, Elaine. 1997 (June 19). Merchants Want To Expand Little Havana's Borders. The Miami Herald.

De Vaus, David A. 1991. Surveys in Social Research, $3^{\text {rd }}$ edition. North Sydney, Australia: Allen and Unwin.

Dear, Michael J. 2003. The Los Angeles School of Urbanism: An Intellectual History. Urban Geography 24(6): 493-509.

Dear, Michael J. (ed). 2002a: From Chicago to L.A.: Making Sense of Urban Theory. Thousand Oaks, CA: Sage.

Dear, Michael J. 2002b. The L.A. School: A Personal Introduction. In Michael J. Dear (ed), From Chicago to L.A.: Making Sense of Urban Theory, pp. 423-426. Thousand Oaks, CA: Sage.

Dear, Michael J. 2002c. Los Angeles and the Chicago School: Invitation to a Debate. City and Community 1: 5-32.

Dear, Michael J. 2002d. The Resistible Rise of the L.A. School. In Michael J. Dear and J. Dallas Dishman (eds), From Chicago to L.A.: Making Sense of Urban Theory, pp. 5-16. Thousand Oaks, CA: Sage.

Dear, Michael, Andrew Burridge, Peter Marlot, Jacob Peters and Mona Seymour. 2008. Critical Responses to the Los Angeles School of Urbanism. Urban Geography 29(2): 101-112.

Dear, Michael and Nicholas Dahmann. 2008. Urban Politics and the Los Angeles School of Urbanism. Urban Affairs Review 44(2): 266-279.

Dear, Michael J. and Steven Flusty. 1998. Postmodern Urbanism. Annals of the Association of American Geographers 88(1): 50-72.

Dear, Michael J., H. Eric Schockman and Greg Hise (eds). 1996. Rethinking Los Angeles. New York, NY: Sage.

DeFilippis, James. 2001. The Myth of Social Capital in Community Development. Housing Policy Development 12: 781-806. 
Dekker, Paul and Eric M. Uslaner (eds). 2001. Social Capital and Participation in Everyday Life. New York, NY: Routledge.

Delameter, John, Daniel Katz and Herbert C. Kelman. 1969. On the Nature of National Involvement: A Preliminary Study. Journal of Conflict Resolution 13: 320-357.

Delhey, Jan and Kenneth Newton. 2005. Predicting Cross-National Levels of Social Trust: Global Pattern or Nordic Exceptionalism? European Sociological Review 21(4): 311-327.

Denton, Nancy A. and Douglas S. Massey. 1991. Patterns of Neighborhood Transition in a Multiethnic World: U.S. Metropolitan Areas, 1970-1980. Demography 28: 4163.

Denzin, Norman K. 1978. Sociological Methods: A Sourcebook. New York, NY: McGraw Hill.

DeSipio, Louis. 2006. Transnational Politics and Civic Engagement: Do Home-Country Political Ties Limit Latino Immigrant Pursuit of U.S. Civic Engagement and Citizenhip? In Taeku Lee, S. Karthick Ramakrishnan and Ricardo Ramírez (eds), Transforming Politics, Transforming America: The Political and Civic Incorporation of Immigrants in the United States, pp. 106-126. Charlottesville, VA: University of Virginia Press.

DeSipio, Louis. 1996. Making Citizens or Good Citizens? Naturalization as a Predictor of Organization and Electoral Behavior among Latino Immigrants. Hispanic Journal of Behavioral Sciences 18(2): 194-213.

DeSipio, Louis and James. R. Henson. 1997. Cuban Americans, Latinos and the Print Media. Harvard International Journal of Press/Politics 2: 52-70.

DeWind, Josh and Philip Kasinitz. 1997. Everything Old is New Again? Processes and Theories of Immigrant Incorporation. International Migration Review 31(4): 1096-1111.

Diaz, William A. 1996. Latino Participation in America: Associational and Political Roles. Hispanic Journal of Behavioral Sciences 18(2): 154-175.

Dluhy, Milan J., Keith Revell and Sidney Wong. 2002. Creating a Positive Future for a Minority Community: Transportation and Urban Renewal Politics in Miami. Journal of Urban Affairs 24(1): 75-95.

Dluhy, Milan J. and Howard A. Frank. 2002. The Miami Fiscal Crisis: Can a Poor City Regain Prosperity? Westport, CT: Praeger. 
Doane, Jr., Ashley W. 1997. Dominant Group Ethnic Identity in the United States: The Role of "Hidden" Ethnicity in Intergroup Relations. The Sociological Quarterly 38(3): 375-397.

Dovidio, John and Samuel Gaertner. 1999. Reducing Prejudice: Combating Inter-group Bias. In American Psychological Association, Current Directions in Psychological Science, pp. 101-105.

Du Bois, W.E.B. 1899 [2007 reprint]. The Philadelphia Negro: A Social Study. New York, NY: Oxford University Press.

Duncan, James S. and Nancy G. Duncan. 2004. Landscapes of Privilege: The Politics of the Aesthetic in an American Suburb. New York, NY: Routledge.

Dunn, Marvin. 1997. Black Miami in the Twentieth Century. Gainesville, FL: University of Florida Press.

Durkheim, Émile. 1984 [1893]. The Division of Labor in Society. New York, NY: The Free Press.

Durkheim, Emile. 1964. Suicide. New York, NY: Free Press.

Durlauf, Steven N. 2002. Bowling Alone: A Review Essay. Journal of Economic Behavior \& Organization 47: 259-273.

Ebaugh, Helen Rose and Janet Saltzman Chafetz. 2000. Religion and the New Immigrant: Continuities and Adaptations in Immigrant Congregations. Walnut Creek, CA: AltaMira Press.

Edmondson, Ricca. 2001. Studying Civic Culture Ethnographically and What It Tells Us about Social Capital: Communities in the West of Ireland. In Paul Dekker and Eric M. Uslaner (eds), Social Capital and Participation in Everyday Life, pp. 5972. London, UK: Routledge.

El Guindi, Fadwa. 1998. From Pictorializing to Visual Anthropology. In H. Russell Bernard (ed), Handbook of Methods in Cultural Anthropology, pp. 459-511. Walnut Creek, CA: Altamira Press.

Ellis, Mark. 2006. Unsettling Immigrant Geographies: U.S. Immigration and the Politics of Scale. Tijdschrift voor Economische en Sociale Geografie97(1): 49-58.

Ellis, Mark, Richard Wright and Virginia Parks. 2004. Work Together, Live Apart? Geographies of Racial and Ethnic Segregation at Home and at Work. Annals of the Association of American Geographers 94(3): 620-637. 
Elwood, Sarah and Helga Leitner. 2003. Community-based Planning and GIS: Aligning Neighborhood Organizations with State Priorities? Journal of Urban Affairs 25: Pp. 77-89.

Engh, Michael E. 2000. At Home in the Heteropolis: Understanding Postmodern L.A. The American Historical Review 105(5): 1676-1682.

Escobar, Arturo. 2001. Culture Sits in Places: Reflections on Globalism and Subaltern Strategies of Localization. Political Geography 20: 243-263.

Espiritu, Yen Le. 1992. Asian American Panethnicity: Bridging Institutions and Identities. Philadelphia, PA: Temple University Press.

Fainstein, Susan S. 2005. Cities and Diversity: Should We Want It? Can We Plan For It? Urban Affairs Review 41(3): 3-19.

Fernández, Damián J. 2001. Why I Love to Love Donna Summer: The United States, Cuba and the Politics of Culture. Georgetown Journal of International Affairs 2(2): 59-66.

Fernández, Damián J. 2000. Cuba and the Politics of Passion. Austin, TX: University of Texas Press.

Fernández, Damián, J. 1987. From Little Havana to Washington D.C.: Cuban-Americans and U.S. Foreign Policy. In Mohammed Ahrari (ed), Ethnic Politics and U.S. Foreign Policy, pp. 115-134. Westport, CT: Greenwood Press.

Fitzgerald, Edmund V. P. 1987. An Evaluation of the Economic Costs to Nicaragua of US Aggression: 1980-1984. In Rose J. Spalding (ed), The Political Economy of Revolutionary Nicaragua, pp. 195-213. Boston: Allen and Unwin.

Fitzgerald, Edmund V. P. 1985. Agrarian Reform as a Model of Accumulation: The Case of Nicaragua since 1979. The Journal of Development Skills 22(1): 208-226.

Flanagan, Constance and Nakesha Faaison. 2001. Youth Civic Development: Implications of Research for Social Policy and Programs. Social Policy Report 15(1): 3-15.

Flores, Juan. 2000. From Bomba to Hip-Hop: Puerto Rican Culture and Latino Identity. New York, NY: Columbia University Press.

Flores, William V. and Rina Benmayor (eds). 1997. Latino Cultural Citizenship: Claiming Identity, Space, and Rights. Boston, MA: Beacon Press. 
Foley, Michael W. and Robert Edwards. 1999. Is it Time to Disinvest in Social Capital? Journal of Public Policy 19(2): 141-172.

Foner, Nancy. 2005. In a New Land: A Comparative View of Immigration. New York, NY: New York University Press.

Foner, Nancy (ed). 2003. American Arrivals: Anthropology Engages the New Immigration. Santa Fe, NM: School of American Research Press.

Foner, Nancy. 2001. Immigrant Commitment to American, Then and Now: Myths and Realities. Citizenship Studies 5(1): 27-40.

Foner, Nancy and Richard Alba. 2006. The Second Generation from the Last Great Wave of Immigration: Setting the Record Straight. Migration Information Source. www.migrationinformation.org/feature/display.cfm?ID=439.

Foner, Nancy and George M. Frederickson. 2004. Immigration, Race, and Ethnicity in the United States: Social Constructions and Social Relations in Historical and Contemporary Perspective. In Nancy Foner and George M. Frederickson (eds), Not Just Black and White: Historical and Contemporary Perspectives on Immigration, Race, and Ethnicity in the United States, pp. 1-19. New York, NY: Russell Sage.

Foot, John. San Salvario, Turin: The Creation of a Dangerous Place, 1990-99. 2001. In Russell King (ed), The New Mediterranean Passage: Migration and New Cultural Encounters in South Europe, pp. 206-230. Liverpool, UK: Liverpool University Press.

Forrest, James and Ron Johnston. 2001. The Geography of the New Ethnicity: Ethnic Residential Segregation in Metropolitan Sydney, 1996. Tijdschrift voor Economische en Sociale Geografie 92(1): 42-59.

Forrest, Ray and Ade Kearns. 2001. Social Cohesion, Social Capital and the Neighborhood. Urban Studies 38: 2125-2143.

Fortney, Judith. 1972. Immigrant Professionals: A Brief Historical Survey. International Migration Review 6(1): 50-63.

Fowler, Floyd J. 2001. Survey Research Methods, $3^{\text {rd }}$ edition. Thousand Oaks, CA: Sage.

Fox, Geoffrey. 1997. Hispanic Nation: Culture, Politics, and the Construction of Identity. Tucson, AZ: University of Arizona Press. 
Fraga, Luis R. and Gary M. Segura. 2006. Culture Clash? Contesting Notions of American Identity and the Effects of Latin American Immigration. Perspectives 4(2): 279-287.

Frank, Kenneth A. and Jeffrey Y. Yasumoto. 1998. Linking Action to Social Structure within a System: Social Capital within and between Subgroups. American Journal of Sociology 104(3): 642-686.

Franklin, Benjamin. 1961 [1706-1782]. Observations Concerning the Increase of Mankind, Peopling of Countries, etc. In The Papers of Benjamin Franklin. Vol. 4. July 1, 1750 through June 30, 1753. New Haven, CT: Yale University Press.

Fraser, James C., 2004. Beyond Gentrification: Mobilizing Communities and Claiming Space. Urban Geography 25(5): 437-457.

Frazier, John and Florence Margai (eds). 2003. Multicultural Geographies: the Changing Racial/Ethnic Patterns of the United States. Binghamton, NY: Global Academic Publishing.

Freeman, Lance. 2006. There Goes the 'hood: Views of Gentrification from the Ground Up. Philadelphia, PA: Temple University Press.

Frey, William H. and Reynolds Farley. 1996. Latino, Asian, and Black Segregation in the U.S. Metropolitan Areas: Are Multiethnic Metros Different? Demography 33: $35-50$.

Friedman-Kasaba, Kathie. 1996. Memories of Migration: Gender, Ethnicity, and Work in the Lives of Jewish and Italian Women in New York, 1870-1924. Albany, NY: State University of New York Press.

Fuchs, Lawrence H. 1990. The American Kaleidoscope: Race, Ethnicity and the Civic Culture. Hanover, NH: University Press of New England.

Fukuyama, Francis. 1995. Trust: The Social Virtues and the Creation of Prosperity. New York, NY: Free Press.

Furuseth, Owen J. and Heather A. Smith. 2006. From Winn-Dixie to Tiendas: The Remaking of the New South. In Heather A. Smith and Owen J. Furuseth (eds), Latinos in the New South: Transformations of Place, pp. 1-17. Hampshire, UK: Ashgate.

Gaertner, Samuel, Mary Rust, John Dovidio, Betty Bachman and Phyllis Anastasio. 1996. The Contact Hypothesis: The Role of Common Ingroup Identity on Reducing Intergroup Bias Among Majority and Minority Members. In Judith L. 
Nye and Aaron M. Brower (eds), What's Social About Social Cognition?, pp. 230-260. Newbury Park, CA: Sage Publications.

Galster, George C. 2001. On the Nature of Neighborhood. Urban Studies 38: 2111-2124.

Galster, George C. 1986. What is Neighborhood? An Externality-space Approach. International Journal of Urban and Regional Research 10: 243-263.

Gans, Herbert J. 1997. Toward a Reconciliation of "Assimilation" and "Pluralism": The Interplay of Acculturation and Ethnic Retention. International Migration Review 31(4): 875-892.

Gans, Herbert J. 1992. Second Generation Decline: Scenarios for the Economic and Ethnic Futures of Post-1965 American Immigrants. Ethnic and Racial Studies 15: 173-192.

Gans, Herbert J. 1979. Symbolic Ethnicity: The Future of Ethnic Groups and Cultures in America. Ethnic and Racial Studies 2: 1-20.

Gans, Herbert J. 1973. Introduction. In Neil Sandberg (ed), Ethnic Identity and Assimilation: The Polish Community, pp. vii-xii. New York, NY: Praeger.

Gans, Herbert J. 1962. The Urban Villagers. New York, NY: Free Press.

García, María Cristina. 2007. Refugees or Economic Immigrants? Immigration from Latin America and the Politics of US Refugee Policy. In Juan Flores and Renato Rosaldo (eds), A Companion to Latino/a Studies, pp. 480-491. Oxford, UK: Blackwell.

García, María Cristina. 1996. Havana USA: Cuban Exiles and Cuban Americans in South Florida. Berkeley, CA: University of California Press.

García Bedolla, Lisa. 2006. Rethinking Citizenship: Noncitizen Voting and Immigrant Political Engagement in the United States. In Taeku Lee, S. Karthick Ramakrishnan and Ricardo Ramírez (eds), Transforming Politics, Transforming America: The Political and Civic Incorporation of Immigrants in the United States, pp. 51-70. Charlottesville, VA: University of Virginia Press.

Geertz, Clifford. 1996. Primordial Ties. In John Hutchinson and Anthony D. Smith (eds), Ethnicity, pp. 40-45. Oxford, UK: Oxford University Press.

Geertz, Clifford. 1994. Primordial Loyalties and Standing Entities: Anthropological Reflections on the Politics of Identity. Delivered at Collegium Budapest on 13 December 1993. Printed as Public Lectures No. 7. Collegium Budapest/Institute for Advanced Study. 
Geertz, Clifford. 1973. The Interpretation of Cultures: Selected Essays. New York, NY: Basic Books.

George, Paul S. 2006. Images of America: Little Havana. Charleston, SC: Arcadia.

Gerstle, Gary and John Mollenkopf (eds). 2001. E Pluribus Unum? Immigrants, Civic Life, and Political Incorporation. New York, NY: Russell Sage Foundation.

Gibson, Margaret A. 1988. Accommodation without Assimilation: Sikh Immigrants in an American High School. Ithaca, NY: Cornell University Press.

Giddens, Anthony. 1990. The Consequences of Modernity. Stanford, CA: Stanford University Press.

Gittell, Ross and Avis Vidal. 1998. Community Organization: Building Social Capital as a Development Strategy. London, UK: Sage Publications.

Glanville, Jennifer L. and Pamela Paxton. 2007. How Do We Learn to Trust? A Confirmatory Tetrad Analysis of the Sources of Generalized Trust. Social Psychology Quarterly 70(3): 230-242.

Glazer, Nathan, and Daniel Patrick Moynihan. 1970 [1963]. Beyond the Melting Pot: The Negroes, Puerto Ricans, Jews, Italians, and Irish of New York City, $2^{\text {nd }}$ edition. Cambridge, MA: MIT Press.

Gleason, Philip. 1980. American Identity and Americanization. In Stephen Thernstrom (ed), Harvard Encyclopedia of American Ethnic Groups, pp. 31-58. Cambridge, MA: Belknap Press of Harvard University.

Glick Schiller, Nina, Linda Basch and Cristina Blanc-Szanton. 1992. Towards a Transnational Perspective on Migration: Race, Class, Ethnicity and Nationalism Reconsidered. Annals of the New York Academy of Sciences 645.

Goist, Park Dixon 1971. City and 'Community': The Urban Theory of Robert Park. American Quarterly 23(1): 46-59.

Goldberg, David T. 1998. The New Segregation. Race and Society 1: 15-32.

Goldfarb, Carl. 1990. Latin Quarter: 2 Words Start a Miami Mini-War. The Miami Herald October 18.

Golledge, Reginald G and Robert J. Stimson. 1997. Spatial Behavior: A Geographic Perspective. New York, NY: Guilford Press. 
Gordon, Milton M. 1964. Assimilation in American Life: The Role of Race, Religion, and National Origins. New York, NY: Oxford University Press.

Gottdiener, Mark and Joe R. Feagin. 1988. The Paradigm Shift in Urban Sociology. Urban Affairs Quarterly 24: 163-187.

Goździak, Elźbieta M. and Susan F. Martin (eds). 2005. Beyond_the Gateway: Immigrants in a Changing America. Lanham, MD: Lexington Books.

Gracia, Jorge J. E. 2000. Hispanic/Latino Identity: A Philosophical Perspective. Malden, MA: Blackwell.

Granovetter, Mark S. 1985. Economic Action and Social Structure: The Problem of Embeddedness. American Journal of Sociology 91(3): 481-510.

Granovetter, Mark S. 1983. The Strength of Weak Ties: A Network Theory Revisited. Sociological Theory 1: 201-233.

Granovetter, Mark S. 1973. The Strength of Weak Ties. American Journal of Sociology 78: $1360-1380$.

Greenfield, Patricia. 1997. Understanding Intergroup Relations through Understanding Cross-Cultural Differences in Basic Value Orientations. Los Angeles, CA: UCLA.

Gregory, Derek. 1981. Human Agency and Human Geography. Transactions of the Institute of British Geographers 6(1): 1-18.

Grenier, Guillermo J. and Lisandro Perez. 2003. The Legacy of Exile: Cubans in the United States. Boston, MA: Allyn and Bacon.

Grenier, Guillermo J. and Max J. Castro. 1999. Triadic Politics: Ethnicity, Race, and Politics in Miami, 1959-1998. The Pacific Historical Review 68(2): 273-292.

Grenier, Guillermo J. and Alex Stepick (eds). 1992. Miami Now! Immigration, Ethnicity, and Social Change. Gainesville, FL: University of Florida Press.

Grieco, Elizabeth M. and Rachel C. Cassidy. 2001. Overview of Race and Hispanic Origin: Census 2000 Brief. U.S. Census Bureau, available at www.census.gov/prod/2001pubs/cenbr01-1.pdf [accessed September 2009].

Grootaert, Christiaan, Deepa Narayan, Veronica Nyhan Jones and Michael Woolcock. 2004. Measuring Social Capital: An Integrated Questionnaire. World Bank Working Paper No. 18. Washington, DC: The World Bank. 
Gualtieri, Sarah M. 2001. Becoming "White": Race, Religion and the Foundations of Syrian/Lebanese Ethnicity in the United States. Journal of American Ethnic History 20(4): 29-58.

Guarnizo, Luis Eduardo. 2001. On the Political Participation of Transnational Migrants. In Gary Gerstle ad John Mollenkopf (eds), E Pluribus Unum? Immigrants, Civic Life, and Political Incorporation, pp. 213-263. New York, NY: Russell Sage Foundation.

Guarnizo, Luis Eduardo, Arturo I. Sánchez, and Elizabeth M. Roach. 1999. Mistrust, Fragmented Solidarity, and Transnational Migration: Colombians in New York City and Los Angeles. Ethnic and Racial Studies 22(2): 367-396.

Guarnizo, Luis Eduardo and Michael P. Smith. 1998. The Locations of Transnationalism. In Michael P. Smith and Luis Eduardo Guarnizo (eds), Transnationalism from Below, pp. 1-32. New Brunswick, NJ: Transaction Publishers.

Guiradon, Virginie and Christian Joppke (eds). 2001. Controlling a New Migration World. London, UK: Routledge.

Gupta, Akhil and James Ferguson. 1992. Beyond Culture: Space, Identity and the Politics of Difference. Cultural Anthropology 7(1): 6-23.

Gurin, Patricia, Arthur H. Miller and Gerald Gurin. 1980. Stratum Identification and Consciousness. Social Psychology Quarterly 43(1): 30-47.

Guterbock, Thomas M. and Bruce London. 1983. Race, Political Organization, and Participation: An Empirical Test of Four Competing Theories. American Sociological Review 48(4): 439-453.

Hagan, Jacqueline Maria. 1998. Social Networks, Gender, and Immigrant Incorporation: Resources and Constraints. American Sociological Review 63(1): 55-67.

Hakim, Catherine. 2000. Research Design: Successful Designs for Social and Economic Research, $2^{\text {nd }}$ edition. London, UK: Routledge.

Halbrook, Allyson L., Melanie C. Green and Jon A. Krosnick. 2003. Telephone versus Face-to-face Interviewing of National Probability Samples with Long Questionnaires: Comparison of Respondent Satisficing and Social Desirability Response Bias. Public Opinion Quarterly 67: 79-125.

Hale, Henry E. 2004. Explaining Ethnicity. Comparative Political Studies 37(4): 458485. 
Hammond, John L. 1993. War-Uprooting and the Political Mobilization of Central American Refugees. Journal of Refugee Studies 6(2): 105-122.

Handlin, Oscar. 2002 [1951]. The Uprooted: The Epic Story of the Great Migrations That Made the American People, $2^{\text {nd }}$ edition. Philadelphia, PA: University of Pennsylvania Press.

Haney López, Ian F. 2006. Colorblind to the Reality of Race in America. The Chronicle of Higher Education. 3 November, B6-B9.

Haney López, Ian F. 2000. Race and Erasure: The Salience of Race to Latinos/as. In Richard Delgado and Jean Stefancic (eds), Critical Race Theory: The Cutting $E d g e, 2^{\text {nd }}$ edition, pp. 369-378. Philadelphia, PA: Temple University Press.

Haney López, Ian F. 1996. White by Law: The Legal Construction of Race. New York, NY: New York University Press.

Hardin, Russell. 2002. Trust and Trustworthiness. New York, NY: Russell Sage Foundation.

Hardin, Russell. 1993. The Street-level Epistemology of Trust. Politics and Society 21(4): 505-529.

Hardwick, Susan. 2008. Slavic Dreams: Post-Soviet Refugee Identity and Adaptation in Portland, Oregon. In Richard C. Jones (ed), Immigrants Outside Megalopolis: Ethnic Transformation in the Heartland, pp. 25-42. Lanham, MD: Lexington Books.

Hardwick, Susan and James Meacham. 2005. Heterolocalism, Networks of Ethnicity, and Refugee Communities in the Pacific Northwest: The Portland Story. Professional Geographer 57(4): 539-557.

Hardy-Fanta, Carol. 1993. Latina Politics, Latino Politics: Gender, Culture, and Political Participation in Boston. Philadelphia, PA: Temple University Press.

Harper-Ho, Virginia. 2000. Noncitizen Voting Rights: The History, the Law and Current Prospects for Change. Law \& Inequality 18: 271-277.

Harris, Fredrick C. 1994. Something Within: Religion as a Mobilizer of AfricanAmerican Political Activism. Journal of Politics 56(1): 42-68.

Harvey, David. 2005. A Brief History of Neoliberalism. New York, NY: Oxford University Press. 
Harvey, David. 1989. The Urban Experience. Baltimore, MD: The Johns Hopkins University Press.

Hayduk, Ronald. 2006. Democracy for All: Restoring Immigrant Voting Rights in the United States. New York, NY: Routledge.

Hayduk, Ronald. 2002. Non-Citizen Voting: Pipedream or Possibility? Online article prepared for The Drum Major Institute for Public Policy, available at www.drummajorinstitute.org/library/article.php?ID=5519 [accessed May 2010].

Hebbert, Michael. 2005. The Street as Locus of Collective Memory. Environment and Planning D: Society and Space 23(4): 581-596.

Herbert, Steve. 2008. Contemporary Geographies of Exclusion I: Traversing Skid Road. Progress in Human Geography 32(5): 659-666.

Herbert, Steve. 2006. Citizens, Cops, and Power: Recognizing the Limits of Community. Chicago, IL: University of Chicago Press.

Herbert, Steve. 2005. The Trapdoor of Community. Annals of the Association of American Geographers 95(4): 850-865.

Hernández-Truyol, Berta E. 2001. On Becoming the Other: Cubans, Castro, and Elián A LatCrit Analysis. Denver University Law Review 78: 687-718.

Hero, Rodney E. 2007. Racial Diversity and Social Capital: Equality and Community in America. New York, NY: Cambridge University Press.

Hero, Rodney E. 2005. Crossroads of Equality: Race/Ethnicity and Cities in American Democracy. Urban Affairs Review 40(6): 695-705.

Hero, Rodney E. 1998. Faces of Inequality: Social Diversity in American Politics. New York, NY: Oxford University Press.

Hero, Rodney E. 1992. Latinos and the U.S. Political System: Two-Tiered Pluralism. Philadelphia, PA: Temple University Press.

Hero, Rodney E. and Anne G. Campbell. 1996. Understanding Latino Political Participation: Exploring the Evidence from the Latino National Political Survey. Hispanic Journal of Behavioral Sciences 18(2): 129-141.

Herzog, Lawrence A. 2006. Return to the Center: Culture, Public Space, and City Building in a Global Era. Austin, TX: University of Texas Press. 
Higham, John. 1963. Strangers in the Land: Patterns of American Nativism, 1860-1925. New York, NY: Atheneum.

Hill, Kevin A. and Dario Moreno. 1996. Second-Generation Cubans. Hispanic Journal of Behavioral Sciences 18(2): 175-193.

Hirschman, Charles. 2005. Immigration and the American Century. Demography 42: 595-620.

Hirschman, Charles. 2004. The Role of Religion in the Origins and Adaptation of Immigrant Groups in the United States. International Migration Review 38(3): 1206-1233.

Hirschman, Charles. 1983. America's Melting Pot Reconsidered. Annual Review of Sociology 9: 397-423.

Hollinger, David A. 2000. Postethnic America: Beyond Multiculturalism, $5^{\text {th }}$ edition. New York, NY: Basic Books.

Holt, Louise. 2008. Embodied Social Capital and Geographic Perspectives: Performing the Habitus. Progress in Human Geography 32: 227-246.

Hooghe, Marc and Dietlind Stolle. 2003. Generating Social Capital: Civil Society and Institutions in Comparative Perspective. New York, NY: Palgrave.

Hooker, Juliet. 2009. Race and the Politics of Solidarity. New York, NY: Oxford University Press.

hooks, b. 1990. Homeplace: A Site of Resistance. In b. hooks (ed), Yearning: Race, Gender, and Cultural Politics, pp. 31-50. Boston, MA: South End.

Hoxie, Frederick E. 1989. A Final Promise: The Campaign to Assimilate the Indians, 1880-1920. New York, NY: Cambridge University Press.

Human Development Report 2004: Cultural Liberty in Today's Diverse World. 2004. New York, NY: United Nations Development Programme.

Hunter, Albert. 1979. The Urban Neighborhood: Its Analytical and Social Contexts. Urban Affairs Quarterly 14: 267-288.

Huntington, Sameul P. 2004. The Hispanic Challenge. Foreign Policy 141: 30-45.

Huntington, Samuel P. 1997. The Clash of Civilizations and the Remaking of World Order. New York, NY: Touchstone. 
Huntington, Samuel P. 1981. American Politics: The Politics of Disharmony. Cambridge, MA: Harvard University Press.

Hurh, Won Moo and Kwang Chung Kim. 1990. Religious Participation of Korean Immigrants in the United States. Journal for the Scientific Study of Religion 29 (March): 9-34.

Hyman, James B. 2002. Exploring Social Capital and Civic Engagement to Create a Framework for Community Building. Applied Developmental Science 6(4): 196202.

Iber, Jorge. 2005. Little Havana. In Susanne Oboler and Deena González (eds), The Oxford Encyclopedia of Latinos and Latinas in the United States, vol. 2, pp. 571572. New York, NY: Oxford University Press.

Iceland, John. 2009. Where We Live Now: Immigration and Race in the United States. Berkeley, CA: University of California Press.

Iceland, John, Daniel H. Weinberg and Erika Steinmetz. 2002. Racial and Ethnic Residential Segregation in the United States: 1980-2000. U.S. Census Bureau, Series CENSR-3. Washington, DC: Government Printing Office. Census Bureau Housing Patterns, available at www.census.gov/hhes/www/housing/housing_patterns/pdf/paa paper.pdf [accessed September 2009].

Isajiw, Wsevolod W. 1974. Definitions of Ethnicity. Ethnicity 1: 111-124.

Jackman, Mary R. and Marie Crane. 1986. Some of my best friends are black...", Interracial Friendship and Whites' Racial Attitudes. Public Opinion Quarterly 50(4): 459-486.

Jackson, John B. 1984. Discovering the Vernacular Landscape. New Haven, CT: Yale University Press.

Jackson, Peter. 1987. The Idea of 'Race' and the Geography of Racism. In Peter Jackson (ed), Race and Racism: Essays in Social Geography, pp. 3-19. London, UK: Allen \& Unwin.

Jackson, Peter (ed). 1987. Race and Racism: Essays in Social Geography. London, UK: Allen \& Unwin.

Jacobs, Jane. 1992 [1961]. The Death and Life of Great American Cities. New York, NY: Vintage Books. 
Jacobson, Matthew F. 1998. Whiteness of a Different Color: European Immigration and the Alchemy of Race. Cambridge, MA: Harvard University Press.

Jarosz, Lucy and Victoria Lawson. 2002. Sophisticated People versus Rednecks: Economic Restructuring and Class Difference in America's West. Antipode 34(1): 8-27.

Jencks, Charles. 1993. Heteropolis: Los Angeles, the Riots and the Strange Beauty of Hetero-Architecture. London, UK: Academy Editions.

Johnson, Kevin R. 2001. Comparative Racialization: Culture and National Origin in the Latina/o Communities. Denver University Law Review 78: 633-655.

Johnson, Kevin R. 1998. Citizens as 'Foreigners.' In Richard Delgado and Jean Stefancic (eds), The Latino/a Condition: A Critical Reader, pp. 198-201. New York, NY: New York University Press.

Johnston, Lynne. 2006. Software and Method: Reflections on Teaching and Using QSR NVivo in Doctoral Research. International Journal of Social Research Methodology 9(5): 379-391.

Johnston, Ron, Michael Poulsen and James Forrest. 2009. Research Note - Measuring Ethnic Residential Segregation: Putting Some More Geography. Urban Geography 30(1): 91-109.

Johnston, Ron, Michael Poulsen, and James Forrest. 2003. And Did the Walls Come Tumbling Down? Ethnic Residential Segregation in Four US Metropolitan Areas, 1980-2000. Urban Geography 24(7): 560-581.

Jones, Karen. 2004. Trust and Terror. In Peggy DesAutels and Margaret Urban Walker (eds), Moral Psychology: Feminist Ethics and Social Theory, pp. 3-18. New York, NY: Rowman and Littlefield.

Jones, Karen. 1996. Trust as an Affective Attitude. Ethics 10: 74-125.

Jones, Richard C. (ed). 2008. Immigrants outside Megalopolis: Ethnic Transformation in the Heartland. Lanham, MD: Lexington Books.

Jones-Correa, Michael A. (ed). 2001. Governing American Cities: Interethnic Coalitions, Competition, and Conflict. New York, NY: Russell Sage Foundation.

Jones-Correa, Michael A. 1998. Between Two Nations: The Political Predicament of Latinos in New York City. Ithaca, NY: Cornell University Press. 
Jones-Correa, Michael A. and David L. Leal. 2001. Political Participation: Does Religion Matter? Political Research Quarterly 54(4): 751-770.

Joppke, Christian and Ewa Morawska (eds). 2003. Toward Assimilation and Citizenship: Immigrants in Liberal Nation-States. New York, NY: Palgrave Macmillan.

Joppke Christian. 1999. Immigration and the Nation-State. Oxford, UK: Oxford University Press.

Joseph, Samantha. 2004. Average Home Price Twice As Much As Most Can Afford, Economist Says. Miami Today, week of June 24, available online at www.miamitodaynews.com/news/040624/story4.shtml [accessed September 2009].

Junn, Jane. 2006. Mobilizing Group Consciousness: When Does Ethnicity Have Political Consequences? In Taeku Lee, S. Karthick Ramakrishnan and Ricardo Ramírez (eds), Transforming Politics, Transforming America: The Political and Civic Incorporation of Immigrants in the United States, pp. 32-47. Charlottesville, VA: University of Virginia Press.

Kanellos, Nicolás. 1994. The Hispanic Almanac: From Columbus to Corporate America. Detroit, MI: Visible Ink Press.

Kaplan, David and Karen Woodhouse. 2007. Research in Ethnic Segregation II: Measurements, Categories and Meanings. Urban Geography 26(8): 737-745.

Kaplan, David and Wei Li. 2006. Landscapes of the Ethnic Economy. Lanham, MD: Rowman and Littlefield.

Karst, Kenneth. 1989. Belonging to America. New Haven, CT: Yale University Press.

Kasinitz, Philip. 2004. Race, Assimilation, and "Second Generations," Past and Present. In Nancy Foner and George M. Frederickson (eds), Not Just Black and White: Historical and Contemporary Perspectives on Immigration, Race, and Ethnicity in the United States, pp. 278-298. New York, NY: Russell Sage.

Kasinitz, Philip, Juan Battle and Inés Myares. 2001. Fade to Black? The Children of West Indian Immigrants in Southern Florida. In Rubén Rumbaut and Alejandro Portes (eds), Ethnicities: Children of Immigrants in America, pp. 267-300. Berkeley, CA: University of California Press.

Kasinitz, Phillip, John H. Mollenkopf, and Mary C. Waters (eds). 2004. Becoming New Yorkers: Ethnographies of the New Second Generation. New York, NY: Russell Sage. 
Kasinitz, Phillip, John H. Mollenkopf, and Mary C. Waters. 2002. Becoming American/ Becoming New Yorkers: Immigrant Incorporation in a Majority Minority City. International Migration Review. 36(4). Pp. 1020-1036.

Kasinitz, Phillip, John H. Mollenkopf, Mary C. Waters and Jennifer Holdaway. 2008. Inheriting the City: The Children of Immigrants Come of Age. Cambridge, MA: Harvard University Press.

Kawachi, Ichiro, Bruce P. Kennedy, Kimberly Lochner and Deborah Prothrow-Stith. 1997. Social Capital, Income Inequality, and Mortality. American Journal of Public Health 87(9): 1491-1498.

Kazal, Russell A. 1995. Revisiting Assimilation: The Rise, Fall, and Reappraisal of a Concept in American Ethnic History. The American Historical Review 100(2): $437-471$.

Kearns, Ade and Michael Parkinson. 2001. The Significance of Neighborhood. Urban Studies 38: 2103-2110.

Keeter, Scott, Cliff Zukin, Molly Andolina and Krista Jenkins. 2002. The Civic and Political Health of the Nation: A Generational Portrait. College Park, MD: CIRCLE, The Center for Information and Research on Civic Learning and Engagement, University of Maryland.

Keith, Michael. 2005. After the Cosmopolitan? Multicultural Cities and the Future of Racism. London, UK: Routledge.

Kelley, Harold H. and Anthony J. Stahelski. 1970. Social Interaction Basis of Cooperators' and Competitors' Beliefs About Others. Journal of Personality and Social Psychology 16(1): 66-91.

Kellstedt, Lyman A. 1974. Ethnicity and Political Behavior: Inter-group and Intergenerational Differences. Ethnicity 1(4): 393-415.

Keogan, Kevin. 2002. A Sense of Place: The Politics of Immigration and the Symbolic Construction of Identity in Southern California and the New York Metropolitan Area. Sociological Forum 17(2): 223-254.

Kim, Kwang Chung and Shin Kim. 2001. Ethnic Role of Korean Immigrant Churches in the United States. In Ho Youn Kwon, Kwang Chung Kim and Stephen Warner (eds), Korean Americans and Their Religions: Pilgrims and Missionaries from a Different Shore, pp. 71-95. University Park, PA: Pennsylvania State University Press. 
King, Desmond. 2001. Making Americans: Immigration Meets Race. In Gary Gerstle and John Mollenkopf (eds), E Pluribus Unum? Immigrants, Civic Life, and Political Incorporation, pp. 143-171. New York, NY: Russell Sage Foundation.

King, Desmond. 2000. Making Americans: Immigration, Race, and the Origins of the Diverse Democracy. Cambridge, MA: Harvard University Press.

Kinloch, Graham C. 1991. Inequality, Repression, Discrimination and Violence: A Comparative Study. International Journal of Contemporary Sociology 28: 85-98.

Kinloch, Graham C. 1981. Comparative Race and Ethnic Relations. International Journal of Comparative Sociology 22: 257-271.

Kirlin, Mary. 2003. The Role of Adolescent Extracurricular Activities in Adult Political Engagement. College Park, MD: CIRCLE, The Center for Information and Research on Civic Learning and Engagement, University of Maryland.

Kleiner, Brian and Chris Chapman. 2000. Youth Service-Learning and Community Service among $6^{\text {th }}$ through $12^{\text {th }}$ Grade Students in the United States: 1996 and 1999. Washington, DC: U.S. Department of Education, Office of Educational Research and Improvement.

Kloosterman, Robert and Jan Rath. 2001. Immigrant Entrepreneurs in Advanced Economies: Mixed Embeddedness Further Explored. Journal of Ethnic and Migration Studies 27(2): 189-201.

Kloosterman, Robert, Joanne van der Leunand Jan Rath. 1999. Mixed Embeddedness: (In)formal Economic Activities and Immigrant Business in the Netherlands. International Journal of Urban and Regional Research 23(2): 252-266.

Knack, Stephen and Philip Keefer. 1997. Does Social Capital have an Economic Payoff? A Cross-country Investigation. Quarterly Journal of Economics 112(4): 12511288.

Kuhn, Thomas S. 1962. The Structure of Scientific Revolutions, $1^{\text {st }}$ ed. Chicago, IL: University of Chicago Press.

Kwon, Victoria Hyonchu, Helen Rose Ebaugh and Jacqueline Hagan. 1997. The Structure and Functions of Cell Group Ministry in a Korean Christian Church. Journal for the Scientific Study of Religion 36(2): 247-256.

Kymlicka, Will. 2003. Immigration, Citizenship, Multiculturalism: Exploring the Links. Political Quarterly 73: 195-208. 
Labissiere, Yves. 1995. Coming to Terms with Black Men: Race and Ethnicity among Haitian American Youth in South Florida, unpublished Ph.D. dissertation. Department of Psychology: University of California at Santa Cruz.

Laguerre, Michel S. 1998. Diasporic Citizenship: Haitian Americans in Transnational America. New York, NY: St. Martin's Press.

Lal, Barbara B. 1990. The Romance of Culture in an Urban Civilization: Robert E. Park on Race and Ethnic Relations in Cities. London, UK: Routledge.

Lamare, James W. 1982. The Political Integration of Mexican-American Children: A Generational Analysis. International Migration Review 16(1): 169-188.

Laurier, Eric, Angus Whyte and Kathy Buckner. 2002. Neighbouring as an Occasioned Activity. Space and Culture 5(4): 346-367.

Lawson, Victoria. 2000. Arguments within Geographies of Movement: The Theoretical Potential of Migrants' Stories. Progress in Human Geography 24(2): 173-89.

Lee, Ericka. 2004. American Gatekeeping: Race and Immigration Law in the Twentieth Century. In Nancy Foner and George M. Frederickson (eds), Not Just Black and White: Historical and Contemporary Perspectives on Immigration, Race, and Ethnicity in the United States, pp. 119-144. New York, NY: Russell Sage.

Lee, Taeku, S. Karthick Ramakrishnan and Ricardo Ramírez (eds). 2006. Transforming Politics, Transforming America: The Political and Civic Incorporation of Immigrants in the United States. Charlottesville, VA: University of Virginia Press.

Lee, Taeku, S. Karthick Ramakrishnan and Ricardo Ramírez. 2006. Introduction. In Taeku Lee, S. Karthick Ramakrishnan and Ricardo Ramírez (eds), Transforming Politics, Transforming America: The Political and Civic Incorporation of Immigrants in the United States, pp. 1-16. Charlottesville, VA: University of Virginia Press.

Lees, Loretta. 2007: Progress in Gentrification? Environment and Planning A 39(1): 228234.

Lefebvre, Henri. 1991 [1974]. The Production of Space. Translated by Donald Nicholson-Smith. Cambridge, MA: Blackwell.

Leighley, Jan E. 1995. Attitudes, Opportunities, and Incentives: A Field Essay on Political Participation. Political Research Quarterly 48(1): 181-209. 
Leighley, Jan E. 1990. Social Interaction and Contextual Influences on Political Participation. American Politics Quarterly 18(4): 459-475.

Leighley, Jan E. and Johnathan Nagler. 1992a. Class Bias in Turnout: The Voters Remain the Same. American Political Science Review 86(3): 725-736.

Leighley, Jan E. and Johnathan Nagler. 1992b. Individual and Systemic Influences on Turnout: Who Votes? 1984. Journal of Politics 54(3): 718-740.

Leighley, Jan E. and Arnold Vedlitz. 1999. Race, Ethnicity, and Political Participation: Competing Models and Contrasting Explanations. The Journal of Politics 61(4): 1092-1114.

Leonard, Karen. 2002. American Muslims, Before and After September 11, 1991. Economic and Political Weekly 37(4): 2293-2297; 2299-2303.

Levine, Hal B. 1999. Reconstructing Ethnicity. The Journal of the Royal Anthropological Institute 5(2): 165-180.

Lewis, Oscar. 1966. La Vida: A Puerto Rican Family in the Culture of Poverty. New York, NY: Random House.

Lewis, Oscar. 1959. Fives Families: Mexican Case Studies in the Culture of Poverty. New York, NY: Basic Books.

Lewis, R. Barry. 2004. NVivo 20. and ATLAS.ti 5.0: A Comparative Review of Two Popular Qualitative Data-Analysis Programs. Field Methods 16(4): 439-469.

Ley, David. 2004. Transnational Spaces and Everyday Lives. Transactions of the Institute of British Geographers 29(2): 151-164.

Ley, David. 1999. Myths and Meanings of Immigration and the Metropolis. Canadian Geographer 43(1): Pp. 2-20.

Li, Wei. 1998. Anatomy of a New Ethnic Settlement: The Chinese Ethnoburb in Los Angeles. Urban Studies 35(3): 479-501.

Lieberson, Stanley. 1985. Unhyphenated Whites in the United States. Ethnic and Racial Studies 8: 159-180.

Lieberson, Stanley. 1980. A Piece of the Pie: Blacks and White Immigrants Since 1880. Berkeley, CA: University of California Press.

Lieberson, Stanley. 1973. Generational Differences among Blacks in the North. American Journal of Sociology 79: 550-565. 
Lieberson, Stanley. 1963. Ethnic Patterns in American Cities. New York, NY: Free Press.

Lieberson, Stanley and Mary C. Waters. 1993. The Ethnic Responses of Whites: What Causes Their Instability, Simplication, and Inconsistency? Social Forces 72: 421450.

Lieberson, Stanley and Mary C. Waters. 1988. From Many Strands: Ethnic and Racial Groups in America. New York, NY: Russell Sage Foundation.

Lien, Pei-te. 1994. Ethnicity and Political Participation: A Comparison between Asian and Mexican Americans. Political Behavior 16(2): 237-264.

Light Ivan H. 1972. Ethnic Enterprise in America. Berkeley, CA: University of California Press.

Light, Ivan H. and Steven J. Gold. 2000. Ethnic Economies. San Diego, CA: Academic Press.

Light, Ivan H., George Sabagh, Mehdi Bozorgmehr and Claudia Der-Martirosian. 1994. Beyond the Ethnic Enclave Economy. Social Problems 41(1): 65-80.

Lin, Jan. 1998. Globalization and Revalorization of Ethnic Places in Gateway Cities. Urban Affairs Review 34(2): 313-339.

Lipset, Seymour M. 1964. The First New Nation. New York, NY: Basic Books.

Lobo, Arun Peter, Roland J. O. Flores and Joseph J. Salvo. 2002. The Impact of Hispanic Growth on the Racial/Ethnic Composition of New York City Neighborhoods. Urban Affairs Review 37(5): 703-727.

Logan, John R. 2005. Re-placing Whiteness: Where's the Beef? City and Community 4: 137-142.

Logan, John R. 2003. How Race Counts for Hispanic Americans. Albany, NY: Lewis Mumford Center for Comparative Urban and Regional Research, University at Albany.

Lopez, David. 1996. Language, Diversity and Assimilation. In Roger Waldinger and Mehdi Bozorgmehr (eds), Ethnic Los Angeles, pp. 139-163. New York, NY: Russell Sage Foundation. 
Lopez, Mark Hugo. 2002. Civic Engagement among Minority Youth. College Park, MD: CIRCLE, The Center for Information and Research on Civic Learning and Engagement, University of Maryland.

Lopez, Mark Hugo, Emily Kirby and Jared Sagoff. 2005. Fact Sheet: The Youth Vote 2004. Vol. 2006. College Park, MD: CIRCLE, The Center for Information and Research on Civic Learning and Engagement, University of Maryland.

Loukaitou-Sideris, Anastasi. 2002. Regeneration of Urban Commercial Strips: Ethnicity and Space in Three Los Angeles Neighborhoods. Journal of Architectural and Planning Research 19(4): 335-350.

Low, Setha M. 1996a. The Anthropology of Cities: Imagining and Theorizing the City. Annual Review of Anthropology 25: 383-409.

Low, Setha M. 1996b. Spatializing Culture: The Social Production and Social Construction of Public Space in Costa Rica. American Ethnologist 23(4): 861879 .

Lowndes, Vivian. 2000. Women and Social Capital. British Journal of Political Science 30(3): 533-537.

Lynch, Kevin. 1960. The Image of the City. Cambridge, MA: MIT Press.

Mahler, Sarah J. 1999. Engendering Transnational Migration: A Case Study of Salvadorans. American Behavioral Scientist 42: 690-719.

Mahler, Sarah J. 1998. Theoretical and Empirical Contributions toward a Research Agenda for Transnationalism. In Luis Eduardo Guarnizo and Michael P. Smith (eds), Transnationalism from Below, pp. 64-100. New Brunswick, NJ: Transaction Publishers.

Mahler, Sarah. J. 1995a. American Dreaming: Immigrant Life on the Margins. Princeton, NJ: Princeton University Press.

Mahler, Sarah J. 1995b. The Dysfunctions of Transnationalism. Vol. 73, Russell Sage Foundation Working Paper. New York, NY: Russell Sage Foundation.

Mahler, Sarah J. and Patricia R. Pessar. 2001. Gendered Geographies of Power: Analyzing Gender Across Transnational Spaces. Identities: Global Studies in Culture and Power 7: 441-459.

Mantero, José María. 2008. Latinos and the U.S. South. Westport, CT: Praeger. 
Mar, Don. 1991. Another Look at the Enclave Economy Thesis: Chinese Immigrants in the Ethnic Labor Market. Amerasia 17: 5-21.

Marcus, Alan I. 1985. The City as Social System: The Importance of Ideas. American Quarterly 37(3): 332-345.

Marquardt, Marie Friedmann. 2005. Structural and Cultural Hybrids: Religious Congregational Life and Public Participation among Mexicans in the New South. In Karen I. Leonard, Alex Stepick, Manuel A. Vásquez, and Jennifer Holdaway (eds), Immigrant Faiths: Transforming Religious Life in America, pp. 189-217. Walnut Creek, CA: AltaMira Press.

Marschall, Melissa J. and Dietlind Stolle. 2004. Race and the City: Neighborhood Context and the Development of Generalized Trust. Political Behavior 26(2): 125-153.

Marston, Sallie. 2002. Making Difference: Conflict over Irish Identity in the New York City St. Patrick's Day Parade. Political Geography 21: 373-392.

Marston, Sallie and Katharyne Mitchell. 2004. Citizens and the State: Citizenship Formations in Space and Time. In Clive Barnett and Murray M. Low (eds), Spaces of Democracy: Geographical Perspectives on Citizenship, Participation and Representation, pp. 93-112. London, UK: Sage.

Martin, Deborah. 2003. Enacting Neighborhood. Urban Geography 24(5): 361-385.

Martin, Leslie. 2007. Fighting for control: political displacement in Atlanta's gentrifying neighborhoods. Urban Affairs Review 42(5): 603-628.

Martínez, George A. 2000. Mexican Americans and Whiteness. In Richard Delgado and Jean Stenfancic (eds), Critical Race Theory: The Cutting Edge, $2^{\text {nd }}$ ed., pp. 379383. Philadelphia, PA: Temple University Press.

Marx, Anthony. 2002. The Nation-state and Its Exclusions. Political Science Quarterly 117(1): 103-26.

Massey, Doreen. 1994. Space, Place, and Gender. Minneapolis, MN: University of Minnesota Press.

Massey, Doreen. 1991. A Global Sense of Place. Marxism Today 35: 24-29.

Massey, Douglas (ed). 2008. New Faces in New Places: The Changing Geography of American Immigration. New York, NY: Russell Sage Foundation. 
Massey, Douglas S. and Nancy A. Denton. 1993. American Apartheid: Segregation and the Making of the Underclass. Cambridge, MA: Harvard University Press.

Massey, Douglas S., Luin Goldring and Jorge Durand. 1994. Continuities in Transnational Migration: An Analysis of Nineteen Mexican Communities. American Journal of Sociology 99(6): 1492-1533.

Massey, Douglas, Michael J. White and Voon-Chin Phua. 1996. The Dimensions of Segregation Revisited. Sociological Methods \& Research 25(2): 172-206.

Masud-Piloto, Felix. R. 1996: From Welcomed Exiles to Illegal Immigrants: Cuban Migration to the U.S., 1959 - 1995. Lanham, MD: Rowman and Littlefield.

Matei, Sorin. 2001. Fear and Misperception of Los Angeles Urban Space: A SpatialStatistical Study of Communication-Shaped Mental Maps. Communication Research 28(4): 429-463.

Matthews, Fred H. 1977. Quest for an American Sociology: Robert E. Park and the Chicago School. Montreal, Canada: McGill-Queen's University Press.

Mayer, Nonna. 2003. Democracies in France - Do Associations Matter? In Marc Hooghe and Dietlind Stolle (eds), Generating Social Capital: Civil Society and Institutions in Comparative Perspective, pp. 43-66. New York, NY: Palgrave.

Mayo, Marjorie. 2000. Cultures, Communities, Identities: Cultural Strategies for Participation and Empowerment. New York, NY: Palgrave.

McBride, Keally D. 2005. Collective Dreams: Political Imagination and Community. University Park, PA: The Pennsylvania State University Press.

McCann, Eugene J. 2003. Framing Space and Time in the City: Urban Politics, Urban Policy, and the Politics of Scale. Journal of Urban Affairs 25: 159-178.

McClosky, Herbert and John Zaller. 1984. The American Ethos. Cambridge, MA: Harvard University Press.

McFadden, Robert D. 2006. Across the United States, growing immigration rallies. The New York Times online edition, April 10, available at www.nytimes.com/2006/04/10/world/americas/10ihtweb.0410.march.html?_r=1\&pagewanted=2 [accessed April 2010].

McHugh, Kevin E. 1989. Hispanic Migration and Population Redistribution in the United States. Professional Geographer 41(4): 429-439. 
McHugh, Kevin E., Ines M. Miyares and Emily H. Skop. 1997. The Magnetism of Miami: Segmented Paths in Cuban Migration. Geographical Review 87(4): 504519.

McPherson, Miller, Lynn Smith-Lovin and Matthew E. Brashears. 2006. Social Isolation in America: Changes in Core Discussion Networks over Two Decades. American Sociological Review 71: 353-375.

McTavish, Don G. and Herman J. Loether. 2002. Social Research: An Evolving Process, $2^{\text {nd }}$ edition. Boston, MA: Allyn and Bacon.

Meegan, Richard and Alison Mitchell. 2001. 'It's Not Community Round Here, It's Neighborhood": Neighborhood Change and Cohesion in Urban Regeneration Policies. Urban Studies 38: 2167-2194.

Meinhof, Ulrike Hanna and Dariusz Galasiński. 2005. The Language of Belonging. New York, NY: Palgrave Macmillan.

Menjivar, Cecilia. 2000. Fragmented Ties: Salvadoran Immigrant Networks in America. Berkeley, CA: University of California Press.

Merton, Robert K. 1972. Insiders and Outsiders: A Chapter in the Sociology of Knowledge. The American Journal of Sociology 78(1): 9-47.

Milbrath, Lester and Madan L. Goel. 1977. Political Participation: How and Why Do People Get Involved in Politics?, $2^{\text {nd }}$ edition. Chicago, IL: Rand McNally.

Miles, Matthew B. and Michael A. Huberman. 1994. Qualitative Data Analysis: An Expanded Sourcebook. Thousand Oaks, CA: Sage.

Miller, Arthur H., Patricia Gurin, Gerald Gurin and Oksana Malanchuk. 1981. Group Consciousness and Political Participation. American Journal of Political Science 25(3): 494-511.

Min, Pyong Gap. 2000. Immigrants' Religion and Ethnicity: A Comparison of Korean Christian and Indian Hindu Immigrants. Bulletin of the Royal Institute for InterFaith Studies 2(1): 121-140.

Mitchell, Katharyne. 2006. Geographies of Identity: The New Exceptionalism. Progress in Human Geography 30(1): 95-106.

Mitchell, Katharyne. 2004. Geographies of Identity: Multiculturalism Unplugged. Progress in Human Geography 28(5): 641-651. 
Mitchell, Katharyne. 2000. Networks of Ethnicity. In Eric Sheppard and Trevor J. Barnes (eds), Companion to Economic Geography, pp. 392-407. London, UK: Blackwell.

Model, Suzanne. 1997. An Occupational Tale of Two Cities: Minorities in London and New York. Demography 34(4): 539-550.

Mohan, Giles and John Mohan. 2002. Placing Social Capital. Progress in Human Geography 26(2): 191-210.

Mohl, Raymond. 1988. Ethnic Politics in Miami, 1960-1986. In Randall M. Miller and George E. Pozzetta (eds), Shades of the Sunbelt: Essays on Ethnicity, Race, and the Urban South, pp. 143-157. Boca Raton, FL: Florida Atlantic University Press.

Morawska, Ewa. 2001. Immigrants, Transnationalism, and Ethnicization: A Comparison of This Wave and Last. In Gary Gerstle and John Mollenkopf (eds), E Pluribus Unum? Immigrants, Civic Life, and Political Incorporation, pp. 175-212. New York, NY: Russell Sage Foundation.

Morawska, Ewa. 1994. In Defense of the Assimilation Model. Journal of American Ethnic History 13: 76-87.

Moreno, Dario and Nicol Rae. 1992. Ethnicity and Partnership: The Eighteenth Congressional District in Miami. In Guillermo Grenier and Alex Stepick (eds), Miami Now: Immigration, Ethnicity and Social Change, pp. 186-204. Gainesville, FL: University Press of Florida.

Morgan, David L. 2002. Focus Group Interviewing. In Jaber F. Gubrium and James A. Holstein (eds), Handbook of Interview Research: Context and Method, pp. 141159. Thousand Oaks, CA: Sage.

Mormino, Gary. 2005. Land of Sunshine, State of Dreams: A Social History of Modern Florida. Gainesville, FL: University Press of Florida.

Mountz, Alison and David Prytherch. 2005. Introduction - Digression Analysis: A Decidedly Editorial Introduction to the Symposium on the State of Urban Geography; Dispatches from the Field. Urban Geography 26(3): 243-246.

Muller, Thomas. 1997. Nativism in the Mid-1990s: Why Now? In Juan F. Perea (ed), Immigrants Out! The New Nativism and the Anti-immigrant Impulse in the United States, pp. 105-118. New York, NY: New York University Press.

Mutz, Diana. 2002. Cross-cutting Social Networks: Testing Democratic Theory in Practice. American Political Science Review 96: 111-126. 
Nackerud, Larry Glenn. 1993. The Central American Refugee Issue in Brownsville, Texas: Seeking Understanding of Public Policy Formulation from Within a Community Setting. San Francisco, CA: Mellen Research University Press.

Nagel, Caroline R. 2009. Rethinking Geographies of Assimilation. The Professional Geographer 61(3): 400-407.

Nagel, Joane. 1994. Constructing Ethnicity: Creating and Recreating Ethnic Identity and Culture. Social Problems 41(1): 152-179.

Narayan, Deepa. 1999. Bonds and Bridges: Social Capital and Poverty. Washington, DC: World Bank.

Nee, Victor and Bret de Bary Nee. 1973. Longtime Californ': A Documentary Study of an American Chinatown. Boston, MA: Houghton Mifflin.

Nevins, Joseph. 2008. Dying to Live: A Story of U.S. Immigration in an Age of Global Apartheid. San Francisco, CA: Open Media/City Lights Books.

New York Times. 1973. Latinization of the Miami Area Is Showing No Signs of Abating. Special to the New York Times. April 18. p. 25. No author.

Newton, Kenneth. 2004. Social Trust: Individual and Cross-national Approaches. Portuguese Journal of Social Science 3(1): 15-35.

Newton, Kenneth. 1999. Social and Political Trust in Established Democracies. In Pippa Norris (ed), Critical Citizens: Global Support for Democratic Government, pp. 169-188. Oxford, UK: Oxford University Press.

Nie, Norman, G. Bingham Powell and Kenneth Prewitt. 1969. Social Structure and Political Participation: Developmental Relationships, Parts I and II. In American Political Science Review 63: 361-378; 808-832.

Nijman, Jan. 2007a. Place-particularity and 'Deep Analogies': A Comparative Essay on Miami’s Rise as a World City. Urban Geography 28(1): 92-107.

Nijman, Jan. 2007b. Introduction - Comparative Urbanism. Urban Geography 28(1):1- 6.

Nijman, Jan. 2000. The Paradigmatic City. Annals of the Association of American Geographers 90(1): 135-145.

Nijman, Jan. 1996a. Breaking the Rules: Miami in the Urban Hierarchy. Urban Geography 17(1): 5-22. 
Nijman, Jan. 1996b. Ethnicity, Class, and the Economic Internationalization of Miami. In John O'Loughlin and Jurgen Friedrichs (eds), Social Polarization in Post-Industrial Metropolises, pp. 283-330. Berlin, Germany: Walter de Gruyter.

Nissen, Bruce and Monica Russo. 2006. Building a Movement: Revitalizing Labor in Miami. Working USA: The Journal of Labor and Society 9: 123-139.

Oberle, Alex P. and Daniel D. Arreola. 2008. Resurgent Mexican Phoenix. Geographical Review 98(2): 171-196.

Odem, Mary E. and Elaine Lacy (eds). 2009. Latino Immigrants and the Transformation of the U.S. South. Athens, GA: University of Georgia Press.

Offe, Claus. 1999. How Can We Trust Our Fellow Citizens? In Mark Warren (ed), Democracy and Trust, pp. 42-87. Cambridge, UK: Cambridge University Press.

Ohlemacher, Stephen. 2007. Incomes lagging behind home values. The Miami Herald online edition, September 12, 2007, available at www.miamiherald.com/163/v-print/story/234472.html [accessed October 2007]. Currently available at: http://decisionfunding.com/advice/mortgage matters/incomes lagging behind $\mathrm{h}$ ome values.html.

Olander, Michael. 2003. How Young People Express Their Political Views. College Park, MD: CIRCLE, The Center for Information and Research on Civic Learning and Engagement, University of Maryland.

Oliver, Eric J. 2000. City Size and Civic Involvement in Metropolitan America. American Political Science Review 94(2): 361-374.

Oliver, Eric J. 1999. The Effects of Economic Segregation on Local Civic Participation. American Journal of Political Science. 43: 186-212.

Oliver, Eric J. and Tali Mendelberg. 2000. Reconsidering the Environmental Determinants of Racial Attitudes. American Journal of Political Science 44: 574-589.

Olsen, Marvin E. 1972. Social Participation and Voting Turnout: A Multivariate Analysis. American Sociological Review 37: 317-333.

Olson, Jr., Mancur. 1965. The Logic of Collective Action: Public Goods and the Theory of Groups. Cambridge, MA: Harvard University Press.

Olson, Philip. 1982. Urban Neighborhood Research: Its Development and Current Focus. Urban Affairs Quarterly 15: 491-518. 
Omi, Michael and Howard Winant. 1986. Racial Formation in the United States: From the 1960s to the 1980s. New York, NY: Routledge.

Orosco, Jose-Antonio. 2007. Neighborhood Democracy and Chicana/o Cultural Citizenship in Armando Rendon's Chicano Manifesto. Ethnics, Place and Environment 10(2): 121-139.

Padgett, Tim. 2009. Behind Florida's Exodus: Rising Taxes, Political Ineptitude. Time, online edition, September 2, available at www.time.com/time/nation/article/0,8599,1919916,00.html [accessed April 2010].

Pallant, Julie. 2007. SPSS Survival Manual, $3^{\text {rd }}$ edition. New York, NY: Open University Press.

Park, Robert E. 1928. Human Migration and the Marginal Man. The American Journal of Sociology 33(6): 881-893.

Park, Robert E. and Ernest W. Burgess. 1921. Introduction to the Science of Sociology. Chicago, IL: University of Chicago Press.

Park, Robert E., Burgess, Eugene W., and Mackenkie, Robert D. 1984 [1925]: The City: Suggestions for Investigation of Human Behavior in the Urban Environment. Chicago, IL: University of Chicago Press.

Paxton, Pamela. 2007. Not All Association Memberships Increase Trust: A Model of Generalized Trust in Thirty-One Countries. Social Forces 86: 47-76.

Paxton, Pamela. 2005. Trust in Decline? Contexts 4(1): 40-46.

Paxton, Pamela. 2002. Social Capital and Democracy: An Interdependent Relationship. American Sociological Review 67: 254-277.

Paxton, Pamela. 1999. Is Social Capital Declining in the United States? A Multiple Indicator Assessment. American Journal of Sociology 105: 88-127.

Paxton, Pamela and Anthony Mughan. 2006. What's to Fear from Immigrants? Creating an Assimilationist Threat Scale. Political Psychology 27: 549-568.

Peach, Ceri. 2005. The Ghetto and the Ethnic Enclave. In David P. Varady (ed), Desegregating the City: Ghettos, Enclaves and Inequality, pp. 31-48. Albany, NY: State University of New York Press. 
Pedraza-Bailey, Silvia. 1985. Political and Economic Migrants in America: Cubans and Mexicans. Austin, TX: University of Texas Press.

Perea, Juan F. 1998. The Black/White Binary Paradigm of Race. In Richard Delgado and Jean Stefancic (eds), The Latino/a Condition: A Critical Reader, pp. 466-477.

New York, NY: New York University Press.

Perea, Juan F. 1996. Suggested Responses to Frequently Asked Questions About Hispanics, Latinos and Latinas. La Raza Law Journal 39: 40-42.

Pérez, Lisandro. 1999. The End of Exile? A New Era in U.S. Immigration Policy toward Cuba. In Max Castro (ed), Free Markets, Open Societies, Closed Borders? Trends in International Migration and Immigration, pp. 197-211. Miami: North-South Center Press.

Pérez, Lisandro. 1994. The Household Structure of Second-Generation Children: An Exploratory Study of Extended Family Arrangements. International Migration Review 28 (4): 736-747.

Perlmann, Joel and Roger Waldinger. 1997. Second Generation Decline? Children of Immigrants, Past and Present - A Reconsideration. International Migration Review 31(4): 893-922.

Persons, Stow. 1987. Ethnic Studies at Chicago 1905-45. Urbana, IL: University of Illinois Press.

Pettigrew, Thomas F. 1998. Intergroup Contact Theory. Annual Review of Psychology 49: 68-85.

Pettigrew, Thomas F. 1971. Racially Separate or Together? New York, NY: McGrawHill.

Pettigrew, Thomas F. 1964. Profile of the American Negro. Princeton, NJ: Van Nostrand.

Pettigrew, Thomas F. and Linda R. Tropp. 2006. A Meta-analytic Test of Intergroup Contact Theory. Journal of Personality and Social Psychology 90: 751-783.

Pettigrew, Thomas F. and Linda R. Tropp. 2000. Does Intergroup Contact Reduce Prejudice? Recent Meta-analytic Findings. In Stuart Oskamp (ed), Reducing Prejudice and Discrimination, pp. 93-114. Mahwah, NJ. Lawrence Erlbaum Associates.

Pew Research Center. 2007. The Latino Electorate: An Analysis of the 2006 Election. Washington, DC: Pew Research Center, available at http://pewhispanic.org/factsheets/factsheet.php?FactsheetID=34. 
Pierce, Neal. 1993. Citistates: How Urban America Can Prosper in a Competitive World. Washington, D.C.: Seven Locks Press.

Pierre, Jemina. 2004. Black Immigrants in the United States and the "Cultural Narratives" of Ethnicity. Identities: Global Studies in Culture and Power 11: 141170.

Pinderhughes, Dianne M. 1987. Race and Ethnicity in Chicago Politics: A Reexamination of Pluralist Theory. Urbana, IL: University of Illinois Press.

Plaza, Dwaine. The Construction of a Segmented Hybrid Identity Among One-and-aHalf-Generation and Second-Generation Indo-Caribbean and African Caribbean Canadians. Identity: An International Journal of Theory and Research 6(3): 207229.

Popielarz, Pamela. 1999. (In)voluntary Assocation: A Multilevel Analysis of Gender Segregation in Voluntary Associations. Gender and Society 13(2): 234-250.

Portes, Alejandro. 1998. Social Capital: Its Origins and Applications in Modern Sociology. Annual Review of Sociology 24: 1-24.

Portes, Alejandro. 1996. The New Second Generation. New York, NY: Russell Sage.

Portes, Alejandro. 1995. Economic Sociology and the Sociology of Immigration: A Conceptual Overview. In Alejandro Portes (ed), The Economic Sociology of Immigration, pp. 1-41. New York, NY: Russell Sage Foundation.

Portes, Alejandro. 1987. The Origin of the Cuban Enclave Economic of Miami. Sociological Perspectives 30(4): 340-372.

Portes, Alejandro. 1981. Modes of Structural Incorporation and Present Theories of Labor Immigration. In Mary M. Kritz, Charles B. Keeley and Silvano M. Tomasi (eds), Global Trends in Migration: Theory and Research of International Population Movements, pp. 279-297. New York, NY: Center for Migration Studies.

Portes, Alejandro and Robert L. Bach. 1985. Latin Journey: Cuban and Mexican Immigrants in the United States. Berkeley, CA: University of California Press.

Portes, Alejandro and Jozsef Borocz. 1989. Contemporary Immigration: Theoretical Perspectives on Its Determinants and Modes of Incorporation. International Migration Review 23: 606-630. 
Portes, Alejandro and Josh DeWind. 2004. A Cross-Atlantic Dialogue: The Progress of Research and Theory in the Study of International Migration. International Migration Review 38(3): 828-851.

Portes, Alejandro and Leif Jensen. 1987. What's an Ethnic Enclave? The Case for Conceptual Clarity. American Sociological Review 52: 768-771.

Portes, Alejandro and Robert. D. Manning. 1986. The Immigrant Enclave: Theory and Empirical Examples. In Susan Olzak and Joane Nagel (eds), Comparative Ethnic Relations, pp. 47-68. Orlando, FL: Academic Press.

Portes, Alejandro and Margarita Mooney. 2002. Social Capital and Community Development. In Mauro F. Guillén, Randall Collins, Paula England and Marshall Meyer (eds), The New Economic Sociology: Developments In An Emerging Field, pp. 3003-3329. New York, NY: Russell Sage Foundation.

Portes, Alejandro and Rubén G. Rumbaut. 1996. Immigrant America: A Portrait, $2^{\text {nd }}$ edition. Berkeley, CA: University of California Press.

Portes, Alejandro and Julia Sensenbrenner. 1993. Embeddedness and Immigration: Notes on the Social Determinants of Economic Action. American Journal of Sociology 98(6): 1320-1350.

Portes, Alejandro and Steven Shafer. 2006. Revisiting the Enclave Hypothesis: Miami Twenty-five Years Later. CMD Working Paper 06-10. Princeton, NJ: Princeton University Center for Migration and Development, available at http://cmd.princeton.ued/papers/wp0610.pdf [accessed February 2010].

Portes, Alejandro and Alex Stepick. 2003. The Transformation of Miami. In John Stone and Rutledge Dennis (eds), Race and Ethnicity: Comparative and Theoretical Approaches, pp. 306-319. Malden, MA: Blackwell Readers in Sociology.

Portes, Alejandro and Alex Stepick. 1993. City on the Edge: The Transformation of Miami. Berkeley, CA: University of California Press.

Portes, Alejandro and Min Zhou. 1993. The New Second Generation: Segmented Assimilation and Its Variants. Annals of the American Academy of Political and Social Sciences 530: 74-96.

Pratt, Geraldine and Brenda Yeoh. 2003. Transnational (Counter)Topographies. Gender, Place, and Culture 10(2): 159-166.

Pred, Allan R. 2004. The Past Is Not Dead: Facts, Fictions, and Enduring Racial Stereotypes. Minneapolis, MN: University of Minnesota Press 
Pred, Allan R. 2000. Even in Sweden: Racisms, Racialized Spaces, and the Popular Geographical Imagination. Berkeley, CA: University of California Press.

Pred, Allan R. 1986. Place, Practice and Structure. Totowa, NJ: Barnes and Noble.

Pred, Allan R. 1984. Place as Historically Contingent Process: Structuration and the Time-geography of Becoming Places. Annals of the Association of American Geographers 74: 279-297.

Prewitt, Kenneth. 2006. Immigrants and the Changing Categories of Race. In Taeku Lee, S. Karthick Ramakrishnan and Ricardo Ramírez (eds), Transforming Politics, Transforming America: The Political and Civic Incorporation of Immigrants in the United States, pp. 19-31. Charlottesville, VA: University of Virginia Press.

Price, Marie and Lisa Benton-Short (eds). 2008. Migrants to the Metropolis: The Rise of Immigrant Gateway Cities. Syracuse, NY: Syracuse University Press.

Price, Patricia L., Christopher Lukinbeal, Richard N. Gioioso, Daniel Arreola, Damián J. Fernández, Timothy Ready, and Maria de los Angeles Torres. Under review. Placing Latino Civic Engagement: A Comparative Analysis of Three Latino Neighborhoods in Transition. Urban Geography.

Price, Patricia L. 2010. Contemporary Immigrant Geographies: New Patterns, Old Divides, Lingering Concerns. Book review essay of Marie Price and Lisa BentonShort (eds), Migrants to the Metropolis: The Rise of Immigrant Gateway Cities (Syracuse University Press, 2008); Audrey Singer, Susan Hardwick, and Caroline Brettell (eds), Twenty-First Century Gateways: Immigrant Incorporation in Suburban America (Brookings Institution Press, 2008); and Richard C. Jones (ed), Immigrants Outside Megalopolis: Ethnic Transformation in the Heartland (Lexington Books/Rowman and Littlefield, 2008). Annals of the Association of American Geographers 100(2): 468-476.

Price, Patricia L. 2009. At the Crossroads: Critical Race Theory and Critical Geographies of Race. Progress in Human Geography 34(2): 147-174.

Price, Patricia L. 2007. Cohering Culture on Calle 8: The Pause and Flow of Latinidad. Globalisations 4(1): 81-99.

Price, Patricia L. 2005. Calle Ocho. In Susanne Oboler and Deena González (eds), The Oxford Encyclopedia of Latinos and Latinas in the United States, vol. 1, pp. 253. New York, NY: Oxford University Press.

Price, Patricia L. 2004. Dry Place: Landscapes of Belonging and Exclusion. Minneapolis, MN: University of Minnesota Press. 
Price, Patricia L. 2001. "The Three Malinches: Betrayal and the Death of an Urban Popular Movement. International Feminist Journal of Politics 3(2): 237-261.

Price, Patricia L. 2000. Inscribing the Border: Schizophrenia and the Aesthetics of Aztlán. Journal of Social and Cultural Geography 1(1): 101-116.

Prucha, Francis P. 1984. The Great Father: The United States Government and the American Indians. Vols. 1 and 2. Lincoln, NE: University of Nebraska Press.

Pulido, Laura. 2006. Black, Brown, Yellow and Left: Radical Activism in Los Angeles. Berkeley, CA: University of California Press.

Purcell, Mark. 2003. Citizenship and the Right to the Global City: Reimagining the Capitalist World Order. International Journal of Urban and Regional Research 27(3): 564-590.

Putnam, Robert D. 2007. E Pluribus Unum: Diversity and Community in the Twenty-first Century. The 2006 Johan Skytte Prize Lecture. Scandinavian Political Studies (Nordic Political Science Association) 30 (2): 137-174.

Putnam, Robert D. 2000. Bowling Alone: The Collapse and Revival of American Community. New York, NY: Simon \& Schuster.

Putnam, Robert D. 1999. Civic Disengagement in Contemporary America. Government and Opposition/Leonard Schapiro lecture. Delivered at the London School of Economics.

Putnam, Robert D. 1995. Tuning In, Tuning Out: The Strange Disappearance of Social Capital in America. PS: Political Science and Politics 28(4): 664-683.

Putnam, Robert D. 1993. Making Democracy Work: Civic Traditions in Modern Italy. Princeton, NJ: Princeton University Press.

Putnam, Robert D., Lewis M. Feldstein and Donald J. Cohen. 2006. Better Together: Restoring theAmerican Community. New York, NY: Simon \& Schuster.

Raco, Mike and John Flint. 2001. Communities, Places and Institutional Relations: Assessing the Role of Area-based Community Representation in Local Governance. Political Geography 20: 585-612.

Radcliffe, Sarah. 1999. Embodying National Identities: Mestizo Men and White Women in Ecuadorian Racial-national Imaginaries. Transactions of the Institute of British Geographers NS 24: 213-225. 
Rahn, Wendy M. and John E. Transue. 1998. Social Trust and Value Change: The Decline in Social Capital in American Youth, 1976-1995. Political Psychology 19(3): 545-565.

Ramakrishnan, S. Karthick and Mark Baldassare. 2004. The Ties That Bind: Changing Demographics and Civic Engagement in California. San Francisco, CA: Public Policy Institute of California.

Ramirez, Roberto R. and G. Patricia de la Cruz. 2003. The Hispanic Population in the United States: March 2002. Washington, D.C.: U.S. Census Bureau, available at www.census.gov/prod/2003pubs/p20-545.pdf [accessed April 2010].

Raskin, Jamin B. 1993. Legal Aliens, Local Citizens: The Historical, Constitutional and Theoretical Meanings of Alien Suffrage. University of Pennsylvania Law Review 141: 1391-1470.

Reagan, Brad. 2007. After the Bust. Smart Money 16(12): 82-88.

Reed-Danahay, Deborah and Caroline B. Brettell. 2008. Introduction. In Deborah ReedDanahay and C aroline B. Brettell (eds), Citizenship, Political Engagement, and Belonging: Immigrants in Europe and the United States, pp. 1-17. New Brunswick, NJ: Rutgers University Press.

Reiff, David. 1999 [1987]. Going to Miami: Exiles, Tourists and Refugees in the New America. Gainesville, FL: University Press of Florida.

Reiff, David. 1993. The Exile: Cuba in the Heart of Miami. New York, NY: Simon \& Schuster.

Reimers, David. 1985. Still the Golden Door: The Third World Comes to America. New York, NY: Columbia University Press.

Reisinger, Mark E. and Eugene Tettey-Fio. 2003. Changing Latino Geographies in the United States. In John W. Frazier and Florence M. Margai (eds), Multicultural Geographies: The Changing Racial/Ethnic Patterns of the United States, pp. 149169. Binghamton, NY: Global Academic Publishing.

Rimer, Sara. 1990. Miami Journal; The Big Uproar Over Little Havana. The New York Times online edition, October 26, available at www.nytimes.com/1990/10/26/us/miami-journal-the-big-uproar-over-littlehavana.html?pagewanted=1 [accessed April 2010].

Robinson, Andy. 2001. Framing Cockerhill: Identity, Agency, and Injustice. Environment and Planning D: Society and Space. Vol. 19. Pp. 81-101. 
Robinson, Jennifer. 2004. In the Tracks of Comparative Urbanism: Difference, Urban Modernity and the Primitive. Urban Geography 25(8): 709-723.

Robinson, William. 2003. Transnational Conflicts: Central America, Social Change, and Globalization. New York, NY: Verso.

Robinson, Robert V. and Elton F. Jackson. 2001. Is Trust in Others Declining in America? An Age-Period-Cohort Analysis. Social Science Research 30: 117-145.

Rocco, Raymond A. 1996. Latino Los Angeles: Reframing Boundaries/Borders. In Allen J. Scott and Edward W. Soja (eds), The City: Los Angeles and Urban Theory at the End of the Twentieth Century, pp. 365-389. Berkeley, CA: University of California Press.

Rodríguez, América. 1998. Racialization, Language, and Class in the Construction and Sale of the Hispanic Audience. In Neil Foley (ed), Reflexiones 1997: New Directions in Mexican American Studies. Austin, TX: Center for Mexican American Studies Books, University of Texas at Austin.

Rodriguez, Margarita. 1999. Different Paths, Same Destinations: US-Bound Nicaraguan and Cuban Migration in a Comparative Perspective, unpublished Ph.D. dissertation. School of International Studies, University of Miami.

Roediger, David R. 1991. The Wages of Whiteness: Race and the Making of the American Working Class. New York, NY: Verso.

Romano-V., Octavio I. 1973. The Anthropology and Sociology of the Mexican American. In Octavio I. Romano-V. (ed), Voices: Readings from El Grito, $1967-$ 1973, pp.13-26. Berkeley, CA: Quinto Sol.

Rose, Gillian. 2007. Visual Methodologies: An Introduction to the Interpretation of Visual Materials, $2^{\text {nd }}$ edition. London, UK: Sage.

Rosenberg, Morris. 1956. Misanthropy and Political Ideology. American Sociological Review 21: 690-695.

Rosenstone, Steven J. and John Mark Hansen. 1993. Mobilization, Participation, and Democracy in America. PS: Political Science 28: 664-683.

Ross, Catherine E., John Mirowsky and Shana Pribesh. 2001. Powerlessness and the Amplification of Threat: Neighborhood Disadvantage, Disorder, and Mistrust. American Sociological Review 66: 568-591.

Rothstein, Bo and Eric M. Uslaner. 2005. All of All: Equality, Corruption, and Social Trust. World Politics 58: 41-72. 
Rotter, Julian B. 1980. Interpersonal Trust, Trustworthiness and Gullibility. American Psychologist 35(1): 1-7.

Rotter, Julian B. 1971. Generalized Expectancies for Interpersonal Trust. American Psychologist 26: 443-450.

Rouse, Roger. 1995. Questions of Identity: Personhood and Collectivity in Transnational Migration to the United States. Critique of Anthropology 15(4): 351-380.

Rumbaut, Rubén G. 2005. Turning Points in the Transition to Adulthood: Determinants of Educational Attainment, Incarceration, and Early Childbearing among Children of Immigrants. Ethnic and Racial Studies 28(6): 1041-1086.

Rumbaut, Rubén G. 1994. The Crucible Within: Ethnic Identity, Self-esteem and Segmented Assimilation among Children of Immigrants. International Migration Review 28: 748-794.

Rumbaut, Rubén G. and Alejandro Portes. 2001. Ethnicities: Children of Immigrants in America. Berkeley, CA: University of California Press.

Ryan, Gery W. and H. Russell Bernard. 2003. Data Management and Analysis Methods. In Norman K. Denzin and Yvonna S. Lincoln (eds), Collecting and Interpreting Qualitative Materials, pp. 769-802. London, UK: Sage.

Saguaro Seminar: Civic Engagement in America, a project of the John F. Kennedy School of Government at Harvard University. 2006 \& 2000. Social Capital Community Benchmark Survey, available at www.cfsv.org/communitysurvey/index.html [accessed April 2010].

Said, Edward W. 1978. Orientalism: Western Conceptions of the Orient. London, UK: Pantheon Books.

Sampson, Robert J. 2008. “After school” Chicago: Space and the City. Urban Geography 29(2): 127-137.

Sanchez, Gabriel R. 2006. The Role of Group Consciousness in Political Participation Among Latinos in the United States. American Politics Research 34: 427-450.

Sánchez-Jankowski, Martín. 2002. Minority Youth and Civic Engagement: The Impact of Group Relations. Applied Developmental Science 6(4): 237-245.

Sandberg, Neil (ed). 1973. Ethnic Identity and Assimilation: The Polish Community. New York, NY: Praeger. 
Sanders, Jimy M. and Victor Nee. 1987. Limits of Ethnic Solidarity in the Enclave Economy. American Sociological Review 52: 745-773.

Sanjek, Roger. 1998. The Future of Us All: Race and Neighborhood Politics in New York City. Ithaca, NY: Cornell University Press.

Sanjek, Roger. 1994. The Enduring Qualities of Race. In Steven Gregory and Roger Sanjek (eds), Race, pp. 1-17. New Brunswick, NJ: Rutgers University Press.

Santa Ana, Otto. 2002. Brown Tide Rising: Metaphors of Latinas/os in Contemporary American Public Discourse. Austin, TX: University of Texas Press.

Santiago, Fabiola. 2010. Little Havana home to art, music and Cuban nostalgia. The Miami Herald online edition, March 30, available at www.miamiherald.com/2010/03/13/1528519/yes-it-has-todays-street-fair.html [accessed April 2010].

Sassen, Saskia. 1996. Whose City Is It? Globalization and the Formation of New Claims, Public Culture 8: 205-223.

Sassen-Koob, Saskia. 1979. Formal and Informal Associations: Dominicans and Colombians in New York. International Migration Review 13(2): 314-332.

Sassen, Saskia and Alejandro Portes. 1993. Miami: A New Global City? Contemporary Sociology 22(4): 471-477.

Sawyer, Peter R. 2005. Socialization to Civil Society: A Life History Study of Community Leaders. Albany, NY: State University of New York Press.

Schwirian, Kent P. 1983. Models of Neighborhood Change. Annual Review of Sociology 9: 83-102.

Scott, Allen J. and Edward W. Soja (eds). 1996a. The City: Los Angeles and Urban Theory at the End of the Twentieth Century. Berkeley, CA: University of California Press.

Scott, Allen J. and Edward W. Soja. 1996b. Introduction to Los Angeles: City and Region. In Allen J. Scott and Edward W. Soja (eds), The City: Los Angeles and Urban Theory at the End of the Twentieth Century, pp. 1-21. Berkeley, CA: University of California Press.

Seale, Clive F. 2002. Computer-Assisted Analysis of Qualitative Interview Data. In Jaber F. Gubrium and James A. Holstein (eds), Handbook of Interview Research: Context and Method, pp. 651-670. Thousand Oaks, CA: Sage. 
Segura, Gary M., Harry Pachon and Nathan D. Woods. 2001. Hispanics, Social Capital, and Civic Engagement. National Civic Review 90(1): 85-96.

Sellers, Jeffrey M. 2005. Re-placing the Nation: An Agenda for Comparative Urban Politics. Urban Affairs Review 40(4): 419-445.

Sharp, Elaine B. 2007. Revitalizing Urban Research: Can Cultural Explanation Bring Us Back from the Periphery? Urban Affairs Review 43(1): 55-75.

Shearmur, Richard. 2008. Chicago and L.A.: A Clash of Epistemologies. Urban Geography 29(2): 167-176.

Sheskin, Ira M. 1985. Survey Research for Geographers. Washington D.C.: Association of American Geographer Resource Publications in Geography.

Shibutani, Tamotsu and Kian M. Kwan. 1965. Ethnic Stratification. New York, NY: Macmillan.

Shils, Edward. 1957. Primordial, Personal, Sacred and Civic Ties: Some Particular Observations on the Relationships of Sociological Research and Theory. The British Journal of Sociology 8(2): 130-145.

Shingles, Richard D. 1981. Black Consciousness and Political Participation: The Missing Link. American Political Science Review 75: 76-90.

Shoer Roth, Daniel. 2008. Cubans' share of Miami-Dade County population up again. The Miami Herald 23 September: A1.

Sibley, David. 1995. Geographies of Exclusion: Society and Difference in the West. New York, NY: Routledge.

Sikkink, David and Edwin I. Hernández. 2003. Religion Matters: Predicting Schooling Success among Latino Youth. South Bend, IN: Institute of Latino Studies, University of Notre Dame.

Silverman, David. 1993. Interpreting Qualitative Data: Methods for Analysing Talk, Text and Interaction. London, UK: Sage.

Simmel, Georg. 1971 [1903]. On Individuality and Social Forms. Chicago, IL: The University of Chicago Press.

Singer, Audrey, Susan W. Hardwick and Caroline B. Brettell (eds). 2008. Twenty-FirstCentury Gateways: Immigrant Incorporation in Suburban America. Washington, DC: Brookings Institution Press. 
Skocpol, Theda. 2003. Diminished Democracy: From Membership to Management in American Civic Life. Norman, OK: University of Oklahoma Press.

Skocpol, Theda and Morris P. Fiorina (eds). 1999. Civic Engagement in American Democracy. Washington, DC and New York, NY: Brookings Institution Press and Russell Sage Foundation.

Skop, Emily. 2008. Émigrés outside Miami: The Cuban Experience in Metropolitan Phoenix. In Richard C. Jones (ed), Immigrants Outside Megalopolis: Ethnic Transformation in the Heartland, pp. 43-63. Lanham, MD: Lexington Books.

Skop, Emily and Wei Li. 2003. From the Ghetto to the Invisiburb: Shifting Patterns of Immigrant Settlement in Contemporary America. In John W. Frazier and Florence M. Margai (eds), Multicultural Geographies: The Changing Racial/Ethnic Patterns of the United States, pp. 113-124. Binghamton, NY: Global Academic Publishing.

Skop, Emily and Cecilia Menjívar. 2001. Phoenix: The Newest Latino Immigrant Gateway? In Darrick Danta (ed), Yearbook: Association of Pacific Coast Geographers, vol. 63, pp. 63-76. Honolulu, HI: University of Hawai'i Press.

Slater, Tom. 2007. Looking at the 'North American City' Through the Lens of Gentrification Discourse. Urban Geography 23(2): 131-53.

Slocum, Rachel. 2009. The Embodied Politics of Pain in U.S. Anti-racism. ACME: An International E-Journal for Critical Geographies 8(1): 18-45.

Smidt, Corwin. 1999. Religion and Civic Engagement: A Comparative Analysis. Annals of the American Academy of Political and Social Science 565: 176-192.

Smidt, Corwin. 1987. Evangelicals and the 1984 Election: Continuity or Change? American Politics Quarterly 15: 419-444.

Smith, Charles. 2000. Content Analysis and Narrative Analysis. In Harry T. Reis and Charles M. Judd (eds), Handbook of Research Methods in Social and Personality Psychology, pp. 313-335. Cambridge, UK: Cambridge University Press.

Smith, Heather and Owen J. Furuseth (eds). 2006. Latinos in the New South: Transformations of Place. Burlington, VT: Ashgate.

Smith, Heather A. and Owen J. Furuseth. 2006. Making Real the Mythical Latino Community in Charlotte, North Carolina. In Heather A. Smith and Owen J. Furuseth (eds), Latinos in the New South: Transformations of Place, pp. 191-215. Hampshire, UK: Ashgate. 
Smith, Heather and William Graves. 2005. Gentrification as Corporate Growth Strategy: The Strange Case of Charlotte, North Carolina and the Bank of America. Journal of Urban Affairs 27(4): 403-418.

Smith, Rogers M. 1997. Civic Ideals: Conflicting Visions of Citizenship in U.S. History. New Haven, CT: Yale University Press.

Smith, Tom. 1990. Ethnic Survey. GSS Topical Report No. 19. Chicago, IL: National Opinion Research Center, University of Chicago.

Sniderman, Paul M. and Michael Gray Hagen. 1985. Race and Inequality: A Study in American Values. Chatham, NJ: Chatham House Publishers, Inc.

Sobel, Joel. 2002. Can We Trust Social Capital? Journal of Economic Literature 40(1): $139-154$.

Soja, Edward W. 1996. Thirdspace: Journeys to Los Angeles and Other Real-andImagined Places. Cambridge, MA: Blackwell.

Soja, Edward W. 1989. Postmodern Geographies. New York, NY: Verso.

Sollors, Werner. 1996. Foreward: Theories of American Ethnicity. In Werner Sollors (eds), Theories of Ethnicity, pp. x-xliv. New York, NY: New York University Press.

Sommers, Laurie Kay. 1991. Inventing Latinismo: The Creation of "Hispanic" Panethnicity in the United States. The Journal of American Folklore 104(411): $32-53$.

Stack, Lois C. 1978. Trust. In Harvey London and John E. Exner, Jr. (eds), Dimensions of Personality, pp. 561-599. New York, NY: John Wiley \& Sons.

Stanley, Harold W. 1987. Voter Mobilization and the Politics of Race: The South and Universal Suffrage, 1952-1984. New York, NY: Praeger.

Stein, Robert, Stephanie Post and Allison L. Rinden. 2000. Reconciling Context and Contact Effects on Racial Attitudes. Political Research Quarterly 53: 285-303.

Stepick, Alex. 2004. God is Apparently Not Dead: The Obvious, the Emergent and the Unknown in Immigration and Religion. In Karen I. Leonard, Alex Stepick, Manuel A. Vásquez, and Jennifer Holdaway (eds), Immigrant Faiths: Transforming Religious Life in America, pp. 11-37. Walnut Creek, CA: AltaMira Press. 
Stepick, Alex. 1998. Pride Against Prejudice: Haitians in the United States. Boston, MA: Allyn \& Bacon.

Stepick, Alex and Guillermo Grenier. 1993. Cubans in Miami. In Joan Moore and Raquel Pinderhughes (eds), In the Barrios: Latinos and the Underclass Debate, pp. 79-100. New York, NY: Russell Sage Foundation.

Stepick, Alex and Carol Dutton Stepick. 2009. Diverse Contexts of Reception and Feelings of Belonging. Forum Qualitative Sozialforschung/Forum: Qualitative Social Research 10(3): article 15, available at http://nbnresolving.de/urn:nbn:de:0114-fqs0903156 [accessed May 2010].

Stepick, Alex and Carol Dutton Stepick. 2002. Becoming American, Constructing Ethnicity: Immigrant Youth and Civic Engagement, Applied Development Science 6(4): 246-257.

Stepick, Alex and Carol Dutton Stepick. 2001a. Generation X Speaks Out on Censuses, Surveys and Civic Engagement: An Ethnographic Approach, The Case of Miami. Miami, FL: Immigration and Ethnicity Institute, Florida International University.

Stepick, Alex and Carol Dutton Stepick. 2001b. Power and Identity: Miami Cubans. In Marcelo Suárez-Orozco and Mariela M. Páez (eds), Latinos: The Research Agenda, pp. 75-92. Berkeley, CA: University of California Press.

Stepick, Alex, Sarah J. Mahler and Terry Rey (eds). 2009. Churches and Charity in the Immigrant City: Religion, Immigration, and Civic Engagement in Miami. Rutgers, NJ: Rutgers University Press.

Stepick, Alex, Carol Dutton Stepick and Yves Labissiere. 2008. South Florida's Immigrant Youth and Civic Engagement: Major Engagement, Minor Differences. Applied Developmental Science 12(2): 57-65.

Stepick, Alex, Guillermo Grenier, Max Castro and Marvin Dunn. 2003. This Land is Our Land: Immigrants and Power in Miami. Berkeley, CA: University of California Press.

Stokes, Atiya K. 2003. Latino Group Consciousness and Political Participation. American Politics Research 31: 361-378.

Stolle, Dietlind. 2001. Clubs and Congregations: The Benefits of Joining an Association. In Karen S. Cook (ed), Trust and Society, pp. 202-244. New York, NY: Russell Sage Foundation. 
Stolle, Dietlind. 1998. Bowling Together, Bowling Alone: The Development of Generalized Trust in Voluntary Associations. Political Psychology 19(3): 497525 .

Stone, John. 2003. Max Weber on Race, Ethnicity, and Nationalism. In John Stone and Rutledge M. Dennis (eds), Race and Ethnicity: Comparative and Theoretical Approaches, pp. 28-42. Marden, MA: Blackwell Readers in Sociology.

Suárez-Orozco, Carola and Marcelo M. Suárez-Orozco. 2001. Children of Immigration. Boston, MA: Harvard University Press.

Suárez-Orozco, Marcelo and Mariela M. Páez. 2002. Introduction: The Research Agenda. In Marcelo Suárez-Orozco and Mariela M. Páez (eds), Latinos: Remaking America, pp. 1-37. Berkeley, CA: University of California Press.

Suárez-Orozco, Marcelo and Audrey Singer. 2002. Latino Growth in Metropolitan America: Changing Patterns, New Location. Brookings Institution Survey Series.

Sullivan, Daniel Monroe. 2007. Reassessing Gentrification: Measuring Residents' Opinions Using Survey Data. Urban Affairs Review 42(4): 583-592.

Sullivan, Mercer L. 1996. Neighborhood Social Organization: A Forgotten Object of Ethnographic Study? In Richard Jessor, Anne Colby, and Richard A. Shweder (eds), Ethnography and Human Development: Context and Meaning in Social Inquiry, pp. 205-224. Chicago, IL: The University of Chicago Press.

Suro, Roberto. 1998. Strangers Among Us: How Latino Immigration is Transforming America. New York, NY: Alfred A. Knopf.

Suro, Robert, Richard Fry and Jaffrey Passel. 2005. Hispanics and the 2004 Election: Population, Electorate and Voters, Available at http://pewhispanic.org/files/reports/48.pdf [accessed April 2010]. Washington, DC: The Pew Hispanic Center.

Suttles, Gerald D. 1972. The Social Construction of Communities. Chicago, IL: University of Chicago Press.

Suttles, Gerald D. 1968. The Social Order of the Slum. Chicago, IL: University of Chicago Press.

Swyngedouw, Erik A. 1989. The Heart of Place: The Resurrection of Locality in an Age of Hyperspace. Geografiska Annaler (series B) 71(1): 31-42.

Szreter, Simon. 2002. The State of Social Capital: Bringing Back in Power, Politics, and History. Theory and Society 31(5): 573-621. 
Tajfel, Henri and John Turner. 1986. The Social Learning Theory of Intergroup Behavior. In Stephen Worchel and William Austin (eds), The Psychology of Intergroup Behavior, pp. 7-24. Chicago, IL: Nelson-Hall.

Tajfel, Henri and John Turner. 1979. An Integrative Theory of Intergroup Conflict. In William Austin and Stephen Worchel (eds), The Social Psychology of Intergroup Relations, pp. 33-47. Monterey, CA: Brooks/Cole Publishing.

Talen, Emily. 1999. Sense of Community and Neighborhood Form: An Assessment of the Social Doctrine of New Urbanism. Urban Studies 36: 1361-1379.

Tate, Katherine. 1993. From Protest to Politics: The New Black Voters in American Elections. New York, NY: Russell Sage.

Taylor, Marilyn. 2003. Public Policy in the Community. New York, NY: Palgrave Macmillan.

Taylor, Paul, Cary Funk and April Clark. 2007. Americans and Social Trust: Who, Where and Why. Pew Research Center: Social Trends Support.

http://pewresearch.org/pubs/414/americans-and-social-trust-who-where-and-why [accessed April 2010].

Teixeira, Ruy A. 1992. The Disappointing American Voter. Washington, DC: Brookings Institution.

Thrift, Nigel. 2004. Transurbanism. Urban Geography 25(8): 724-734.

Tocqueville, Alexis. 1973 [1840]. Democracy in America. New York, NY: Washington Square Press.

Tompkins, Wayne, Miami Poverty Rate Among Highest in US, Census Report Says. In the Miami Herald. No date given, available at www.miamitodaynews.com/news/070830/story7.shtml [accessed January 2008].

Tönnies, Ferdinand. 1963 [1887]. Community and Society (Gemeinschaft und Gesellschaft). Translated and edited by Charles P. Loomis. New York, NY: Harper Torchbooks.

Torres, María de los Angeles. 1999. In the Land of Mirrors: Cuban Exile Politics in the United States. Ann Arbor, MI: University of Michigan Press.

Torres, María de los Angeles. 1998. Transnational Political and Cultural Identities: Crossing Theoretical Borders. In Frank Bonilla, Elwin Meléndez, Rebecca 
Morales and María de los Angeles Torres (eds), Borderless Borders: U.S.

Latinos, Latin Americans, and the Paradox of Interdependence, pp. 169-182.

Philadelphia, PA: Temple University Press.

Touraine, Alain. 2000 [1997]. Can We Live Together? Equality and Difference.

Translated by David Macey. Stanford, CA: Stanford University Press.

Tsing, Anna L. 2005. Friction: An Ethnography of Global Connection. Princeton, NJ: Princeton University Press.

Tuan, Yi-Fu. 1979. Landscapes of Fear. New York, NY: Pantheon Books.

Tuan, Yi-Fu. 1977. Space and Place: The Perspective of Experience. Minneapolis, $\mathrm{MN}$ : University of Minneapolis Press.

Uhlaner, Carole J., Bruce E. Cain and D. Roderick Kiewiet. 1989. Political Participation of Ethnic Minorities in the 1980s. Political Behavior 11(3): 195-231.

Uslaner, Eric M. 2002. The Moral Foundations of Trust. Cambridge, UK: Cambridge University Press.

Uslaner, Eric M. 1999. Democracy and Social Capital. In Mark E. Warren (ed), Democracy and Trust, pp. 121-150. Cambridge, UK: Cambridge University Press.

Uslaner, Eric M. and Richard S. Conley. 2003. Civic Engagement and Particularlized Trust: The Ties that Bind People to their Ethnic Communities. American Politics Research 31(4): 331-360.

United States Census. 2003. Population Division. www.census.gov/popest/national/asrh [accessed July 2010].

United States Census. 2000. Census of Population and Housing, Summary Files 1 and 3. Washington, D.C.: U.S. Bureau of the Census.

United Nations Development Program. 2004. Human Development Report 2004:

Cultural Liberty in Today's Diverse World. New York, NY: UNDP.

Van den Berghe, Pierre L. 1967. Race and Racism. New York, NY: Wiley.

Vedlitz, Arnold, Jon Alston and Carl Pinkele. 1980. Politics and the Black Church in a Southern Community. Journal of Black Studies 10(3): 367-375.

Verba, Sidney and Norman H. Nie. 1972. Participation in America: Political Democracy and Social Equality. New York, NY: Harper \& Row. 
Verba, Sidney, Norman H. Nie and Jae-on Kim. 1978. Participation and Political Equality: A Seven Nation Comparison. New York, NY: Cambridge University Press.

Verba, Sidney, Kay Lehman Schlozman and Henry E. Brady. 1995. Voice and Equality. Cambridge, MA: Harvard University Press.

Verba, Sidney, Kay Lehman Schlozman, Henry E. Brady and Norman H. Nie. 1993. Race, Ethnicity and Political Resources: Participation in the United States. British Journal of Political Science 23(4): 453-497.

Visweswaran, Kamala. 1998. Race and Culture of Anthropology. American Anthropologist 100(1): 70-83.

Wacquant, Loïc. 2004. Ghetto. International Encyclopedia of the Social \& Behavioral Sciences. Elsevier Ltd.

Waldinger, Roger (ed). 2001. Strangers at the Gates: New Immigrants in Urban America. Berkeley, CA: University of California Press.

Waldinger, Roger and Cynthia Feliciano. 2004. Will the New Second Generation Experience 'Downward Assimilation'? Segmented Assimilation Re-assessed. Racial and Ethnic Studies 27(3): 376-402.

Waters, Mary C. 1999. West Indian Immigrant Dreams and American Realities. Cambridge, MA: Harvard University Press.

Waters, Mary C. 1996. Optional Ethnicities: For Whites Only? In Silvia Pedraza and Ruben G. Rumbaut (eds), Origins and Destinies: Immigration, Race and Ethnicity in America, pp. 444-454. Belmont, CA: Wadsworth.

Waters, Mary C. 1994. Ethnic and Racial Identities of Second-Generation Black Immigrants in New York City. International Migration Review 28(4): 795-820.

Waters, Mary C. 1990. Ethnic Options: Choosing Identities in America. Berkeley, CA: University of California Press.

Waters, Mary C. and Tomás R. Jiménez. 2005. Assessing Immigrant Assimilation: New Empirical and Theoretical Challenges. Annual Review of Sociology 31: 105-126.

Watson, Goodwin. 1947. Action for Unity. New York, NY: Harper.

Weber, Max. 1968 [1922]. Economy and Society. New York, NY: Bedminster Press. 
Weiss, Robert S. 1994. Learning from Strangers: The Art and Method of Qualitative Interview Studies. New York, NY: The Free Press.

Wellman, Barry and Barry Leighton. 1979. Networks, Neighborhoods, and Communities: Approaches to the Study of the Community Question. Urban Affairs Quarterly 4: 363-390.

Whyte, William F. 1993 [1943]. Street Corner Society: The Social Structure of an Italian Slum, $4^{\text {th }}$ edition. Chicago, IL: The University of Chicago Press.

Wilcox, Clyde and Leopoldo Gomez. 1990. Religion, Group Identification, and Politics among American Blacks. Sociological Analysis 51(3): 271-285.

Williams, Jr., J. Allen, Nicholas Babchuk and David R. Johnson. 1973. Voluntary Associations and Minority Status: A Comparative Analysis of Anglo, Black, and Mexican Americans. American Sociological Review 38(5): 637-646.

Williams, Jr., Robin M. 1947. The Reduction of Intergroup Tensions. New York, NY: Social Science Research Council.

Wilson, Kenneth L. and W. Allen Martin. 1982. Ethnic Enclaves: A Comparison of the Cuban and Black Economies in Miami. The American Journal of Sociology 88(1): 135-160.

Wilson, Kenneth L. and Alejandro Portes. 1980. Immigrant Enclaves: An Analysis of the Labor Market Experiences of Cubans in Miami. American Journal of Sociology 86(2): 295-319.

Wilson, William J. 1987. The Truly Disadvantaged: The Inner City, the Underclass, and Public Policy. Chicago, IL: University of Chicago Press.

Winders, Jamie. 2008. An "Incomplete" Picture? Race, Latino Migration, and Urban Politics in Nashville, Tennessee. Urban Geography 29(3): 246-263.

Winders, Jamie. 2005. Changing Politics of Race and Region: Latino Migration to the U.S. South. Progress in Human Geography 29(6): 683-699.

Winders, Jamie. 2003. White in All the Wrong Places: White Rural Poverty in the Postbellum U.S. South. Cultural Geographies 10: 45-63.

Winders, Jaime, John P. Jones and Michael Higgins. 2005. Making Güeras: Selling White Identities on Late-night Mexican Television. Gender, Place, and Culture 12: 71-93. 
Wirth, Louis. 1969 [1964]. On Cities and Social Life: Selected Papers. Chicago, IL: The University of Chicago Press.

Wirth, Louis. 1964 [1928]. The Ghetto. Chicago, IL: University of Chicago Press.

Wolf, Eric R. 1994. Perilous Ideas. Current Anthropology 35(1): 1-12.

Wolfinger, Raymond and Steven J. Rosenstone. 1980. Who Votes? New Haven, CT: Yale University Press.

Wong, David. 2008. A Local Multi-dimensional Approach to Evaluate Changes in Segregation. Urban Geography 29(5): 445-472.

Wong, David. 2002. Spatial Measures of Segregation and GIS. Urban Geography 23(1): $85-92$.

Wood, Joseph. 1997. Vietnamese American Place Making in Northern Virginia. Geographical Review 87: 214-223.

Woolcock, Michael. 1998. Social Capital and Economic Development: Toward a Theoretical Synthesis and Policy Framework. Theory and Society 27: 151-208.

Wright, Richard and Mark Ellis. 2000. Race, Region, and the Territorial Politics of Immigration in the U.S. International Journal of Population Geography 6: $197-$ 211.

Wright, Richard, Mark Ellis and Virginia Parks. 2005. Re-placing Whiteness in Spatial Assimilation Research. City and Community 4: 111-136.

Wright, Richard, Mark Ellis and Virginia Parks. 2004. Work Together, Live Apart? Geographies of Racial and Ethnic Segregation at Home and at Work. Annals of the Association of American Geographers 94(3): 620-637.

Wright, Steve. 2002. A peek into Little Havana. Latino Leaders: The National Magazine of the Successful American Latino online edition, Oct-Nov, available at http://findarticles.com/p/articles/mi m0PCH/is 5 3/ai 113053671/ [accessed April 2010].

Wrightsman, Lawrence S. 1992. Assumptions about Human Nature: Implications for Researchers and Practitioners. Newbury Park, CA: Sage.

Wrinkle, Robert D., Joseph Stewart, Jr., J.L. Polinard, Kenneth J. Meier and John R. Arvizu. 1996. Ethnicity and Nonelectoral Political Participation. Hispanic Journal of Behavioral Sciences 18(2): 142-153. 
Wuthnow, Robert. 2002. Religious Involvement and Status-Bridging Social Capital. Journal for the Scientific Study of Religion 41(4): 669-684.

Wuthnow, Robert. 1999. Mobilizing Civic Engagement: The Changing Impact of Religious Involvement. In Theda Skocpol and Morris P. Fiorina (eds), Civic Engagement in American Democracy, pp. 331-363. Washington, DC and New York, NY: Brookings Institution Press and Russell Sage Foundation.

Wuthnow, Robert. 1998. The Foundations of Trust. Philosophy \& Public Policy Quarterly 18(3): 3-8.

Wyly, Elvyn. 2004. Commentary: The Accidental Relevance of American Urban Geography. Urban Geography 25(8): 738-741.

Yamagishi, Toshio. 2001. Trust as a Form of Social Intellingence. In Karen Cook (ed), Trust in Society, pp. 121-147. New York, NY: Russell Sage Foundation.

Yamagishi, Toshio. 1998. Structure of Trust: Evolutionary Game for Mind and Society. Tokyo, Japan: University of Tokyo Press.

Yamagishi, Toshio and Midori Yamagishi. 1994. Trust and Commitment in the United States and Japan. Motivation and Emotion 18: 129-166.

Yancey, William L., Eugene R. Ericksen and George H. Leon. 1985. The Structure of Pluralism: We're All Italian Around Here, Aren't We, Mrs. O'Brien. Ethnic and Racial Studies 8(1): 94-116.

Yanez, Luisa, Jose Cassola, Jennifer Lebovich, and Fabiola Santiago. 2010 (March 25). Tens of thousands join Gloria Estefan in Calle Ocho march for Ladies in White. The Miami Herald online edition, March 25, available at http://www.miamiherald.com/2010/03/25/1547498/calle-ocho-packed-withmarchers.html [accessed April 2010].

Yoo, Jin-Kyung. 1998. Korean Immigrant Entrepreneurs: Network and Ethnic Resources. New York, NY: Garland Publishing.

Yosano, Arinori and Nahoko Hayashi. 2005. Social Stratification, Intermediary Groups, and Creation of Trustfulness. Sociological Theory and Methods 20: 27-44.

Youniss, James, Susan Bales, Verona Christman-Best, Marcelo Diversi, Milbrey McLaughlin and Rainer Silbereisen. 2002. Youth Civic Engagement in the Twenty-First Century. Journal of Adolescent Research 16(5): 121-148. 
Youniss, James, Jeffrey A. McLellan and Barbara Mazer. 2001. Voluntary Service, Peer Group Orientation, and Civic Engagement. Journal of Adolescent Research 16(5): 456-468.

Youniss, James and Miranda Yates. 1997. Community Service and Social Responsibility in Youth. Chicago, IL: National Society for the Study of Education.

Zelinsky, Wilbur. 2001. The Enigma of Ethnicity: Another American Dilemma. Iowa City, IO: University of Iowa Press.

Zelinsky, Wilbur and Barrett A. Lee. 1998. Heterolocalism: An Alternative Model of the Sociospatial Behaviour of Immigrant Ethnic Communities. International Journal of Population Geography 4: 1-18.

Zhou, Min. 2004. Revisiting Ethnic Entrepreneurship: Convergencies, Controversies, and Conceptual Advancements. International Migration Review 38(3): 1040-1074.

Zhou, Min. 1997. Segmented Assimilation: Issues, Controversies, and Recent Research on the New Second Generation. International Migration Review. 31(4): 975-1008.

Zhou, Yu. 1998. How Do Places Matter? A Comparative Study of Chinese Ethnic Economies in Los Angeles and New York City. Urban Geography 19(6): 531-553.

Zúñiga, Víctor and Rubén Hernández-León (eds). 2005. New Destinations. New York, NY: Russell Sage Foundation. 
Appendix A: NSF Comparative Neighborhood Study Questionnaire (English)

\section{Interviewer}

Date

Census Tract\#

Address
Original Parcel \#

Actual Parcel \#

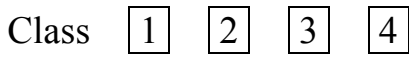

Type 1 single 2 duplex 3 apt 4 other

Hi. My name is and I am part of a research Project conducted by FIU professors on civic and place engagement in Little Havana. If you are at least 18 years of age, we are interested in your opinions and would like for you to answer a survey on these topics. The survey will take about 20 minutes. We will ask you a number of questions which you will answer orally. There is no cost and we do not compensate you for your participation. All the information is confidential and for the exclusive use of the researchers. We will not identify you or your family. Would you like to participate?

$$
\text { Yes }
$$

For your information, if you have any problems, would like additional details, or would like to complain about our procedures, you may call Dr. Tubman at (305) 348-3024.

1. Gender: 1 Male 2 Female

2. How people live in this house?

3. How many people under 18 years of age live here (if any)?

4. In what year were you born?

5. Where were you born?

1 United States a. City/Town b. State

2 Country b. City c. Province

a. In what year did you come to live the U.S.?

6. What is your occupation 
7. People use different terms to describe themselves, such as "Black," "White," "NicaraguanAmerican," "Cuban-American," "Cuban," or "Mexican." What term(s) do you use to describe yourself?

a.

b.

c.

8. Do you identify yourself as Latino/Hispanic? (Note: We are talking about use of the words "Latino" and "Hispanic")

1 No (skip to 9)

2 Hispanic

3 Latino $\longrightarrow$

4 Hispanic \& Latino

5 I'm not sure

a. Do you feel solidarity with the hispanic population in the US?

1 No

2 Yes

9. Do you consider your race to be:

1 White

2 African-American/Black

3 American Indian/Alaskan Native

4 Asian/Pacific

5 Other

a. Hispanic (Interviewer: Please fill out based on national origin; do not ask) 1 No
2 Yes

10. What is the name of this neighborhood?

11. How long have you lived in this house/apartment?

12. How long have you lived in this neighborhood? 
13. Do you or your family own your home or pay rent?

1 Own (skip to \#14)

2 Pay rent $\rightarrow$ a. Would you buy a home in this neighborhood?

$$
\begin{aligned}
& 11 \text { No } \\
& 2 \text { Yes }
\end{aligned}
$$

14. In the past two years, has your home been burglarized?

1 No

2 Yes

3 There was an attempted burglary but they did not take anything.

15. In the past two years, have you been a victim of violent crime within your neighborhood?

1 No

2 Yes $\rightarrow$ a. What crime?

16. How safe do you feel in your neighborhood?

1 very unsafe

2 somewhat unsafe

3 neither safe nor unsafe

4 fairly safe

5 very safe

17. In an average week, how many times do you converse with your neighbors?

$\begin{array}{llll}1 & 0 & 3 & 3-5\end{array}$

2 1-2 4 more than 5 
18. In the last month, how many times have you visited a neighbor in his/her home?

10

2 1-2

3 3-5

4 more than 5

19. In the last month, how many times has a neighbor visited you in your home?

10

2 1-2

3 3-5

4 more than 5

20. Now I am going to read to you various statements. Please tell me if in general, you agree, disagree, or have no opinion regarding the following statements:

A. Most people in this neighborhood can be trusted.

1 Agree 2 Disagree 3 No Opinion

B. Most people in this neighborhood will take advantage of you if you let them.

1 Agree 2 Disagree 3 No Opinion

C. Most people in this neighborhood don't trust each other.

1 Agree 2 Disagree 3 No Opinion

D. Most people tend to trust only their family members.

1 Agree 2 Disagree 3 No Opinion

E. Most people tend to trust only people from their own ethnic or national group.

1 Agree 2 Disagree 3 No Opinion

F. People in this neighborhood care about the well-being of their neighbors.

1 Agree 2 Disagree 3 No Opinion 
G. People in this neighborhood care about conditions in the neighborhood.

1 Agree 2 Disagree 3 No Opinion

21. On a scale from 1 to 5 , how much do you believe you can trust in the following groups? ( 1 is least, 5 is most, no opinion $=3$ )
A. Puerto Ricans:
$1125 \quad 3 \quad 4 \quad 5$
B. Cubans:
\begin{tabular}{lllll}
1 & 2 & 3 & 4 & 5 \\
\hline
\end{tabular}
C. Nicaraguans:

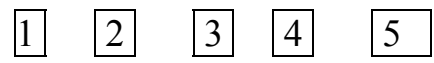
D. Dominicans:

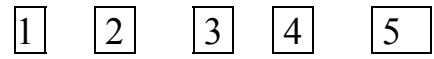
E. Colombians:

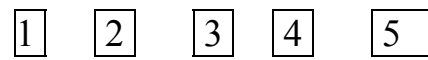
F. Mexicans:

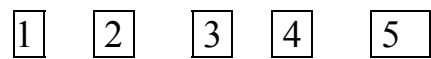
G. Americans (non-latino):
\begin{tabular}{lllll}
1 & 2 & 3 & 4 & 5 \\
\hline
\end{tabular}
H. African Americans:

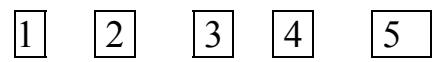
I. Hondurans:

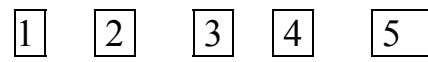

22. Do people from different countries who live in this neighborhood work together to make this community a better place?

1 No

2 Yes 3 not sure

23. How satisfied are you with your neighborhood?

1 very unsatisfied

2 unsatisfied

3 neither satisfied nor unsatisfied
4 satisfied

5 very satisfied 
24. Where do you shop for groceries?

1.

Name of Store

Intersection/Address

2.

Name of Store

Intersection/Address

25. What restaurants do you go to most often?

1.

Name of Restaurant

Intersection/Address

2.

Name of Restaurant

Intersection/Address

26. Where do you get your hair cut/done?

1.

Name of Place

Intersection/Address

2.

Name of Place

Intersection/Address 
27. Where do your children go to school?

$\square$ No children in the household

1. Name of school

Intersection/Address

2.

Name of school

Intersection/Address

28. Where do you meet with your friends?

1.

Name of Place

Intersection/Address

2.

Name of Place

Intersection/Address

29. What parks or playgrounds do you go to? (Parks, beaches, playgrounds, etc.)

1.

Name of Park/Playground

Intersection/Address

2.

Name of Park/Playground

Intersection/Address 
30. What is the most serious issue or problem affecting this neighborhood?

A. During the past two weeks, have you talked to anyone about this problem?

1 No (skip to 31)

2 Yes $\rightarrow \quad$ B. With whom did you talk to about this problem?

1 Spouse/Family member

2 Neighbor

3 Other friend(s) not in the neighborhood

4 Police officer or government official

31. How interested are you in local community politics and local community affairs?

1 Not interested 2 Slightly interested 3 Interested 4 Very Interested

32. How often do you discuss local community politics or local community affairs with others?

1 Never 2 Less than once a week $\quad 3$ Once or twice a week 4 Everyday

33. How interested are you in national politics and national affairs?

1 Not interested 2 Slightly interested 3 Interested 4 Very Interested

34. How interested are you in international politics and international affairs?

1 Not interested 2 Slightly interested 3 Interested 4 Very Interested 
35. Now I am going to read some statements. Please tell me if in general, you agree, disagree, or have no opinion regarding the following statements:

A. Sometimes city politics and government are too complicated for me to understand.

1 Agree 2 Disagree 3 Not Sure

B. I don't think local officials care much what people like me think.

1 Agree 2 Disagree 3 Not Sure

C. By working together people in my neighborhood can influence the decisions that affect the neighborhood.

1 Agree 2 Disagree 3 Not Sure

D. New residents are less interested and less engaged in the neighborhood than long-time residents.

1 Agree 2 Disagree 3 Not Sure

E. Recent immigrants are more interested in what happens in their countries of origin than in what takes place in this neighborhood.

1 Agree 2 Disagree 3 Not Sure

36. In the past two years, have you...

\begin{tabular}{|l|l|l|}
\hline & $\frac{1}{2}$ No \\
Yes \\
\hline $\begin{array}{l}\text { A. ever attended a public meeting about a problem in the neighborhood } \\
\text { you live in? }\end{array}$ & $\begin{array}{l}\text { B. been invited/asked to attend a public meeting about a problem in the } \\
\text { neighborhood you live in? }\end{array}$ \\
\hline $\begin{array}{l}\text { C. ever worked together informally with someone or some group to solve a } \\
\text { problem in the neighborhood you live in? }\end{array}$ & $\begin{array}{l}\text { D. have your ever signed a petition about a problem in the neighborhood } \\
\text { you live in? }\end{array}$ \\
\hline $\begin{array}{l}\text { E. ever participated or joined in a protest or demonstration about a problem in the } \\
\text { neighborhood you live in? }\end{array}$ & \\
\hline
\end{tabular}


37. In the past two years, have your ever contacted an elected or government official by letter or phone or in person about some need or problem?

1 No (skip to 38)

2 Yes $\rightarrow$ a. Was it related to a personal problem or one that affected the community?

1 Personal 2 Community 3 Both

b. What was the problem?

38. How often do you attend religious services?

1 Never (skip to 39)

2 A few times a year 3 a few times a month 4 at least once a week

$\rightarrow \mathbf{A}$. If you attend, which church/house of worship do you attend?

Name of church/house of worship

Intersection/Address

B. Over the past two years, have you been to a meeting in your church/house of worship regarding some local or national sociopolitical issue or problem?

1 No

2 Yes

39. In the last two years, have you been a member of a professional group related to your job, such as a chamber of commerce, professional association or union?

1 No

2 Yes $\rightarrow$ a. Which one? 
40. In the past two years, have you been a volunteer with any non-profit or community organization?

1 No

2 Yes $\rightarrow$ a. Which one?

b. Intersection?

41. In the past two years, have you participated in a meeting at a school?

1 No 3 N/A (no children at home)

2 Yes $\rightarrow$ a. ¿What was the meeting about? 1 Parent/Teacher conference (about your child)

2 Another matter

42. In the past two years, have you participated in a sports team or league?

1 No

2 Yes $\rightarrow$ a. Which one?

b. Where do they play?

43. Are you registered to vote?

1 No (skip to 45)

2 Yes

44. Lots of people find it difficult to get out and vote. Have you voted in a U.S. election in the past two years?

1 No

2 Yes

45. In the past two years have you worked as a volunteer for a (political) party or candidate?

1 No

2 Yes 
46. Have you voted in an election or referendum in another country in the past two years?

1 No

2 Yes A. Which country?

B. Which election?

47. Do you have family residing in another country(ies)?

1 No 2 Yes

48. In the past year, have you sent money to someone in another country?

1 No 2 Yes

49. In the past year have you participated in any effort to resolve a local/neighborhood problem in another country?

1 No

2 Yes $\rightarrow \quad$ a. What problem?

50. What is the highest degree or level of school that you have completed? [If necessary say: By school we mean nursery school, kindergarten, elementary school, schooling that leads to a high school diploma or a college degree]

1 No schooling completed

2 Nursery school to $4^{\text {th }}$ grade

$35^{\text {th }}$ grade or $6^{\text {th }}$ grade

$47^{\text {th }}$ grade or $8^{\text {th }}$ grade

$5 \quad 9^{\text {th }}$ grade

$610^{\text {th }}$ grade

$7 \quad 11^{\text {th }}$ grade

$812^{\text {th }}$ grade, NO DIPLOMA

9 HIGH SCHOOL GRADUATE (diploma or equivalent such as a GED)

10 Some college credit, but less than 1 year 
111 or more years of college, no degree

12 Associate degree (example: AA, AS)

13 Bachelor's degree (example: BA, AB, BS)

14 Master's degree (example: MA, MS, MEd, MSW, MBA)

15 Professional degree (example: MD, DDS, DVM, LLB, JD)

16 Doctorate degree (example: $\mathrm{PhD}$, Ed.D)

51. What language(s) is spoken most often at home?

1 English

2 Spanish

3 English/Spanish

4 Haitian Creole

5 Portuguese

6 Other

52. Do you speak Spanish fluently?

1 No

2 Yes

3 Speak/Understand a little 
53. What is your marital status? Are you:

1 Single $\rightarrow$ a. Are you living with a partner? 1 No

2 Yes $\rightarrow$ b. Man or Woman?

\begin{tabular}{|l|l}
\hline 1 & Man \\
\hline 2 & Woman
\end{tabular}

2 Married

3 Widowed

4 Divorced

5 Separated

7 Other

54. Are you a US citizen?

1 No

2 Yes (skip to 55)

A. If not, have you applied for citizenship?

1 No

2 Yes (skip to 55)

B. If not, are you planning to apply for citizenship?

1 No

2 Yes (skip to 55)

C. Are you a legal resident?

1 No

2 Yes (skip to 55)

D. Are you planning to apply for residency?

1 No

2 Yes 
55. What is your total household income before taxes?

\begin{tabular}{|l|l|l|l|l|l|l|l|}
1 & 2 & 3 & 4 & 5 & 6 & 7 & 8 \\
\hline
\end{tabular}

1) less than $10,000 \quad$ less than 833 per month

2) 10,000 to $24,999 \quad 833$ to 2,083 per month

3) 25,000 to $49,999 \quad 2,084$ to 4,167 per month

4) 50,000 to $74,999 \quad 4,168$ to 6,249 per month

5) 75,000 to 99,999 6,250 to 8,333 per month

6) 100,000 to $149,999 \quad 8,334$ to 12,499 per month

7) 150,000 o more 12,500 or more

56. Thank you for participating in our survey. In the future we will be doing more in-depth interviews as phase two of our study. Would you be interested in participating in an interview?

1 No

2 Yes 
Appendix B: NSF Comparative Neighborhood Study Questionnaire (Spanish)

Interviewer

Date

Census Tract\#

Address

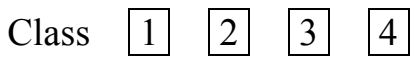

\section{Original Parcel \#}

Actual Parcel \#

Type 1 single 2 duplex 3 apt 4 other

Hola, mi nombre es y soy parte de un proyecto de investigación patrocinado por profesores de FIU sobre participación cívica y uso de espacios públicos. Si usted es mayor de 18 años, nosotros estamos interesados en su opinión y nos gustaría que contestara unas preguntas referentes a estos tópicos. La encuesta tomara unos 20 minutos. Le preguntaremos un número de preguntas que usted contestara oralmente. No hay ningún costo y no prestamos ninguna compensación o remuneración por su participación. Toda la información es confidencial y para el uso exclusivo de los investigadores. En ningún momento divulgaremos el nombre de usted o de su familia. ¿Quisiera usted participar?

Si

Si tiene usted alguna pregunta, problema o queja sobre nuestro procedimiento, puede llamar al Dr. Tubman a (305) 348-3024.

1. Género: 1 Masculino 2 Femenino

2. ¿Cuántas personas viven en esta casa?

3. ¿Cuántas personas menores de 18 años viven aquí?

4. ¿En que año nació usted?

5. ¿Dónde nació?

1 Estados Unidos. Ciudad b. Estado

2 Otro país Ciudad Provincia/Edo

a. ¿En que año vino a los Estados Unidos?

6. ¿En que trabaja usted? 
7. Las personas usan términos distintos para describirse a sí mismas, tales como "Negro", "Blanco" "Nicaragüense-americano," "Argentino", "Cubano", o "Cubano-Americano". ¿Qué términos usa usted para describirse a si mismo?

a.

b.

c.

8. ¿Usted se identifica como Latino o Hispano? (Note to interviewer: we are talking about whether the interviewee identifies with the words "Hispano" and "Latino")

1 No (salta a 9)

2 Hispano

3 Latino

4 Hispano y Latino

a. ¿Siente usted solidaridad con la población hispana

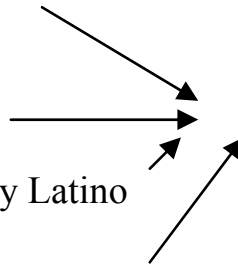

5 No esta seguro

1 No

2 Sí

9. ¿Cuál de las siguientes razas usted se considera?

1 Blanco

2 Afro-americano/Negro

3 Indio Americano/nativo de Alaska

4 Asiático/de la zona del Pacífico

5 Otro

a. Hispano (Interviewer: Do not ask; please fill out based on national origin) 1 No

2 Sí

10. ¿Cuál es el nombre de este vecindario?

11. ¿Por cuánto tiempo ha vivido en esta casa/apartamento?

12. ¿Por cuanto tiempo ha vivido en este vecindario? 
13. ¿Usted o su familia son dueños de este lugar o lo alquilan?

1 Dueños (salta al 14)

2 Alquilan $\rightarrow$ a. ¿ compraría en este vecindario?

1 No

2 Sí

14. En los últimos 2 años, ¿alguien ha robado algo de su casa?

1 No

2 Sí

3 Intentaron pero no se llevaron nada

15. En los últimos 2 años, ¿ha sido usted víctima de un crimen serio?

1 No

2 Sí $\rightarrow$ a. ¿Qué crimen?

16. ¿Qué tan seguro se siente en este vecindario?

1 muy inseguro

2 un poco inseguro

3 ni segura ni inseguro

4 seguro

5 muy seguro

17. ¿Aproximadamente cuántas veces conversa con sus vecinos en una semana?

10

2 1-2

\begin{tabular}{l|l}
3 & $3-5$
\end{tabular}

4 más de 5 
18. En el último mes, ¿cuántas veces ha visitado a un vecino en su casa?

10

2 1-2

3 3-5

4 más de 5

19. En el ultimo mes, ¿cuántas veces su vecino(a) lo ha visitado a usted en su casa?

10

2 2 $1-2$

3 3-5

4 más de 5

20. Ahora le voy a leer varias afirmaciones. Dígame si esta de acuerdo, en desacuerdo o no tiene ninguna opinión sobre lo siguiente:

A. Se puede confiar en la mayoría de las personas en este vecindario.

1 De acuerdo 2 En desacuerdo 3 Ninguna opinión

B. La mayoría de las personas en el vecindario se aprovecharían de los demás si las dejan.

1 De acuerdo 2 En desacuerdo 3 Ninguna opinión

D. La mayoría de las personas en el vecindario no confían unas en otras.

1 De acuerdo 2 En desacuerdo 3 Ninguna opinión

E. La mayoría de las personas suele confiar sólo en miembros de la familia,

1 De acuerdo $\quad 2$ En desacuerdo 3 Ninguna opinión

F. La mayoría de las personas suele confiar sólo en personas de su propio grupo étnico o nacionalidad

1 De acuerdo 2 En desacuerdo 3 Ninguna opinión 
H. Las personas en este vecindario se preocupan por el bienestar de los demás.

1 De acuerdo 2 En desacuerdo 3 Ninguna opinión

I. A las personas en el vecindario les importa las condiciones en que esté el vecindario.

1 De acuerdo $\quad 2$ En desacuerdo 3 Ninguna opinión

21. ¿En una escala de 1 a 5 cuanto cree que se puede confiar en: ( 1 least, 5 most, no opinion=3)
A. Puertorriqueños:
$10253 \quad 4 \quad 5$
B. Cubanos:
$1125 \quad 3 \quad 4 \quad 5$
C. Nicaragüenses:

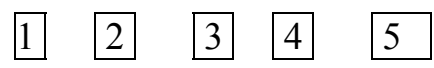
D. Dominicanos:

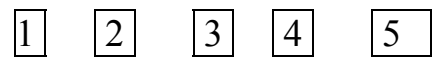
E. Colombianos:
\begin{tabular}{lllll}
1 & 2 & 3 & 4 & 5 \\
\hline
\end{tabular}
F. Mexicanos:

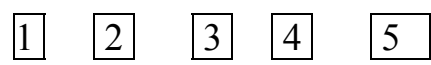
G. Americanos (no latinos):

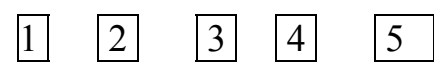
H. Negros Americanos:
\begin{tabular}{lllll}
1 & 2 & 3 & 4 & 5 \\
\hline
\end{tabular}
I. Hondureños:

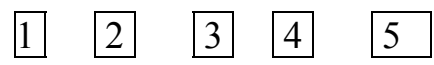

22. Las personas de distintos países que viven en este vecindario, ¿trabajan unidos para que esta comunidad sea un lugar mejor?
1 No
2 Sí

23. ¿Cuán satisfecho(a) está usted de este vecindario?

1 muy insatisfecho

2 insatisfecho

3 ni satisfecho o insatisfecho

4 satisfecho

5 muy satisfecho 
24. ¿Dónde compra los víveres (la comida)?

2.

Nombre de la tienda

Intersección/Dirección

2.

Nombre de la tienda

Intersección/Dirección

25. ¿A qué restaurantes va con más frecuencia?

3.

Nombre del restaurante

Intersección/Dirección

4.

Nombre del restaurante

Intersección/Dirección

26. ¿Dónde se corta o se arregla el cabello?

3.

Nombre del lugar

Intersección/Dirección

4.

Nombre del lugar

Intersección/Dirección 
27. ¿A qué escuela van sus hijos/los niños que viven en la casa? $\square$ No tiene hijos/niños

1.

Nombre de la escuela

Intersección/Dirección

2.

Nombre de la escuela

Intersección/Dirección

28. ¿Dónde se reúne con sus amigos?

1.

Nombre del lugar

Intersección/Dirección

2.

Nombre del lugar

Intersección/Dirección

29. ¿A qué parques o lugares de recreo va usted? (Parques, playas, playgrounds, etc.)

1.

Nombre del parque o lugar de recreo

Intersección/Dirección

2.

Nombre del parque o lugar de recreo

Intersección/Dirección 
30. ¿Cuál es el tema o problema más serio que afecta a este vecindario?

A. Durante las últimas dos semanas, ¿ha hablado con alguien sobre este problema?

1 No (salta a 31)

2 Sí $\rightarrow \quad$ B. ¿Con quién habló sobre este problema?

$1 \quad \operatorname{Esposo}(\mathrm{a}) /$ pariente

2 Vecino

3 Otro(s) amigo(s) que no viven en el vecindario

4 Policía o miembro del gobierno

31. Pensando en su vecindario, cuán interesado está usted en la política local y en los asuntos locales de la comunidad?

1 Ningún interés 2 Un poco interesado 3 Interesado 4 Muy interesado

32. ¿Con qué frecuencia usted discute la política o los asuntos locales de su comunidad con otras personas?

1 Nunca 2 Menos de una vez a la semana

3 Una o dos veces a la semana 4 Todos los días

33. ¿Cuán interesado está usted en la política o los asuntos nacionales?

1 Ningún interés 2 Un poco interesado 3 Interesado 4 Muy interesado

34. ¿Cuán interesado está usted en política y asuntos internacionales?

1 Ningún interés 2 Un poco interesado 3 Interesado 4 Muy interesado 
35. Ahora le voy a leer otro grupo de afirmaciones. Dígame si esta de acuerdo, en desacuerdo o no tiene ninguna opinión sobre lo siguiente:

A. A veces la política y el gobierno de la ciudad son muy complicados para que yo los entienda.

1 De acuerdo 2 En desacuerdo 3 No estoy seguro(a).

B. No creo que los políticos locales estén muy interesados en lo que piensan personas como yo.

1 De acuerdo $\quad 2$ En desacuerdo $\quad 3$ No estoy seguro(a).

C. Trabajando juntos las personas en mi vecindario podrían influir en decisiones que afectan al vecindario

1 De acuerdo 2 En desacuerdo 3 No estoy seguro(a).

D. Los residentes nuevos están menos interesados y menos involucrados en el vecindario que los que han vivido mucho tiempo en el vecindario.

1 De acuerdo 2 En desacuerdo 3 No estoy seguro(a).

E. Los inmigrantes recientes están más interesados en lo que pasa en su país de origen que en lo que pasa en este vecindario.

1 De acuerdo $\quad 2$ En desacuerdo $\quad 3$ No estoy seguro(a).

36. En los últimos dos años,

\begin{tabular}{|l|l|l|}
\hline & NO & SI \\
\hline $\begin{array}{l}\text { A. ¿ha asistido alguna vez a una reunión pública sobre un problema en su } \\
\text { vecindario? }\end{array}$ & & \\
\hline $\begin{array}{l}\text { B. ¿ha sido invitado o lo han pedido que asista a una reunión pública sobre algún } \\
\text { problema en el vecindario? }\end{array}$ & \\
\hline $\begin{array}{l}\text { C. ¿ha trabajado alguna vez de forma informal con algún grupo para resolver algún } \\
\text { problema en el vecindario? }\end{array}$ & \\
\hline \begin{tabular}{l} 
D. ¿ha firmado alguna petición sobre algún problema en el vecindario en que vive? \\
\hline $\begin{array}{l}\text { E. ¿ha participado en alguna protesta o manifestación sobre algún problema } \\
\text { en el vecindario? }\end{array}$
\end{tabular} & \\
\hline
\end{tabular}


37. En los últimos dos años, ¿se ha puesto alguna vez en contacto con un funcionario publico por carta, por teléfono o en persona sobre alguna necesidad o problema?

1 No (salta a 38)

2 Sí $\rightarrow$ a. ¿Se trataba de un problema personal o un problema que afectaba la comunidad?

1 Personal 2 Comunidad 3 Ambos

b. ¿Cuál era el problema?

38. ¿Con qué frecuencia asiste a servicios religiosos?

1 Nunca (salta a 39)

2 varias veces al año 3 varias veces al mes 4 por lo menos una vez a la semana

$\rightarrow$ a. Si va a la iglesia, ¿a qué iglesia o templo va?

Nombre de iglesia/o templo de oración

Intersección/Dirección

a. Durante los dos últimos años, ¿ha ido a alguna reunión en su iglesia o templo sobre algún problema o tema sociopolítico, local o nacional?

1 No

2 Sí

39. En los ultimos 2 años ha sido miembro de un grupo profesional asociado con el trabajo, tal como un camara de comercio, una asociación profesional, una union o un sindicato?

1 No

2 Sí $\rightarrow$ a. Cual?

40. En los ultimos 2 años, ha sido voluntario por alguna organización sin fines de lucro?

1 No

2 Sí $\rightarrow$ a. Cual?

b. intersección? 
41. En los últimos 2 años, ha participado en una reunión en una escuela?

1 No

3 N/A (no hay niños en la casa)

2 Sí $\rightarrow$ a. ¿de que se trataba la reunion? 1

Padre/Maestro- especifico a un niño de la familia

2 Otra cosa

42. En los ultimos 2 años, ha participado en un equipo o liga de deportes?

1 No

2 Sí $\rightarrow$ a. Cual?

b. Donde Juegan?

43.¿Está usted inscrito para votar?

1 No (salta a 45)

2 Sí

44. A muchas personas les es difícil salir a votar. ¿Ha votado usted en elecciones en Estados Unidos en los últimos dos años?

1 No

2 Sí

45. En los últimos dos años, ¿ha trabajado como voluntario para un partido político o candidato?

1 No

2 Sí

46. ¿Ha votado en elecciones o referendos en otro país en los últimos dos años?

1 No

2 Sí $\rightarrow \quad$ a. ¿En qué país?

b. ¿En qué elección? 
47. ¿Tiene usted familiares que viven en otro(s) país (es)?

1 No 2 Sí

48. En el último año, ha mandado dinero a alguien en otro pais

1 No

2 Sí

49. En el ultimo año, ha participado en algun esfuerzo para resolver algun problema local en otro pais?

11 No

2 Sí $\rightarrow$ a. ¿Que problema?

50. ¿Cuál es el diploma o nivel escolar más elevado que ha alcanzado [ Si hace falta, explique que por escuela queremos decir kidergarden, escuela primaria, secundaria, universitaria, etc,)

1 Ninguna escuela

2 De preprimaria a cuarto grado

$35^{\text {to }}$ o 6 to grado

$47^{\mathrm{mo}}$ o 8 vo grado

$59^{\text {no }}$ grado

$610^{\text {mo }}$ grado

$711^{\text {vo }}$ grado

$812^{\text {do }}$ grado

9 Diploma de secundaria( o "High School” o equivalente tal como GED)

10 Algunos créditos universitarios o de "college" pero menos de un año

11 uno o más años de "college" pero sin título

12 Título de "Associate" o dos años de universidad

13 Título de Bachelor's (ej.: BA, AB, BS) o licenciatura (incluyendo arquitectura e ingeniería)

14 Título de "Master's" o maestría (ej..: MA, MS, MEd, MSW, MBA)

15 Título profesional (ej: MD, DDS, DVM, LLB, JD) (abogado, médico)

16 Título de doctor (ej.: PhD, Ed.D) 
51. ¿Que idioma(s) se habla más a menudo en la casa?

1 Inglés

2 Español

3 Inglés/Español

4 Creole de Haití

5 Portugés

6 Otro

52. ¿Domina el inglés?

1 No

2 Sí

3 Hablo/entiendo poquito

53. ¿Cual es su estado civil?

1 soltero(a) $\rightarrow$ a. ¿vive con su pareja? 1 No

$$
\begin{gathered}
2 \text { Sí } \rightarrow \text { b. ¿Hombre o mujer? } \\
1 \text { hombre } \\
2 \text { mujer }
\end{gathered}
$$
2 casado(a)
3 Viudo (a)
4 Divorciado (a)
5 Separado (a)
7 Otro 
54. ¿Es usted ciudadano de EEUU?

1 No

2 Sí (salta a 55)

A. Si no. ¿ha solicitado la ciudadanía?

1 No

2 Sí (salta a 55)

B. If no, ¿planea solicitarla?

1 No

2 Sí (salta a 55)

C. ¿Es usted un residente legal??

1 No

2 Sí (salta a 55)

D. ¿Planea solicitar la residencia??

1 No

2 Sí 
55. ¿Cuáles son los ingresos anuales de la casa? (antes que saquen impuestos)

\begin{tabular}{|l|l|l|l|l|l|l|l|}
1 & 2 & 3 & 4 & 5 & 6 & 7 & 8 \\
\hline
\end{tabular}

\begin{tabular}{|c|c|c|}
\hline 1) & menos de 10,000 & menos de 833 mensual \\
\hline 2) & 10,000 a 24,999 & de 833 a 2,083 mensual \\
\hline 3) & 25,000 a 49,999 & de 2,084 a 4,167 mensual \\
\hline 4) & 50,000 a 74,999 & de 4,168 a 6,249 mensual \\
\hline 5) & 75,000 a 99,999 & de 6,250 a 8,333 mensual \\
\hline 6) & 100,000 a 149,999 & de 8,334 a 12,499 mensual \\
\hline 7) & 150,000 o más & 12,500 o mas \\
\hline
\end{tabular}

56. Gracias por participar en nuestra encuesta. Mas adelante vamos hacer entrevistas como una segunda etapa de nuestro estudio. ¿Usted estará interesado en participar en una entrevista?

1 No

2 Sí 
Appendix C: Interview Guide (English)

Our team is working on a research project in this neighborhood about civic participation, that is...(inset definition here)... and how the physical space, including the design and facilities of the neighborhood, affect the lifestyle of its residents. We have already completed 400 surveys with various neighborhood residents and it is now time for us to complete 40 interviews, more in-depth conversations to complement the information that we have collected in the surveys. We want to know your opinion about life in the neighborhood, the changes that are happening here, and the level of connection that you feel with your neighbors and the city of Miami. We will also ask you to draw a mental map, which is a small representation of the places in the neighborhood that are important in your life.

\section{Reactions to the neighborhood/physical space}

- How long have you live in this house/apartment?

- Do you like living here?

- What do you think about this/your street?

- How long have you lived in (name of neighborhood)?

- How did you come to live here/choose this neighborhood?

- Is this the only house/apartment that you have live in (name of neighborhood)?

- Do you know your neighbors? Which ones? How did you meet them?

- In the other house(s)/apartment(s) that you have lived in, did you know your neighbors?

- Do you believe that the physical design of the neighborhood, for example the placement of the houses, street, parks, affect the way in which you interact with your neighbors? How so?

\section{Ethnic identification/solidarity}

- What kind of people live in (name of neighborhood)?

- What is the ethnic composition of the neighborhood? What countries do your neighbors come from? What socio-economic class did they belong to there?

- What country are you from?

- What do you think about your neighbors from other countries?

- Do you think you are similar to your neighbors? How?

- What does solidarity mean to you? Do you think that there is solidarity between Latinos in general? How do you contribute to solidarity? Is it only a feeling? Are there any other aspects to solidarity? Have you given or received any benefit from this solidarity? How so?

- Do you feel solidarity with other Latinos in your neighborhood? In Miami? In other parts of the USA?

\section{Formal civic engagement at the neighborhood level}

- Is there a neighborhood association here in (name of neighborhood)? What about any community organizations?

- Have you ever participated in this/these association(s)? 
- Why or why not?

- Would you like to participate in a neighborhood association?

- What kind of things could motivate you to participate?

\section{Civic awareness (public services)}

- Do you know who to call to solve a problem on your street or neighborhood if anything were ever to happen (like a broken street lamp or if your trash is not picked up)? Who would you call?

- If not, do you know how to look for/find this information?

- Would you want to know the answer to these questions?

\section{Civic awareness (elected officials)}

- Do you think that there is someone that represents your interests here in Miami?

- Do you know who your local commissioner is?

- Do you know who the public officials here in Miami are?

- Do you know who represents this district in the National Congress in Washington?

- (If the respondent is from another country) In your home country of (name of country), did you know who the local/municipal/state government representatives were? Did you know them personally?

- Why there yes and here no?

\section{Personal networks}

- When you have a problem, who can you count on? What about outside of the family?

- If you had an economic problem, who would help you?

- What about with an emotional problem?

- Has anyone ever helped you achieve or obtain something important since you have lived in this neighborhood, like a job, a house/apartment or to resolve an economic problem? What did that person do specifically?

- Have you ever helped a person in your neighborhood to get a job, house/apartment or resolve an economic problem? What did you do for $\mathrm{him} / \mathrm{her} / \mathrm{them}$ ?

- Do you prefer to shop in stores that are owned by people from your same country?

- Are you more disposed to help/lend a hand to people from your own country?

\section{Sense of community}

- When you hear the word community, what does it mean to you?

- Do you belong to a community?

- Who are the people that make up your community?

- What kind of things do they have in common that makes them a community? 


\section{Connectivity to the city/notion of "home"}

- Do you feel like a part of your neighborhood? Of Miami? Which one do you feel more connected to? Why?

- If you had to name one place in the world to call home, what would it be?

\section{Changes in physical space/gentrification}

- Since you have lived in this neighborhood, have you noticed any changes going on? (for example, new construction, new neighbors, better or worse physical conditions of the houses in the neighborhood)?

- What do you think about these changes?

- Have you realized that various new condominiums are being built nearby?

- What do you think about Calle $8 / 8^{\text {th }}$ Street as a tourist destination?

- Have you ever gone into any of the tourist-y shops on Calle 8? Which ones? How often do you go?

- Have you ever gone to 'cultural Fridays/viernes culturales'?

\section{Photo Elicitation}

\section{Cognitive Mapping}


Appendix D: Interview Guide (Spanish)

\section{Introduction}

Estamos realizando una investigación en este vecindario sobre la participación cívica, o sea...insert a brief definition of what this means to us...y cómo el espacio físico, o sea el diseño y las instalaciones del vecindario, afecta su estilo de vivir. Ya hemos hecho 400 encuestas con varios residentes del vecindario y ahora nos tocan 40 entrevistas, conversaciones a profundidad para complementar la información que hemos recogido con las encuestas. Queremos saber sus opiniones sobre la vida en este vecindario, los cambios que están ocurriendo en él, y el nivel de conexión que siente con sus vecinos y con la ciudad de Miami. Le pediremos también que nos dibuje un 'mapa mental,' o sea, una pequeña representación de los lugares en el barrio forman parte de su vida.

\section{Reactions to the neighborhood/physical space}

- ¿Cuánto tiempo tiene viviendo en esta casa/apartamento?

- ¿Le gusta vivir aquí?

- ¿Qué opina de esta calle?

- ¿Cuánto tiempo tiene viviendo en (nombre del vecindario)?

- ¿Cómo llegó Ud. a vivir aquí?

- ¿Es este la única casa/apartamento en que ha vivido aquí en (nombre del vecindario)?

- ¿Conoce a sus vecinos? ¿A cuáles? ¿Cómo los conoció?

- ¿En la otra casa/apartamento donde vivió, conocía a sus vecinos?

- ¿Cree que el diseño físico del vecindario, por ejemplo la ubicación de las casas, las calles, los parques (si hay) afecta la manera en que interactúa con sus vecinos? ¿De qué forma?

\section{Ethnic identification/solidarity}

- ¿Qué tipo de personas viven aquí en (nombre del vecindario)?

- ¿Cuál es la composición étnica del vecindario? ¿De qué países son sus vecinos?

- ¿De qué país es Ud.?

- ¿Qué opina de los vecinos que son de otros países?

- ¿Qué significa ‘solidaridad' para Ud.? ¿Cree que existe una solidaridad entre los latinos en general? ¿Cómo contribuye Ud. a la solidaridad? ¿Es sólo un sentimiento? ¿Hay otro aspecto de la solidaridad? ¿Ha dado o recibido algún beneficio a raíz de la solidaridad? ¿De qué forma?

- ¿Siente solidaridad con otros latinos en su vecindario? ¿En Miami? ¿En otra parte de EEUU?

\section{Formal civic engagement at the neighborhood level}

- Aquí en (nombre del barrio), ¿existe una asociación de vecinos? ¿Una asociación comunitaria?

- ¿Ha participado de alguna forma con esa asociación?

- ¿Por qué no?

- ¿Le gustaría participar en una asociación de vecinos?

- ¿Qué cosas podrían motivarle a Ud. a participar? 


\section{Civic awareness (public services)}

- ¿Sabe a quién puede llamar para resolver un problema de su calle o barrio si llegara a suceder (por ejemplo, si se rompe un faro o si no vienen a recoger la basura)? ¿A quién llamaría Ud.?

- ¿Si no, sabe cómo buscar esa información?

- ¿Le interesa saber?

\section{Civic awareness (elected officials)}

- ¿Cree que exista alguien que represente sus intereses aquí en Miami?

- ¿Sabe quién es su comisionado?

- ¿Sabe quiénes son los funcionarios públicos?

- ¿Sabe quién representa este distrito en el Congreso en Washington?

- (Si es de otro país), en (nombre del país) ¿sabía Ud. quiénes eran sus representantes locales/municipales/departamentales? Ud. les conocía personalmente?

- ¿Por qué allá sí y aquí no? (if applicable)

\section{Personal networks}

- ¿Cuando tiene un problema, con quién puede contar?

- ¿Si tuviera un problema económico, quién le ayudaría a Ud.?

- ¿Y si tuviera un problema emocional?

- ¿Le ha ayudado alguien a conseguir algo importante en su vida, así como un trabajo, una vivienda o con un problema legal? ¿Cómo le ha ayudado a Ud. específicamente?

- ¿Ha ayudado Ud. a otra persona a conseguir vivienda, trabajo, o a resolver algún problema económico?

- ¿Tiene Ud. la preferencia de frecuentar negocios de personas de su mismo país?

- ¿Está Ud. más dispuesto a ayudar a personas que vienen de su mismo país?

\section{Sense of community}

- ¿Pertenece Ud. a una comunidad?

- ¿Quiénes son las personas que hacen parte de esa comunidad?

- ¿Qué tienen en común que hace que constituyan una comunidad?

\section{Connectivity to the city/the notion of "home"}

- ¿Se siente como una parte de su vecindario? ¿De Miami? ¿Con cuál se siente más conectado? ¿Por qué?

- Si tuviera que nombrar un solo lugar en todo el mundo que Ud. considera su hogar/casa - un lugar que es suyo, donde Ud. Pertenece, ¿cuál diría?

\section{Changes in physical space/gentrification}

- En el tiempo que tiene viviendo aquí en (nombre del barrio), ¿ha observado Ud. cambios en el vecindario? (por ejemplo, construcciones nuevas, vecinos diferentes, mejorar/empeorar las condiciones de las casas)?

- ¿Qué opina de estos cambios?

- ¿Se ha dado cuenta de que están construyendo varios condominios nuevos cerca de aquí? 
- ¿Qué opina de eso?

- ¿Qué opina del uso la Calle 8 como destino turístico?

- ¿Ha entrado Ud. en alguna tienda turística en la Calle 8? ¿Con qué frecuencia va Ud. a esos locales?

- ¿Ha ido Ud. alguna vez a 'viernes cultural'?

\section{Photo Elicitation}

\section{Cognitive Mapping}


Appendix E: Variables, Statistical Analysis, and Reporting Notes

Independent Dichotomous Variables

Q\# 54: Citizenship

\begin{tabular}{|c|c|}
\hline & $\%$ \\
\hline Citizen & 47.1 \\
\hline Non-citizen & 52.9 \\
\hline
\end{tabular}

Q\# 1: Gender

\begin{tabular}{|l|c|}
\hline & $\%$ \\
\hline Male & 45.6 \\
\hline Female & 54.4 \\
\hline
\end{tabular}

Q\# 13: Home Ownership

\begin{tabular}{|c|c|}
\hline & $\%$ \\
\hline Own & 29.4 \\
\hline Rent & 70.6 \\
\hline
\end{tabular}

Q\# 53: Domestic Status (Recoded) ${ }^{177}$

\begin{tabular}{|c|c|}
\hline & $\%$ \\
\hline Partnered & 58.6 \\
\hline Unpartnered & 41.4 \\
\hline
\end{tabular}

Q\# 5: Nativity

\begin{tabular}{|c|c|}
\hline & $\%$ \\
\hline US-born & 8.3 \\
\hline Foreign-born & 91.7 \\
\hline
\end{tabular}

${ }^{177}$ Recoded into those currently partnered vs. those currently unpartnered, on the general hypothesis that being partnered (whether formally married or not) leads to different behaviors and beliefs than being unpartnered (regardless of cause: divorce, never married, separated, widowed). There was no perfect way to recode this. 
Q\# 3: Children $(<18)$ in the Household (Recoded)

\begin{tabular}{|c|c|}
\hline & $\%$ \\
\hline Yes & 36.2 \\
\hline No & 63.8 \\
\hline
\end{tabular}

52: Language (Recoded) ${ }^{178}$

\begin{tabular}{|c|c|}
\hline & $\%$ \\
\hline English + & 64.4 \\
\hline Spanish only & 35.6 \\
\hline
\end{tabular}

Q\# 5: Dominant-Subordinate Group (Recoded) ${ }^{179}$

\begin{tabular}{|l|c|}
\hline & $\%$ \\
\hline Cuba (dominant) & 48.7 \\
\hline Other Latino (subordinate) & 52.3 \\
\hline
\end{tabular}

$\underline{\text { Independent Continuous Variables }}$

List of Continuous Independent Variables with the Categories

\begin{tabular}{|l|c|c|c|}
\hline \multicolumn{1}{|c|}{ Education } & Income & Age & $\begin{array}{c}\text { Years in Little } \\
\text { Havana; Years in } \\
\text { U.S. }\end{array}$ \\
\hline $\begin{array}{l}\text { No HS } \\
\text { diploma }\end{array}$ & $<\$ 10 \mathrm{~K}$ & $18-25$ & $<1$ \\
\hline HS diploma & $\$ 10 \mathrm{~K}-\$ 24,999 \mathrm{~K}$ & $26-35$ & $1-2$ \\
\hline $\begin{array}{l}\text { Beyond HS } \\
\text { diploma }\end{array}$ & $\$ 25 \mathrm{k}-\$ 49,999 \mathrm{~K}$ & $36-45$ & $3-5$ \\
\hline & $\$ 50 \mathrm{~K}+$ & $46-55$ & $6-10$ \\
\hline & & $56-65$ & $11-20$ \\
\hline & & $66+$ & $20+$ \\
\hline
\end{tabular}

\footnotetext{
${ }^{178}$ Recoded into monolinguals (English or Spanish) and those who speak combinations (with varying degrees of proficiency) of both languages, on the general hypothesis that monolingualism (esp. Spanish monolingualism in an English-dominant society) hampers social capital, civic engagement, etc.

${ }^{179}$ This variable was created using data on country of birth.

${ }^{180}$ Abbreviation for high school
} 


Q\# 50: Education (Recoded)
\begin{tabular}{|c|c|}
\hline 181 \\
\hline Level of Education & $\%$ \\
\hline Did not complete High School & 44.0 \\
\hline Complete High School & 23.7 \\
\hline Complete High School and Beyond & 32.3 \\
\hline
\end{tabular}

Q\# 55: Income (Recoded) ${ }^{182}$

\begin{tabular}{|c|c|c|}
\hline Annual household income & $\%$ & Valid $\%^{183}$ \\
\hline Less than $\$ 10,000$ & 26.8 & 28.2 \\
\hline$\$ 10,000-\$ 24,999$ & 37.5 & 39.5 \\
\hline$\$ 25,000-\$ 49,999$ & 20.1 & 21.1 \\
\hline Over $\$ 50,000$ & 10.7 & 11.2 \\
\hline No Response & 4.9 & - \\
\hline
\end{tabular}

Q\# 4: Age (Recoded) ${ }^{184}$

\begin{tabular}{|c|c|c|}
\hline Age Categories & $\%$ & Valid $^{185}$ \\
\hline $18-25$ & 10.9 & 11.1 \\
\hline $26-35$ & 16.9 & 17.1 \\
\hline $36-45$ & 15.4 & 15.5 \\
\hline $46-55$ & 17.7 & 17.9 \\
\hline $56-65$ & 9.4 & 9.5 \\
\hline $66+$ & 28.6 & 28.9 \\
\hline NR & 1.0 & - \\
\hline
\end{tabular}

\footnotetext{
${ }^{181}$ There were 16 education response categories on the survey Q\# 50 (see Appendix X). These categories were collapsed into three categories for statistical analysis.

182 There were seven income response categories on the survey Q\# 55(see Appendix X). These categories were collapsed into four categories for statistical analysis; those who did not respond to the question were excluded from statistical analysis.

${ }^{183}$ The valid percent was used for statistical analysis. In this case, those who did not respond were excluded.

${ }^{184}$ Derived from Q\# 4, “In what year were you born?” by subtracting from 2005, year of survey. Ages were then put into the six categories found in the table.

${ }^{185}$ The valid percent was used for statistical analysis. In this case, those who did not respond were excluded.
} 
Q\# 12: Years lived in Little Havana (Recoded) ${ }^{186}$

\begin{tabular}{|c|c|}
\hline Years in Little Havana & $\%$ \\
\hline$<1$ & 9.9 \\
\hline $1-2$ & 12.2 \\
\hline $3-5$ & 13.8 \\
\hline $6-10$ & 18.2 \\
\hline $11-20$ & 19.3 \\
\hline $20+$ & 26.6 \\
\hline
\end{tabular}

Q\# 5-A: Years lived in the US (Recoded) ${ }^{187}$

\begin{tabular}{|c|c|c|}
\hline Years in US & $\%$ & Valid $\%^{188}$ \\
\hline$<1$ & 1.8 & 2.0 \\
\hline $1-2$ & 3.1 & 3.4 \\
\hline $3-5$ & 7.6 & 8.3 \\
\hline $6-10$ & 12.0 & 13.2 \\
\hline $11-20$ & 26.6 & 29.3 \\
\hline $20+$ & 39.6 & 43.7 \\
\hline N/A & 8.3 & - \\
\hline NR & 1.0 & - \\
\hline
\end{tabular}

\section{Dependent Variables}

The dependent variables on identity, trust, and civic engagement are presented and discussed in Chapters Four, Five, and Six, respectively. Most of them are categorical. As per the statistics consultant at FIU, Likert scales were proxied as continuous variables.

\footnotetext{
${ }^{186}$ The categories were constructed for analysis. The data were derived from the question "how long have you lived in this neighborhood?" Q\# 12.

${ }^{187}$ The categories were constructed for analysis. The data were derived from the question "in what year did you arrive in the US?" Q\# 5-A. The category 'N/A' contains those respondents who are US-born and therefore for whom the question is not applicable. Those respondents who were born in the US and those who did not respond were not included in statistical analysis.

${ }^{188}$ The valid percent was used for statistical analysis. In this case, those who did not respond and those born in the US were excluded.
} 
Chi-Square (crosstabs) were used in cases where: categorical IV, categorical DV.

- For 2X2 tables, "continuity correction" value for significance (asymp. sig value .05 or smaller) was used.

- For 2X3 tables: "pearson chi-square" value for significance (asymp. sig value .05 or smaller) was used.

Mann-Whitney U (MWU) and Kruskal-Wallis (KW) analyses are non-parametric alternatives for ANOVA, where the DV can be ranked and a median value calculated/proxied (IV categorical).

- MWU was used for dichomous DVs

- KW was used for 3+ DVs

Only those cases from the database that were identified by surveyors as Latino (Q\# 9-A) are included in the statistical analysis done for this dissertation.

- The total number of surveys performed in Little Havana was 400, of which 384 of them were classified as Latino. Therefore, $n=384$.

$\underline{\text { Reporting convention used for significance levels is: }}$

\begin{tabular}{|c|c|c|}
\hline P-value & Significance & Symbol \\
\hline$<0.05$ & Significant & $*$ \\
\hline$<0.01$ & Very significant & $* *$ \\
\hline$<.001$ & Highly significant & $* * *$ \\
\hline
\end{tabular}


VITA

RICHARD N. GIOIOSO

2010, August

2008, December

2007-2005

2006, Summer

1998

PUBLICATIONS

2010, May
Doctoral Candidate in International Relations Florida International University (FIU)

Miami, Florida

Research, Research Institute on Social and

Economic Policy (RISEP)

Florida International University

Miami, Florida

M.A., International Studies

Florida International University

Miami, Florida

Dissertation Year Fellow

Florida International University

Miami, Florida

Research Assistant on NSF-funded Project

Florida International University

Miami, Florida

United States Department of Education Summer Foreign Language Area Studies Scholarship. Haitian Creole Summer Institute at FIU

Tinker Foundation, Latin American and Caribbean Center and Center for Transnational and Comparative Studies, FIU. "Civic and Place Engagement in Medellín and Bogotá, Colombia"

B.A., Spanish

St. Joseph's University

Philadelphia, Pennsylvania

Book review of Lúcia Sá, 2007, Life in the Megalopolis: Mexico City and São Paolo (New York: Routledge), in Journal of Regional Science 
2008, November

October

2007, August.

\section{PRESENTATIONS}

2008, November

2007, December

April

2006, March
Book review of Jon C. Teaford, 2008, The American Suburb: The Basics (New York: Routledge), in Journal of Regional Science.

Katrin Hansing, Alex Stepick, and Richard N. Gioioso, "'Son como fantasmas, están pero no se ven': Central American Arts and Artists in Miami." Prepared for the Spanish Cultural Center of Miami, Mirando al Sur/Facing South' Central American migration project

Book review of Saskia Sassen, 2006, Territory, Authority, Rights (Princeton: Princeton University Press), in Journal of Regional Science 48 (4): 845847.

Book review of Lawrence Herzog, 2006, Return to the Center (Austin: University of Texas Press), in Journal of Regional Science 47 (4): 840-842.

Race, Ethnicity and Place Conference 2008. Miami, FL. Panel Title: Comparative Civic and Place Engagement in Three Latino/a Enclave Neighborhoods in Transition.

American Anthropological Association 2007 Annual Meeting, Washington, DC. Panel Title: Transforming Inequalities: Neoliberal Development, Immigrants and Native Minorities in South Florida. Paper title: "Identity and Change in Little Havana, Miami"

Association of American Geographers annual meetings, San Francisco, CA. Panel Title: Latino/a Civic and Place Engagement. Paper title: "Little Havana, Miami: A Case of Mistaken Identity in an Ethnic Enclave Neighborhood?"

Latin American Studies Association's XXVI International Congress, San Juan, Puerto Rico. Roundtable on NSF project Civic and Place Engagement in Three Latino Enclave Neighborhoods in Transition 